\title{
Selves and Spaces in Science Fiction
}

\author{
by
}

\section{Brett Davidson}

\author{
A thesis \\ submitted to the Victoria University of Wellington \\ in fulfilment of the \\ requirements of the degree of \\ Doctor of Philosophy \\ in English
}

Victoria University of Wellington

2010 



\section{Abstract}

This thesis proposes a critical framework by which science fiction can be read as an indicator of significant trends and debates in science and culture. It takes as its starting point Brian Aldiss's statement that science fiction's purpose is to articulate in fictional form a definition of humanity and its status in the universe that will stand in the light of science. Science fiction exists as a means by which scientific concepts are constructed as cultural interpretations, and as both have changed significantly over the period from the emergence of the genre in the mid nineteenth century through the twentieth century, analysis of science-fictional forms and practices can reveal the processes of their evolution.

A critical framework is constructed based on Aldiss' definition, identifying first, a construction of selfhood and spatiality - physical and metaphysical - as being fundamental, and secondly, identifying the emergence and evolution of major 'Orders' that take different approaches to key issues and which engage with each other both antagonistically and creatively.

The thesis begins with an investigation of the cultural construction of space and then covers the emergence of science fiction as it relates to the project to define humanity and its standing in the universe in a manner consistent with science. Three Orders and their emergence are then described according to their architectonic schemae and their epistemological and creative processes. The first is the Modernist Order, based on Cartesian spatiality and mind-body dualism and empirical scientific practice. The second, which emerged as an attempt to synthesise modern science with traditional culture, is the Neohumanist Order. The third, still very much in flux, is the Posthumanist Order, which is very much inspired both by postmodernism and cybernetics. The three following chapters deal with the Orders in turn, selecting exemplary texts from their emergent and developed (or developing) stages, suggesting also the points in the development of each where another Order has disengaged and emerged in its own right.

Because science and culture evolve over time, examination of the Orders is intrinsically linked to a concept of science fiction as being an ongoing discourse, each 
selected text is interpreted as being a response to a particular issue at a particular cultural moment, but nonetheless connected to predecessor and successor texts that represent a line of argument pursued over time within and between Orders.

The Orders are not hermetic by any means, and their most enlightening aspects can be their varying treatment of a common concept. The cyborg furnishes an excellent example, being treated differently by each of the Orders as it is an image of the integration of humanity and technology. Issues such as self, body, boundary, location, the other and communication are all represented in the cyborg and the next two chapters discuss the cyborg as treated by different Orders, in the first case, as a body and in the second case, as an inhabitant and creation of architectonics and culture.

The conclusion then discusses the current state of affairs regarding the system of Orders as a critical method. It is shown that 'impure' texts that contain aspects of each of the Orders do not negate their usefulness, but rather demonstrate it as texts (and postmodern texts in particular) provide stages on which the Orders can be displayed engaging with each other. 


\section{Acknowledgements}

The whole point of a $\mathrm{PhD}$ is to learn, the thesis being mere evidence of this process. With that in mind therefore, I present this thesis with some satisfaction, but more importantly, I present it with gratitude for the teaching that I have received from Brian Opie and Geoff Miles, who have been my supervisors for the last few years. When one embarks on a $\mathrm{PhD}$, it is vitally important that one establishes a good working relationship with one's supervisors, and I can say in all honesty that this has been the case with Brian and Geoff. They have been continually supportive and have put me at my ease while their criticism has been academically rigorous, meticulous and intensely detailed, highlighting the great and the small and relating the two to each other and provoking me to continue my work with enthusiasm and inspiration. It has truly been both a pleasure and privilege to have been supervised by them.

Many other people have of course been very helpful and supportive of me in the process of my study, financially, intellectually and personally. I would like to thank Sky Marsen, Shenuka De Sylva, Alexandra Hills, Daniele Abreu e Lima and Chris MacDonald, who have, knowingly or not, greatly aided me in my progress as a $\mathrm{PhD}$ candidate.

I would like to thank especially my good friend, editor and publisher, Andy Robertson, who has guided my in my exploration of the work of William Hope Hodgson. I would not have been able to do justice to this project without his help, reflection and inspiration, and indeed, I might not even have started it.

In addition, I have had several tolerant and supportive friends, notably Grant Buist, Julie Fairless, Sarah Brueckner, Russell and Danka Murray, John Ercolano, Margaret Elliot, Lubica Lucina, Lisa Cumming and Tane Moleta, who have offered support and encouragement or have at least been sounding boards for me.

Throughout, and especially in the late stages of the composition of this thesis, absolutely vital support throughout and a comfortable environment for the 
compilation of a focused draft has been provided for me by my mother, Nolene Denton, and her husband, Josef Van Pels.

It is to my deep regret that I cannot show my late father, William George Davidson, what I have achieved.

I have never met Edward James Olmos, Mary McDonnell, Michael Hogan, Kate Vernon, Ronald Moore or Bear McCreary, but fanboy that I am, I would very much like to. The likelihood of me meeting and thanking H. G. Wells and William Hope Hodgson is, of course, zero.

Obviously, any faults in this thesis are entirely my own responsibility. 


\section{Contents}

Abstract

$\begin{array}{lll}\text { Acknowledgments } & \text { iii }\end{array}$

1. Introduction 1

1.1 Science \& 'Science Fiction' 1

1.2 Self \& Medium 3

1.3 Narrative, Dwelling \& Being 5

1.4 Process 7

$\begin{array}{lll}\text { 2. Architectonics } & 11\end{array}$

$\begin{array}{lll}2.1 & \text { Space \& Language } & 12\end{array}$

2.2 The Classical Foundations \& Strategies of Spatiality 14

2.3 Prophylactic Strategies 20

2.4 Transgression, Contamination \& the New Order 21

2.5 The Centre at Large 26

3. Genre Formation: The Aesthetics \& Strategies of Science Fiction 30

3.1 The Genre's Definition \& Historical Emergence 31

3.2 Thought Experiments \& Games 34

3.3 Estrangement 41

3.3 The Sense of Wonder 43

3.4 Epics in Miniature Portions: Infodumps \& Future Histories 46

3.5 Panoramas of Thought 48 
4.1 The Three Orders \& Their Emergence 53

4.2 The Modernist Order: Space, Time \& Knowledge 58

4.3 The Neohumanist Order: Synthesis \& Transcendence 62

4.4 The Posthumanist Order: Fluid Machines 69

4.5 The Posthumanist Order: Gender 75

$\begin{array}{lll}4.6 & \text { Fissures \& Budding Nodes } & 80\end{array}$

$\begin{array}{llr}\text { 5. The Modernist Order } & 84\end{array}$

$5.120,000$ Leagues Under the Sea: The Empire of the Eye 85

5.2 The Invincible: The Empire of Unreason 95

5.3 No Sex Please, We're Cartesians 100

$\begin{array}{ll}\text { 6. The Neohumanist Order } & 102\end{array}$

6.1 The Night Land: Jerusalem Built in a Terminal Eden 103

6.2 The Cosmology of The Night Land 107

6.3 Reading The Night Land as Myth 113

6.4 Literary \& Scientific Synthesis: The Origin of the End 115

6.5 Robert Charles Wilson: A Newer Synthesis 121

$\begin{array}{lll}6.6 & \text { The Alien(,) Subject } & 123\end{array}$

$\begin{array}{ll}\text { 6.7 Everything that Converges Must Rise } & 125\end{array}$

$\begin{array}{ll}\text { 7. The Posthumanist Order } & 130\end{array}$

$\begin{array}{lll}7.1 & \text { Recasting } & 132\end{array}$

7.2 Wolfbane: Structural Ambiguity 136

7.3 Schismatrix: Everything that Rises Must Diverge 140

7.4 Gender Deconstruction \& Reconstruction 144

7.5 The Buonarotti Cycle: There Are No Aliens 148

7.6 Nothing is True, Everything is Rewritten 153 
8. Architectonics of Identity: The Embodied Self

8.1 This Quintessence of Mud 158

8.2 The Technological Metaphor \& Subjectivity 161

$\begin{array}{lll}8.3 & \text { The Annihilation of the Self } & 168\end{array}$

8.4 Bios: Another Green World 172

8.5 Chaotic Bodies: Long Live the New Flesh 175

$\begin{array}{lll}\text { 9. Architectonics of Identity: The Social Body } & 187\end{array}$

9.1 The Softening Machine: Castration by Prosthesis 188

9.2 We, Dalek: The Superorganism 190

9.3 Sterile \& Fertile Hives 193

9.4 The Hive, the Hero \& Ideal Love 198

9.5 Borg(es) Rewritten 203

9.6 No Aleutian is an Island: Dividing \& Sharing 210

9.7 The House that Peenemünde Built: Being-in-Transit 215

10. Conclusion: Application of the Orders

223

10.1 The Orders Themselves 223

10.2 Mixed Media, Impure Thoughts 226

10.3 The Hybrid: Battlestar Galactica 229

10.4 The Orders Entangled 239

$\begin{array}{lr}\text { Bibliography } & 242\end{array}$ 


\section{Introduction}

Science enjoyed a peculiar privilege in twentieth century culture as the denominator of truth in a proposition and that privilege looks likely to continue for some time yet. As it emerged after the Enlightenment, it gained institutional authority along with cultural authority. In parallel with the rise of science as a major force in culture through the nineteenth century, the literary genre of science fiction emerged and became fully identified as such in the twentieth century. Science fiction is a unique form of literature in that it relates itself to the specific practice of science. If we want to study science's interaction with culture, then science fiction provides an ideal representation.

As a genre, science fiction contains a broad set of subgenres. Any definition that intends to be comprehensive runs the risk of either excluding large portions of the field or being so general as to be practically useless. A more useful approach might be to look at a description of science fiction's purpose and processes and to examine their contexts and consequences.

\section{1}

\section{Science \& 'Science Fiction'}

Defining the 'purpose' of science fiction may seem to be an impossible task considering the fact that rather than having no manifesto, it has innumerable ones. However, one need not look for a mission statement universally and consciously acknowledged by all authors and readers. It may well be one that exists de facto and need not be overt or consciously intended on the part of any author or reader; it may be indicative of a general cultural ethos and process. This search is abetted by the fact that science fiction identifies itself as science fiction. Alternative names have been proposed, such as 'speculative fiction', but they have not endured and the default has remained. This is no accident: science fiction is fiction that aligns itself in one way or 
another with science (and technology). This alignment may be supportive, opportunistic or hostile, but in any case, science fiction relates in some ways with the practice of science. This relationship between science and fiction provides a critical reference point: science is representative of a culture's cognitive practices. Science fiction functions as a means by which scientific discoveries and their implications are translated into cultural forms or a means by which culture extracts images and ideas from science and uses them for its own purposes.

The above definition of functional purpose is open. Science evolves, which is not merely a consequence of its practice; it is its own purpose. Science is based on the proposition that there is much that is not known but which can be known through the systematic application of transparent investigative and cognitive processes to assimilate the knowledge that has been gained into an overall understanding of the world. This process presents itself as neutral and disinterested, but it is dependent on what a culture considers to be neutral at a given time, and cultures change in their own way along with science. Therefore, one cannot find a constant definition of science and culture, but one can see how changes in one affect the other and vice versa by observing changes in that which serves to connect the two - which is science fiction. The openness of the definition then is not a problem, but an opportunity for research.

The purpose of this thesis is to investigate the connections between science and culture as revealed in science fiction. The changes in science and culture are not merely contingencies, but themselves become fundamental to the process and findings of the investigation. As we see science fiction changing, the changes of scientific and cultural paradigms are revealed.

This thesis proposes a critical framework based on 'Orders', which are sets of practices and cognitive schemae that perform the activity of appropriating scientific information and concepts and creating narratives using them. These Orders arise according to particular cultural and scientific paradigms and are clearly definable in terms of their basic premises. Two related concepts may be seen as integrally related to the entangled processes of science and culture and their variations reveal the fundamental premises and changes that occur in science and culture. These are the self and the architectonics of the cosmos and the relationship between them.

The self is a surprisingly complex and changeable concept, but generally it can be taken to mean that which is possessed of subjectivity, a node that is either 
constructed by external influences or of a fixed essence that is spared and protected from external influences. The interchanges that occur between self and other are not arbitrary and chaotic - at least not according to the structures that use the concept of the self - there is inevitably a relationship between self and other and that relationship can be described and categorised. This is what is meant by architectonics: that there is a certain 'grammar' of structure in a relationship between the self and the other. Neither self nor other are constant in their nature or in their relationship, though at any given time they are presented as such: rather, their construction reveals the processes of science and culture practiced at a particular moment. To serve this end, I propose the system of the Orders, and their analysis as entities that are representative of their times and evolving in time.

\section{2}

\section{Self \& Medium}

As culture has changed, technology has changed, both as a cause and as a consequence. In the nineteenth century, print was the dominant means by which the discourse between author and audience was conducted. The hard-bound novel was a high status object, but much of the material that found publication in hard covers was first presented in mass-circulation periodicals. ${ }^{*}$ Through the early and mid twentieth century, there was something of a split between the British (and Western European) and American markets, with paperback magazines taking a major role in the definition and evolution of science fiction. Many of the major science fiction novels published in America in the late-mid twentieth century were assemblages of texts 'fixups' - that had seen first publication as more-or-less independent short stories. Isaac Asimov's Foundation trilogy (fixup 1951-3) and Frank Herbert's Dune (fixup 1965 ) both went through this process. At about this time, film and television became major outlets and these media imposed their own constraints and generated new possibilities for narrative, affecting thereby their reading and understanding; as Marshall McLuhan put it in Understanding Media (1964), "The medium is the message" (7). Arguably, so different were these media from print that they were also

\footnotetext{
* See Stableford, Scientific Romance (1985), 11-17, for an overview of the market for literature and scientific romance, particularly in the late nineteenth century.
} 
effectively different parallel genres, but in practice, while film and television do impose restraints and permit spectacles fundamentally different from those required by and possible in print, authorship and readership overlap greatly; there is still at least some synchrony between them.

The Internet has fundamentally changed the nature of communications in the late twentieth and early twenty-first centuries, but it has not created a discontinuity. If anything, digital technology has brought other media together and thoroughly integrated them. Certainly this is the case in the marketplace: even if a work is conceived as print, it will be doubtless supported by its publisher in other media and its author will make appearances on television, radio, and most likely, online. A film with a large production and marketing budget behind it will have corollary productions across a wide swath of media. This is not however mere marketing: a film such as Avatar (2009) is immensely detailed, but there is still only so much that can be shown in a couple of hours of screen time and the whole exercise of worldbuilding that supports the imagery seen on screen can best be expressed in media other than film. Iindeed, there are books and other media productions associated with the film explaining the nature of its setting in the manner of a print encyclopaedia. When we talk about a 'text' in the postmodern context of the Internet, we necessarily refer to a set of concepts that can be presented in various and parallel media. If we are to usefully chart the evolution of science fiction, then we must take cognisance of its relationship with and expression in media. Early science fiction is certainly printbased, but later science fiction has to be thought of as a multiple-media enterprise and texts as entities that are not embodied between hard covers, but presented in multiple formats.

The other major effect of digital media is to present a new paradigm of identity. If one is to take an essentialist view of identity, then one can see the self as being something like a statue or a portrait: fixed and unchanging, with any alteration being a defacement. However, in a digital context, stasis is untenable. A file can be modified; digital information that is copied is a simulacrum that has no 'original'; a platform can run multiple applications and terminals can draw from a common network. As a text is an entity conditioned by its technological context, so too is the self, at least according to postmodern criticism and science fiction that has been influenced by it. 
In fact, the postmodern philosophies that emphasise the entanglement of being and technology, or body and architecture have not emerged out of a vacuum and have not even emerged through the recent development of cybernetics. What they represent is a new phase of our ongoing attempt to articulate the relationship between self and environment and the means by which that relationship is constructed. To understand this, we must consider how narrative relates the (natural or artificial) environment to the self and how technology and architecture can either relate the self to the environment, or become the environment... or become the self.

\section{3}

\section{Narrative, Dwelling \& Being}

Cognitive engagement with our environment and its phenomena is an active search for meaning and structure, and the search becomes a creative act - storytelling in fact. David Mamet explains that if we consider two objectively unrelated events as if they were somehow linked, then we have made a story about them and us:

It is in our nature to dramatize. At least once a day we reinterpret the weather - an essentially impersonal phenomenon - into an expression of our current view of the universe: “Great. It's raining. Just when I'm blue. Isn't that just like life?"

Or we say: "I can't remember when it was this cold," in order to forge a bond with our contemporaries. Or we say: "When I was a lad the winters were longer," in order to avail ourselves of one of the delights of aging.

The weather is impersonal, and we both understand it and exploit it as dramatic, i.e., having a plot, in order to understand its meaning for the hero, which is to say for ourselves. (Mamet, 3)

We will not just appropriate the weather to our stories of self. We concoct structures of meaning that exist to generate stories and which link us to phenomena that are not in themselves overtly linked to us as events, but which are perceived by us as phenomena. Such schemae, as we may call them, require active participation and 
maintenance. They are, in a way, laws. If we follow those laws, we demonstrate our engagement.

Martin Heidegger says of dwelling, in 'Building Dwelling Thinking' (1954):

Man's relation to locations, and through locations to spaces, inheres in his dwelling. The relationship between man and space is none other than dwelling... [buildings] are locations that allow spaces. That is why building, by virtue of constructing locations, is the founding and joining of spaces. $(155-6)$.

Only if we are capable of dwelling, only then can we build (ibid 157).

The essence of narrative and dwelling is the making of a comprehensible relationship between the human subject and the structures that accommodate it. Winston Churchill expressed a similar sensibility when he argued for the reconstruction of the House of Commons after it had been destroyed by a German bomb: "we shape our buildings, and afterwards our buildings shape us" (Churchill 358).

Our relationships with spaces - $d$ welling-in-space - are not passive, they are dynamic, and the emergence of the concept of the cyborg in the latter half of the twentieth century only further reinforced that fact. The cyborg is the most overt representation of the entanglement of the human self and technology, but it was named as such only fairly recently. The concept that underlies the cyborg is much older.

Writing in the Christchurch Press in 1863-1865, Samuel Butler alternated the noms de plume of Cellarius ('Darwin Among the Machines') and Lucubratio Ebria ('Lucubratio Ebria') to lay out two different post-Darwinian visions of our current and future relations with machines (visions that he then published in Erewhon as 'The Book of the Machines'). The former suggested that machines could be considered living organisms in their own right and their makers - humans - their reproductive organs. The latter, however, that human beings who used tools adopted these as extra temporary bodily organs and that rather than being used by machines, we simply increased our complexity by assimilating machines into our personal systems. A person who incorporated mechanical components into the system of their total identity was simply an 'organised man' who existed at relatively higher or lower 
levels of organisation, depending on how many tools and services they happened to use. 'Selfhood' was something that extended beyond the body and encompassed a whole network of facilities.

Together, the 'Cellarian' and 'Ebrian' scenarios give what is perhaps the first full representation of the cyborg as opposed to mere prosthesis. The cyborg is, in essence, a system and Butler's recognition (as Cellarius) of the potential for machines to become at least partially autonomous or have their own agendas is critical: a prosthesis is by definition a passive extension of human need, but the elements of a cyborg system actively react as part of a cyclic feedback system (implied by Butler wearing his Ebrian hat). Butler concocted his scenarios by applying Darwinian theory to machines, a mathematical understanding of living systems by Norbert Wiener later gave us cybernetics (Edwards 190). Subsequently, Manfred Clynes and Nathan Kline coined the term 'cyborg' to denote an intimate hybrid human-machine system (Gray 29-33). More recently, the eminent microbiologist Lynn Margulis referred to Butler to illustrate the principle of symbiosis in cellular evolution and as a future possibility for humanity (Microcosmos 256-7, What is Life? 195), while Donna Haraway wrote a manifesto proclaiming the cyborg as a symbol of revolutionary cultural and existential change. Butler may have been facetious in his presentation - the two names that he adopted mean 'from the cellar' and 'nocturnal study while drunk' respectively - but his wine-fueled reveries have marked the initiation of nearly a century and a half of serious thought about how we relate to machines - and how as a consequence we define ourselves in both science and science fiction.

\section{4 \\ Process}

The purpose of this study is to look at the definition of the self and its relations to space in science fiction. Accordingly, a definition of science fiction that serves as a standard of comparison would be ideal and so the touchstone for the literary side of this investigation is Brian Aldiss' definition of science fiction, which was first presented in Billion Year Spree, and subtly revised in Trillion Year Spree (1986): 
Science fiction is the search for a definition of mankind and his status in the universe which will stand in our advanced but confused state of knowledge (science), and is characteristically cast in the Gothic or post-Gothic mode $(25){ }^{*}$

This definition, which I will examine in some detail later, is somewhat contentious, but will suffice to focus this study of a particular preoccupation of science fiction with defining what humanity is and how it goes about dwelling in the universe. What makes it most useful is that it concentrates on the purpose of science fiction: what, as an intellectual exercise, it takes as its mission rather than what forms and tropes are used to send the signal that 'this is sci-fi'.

As we will see, there are fundamentally different concepts of what science fiction should do, even within the framework of Aldiss' prescription. I propose therefore a set of Orders that are each based in identifiable sets of premises and which are the generators of particular tropes and narrative treatments. Each of these is a framework for a definition of the self and of humanity and each attempts to integrate scientific in literary practice, though in distinct and often antagonistic ways. The base Order of the twentieth century is the Modernist, which is dedicated to the speculative examination of ideas according to a vision of strictly empirical science and Cartesian rationalism. However, this Order has brought forth a number of contradictions, which have in turn provoked reactions in the form of new splinter Orders, which I have labelled Neohumanist and Posthumanist. Both of these have quite different strategies in addressing the issue of dwelling.

Neohumanism and Posthumanism themselves also have different premises on which they build images of beings - cyborgs - that integrate themselves most intimately with technology and space, and how space itself is layered. The former among other things - tends towards the static and a transcendentally layered metaphysical structure, while the latter tends to emphasise the contingent, the dynamic and the immanent as opposed to the transcendental.

Within each Order there may be disagreements over the moral, ideological and aesthetic worth of a specific idea or strategy, but it is their acceptance of common epistemological processes that defines them. Because the Orders are bound together

\footnotetext{
* 'Mould' in the original became 'mode' in Trillion Year Spree.
} 
internally by their essential epistemologies and are separated from other Orders by them, different 'kits' of intellectual tools are needed to investigate them in depth. Therefore this study has utilised the critical methodologies that are most appropriate to each Order to reveal their vital elements and dynamics.

Architectonic analysis is one of the most useful tools in analysing an Order. Fundamental to each Order is a concept of spatiality, not only in physical space as it is perceived by the senses, but space as it is conceived existentially. If one is to place oneself in a field relative to context and other entities, then the nature of one's relationships with that which one defines as different from but in some way related to oneself (even by opposition) will reflect a particular concept of space as a philosophical construct. The Cartesian concept of space, for example, which holds that space is homogenous and can be described by a universal system of co-ordinates, carries with it an assumption that every place is potentially identical to every other place and can be described in the same terms and implies a cosmology in which every experience and value-judgement could be the same. It is not by coincidence that this concept of space is embraced by empirical science, which likewise subscribes to a belief in and use of universalising techniques of description. This is integral to twentieth century Modernism in science fiction. However, Cartesianism is not the only possible spatial schema. The Heideggerean definition, congruent as it is with Mamet's description of the essence of narrative, is an ideal starting-point for what I label Neohumanist spatiality. The Postmodern construction of spatiality, which informs Posthumanism, is intimately tied with modern cyborg theory and requires a new theoretical basis, which will also have to be explored. Gilles Deleuze, who relied heavily on Heidegger's work in formulating his own philosophical system, and was also inspired by seminal science fiction author William S. Burroughs, is the cultural critic whose insights most clearly illuminate Posthumanism.

The revolution of cultural moments has caused the emergence of divergent Orders, and it has also provoked evolutionary changes within the Orders. These internal changes can be charted by the varying representations of a particular iconic figure, such as the cyborg. The cyborg is not only iconic of science fiction alone: its presentation of an intimately entangled system of the body and technology means that it inevitably serves as an excellent indicator of attitudes to the engagement of science and technology with the body - and also the changes going on within science fiction and the fissures between the Orders or the budding nodes of new Orders. On one 
hand, it may appear as a human being encased with powered armour - the 'warrior cyborg' - but increasingly, the one nearest Wiener's, Clynes' and Kline's is gaining ascendancy, with its paradigm of the self as no longer a discrete, self contained body, but a confluence of currents generated by a broad stream of allegiances and interactions. It is the cyborg then that emerges as perhaps the most critical object in this study. 


\section{2}

\section{Architectonics}

The central concern of this study is with architectonics - the structuring of spatial perceptions according to particular philosophical and aesthetic conceptions of space and what it means in terms of cultural expression and interpretation in literature. Architecture is a concretisation in matter of deep cultural structures and literature is a concretisation in narrative of the same. Both use metaphors of place, structure and movement, which entail processes of inclusion and exclusion, demarcation and engagement. Therefore, a culture can be read through its literary as well as its architectural productions by using a congruent methodology.

As we are dealing with science fiction, which clearly deals with space as both a literal and metaphorical term (and often simultaneously), some clarification of certain terms is necessary at this point. The exact meaning of the word space depends on use, but it will be clear from context whether architectonic space or interstellar space is indicated. World denotes an experiential concept of the environment as opposed to the more literal planet. Cosmos denotes an ordered and comprehensible absolute realm including the metaphysical while universe is the more literally understood set of spaces, locations and inhabitants.

These differing categories of meaning - world, cosmos and so forth - are all at least conditioned by culture and by different cultural mechanisms. These mechanisms are: language, traditional ritual practice, the processes used to manage discourse between 'inside' and 'outside', the resulting characterisation given to 'monsters' that inhabit the outer world and finally the extrapolation of future possibilities. Language gives us the concepts of spatiality and ritual enacts those concepts in physical space, imbuing it with significance as a stage for narrative and thereby linking the invisible, ideal world of meaning and the mundane world of action. The establishment of the centre and the periphery and their separation are fundamental to traditional rituals of spatial establishment and this creates the opposed categories of familiar and strange, self and other. Intellectual systems then are constructed in order to cognitively map 
and manage the various beings, objects and forces of the world and to sort them into their appropriate categories and manage them. Those things that do not fit the category of familiar are by definition strange and disruptive phenomena: monsters, plagues and miraculous cures. Finally, extrapolation in the form of speculative storytelling that proceeds from the shared intellectual structures of a culture, which is in this case science fiction that draws on the basis of scientific principles, reveals a culture's expectations generated by its structures. Science fiction, because it uses the motif of space travel so often, presents in literal form the movement of the centre away from a fixed, stationary location and reveals its own basic paradox: centre is defined in relation to context, but when the context is changed, must not the centre also change, or is the centre always constant and unchanging? Each of these mechanisms must be examined in turn in order to find the often conflicting answers that they generate.

\section{1}

\section{Space \& Language}

The understanding of space is a cultural product. Margaret Wertheim, writing on cyberspace, explains that spaces and the language for defining spaces are communally produced and as such are dependent upon the paradigms of their originating cultures:

Just as cyberspace is communally produced, so in a profound sense are all spaces. Whether we are talking about medieval conceptions of spiritual space, or scientific conceptions of physical space, every kind of space must be conceptualised, and hence "produced" by a community of people. Here again, language is key, for every different kind of space requires a different kind of language. Just as cyberspace did not come into being until new kinds of languages for electronic communication had been developed, so any new kind of space requires the development of a new language (The Pearly Gates of Cyberspace 305).

When a system changes, so too do the seemingly eternal, existential concepts that it generates. 
With each shift in our conception of space also comes a commensurate shift in our conception of our universe - and hence of our own place and role within that universe. In the final analysis, our conception of ourselves is indelibly linked to our conception of space. ...people who see themselves embedded in both physical space and spiritual space cannot help but see themselves in a dualistic sense, as physical and spiritual beings. But a people who conceive of space in purely physical terms are virtually compelled to see themselves as purely physical beings (ibid 308).

In a postmodern culture in which the authority of the centre breaks down and all orientations are contingent, even physically-constructed architectural space, if it is a direct product of that decentred culture, becomes a 'hyperspace'. Fredric Jameson writes of the sleekly anodyne Bonaventure Hotel in Los Angeles* that he finds the space 'impossible to seize', because of a combination of lack of directionality and depth compounded by constant motion and ubiquitous reflectivity and repetition. This is no longer a modern space, but something beyond that, a postmodern hyperspace:

$[\mathrm{P}]$ ostmodern hyperspace - has finally succeeded in transcending the capacities of the individual human body to locate itself, to organize its immediate surroundings perceptually, and cognitively to map its position in a mappable external world. It may now be suggested that this alarming disjunction point between its body and its built environment - which is to the initial bewilderment of the older modernism as the velocities of spacecraft to those of the automobile - can itself stand as the symbol and the analogon of that even sharper dilemma, which is the incapacity of our minds, at least at present, to map the great multinational and decentered communicational network in which we find ourselves caught as individual subjects (Postmodernism 44).

\footnotetext{
* Designed by John Portman and Associates, constructed 1974-7.
} 
This is an interpretation based on the assumption that there is an essentially unchanging 'natural' and 'true' body against which architecture is measured. However, if hyperspaces such as the Bonaventure Hotel are direct outgrowths of the culture which Jameson attempts to 'cognitively map', then the body and the self are not 'embedded' as something other than their environment, but, according to Wertheim's line of reasoning, construct themselves and their possibilities for placement and movement in relation to its environment. An important point to note here is that the self is related to the cosmos via a sense of spatiality. Ideally, architecture and language allow us to be authentic dwellers in the cosmos, changing as culture changes.

\section{2}

\section{The Classical Foundations \& Strategies of Spatiality}

Martin Heidegger, in examining the structures, elements and relationships that indicate $d$ welling, notes four essential qualities, or the 'fourfold'. These are earth, sky, divinities and mortals: earth is the material basis for existence and the place of building; the sky manifests the changing phases of days and seasons, and brings the weather and other external forces and is the manifest face of the cosmos; the divinities are the invisibly present qualities of the godhead - the genius loci that indicates the transcendent quality immanent in earthly things and places - and finally, the mortals are ourselves; we dwell because we know that living bound to the world of the here and now, we will die (147-8). Building does not merely shelter or serve utilitarian purposes; it must also, to be a true dwelling, establish the integrity of the fourfold and by this means, allows to be authentic dwellers in space. A building that expresses cognisance of the fourfold serves to ensure that the dweller may 'remain at peace within the free sphere that safeguards each thing in its nature.' Thus, the 'fundamental character of dwelling is this sparing and preserving' (147, emphasis in original).

Architectural historians and theorists, in their understanding of the classical legacy, in built form, ethnography and writing (for example, Vitruvius and Plutarch) have articulated Heidegger's fourfold in their own terms, paying attention to how they are present in the physical and diagrammatic forms of building. Christian Norberg- 
Schulz is one of the most significant writers on architectural practice in the middle of the twentieth century, and his Existence, Space and Architecture (1971) is a systematic attempt to define and describe the essential elements of architecture, as he understood it, clearly recalling what he sees as the eternal and essential qualities of the classical legacy.

Architectural space certainly has to adapt itself to the needs of organic action as well as facilitating orientation through perception. It could also 'illustrate' certain cognitive theories of space, as when building a Cartesian co-ordinate system with concrete materials. But above all it is related to the space schemata of man's individual and public world. Obviously man's schemata are created through interaction with existing architectural spaces, and when these do not satisfy him, that is, when his image becomes confused or too unstable, he will have to change architectural space. Architectural space, therefore, can be defined as a concretisation of man's existential space (11-2).

Architecture, in whatever historical context, constitutes a schema. In Christian Norberg-Schulz's definition, it is existential; Charles Jencks describes his position as almost mystical (301), depending as it does partly on references to the theologian Rudolf Schwarz. As such, it is typical of the period post-World War Two, when modernist architects such as Le Corbusier and Louis Kahn were expressing deeper resonances in their architecture than mere functionalism, up into the rise of postmodern architecture, when techniques of literary criticism and composition began to be applied.

Norberg-Schulz establishes his conceptual language step by step. He starts with reference to classical Greek geometry, but finds Euclidean spatial concepts unsatisfactory and builds up a vocabulary of space and place following later developments in classical philosophy, custom and ritual. The most basic elements of architecture and those that have the greatest existential significance are the centre, the edge and the vertical.

On the centre, he says:

In terms of spontaneous perception, man's space is 'subjectively centred'. The development of schemata, however, does not mean only that the notion of 
centre is established as a means of general organization, but that certain centres are 'externalized' as points of reference in the environment. This need is so strong that man since remote times has thought of the whole world as being centralized. In many legends the 'centre of the world' is concretised as a tree or a pillar symbolizing a vertical axis mundi (18).

Surrounding the centre and the known spaces within which one creates the territory of dwelling, there is the circle and, in Norberg Schulz's own translation of the theologian Rudolf Schwarz,

'The ring unites man to man through the infinite chain of hands. The individual is absorbed in the superior form, and thereby he becomes stronger. When men agree, they form a ring, as if they were following a secret law... The eyes are brought together at the centre as the common focus. Thereby the fellowship attains a stricter form... Between the centre and the ring, a star is formed, through which men transmit their existence to the world around' (20).

On the vertical:

The vertical, therefore, has always been considered the sacred dimension of space. It represents a path towards a reality which may be 'higher' or 'lower' than daily life, a reality which conquers gravity, that is, earthly existence, or succumbs to it. The axis mundi is thus more than the centre of the world, it represents a connection between the three cosmic realms, and it is only at the central axis that a breakthrough from one realm to the other can occur (21).

Given the state of the world as described by Norberg-Schulz, a culture must create strategies for its dwelling and an excellent guide to these strategies is Joseph Rykwert's The Idea of a Town: The Anthropology of Urban Form in Rome, Italy and the Ancient World (1976). This is a landmark text describing the foundation of cities in classical antiquity and is used as a standard reference in the field. According to Rykwert, once a general site had been determined, based on readings of the winds and other factors, the exact central point of the city had to be fixed. To do this, Roman surveyors worked by first placing an upright bronze rod, a sciotherum or gnomon, in 
the centre of a circle. From that, observing the fall of shadows in morning and afternoon, they derived the north-south axis of the cardo and the east-west axis of the decumanus. These became the main streets quartering the town (50). Following this establishment, a sacrifice was offered and the liver of the slaughtered animal was examined for indications of the gods' favour. Vitruvius insists on the importance of this (Vitruvius 20). Rykwert notes that this method of divination was not peculiar to Rome, but was observed in many ancient cultures (Rykwert 51-8).

Following the establishment of centre and axes, the city had to be prepared for inhabitation by further ritual, such as the digging of a hole, a mundus (from which is derived 'mundane' or 'worldly'), into which were cast offerings. This pit might be at the actual crossing of the cardo and decumanus or at least at a point associated with the crossing and it would become the focus of the city. It would be covered, a shrine built and it would become the umbilicus or navel of the city that was to grow. At this point, it was likely that the city received its name and a particular god was assumed to have given their patronage (ibid 58-9).

One of the most important ceremonies of the founding process was the cutting of the first furrow, or sulcus primigenius. The founder would take with them their followers and plough a line around the perimeter of the city grounds. The plough blade would be slanted, that is, asymmetric so that the appearance of the inside edge was different from that on the outer side. This line would determine the position of the city walls, which were regarded as sacred. Where there were to be gates, which were covered by civil authority, the plough was lifted and carried to the point where the wall would resume (ibid 65). While the Romans laid out their new cities as squares, for defensive purposes, Vitruvius suggests a circular perimeter that would allow a view of any enemy (Vitruvius 22). We often find in the design for ideal cities and fortifications, the square and the circle are in competition or strenuous efforts are made to reconcile them.

Traditional Chinese urbanism shares the same essential characteristics as Roman urbanism. Rykwert notes the importance in China of first fixing the central point of a city using a gnomon within a circle (183). He also notes strong analogies with the Roman system, though of course within the matrix of Chinese philosophy (ibid 179-87). While the city of Rome itself is today a chaotic palimpsest of influences, this thinking can still be seen clearly today in the structure of the city of 
Beijing and particularly the Forbidden City itself. In abstract, the realm of humankind and artifice is square and thus is the basis of the design of habitation.

It is worth noting here that although Vitruvius advises on the factors determining an ideal location, the centre, which is so crucial to the process of city foundation, is a choice and a declaration. In China, the element of human decision making is also crucial and the capital, nominally the centre of the universe, was moved several times throughout history. Logically no city can occupy the centre, because then all other cities could not have centres. Insofar as free will can be conceived within a metaphysical system, the establishment of a city centre is a declaration of human will and of the specific identity and integrity of each single city by a system of co-ordinates in relation to its context. Once it has done so, it can make the best use of the elements and forces surrounding it. Chinese design depends on a city being oriented to receive good fortune that always comes from the south, for example, and Vitruvius himself writes extensively on the necessity of arranging a city and its streets and even the rooms and galleries of individual houses according to the patterns of the winds $(24-31,170-80)$. Thus the city, a microcosm, is tied to the macrocosm.

Rome and China are but two examples, but their basic principles are widespread. In various forms and elaborations, these are the concepts that are repeated in many ancient rites of foundation: principally, the determination of the centre of a circle, which is usually related to the sun and the winds, and as a necessary corollary, a quartering and a definition of the edge, which establishes a human domain within but excluding nature. Circular or pyramidal stepped mounds with axes and a protected but privileged centre are characteristic of the most important tombs, temples or monuments of so many societies from South America through Asia and Egypt to Europe as to be well established as archetypal.

The mandala, a representation of unity and integration, is not simply a symbol, but is the ideal (in the Platonic sense) for the human living space. The architectural Mandala can be summarised thus: first, it is intimately related to the idealised human form; second, it has a centre; third, it consists of concentric circular or square forms and usually both; fourth, it is quartered and measured and aligned north-south and east-west; fifth, it is surrounded by a border which separates it from its surroundings, establishing order within and chaos without and this border mediates the relationship 
between the two. Strategies of dwelling, in rituals of foundation and in regular observance, are consequently determined by this understanding.

Lest we think that the Mandala is a mystical form, we should consider the Panopticon, Michel Foucault's prime architectural specimen. It is an entirely functional structure, made of solid material, and yet in being so, it is a representation of abstract processes of knowledge, assimilation and control. First proposed by the Utilitarian philosopher, Jeremy Bentham, the Panopticon is a form of prison that uniquely for its time - was designed to rehabilitate rather than merely confine its inmates. In essence, its structure consists of circular periphery of cells, brightly lit by daylight, and a central guard post that remains in shadow. Every inmate is potentially subject to the gaze of a guard, but cannot tell if at any specific time if in fact this is the case. As a consequence of the perpetual possibility of surveillance, the inmates will be conditioned to act at all times as if they are actually under observation. The Panopticon's power lies in the institutional and classified knowledge linked to specific strategies of enforcement and the perpetual potential for action that every inmate knows could be used; the guards are not only in the guard post, they are in the inmates' minds. This edifice, much-discussed by architectural theorists, could not come into existence without the encyclopaedia existing first because it is the realisation in architectural form of the principle that knowledge itself is power. The Panopticon's operation is able to enact the imposition of discipline by observation, because it ties analysis to command:

Thanks to its mechanisms of observation, it gains in efficiency and in the ability to penetrate into men's behaviour; knowledge follows the advances of power, discovering new objects of knowledge over all the surfaces on which power is exercised (Foucault Discipline and Punish 204).

The prisoners are ambiguous creatures, chaotic beings on the periphery of society, but the Panopticon is established to condition them to the procedures and reflexes of society and to re-assimilate them, as society conditions its fully franchised citizens. The techniques for the control of misbehaviour in the prison were translated smoothly from techniques for the control of criminality and disease without and are reapplied in society to deal with all potential deviance - not by eliminating it, but by assimilating it into systems of control, be they security and surveillance, public health programmes 
or seemingly innocuous market research. In fact, order was always intrinsic to culture and what the treatment of plague and misbehaviour show is the crystallisation of a particular mode of order that became possible after the Enlightenment.

What we have now is a total system that at once maintains order and is able to deal with threats to that order exclusively on its own terms.

\section{3}

\section{Prophylactic Strategies}

The opposite of an established dwelling-space is not another dwelling-space, but the thing without that wants to get in, or the thing within that must be expelled so that what is within may be spared and preserved. That thing, be it a criminal, a plague or an entirely novel phenomenon, is a remarkable exception to established mundane order and call its stability into question. By definition, these exceptional things are monsters, the word being derived from the Latin monstrum, meaning an omen or warning.

A prototype for the classical urban plan might be described by the following image: imagine a small encampment of early humans who have built a fire in a forest clearing to keep themselves warm at night. The fire, essential for survival, provides warmth and keeps predators at bay but it cannot be approached too closely, or else one will be burned. The light of the fire decreases with distance according to the inverse square rule, so that at a certain point, it becomes imperceptible and darkness is dominant. In the darkness, with their eyes reflecting the light of the fire, wolves gather. They desire their human prey, but they dare not come close to the fire. The band of humans naturally forms a circle in the 'temperate zone' of light and warmth between the fire and the wolves. Those who are most privileged are nearer the centre and those who are less fortunate find themselves pushed towards the edge into the darkness. Not utilising a system of categorisation by species, it is possible in the minds of the people that to be pushed into the darkness is to be of the darkness and therefore like a wolf, despite being their prey, an outcast human an unpredictable and lawless being that is as much a threat to the community as a wolf. In order to protect the community, it must define itself and so a line is drawn at some midpoint of the continuum from light to dark and thereafter all within is absolute lightness and all 
without is absolute darkness. Thus the human community acquires its boundary, just as the body has a skin and a face quite distinct from that of the wolf.

The ultimate wolves are what Norman Cohn calls chaos-monsters. These are beings that transcend mere violence to represent a fundamental malign force of the universe. As he explains in Cosmos, Chaos and the World to Come (1993), taking the Egyptian monster Apophis as the prototype:

The world and the gods had a beginning, but chaos had no beginning, and nor had chaos-monsters. This is true not only of Apophis, but of the whole army of strange, menacing beings - hybrid creatures, monstrous beasts, headless men - who are shown on the walls of the tombs in the Valley of the Kings, lining the banks of the underground river, threatening the sun-boat as it passes by. All these existed outside the ordered world, they were not part of creation, they were there from all eternity. The most that could be achieved was to hold them at bay (22).

The gods, for all their capriciousness and cruelty, are benign compared to the chaosmonsters. They have created an enclave of life that is held together by laws and defended by heroes. The gods have made the centre and rule over it, the 'most civilised' are closest to that centre, barbarians are at the periphery, where they may fall prey to or be corrupted by the influence of the chaos-monsters that themselves prowl the dark perimeter.

\section{4}

\section{Transgression, Contamination \& the New Order}

Divisions are artifices and while chaos-monsters and vampires are definitely outsiders, the fact that the border is an artificially created and contested zone inevitably implies ambiguity. Beings that exist in this twilight zone are called liminal beings (after the Latin limes, meaning boundary).

In myth and fantasy, vampires present a perfect case of the monstrous outsider that covets human resources - souls, blood, wealth and power. However, what makes them particularly horrible is their human origin form allied with inhuman substance. 
They have crossed over a line that must not be crossed. As we can see, they are associated with what we call the supernatural versus the world of the natural.

Magical thought is opportunistic in that it seizes upon pairings of observed effect and a single assumed cause, which is itself often of the nature of deliberate malicious or benign intention. If the rain necessary for the crops does not come in time, it is because the rain has refused to come or some entity has prevented it from coming. If wolves are deadly to the community, it is because wolves hate humans and if the existence of vampires is an assumed fact like wolves, then vampires and wolves are members of the same order and one may even metamorphose into the other. There is a direct one-to-one correspondence here, not an understanding of the patterns of climatology and precipitation or the ecology of mammalian predators.

This is not to say that belief in vampires or the inherent malice of wolves is foolish. Indeed, decaying corpses and wolves are dangerous and must be separated from the community. Fear of vampires and wolves requires the demarcation of an essential difference between the human community and nature in a metaphysical sense, but also in a practical sense. Whether or not vampires are real, the community is protected and moreover, it is bound tightly together.

Like vampires, fairies represent not only a fear of death, but of the dead. As walls define divisions of space, rituals such as baptism and burial define divisions in time and states of being. If a person has died before their time or has not received the proper rite of passage from life to death, then their spirit persists in the twilit zone and preys upon the living. Many of the fairy myths centre around lost children and in particular those who have not yet undergone the rite of passage into society.

It must be remembered that infant mortality was very high even up into the early twentieth century and conditions like Down Syndrome were not understood until very recently. Fear of the loss of a child was the fear of a very real and tangible fate for many mothers and if a child was 'odd', then it could often be explained as a changeling, not the real, 'proper' child. The Victorians are accused of miniaturising and sentimentalising fairies, but in fact their use of the fairy was more complex and had a darker edge than one might assume and J. M. Barrie's Peter Pan stories did not gloss over the association of fairies with death (Purkiss 265-83).

One might think that with the rise in cultural authority of science, 'superstitious' and 'folk' beliefs in fairies and suchlike would evaporate like mist in sunlight, but it is often the case that atavistic patterns of thought simply recast 
themselves in quasi- or pseudo-scientific form, borrowing new trappings of truthfulness. Indeed, it was comfortably assumed by eminent and rational persons such as Sir William Crookes, Sir Arthur Conan Doyle, Alfred Russell Wallace, Edward Gardner and Geoffrey Hodson that science would expand to encompass fairies (Silver 51-6). ${ }^{*}$ This may seem odd now, in the twenty-first century, but even if they are not called fairies, it is very clear that many of the entities depicted in science fiction are beings that perform the same role as fairies did. The Borg may not be called the Sidhe or look like exactly them, but they certainly act just like them.

A central motif of fictional and non-fictional writing on race in the twentieth century, or at least as it has been defined by postmodern authors, is the concept of the foreign as 'other'. In terms of nineteenth century debate, the more accurate definition is 'lower'. In her study, The Gothic Body (1996), Kelly Hurley adopts William Hope Hodgson's term 'abhuman', denoting that which has fallen away from the state of ideal humanity. Sadly, racial 'contamination' and 'degeneration' have all too often been covered by the metaphor of plague, and even if a society remains 'racially pure', there is always the threat within that no walls keep out and which will lead to the dissolution of a people into the unrefined mire that is the true nature of lesser cultures. The popular term for this was Degeneration, the title of a hysterical book written by Max Nordau, first published in English in 1895. It was not taken very seriously by the medical establishment but nonetheless became a much talked-about bestseller and was embedded in a much wider cultural debate expressing fears of imminent racial and cultural degeneration (Chapter 4: 'Entropic Bodies' 65-88, Nordau is discussed 76-7).

Nordau's concern, as his title suggests, was with the damaging effect of 'degenerate' behaviour on the culture and the soma of the 'civilised' races. The effects of personal deviance (particularly sexual deviance) were supposed to pass themselves on to subsequent generations, compounding all the while. In what seems to us an example of comical bigotry, Nordau blames in particular steam power and the increasing intellectual activity of women, indicating an anxiety about the influence of

\footnotetext{
* It seems that their theories had some influence on the science fiction writer, William Hope Hodgson, who wrote stories of a scientifically-technologically assisted spiritual investigator, Carnaki, and the high-tech fortress of the Last Redoubt assailed by supernatural entities in The Night Land.
} 
women in 'male society' and the 'feminisation' of men caused by the introduction of labour-saving devices.

Degeneration, if it even exists, is a description of a trend, and disease is the effect of microbes, but the two have been entwined in cultural consciousness, each representing the other, as Susan Sontag has written with passion and lucidity in Illness as Metaphor and AIDS and its Metaphors. The means used to combat illness have provided the means to control the degenerate too - and the potentially degenerate, meaning everyone.

Plague as a cultural phenomenon has had a complex history. While we now take for granted the germ theory of infection, in Mediaeval, Renaissance and even later times, plague was often interpreted as either arising directly from the wrath of God, evil omens in the heavens ('dis-aster' means 'bad star') or from a 'miasma' of poisoned air. The assumed causes of plague therefore provoked responses intended to counter these specific causes, depending on their interpretation.

People did not have to look far to find causes of spiritual pollution. The appearance of plague often provoked the persecution of Jews and 'sodomites'. In their history of the Black Death, The Black Death and the History of Plagues, 1345 1730 (2000), William Naphy and Andrew Spicer note that during the first outbreak of the fourteenth century, first the general piety of the community or clergy would be examined, then the 'ungodly' within the community would be identified and finally they would be either expelled, eliminated (massacred) or at least strictly regulated (63-7, 70-5). When these measures failed, only then would other relatively practical measures be instituted, such as the quarantining of affected areas and control of refugees, though again these could be coupled with further scapegoating. The appearance of a disease amongst a community indicates that the outer border has been transgressed and the monsters are within, perhaps invisible, spreading their effects like vampires. The presentation of Jews in Nazi propaganda as an infestation of rats and the hysteria roused against gay and bisexual men in the West during the early stages of the modern HIV/AIDS pandemic indicates that this response is still prevalent:

Plague as a medical disease may no longer be a threat to the stability of society or the life of the individual but as a social construct and a powerful memory it is still able to send an advanced, progressive community fleeing 
into its fortress, looking for infectious scapegoats to expel. Thanks to plague and epidemic disease, cleanliness is still next to godliness and moral diversity remains physically dangerous. Healthiness, purity and sanitary remain concepts as deeply entwined with the metaphysical, the moral, and the spiritual as they do with medicine, science and sanitation (ibid 173).

Edgar Allan Poe's 'The Masque of the Red Death' (1842) is still a delightfully frightening tale (Tales of Mystery and Imagination 245-50). In this tale, which is inspired by Poe's characteristic perversity, we see an inversion of Shakespeare's The Tempest in the shared name of the protagonist, Prospero and an echo of Boccaccio's Decameron, in which a group isolates itself in an abbey away from a plague scouring the countryside. Poe's Prospero has richly morbid tastes, decorating the halls of his edifice in intense colours, erecting an enormous ebony clock to count down the hours and so forth. At the climax, a masquer with tastes too outré even for this decadent community is revealed to be an avatar of the eponymous plague and slays all within the abbey. It is a masterful irony that the destroyer may be a version of the Grim Reaper made real, but is deadly also to the pretence of the survivors by being revealed as a fake masquer and not simply truth knocking at their door. Like any great short story, 'The Masque of the Red Death' presents an essential idea in its pure, simple and concentrated form, which can then be subjected to endless elaboration by others.

An outbreak of plague is the eruption of chaos within a formerly ordered world, and when culture is thereby presented with its antithesis that orderely culture most aggressively and systematically asserts itself. Writing in Discipline and Punish (1975) Michel Foucault describes a strategy to combat plague - leprosy - that is precisely architectural and is rooted in the data-gathering and encyclopaedic processes of the Enlightenment:

The plague is met by order; its function is to sort out every possible confusion: that of the disease, which is transmitted when bodies are mixed together; that of the evil, which is increased when fear and death overcome prohibitions. It lays down for each individual his place, his body, his disease and his death, his well-being, by means of an omnipresent and omniscient power that subdivides itself in a regular, uninterrupted way even to the ultimate determination of the individual, of what characterizes him, what belongs to him, of what happens to 
him. Against the plague, which is a mixture, discipline brings into play its power, which is one of analysis (197).

A plague is an extraordinary disaster, but that is the point, and the Panopticon, as used by Foucault and others, has insidiously become a representation of the normal functioning of society. As Foucault points out, once a disaster is met with an effective strategy, that strategy becomes institutionalised, and as science is progressive, so it spreads to permeate society.

Learning by its nature is expansive. The next step then is to investigate the greater vista of cosmic time and space, and with it, the connection of the central guard-post of the Panopticon with that wider vista.

\section{5}

\section{The Centre at Large}

Science fiction juxtaposes the values of the centre - earth and humanity - with its antithesis -aliens or other exotic beings - in order to clarify or interrogate both, often through the representation of some technological-scientific edifice that can serve as the emblem of the culture. The immobile redoubt in a hostile environment is one popular form and the other is the spaceship, which by its mobility can carry an encapsulated micro-society from the point of its origin to the very boundaries of the unknown. The spaceship is virtually the defining icon of science fiction and the fact that it is symbolic is as significant as the fact that a city wall is symbolic in NorbergSchulz and Rykwert.

Spaceships are not exactly cities, though they may be large enough to contain cities. The defining aspect of a city is that it is geographically fixed, whereas a spaceship is mobile in space. A mobile community can take on the tropes of a mobile being, often a human body, but snail-like, it can carry aspects of the formerly fixed home with it. Jules Verne's Nautilus is the prototype of the science-fictional spaceship. Indeed, the opening preamble of the classic Star Trek could at least be used as the non-political half of Captain Nemo's mission statement with relatively little alteration or addition. The most telling example of a fictional spaceship however is Discovery, the spaceship of 2001: A Space Odyssey (1968), not least 
because we have plenty of clear images of it. This is a white, brightly-lit, obviously hi-tech and presents a perfect example of rational design. Stanley Kubrick hired NASA engineers as consultants who reasoned through every feature, justifying each according to the logic of engineering (Bizony 81). However, practicality and symbolism can converge and produce a result that is extremely compelling. It is logical for example that the inhabited section of a spaceship be spherical: this allows the greatest enclosure with the smallest surface area, easing radiation protection and reducing the mass of material used and it is moreover easier to pressurise than any other shape. However, a sphere also calls to mind a skull or an egg and Kubrick advised his designers to create a form evocative of both. The command section of Discovery is round, but there is a visor-like slot in the front at about the expected position of eyes on a head and there are large circular hatches place where one would find a mouth and which in fact open like mouths.

Presiding over Discovery is its brain and master, HAL 9000, the sentient computer that decides that he - the dwelling - is more important than his dwellers and turns the life-support systems against his crew, killing most of them. Discovery is at once a vital supporting environment and a bed of Procrustes for its crew.

Evolutionary transcendence can only occur when the last surviving astronaut overthrows the merely human-designed order of HAL and leaves the vessel to meet the godlike alien intelligences that have been waiting for him. 2001: A Space Odyssey ends on a transcendent note that is very typical of much of science fiction and of religion. The fact that the parallel is made so clear here serves to remind us that science fiction that meets the criteria established by Aldiss is attempting to address the same ends as transcendental religion and can often as a result come up with similar answers.

If we return to Norberg-Schulz's and Rykwert's classical concept, we can easily analyse the Panopticon on their terms: authority is at the centre and chaos at the periphery, but now control is a radiative force, reason is like light penetrating darkness and infusing that darkness with its own quality of order. It is in the case of exploration, particularly the exploration of outer space in science fiction, that knowledge is shown to be perpetually advancing and 'discovering new objects of knowledge.' Science cannot acknowledge the existence of absolute and irreducible mystery. Even the word 'chaos' is something of a misnomer in scientific parlance today as it now denotes phenomena governed by physical law that are 'non-linear,' 
'complex' and which have 'emergent order.' The study of atmospheric dynamics illustrates this attitude very well: weather systems, while traditionally regarded as the epitome of capriciousness and unpredictability nonetheless exhibit recognisable structures and cycles. Jupiter's bands and Great Red Spot, for example, are not solid and are continually in motion, but they have been observed continually for over three centuries, examined closely by space probes and modeled by supercomputers. The planet continues to present surprises, but each surprise is taken as an indication that there is more to be learned so that its essential orderliness according to natural law will be progressively revealed, not that it is inherently incomprehensible. To a modern scientist, chaos is merely darkness that has not yet been illuminated.

Theoretically, a spaceship is, in being mobile, independent of the centre and carries with it the qualities of reason and power. The Roman and Chinese cities were established according to a system of co-ordinates, tying them to their contexts, and were comprehended on terms that articulated a sympathetic relationship between the microcosm of the city and the macrocosm of nature. In Cartesian space, there is nothing special about any particular location based purely on its co-ordinates, and any mobile vessel such as a spaceship is no more or less at home in any single place. That can mean that either a spaceship is always alien wherever it goes, or always at home. Both contentions rest on the assumption that both space and knowledge are absolutely and universally neutral. By implication, if exploration is an endeavour that will be of benefit to earth (or any version of home), systems of cognition learned on earth are entirely applicable throughout the universe.

This is a notion that has of course been vigorously challenged and Stanislaw Lem's novel Solaris (1961) is exemplary. In many ways the titular ocean portrayed in the story fulfills the criteria of a chaos-monster in that it is identified with an ungovernable natural force. It is sentient and it is possessed of godlike powers: control of weather, the ability to alter the orbit of its planet around a double star, the ability to create quasi-autonomous living entities from the minds of its human observers and so forth. However, the ocean is not characterised as either explicitly or implicitly evil but as intractably alien and subject to its own limitations. The scientist characters of the novel do not attempt to destroy or oppose the ocean, and neither do they fear it in any metaphysical manner. Instead they attempt to understand and describe it. Lem's point in the novel (a major concern of the author's, but virtually 
ignored in both film adaptations) is that so long as human perception remains anthropocentric, it cannot comprehend the inhuman cosmos.

One of the disillusioned explorers, Snow, eloquently and sardonically puts forth Lem's thesis:

We don't want to conquer the cosmos, we simply want to extend the boundaries of the Earth to the frontiers of the cosmos. For us, such and such a planet is as arid as the Sahara, another as frozen as the North Pole, and yet another as lush as the Amazon basin. We are humanitarian and chivalrous; we don't want to enslave other races, we simply want to bequeath them our values and take over their heritage in exchange. We think of ourselves as Knights of the Holy Contact. That is another lie. We are only seeking Man. We have no need of other worlds. We need mirrors (Solaris 72).

The declared purpose of science fiction - as will be shown in the following chapter is to call into question the presumptions that define earthly human experience as the norm to which the rest of the universe is compared. What is implicit in Snow's complaint is that the enterprise of science fails on its own terms if it is not changed by contact with new contexts. Science fiction is therefore most interesting and challenging when the borders are breached, something antithetical to the conservative project of Norberg-Schulz and Rykwert's city founders - and therefore provocative. Once one thread is plucked, the whole garment is at risk of unraveling and must be knitted again in a new mode. Science fiction, to be true to itself, does not simply find new rationales for old castles and monsters; it also has to remake the cognitive structures that support them and depending on where one begins, the whole process of remaking and what results can be very different. 


\section{Genre Formation: The Aesthetics \& Strategies of Science Fiction}

As well as being dedicated to the creation of physical form, architecture as a discipline also represents a community tied together by culture, heritage, technique and practice. It has deep cultural roots, drawing on the patterns of existential space to realise them in physical form, and while it often has its styles and movements that may spring from consciously contrived manifestoes, these too spring from basic cultural and epistemological assumptions and practices. Both narrative fiction and spatial design are intimately linked with their originating cultures. As Margaret Wertheim writes, we conceive of ourselves in space according to the language that we have to describe our situation and that language is by necessity communal (The Pearly Gates of Cyberspace, 1999, 308).

The most useless thing in the world is one telephone. After all, it must be connected to at least one other in order to be what it is. Finding the 'first true science fiction text' is a diverting exercise, but it misses the point of what makes it a genre; that it is a set of texts related to one another that collectively produce a set of tropes and principles subscribed to by those who identify with the genre. The simile with a telephone network is not facile: science fiction is very much a means of communication and discourse, and its writers and readers know that. To understand science fiction, you must know that it is a generator of an intellectual community as well. It is also necessary to understand its intimate relationship with science, emerging in parallel with nineteenth-century science to the state where it stands between science and literarature as a generator of critical and speculative discourse that mediate specifically between science and general culture. As is the case with architecture, which relies upon its particular heritage and practices to generate new forms, science fiction has evolved specific cognitive and cultural practices aligned with scientific practices in order to generate narratives. 
This seems to be a rather mechanistic description of genre, and it is appropriate here. Science is linear and systematic, technology is the application of science to specific problems and science fiction is a cognitive exercise applying scientific forms and methods in the overlapped space of science and cultural practice. There is a definition of genre that follows this paradigm: in his essay, 'Cybernetics and Ghosts', Italo Calvino proposes what he calls the 'literature machine': a set of formal or implied rules that may be combined in a near-infinite number of ways to produce texts that are unique and are identifiable as kin to one another (The Literature Machine 3-27). Hypothetically, a computer given an appropriate database and grammar of combination could produce any number of texts that will be indelibly stamped with whatever generic identity one selects. Genre is not a set of stereotypical rules that place absolute restraints on cultural products, it is a set of structural connections and processes surrounding and permeating those products.

Is there a formula or blueprint for any given genre machine then? Definitions of science fiction are common and diverse. This study is concerned with charting the role of science fiction as representing concepts of humanity and its relationship with its cosmological context according to science as it has evolved and therefore, the definition of science fiction that emerges here is based on the history of science fiction and how it has dealt with that issue in particular. There is no simple one-line description that can do so, but it is possible to describe the cluster of influences and qualities that form a complete system. To do so, the form and history of science fiction itself as a genre - as it relates to the existential concerns indicated above must be examined, with the characteristics that distinguish it from and link it to science and other literary fields. Along the way, this examination highlights a number of aesthetic and narrative qualities that are peculiar to the genre.

\section{1}

\section{The Genre's Definition \& Historical Emergence}

Brian Aldiss' definition is effectively a charter for science fiction. It has provoked much argument and is itself far more precise and complex in its implications than it first may seem. He nominates Mary Shelley's Frankenstein, or: The Modern Prometheus (1818) as the first true science fiction novel - hence his emphasis on the 
Gothic heritage - and writers such as Lucian of Samosata (Trillion Year Spree 68) and Jonathan Swift (ibid 81) as 'honourable ancestors', thereby establishing an emphasis on lineage rather than a picture of the current (that is, transitory) state of the art.

Overall, Aldiss' definition is focused on the largely English tradition of science fiction that evolved clearly out of 'scientific romance' of the sort written by H. G. Wells. Wells' scientific romances certainly fit Aldiss' definition of the genre of science fiction that developed from the late nineteenth through the twentieth centuries. He was very much concerned with producing a clear image of the human species in terms of its relations with the animal world from which it has evolved - as The Island of Doctor Moreau (1896) shows - and its status in time and space: much of the commentary by the narrator of The War of the Worlds (1898) is concerned specifically with this question. There are plenty of authors who followed from this precedent and who have explicitly given homage to Wells, such as Olaf Stapledon, Stanislaw Lem, Stephen Baxter, and Peter Watts, who, in stories of contact with exotic beings, have integrated explicit essaying on the nature and status of humanity in scientific terms with narrative.

Aldiss' history and definition of science fiction in Trillion Year Spree (and its earlier edition, Billion Year Spree) is highly contentious, and has attracted strong criticism for its perceived biases. Samuel Delany, for example, has described it specifically as 'basically useless' (Science Fiction and "Literature" - or, the Conscience of the King.' 445), and by implication as 'preposterous', 'historically insensitive' and motivated by 'pedagogic snobbery' (McCaffery Across the Wounded Galaxies 78). There is no reason why, he says, any history of the genre should extend much further back beyond Hugo Gernsback's first use of the term 'scientifiction' in 1926 (ibid 79). Indeed, popular twentieth century science fiction, after it was named as such (approximately), is very different from that of the previous century and it has spawned diverse progeny. However, ultimately it is Delany's own attack that is historically insensitive, ignoring as it does the explicit acknowledgment by authors such as Wells, writing in 1934, places his own work in the same class as Lucian and Mary Shelley and acknowledges his lifelong debt as a writer to Jonathan Swift (Wells, The Complete Science Fiction Treasury iii). A literary definition that is closely focused on recent practice and clear nominal boundaries, as Delany implies, would have its advantages, but if we are to derive any useful knowledge of how a philosophical debate on the condition and status of humanity has evolved through 
history, we must use as a reference a definition that acknowledges lineage as Aldiss' does.

Brian Stableford, another writer of science fiction and historian of science fiction, has, like Aldiss, emphasized the link between science and science fiction; Aldiss' phrase, 'which will stand in our advanced but confused state of knowledge (science)' is implicitly adopted by him also as an indicator of the essential character of science fiction's explorations. In his Scientific Romance in Britain, 1890-1950 (1985), he attempts to define a peculiarly British mode that was definitely modern while drawing upon past influences. In particular, he identifies the imaginary voyage, such as Swift's, and utopian writing as being of crucial importance. To these he adds the new element of evolutionary romance, a type of speculative story inspired by the implications of evolutionary theory. What these elements share is the technique of a superficially (or ironically) plain and reasonable description of the fantastic or speculative.

Stableford identifies the first use of the term, 'scientific romance', by Charles Howard Hinton as the title for a collection of short fiction and essays in 1886 (5). While the label can be attached to a speculative essay, it has generally come to mean fiction, somewhat obscuring its initial and still vital origin in scientific speculation. The practice of science requires strict discipline on the imagination, but it requires that discipline because it also requires imagination. It has not been uncommon for scientists to engage in speculation outside of formal scientific discourse through a form of essay that is not constrained by the strict rules of scientific discourse but which nonetheless addresses the same issues as science. This type of writing can be observed in late nineteenth and early twentieth century writing such as Julian Huxley's Essays of a Biologist (1923) and J. B. S. Haldane's Possible Worlds (1927) (ibid 5-6). H. G. Wells' own early popular scientific journalism, which included a large amount of speculation, logically belong with this set. In recent decades, the popular works of Carl Sagan, such as The Cosmic Connection and The Dragons of Eden, and Freeman Dyson's numerous books and lectures have continued that tradition.

Scientific romance could also extend itself into the truly cosmic and the quasimythical, as is evidenced by Olaf Stapledon's speculative novels such as Last and First Men (1930) and Star Maker (1937) and Arthur C. Clarke's Childhood's End (1953) and 2001: A Space Odyssey. Both modestly speculative essays and quasi- 
mythical epics, provided they are based on a specifically scientific attitude towards and an understanding of the universe as it is currently described by science without obviously contradicting what is known, admirably support the thesis that science fiction is about the search for a definition of ourselves in the universe.

Stableford's identification of scientific romance with the intersection of professional science and speculation is highly pertinent to the current practice of science fiction, significantly to the practice of reading science fiction as well. Traditionally, 'hard' science fiction has been loosely defined as that which displays the closest fidelity to the body of scientific knowledge as it exists at a given time. This has enabled scientists to engage in speculation unfettered by empiricism and it has also permitted fans who are familiar with science (but not conventional literary criticism) to engage with scientific practice together with scientists. It has also allowed science fiction writers who are not professional scientists to engage with scientists. It is science fiction's engagement with science that is critical to its emergence, and it remains critical to its existence today.

\section{2}

\section{Thought Experiments \& Games}

A science fiction writer's creative technique is identical to (and needs no more apology than) Albert Einstein's famous thought experiment on the experience of riding a beam of light that led to the Special and later General Theory of Relativity. A 'thought experiment' is a kind of intellectual game in which the laws and principles of science are translated into a different or allied context where they can be examined in allegorical or metaphorical terms in order to suggest more formal scientific applications. Thus, Einstein does not need to actually ride a beam of light, which would be in itself impossible, but rather to imagine that if he could ride a beam of light, certain consequences would follow that were otherwise consistent with science. Just as Relativity does not stand or fall on whether a human being can ride a beam of light but on the results gained by telescopes, nuclear reactors and particle accelerators, The War of the Worlds does not stand or fall according to whether there are Martians in tripedal fighting machines. Rather, the point is that if humans dominate the earth because we happen to be successful predators according to the principles of biology 
and ecology - for which there is plenty of scientific evidence - rather than divinelyordained destiny - for which there is no scientific evidence - then if a superior predator were to appear, our position would be challenged. In the novel, Wells plays by the rules of biology and ecology as he knows them, and of course we do indeed suffer a serious challenge to our supremacy. The novel is a thought experiment played consistently, with the one significant imaginary element being the Martians, but every consequence of their evolution and appearance being consistent with a scientific model of the universe, not a divinely-ordained one.

With the model of the thought experiment as a creative technique in mind, hard science fiction can be defined in this study as occupying a prominent position in science fiction's range because the degree of its rigorous fidelity to known scientific principles distinguishes it from other sets of fantastic literature and places it closest to nonfictional scientific speculation, which, as Stableford shows, is historically integral to the development of scientific romance and which still exerts a strong influence.

There are indeed many stories categorised as science fiction in which things known to be impossible still happen. However, there can be justification for this deviance. For example, both time travel and faster than light propulsion are only tenuously implied by quantum physics and are impossible according to relativity theory, but both are common means to particular ends. The Time Machine is not about time travel, but about social Darwinism as displayed through processes of evolutionary Darwinism. The time machine, while a marvelous hook to catch the reader's interest, merely allows the narrator to see the long-term implications of class divisions; the cognitive project is within the framework of sociology and biology, not physics. Likewise, while the starship Enterprise is a charismatic character as much as it is a transportation vessel and compels the kind of identification that makes it seem real to the audience, the warp drive of Star Trek is not the object of the narrative. Instead, it is a device (in the narrative as well as technological sense) that permits the crew of the ship to 'boldly go' and explore 'strange new worlds' and the resulting situations provide the true cognitive object of the narrative. This allowance of peripheral deviations or lapses of rigour in order to allow greater fidelity in the object of the narrative is essentially true of science fiction insofar as it is science fiction. 'Hard' science fiction would be that which reduces to an absolute minimum the peripheral deviations, while 'soft' science fiction may allow extravagant physical impossibilities to permit a focus on a sociological issue for example. These two 
represent a range of variation within an overall set of speculative literature, the common factor being the mode and process of speculation.

This selectivity of focus and willingness to suspend criticism allows literary science fiction to bypass one contradiction between literary and professional scientific practice: that science is progressive and necessarily discards the 'obsolete', while literature accumulates and does not discard The War of the Worlds, for example, simply because we now know that Mars is uninhabitable for blood-drinking octopoids.

Conversations between authors can take place outside the writers' community, logically enough considering science fiction's overt connection with the scientific community. An example of this process is the development of Larry Niven's Ringworld series, begun with the novel of that name in 1970. The original Ringworld was itself a 'Big Dumb Object', a ring encircling a star, spun at such a rate as to ensure artificial gravity on its inner surface by centrifugal force. This sort of extrapolation is typical of science fiction and generated a fascinating aesthetic image as well. From there, the story about the series of stories takes some interesting turns. Allegedly, when Niven arrived at the 1971 World Science Fiction Convention, he was greeted by placard-wielding protesters who were concerned not with any political or conventionally aesthetic issue, but with the orbital stability of his hypothetical object. The protesters were mathematicians and physicists who had calculated that the Ringworld would slowly drift off-centre, leading to catastrophe for its inhabitants ('Ringworld'). Other scientific critics found other problems, such as the tendency for rivers to deposit topsoil in oceans without any natural geological means to replenish it on land. Rather than ignoring or cursorily addressing these criticisms, Niven deliberately made them a basis of his creative approach to sequels. In the first book to follow, The Ringworld Engineers (1979) Niven suggested that powerful attitudecontrol jets, fueled by the Ringworld's own sun, could keep it centred and then explored the consequences of a breakdown of this system and its remedy as the basic plot line. Further extrapolations have generated further sequels.

Games of the sort described above do not exist solely to amuse, but rather make explicit the fact that science fictional writing and reading are self-conscious and are continually reinforcing the genre's internal connections and connections with science and referring to specific given questions for communal debate. Not only does this support the peculiar dynamic of the genre, it also serves to parallel the exchange 
of papers and criticism in the scientific community; this is not mere imitation, but a means of establishing a connection between the deductive and the creative through a synchronisation of processes.

Because science fiction is so closely aligned with scientific practice, it is not surprising that it has on one hand taken encyclopaedias and drawn stories from them, but also written stories that are encyclopaedias. Jorge Luis Borges was a great fan of encyclopaedias and they didn't need to be true to please him. One short story, 'Tlön, Uqbar, Orbis Tertius', is about an academic conspiracy to infiltrate into the body of accepted knowledge the history and culture of a fictitious world and science fiction has been doing the same (Labyrinths 27-43). Admittedly there is no deliberate deceit involved, but the object is nonetheless as serious as deceit: it is to inspire readers, already used to the conventional game of science fiction described above, to now imagine the present world placed in encyclopaedias as simply one entry among others in one encyclopaedia that describes simply one possible world among others.

Wells' own thought experiments could tend towards the self-consciously playful: his early essay, 'The Man of the Year Million' (1893) imitates the style of Carlyle's Sartor Resartus in suggesting a vision of a strange but possible state of affairs by the device of describing an imaginary book (H. G. Wells: Journalism and Prophecy 1893-1946 3-9). While science fiction is obviously fiction, it is by its history inseparably related to scientific practice and consequently it is an attempt to engage with that practice and create a cognitive map of the body and process of science by augmenting established fact with extrapolation. As a cognitive mapping system, science fiction explores the zone between fact and fiction that is conducted with the rigour of a game or thought experiment. Encyclopaedias and texts that are themselves thought experiments constitute a significant portion of current science fiction publication - and popular scientific nonfictional publication that is in all but name scientific romance of the original kind. For the sake of discussion, I will call the former type 'pseudofactual', these being texts that present themselves as factual texts describing fictional worlds in order that readers may sustain pretence, while I will call the latter 'quasifactual' because they relate to scientific practice and factual texts as their sources and use speculation to provoke further thought in the manner of thought experiments. Of course the two categories approach each other and overlap, as we shall see, and that overlap is itself yet another symptom of the dynamic interrelationship of science and science fiction. 
Science fiction fandom has embraced pretence as a social activity, which is not unusual to literary appreciation, but it is unusual in the degree to which it is done and the manner in which writers, publishers and studios foster pretence. There is a vast industry of fan fiction, parody and film, slash fiction, cosplay (making and wearing costumes based on those of fictional characters), role-play and so on. The studios that own - in a legal and financial sense - Star Trek and Star Wars seek to control and exploit this phenomenon through copyright, sponsorship, merchandising and occasional indulgences (independent creative work by fans is sometimes permitted provided that it is not for profit or deemed offensive) and their regulation of what is 'canonic'. Fans on the whole collaborate willingly, and the most pedantic are especially aggressive in arguing for absolute consistency of 'canon' or the 'true' history of their fictional universes.

These fans are abetted in their desire to fix the 'facts' of their imaginary universes by the numerous 'technical manuals' and 'official novelisations' supporting the ponderously complex franchises of Star Trek and Star Wars, which serve to 'canonise' chosen texts by their references. The establishment of a body of canonical texts supports the identity of the studio-owned whole by drawing a line between the 'official' and the 'unofficial', excluding in particular erotic slash fiction (the parallels with urban demarcation between civic life and wild nature as described by Rykwert should be obvious). Hence, as their goal is to establish fixed truths in the realm of fiction, the term pseudofactual is appropriate as a description.

Another unusual and significant factor in fandom is the fact that many people in the field begin as fans and end as authors, starting first by creating non-commercial fan magazines or 'fanzines' in the past and blogs and podcasts today and then quite often moving on to becoming major producers of literature (see Aldiss and Harrison for memoirs by Pohl, Aldiss etc). Science fiction reading tends to cross boundaries between readership and authorship as a social phenomenon, as a career path and as a reading/writing strategy.

As opposed to the commercially-dominated franchises, the quasifactual encyclopaedia does not depend on strict demarcation of official and unofficial interpretations, but functions as an alternative to linear narrative in exploring the form of their underlying schemae. A quasifactual text is often deliberately open-ended, inviting further creative description as either a tool for pedagogy or inspiration for play - or both. Its origins lie more in the speculative essay written by a professional 
scientist outside the forum of scholarly journals or an interested popular journalist wishing to educate the public on real scientific processes and principles through imaginative illustration. This tradition of scientific romance exemplified in Wells, Haldane and Stapledon continues in a currently thriving mode of quasifactual documentary in a variety of media. Scottish palaeontologist Dougal Dixon has produced a number of books, all of which are rich illustrations of detailed alternative and far future evolutionary scenarios in which humanity is represented as but a minor participant (or, as in the case of The New Dinosaurs, absent altogether). Stephen Baxter has also, in Evolution, attempted a Stapledonian narrative of life on earth from the extinction of the dinosaurs to the end of all life on earth, while his vast Xeelee sequence has many passages and stories that are deliberately modelled on encyclopaedia entries and essays ('Secret History’ Vacuum Diagrams 327-339). In addition, there are a number of websites devoted to encyclopaedic descriptions of imaginary worlds that are still based on serious extrapolation such as those by the artist Nemo Ramjet (now offline). Wayne Barlowe's art book Expedition (1990) became the basis of a speculative documentary, Alien Planet (2005), featuring eminent scientists such as Stephen Hawking discussing the issues that it raised. The phenomenon shows no sign of abating, and if anything, will most likely grow.

Significantly, as opposed to the Star Wars and Star Trek pseudofactual encyclopaedias, Dougal Dixon's texts are presented as variant iterations from the initial set of conditions, an intention that is emphasised by the nearly identical graphic design and structure of his books. In his first book of the set, After Man: A Zoology of the Future (1981), history has proceeded as we know it up to the present and shortly beyond, but at some near point, humanity is assumed to become extinct and fifty million years later, a new biosphere has emerged, descended from the flora and fauna that we have permitted to outlive us (the descendents of rats do particularly well). The next year, Omni magazine published an alternative scenario by Dixon, 'Visions of Man Evolved' (Weintraub 90-5), depicting the man of the year fifty million, who closely resembled Wells' man of the year million. In The New Dinosaurs (1988), whatever circumstance it was that caused the extinction of the dinosaurs failed to occur and the setting is the present day minus humanity but filled with the progeny of an extended Mesozoic era. In Man After Man (1990), none of these scenarios is true and instead humanity itself is seen as subject to the evolutionary phenomenon of adaptive radiation. Most recently, a television series, The Future is Wild (2004), and 
its associated spinoffs, has returned to the premise of human extinction in the near future, but substantially broadened its scope of time by extending itself out to two hundred million years with a hint of further evolutionary possibilities (and broadened the base of expertise through collaboration with scientists in many disciplines). Notably, neither 'Visions of Man Evolved' nor The Future is Wild are direct sequels to After Man; they share none of the creatures or conditions depicted in that book, but start afresh, 'rebooting' the scenario in current parlance. In all these cases, despite and in fact because of their variations, the schema to be delineated is that of Darwinian theory; it remains changeless, only its iterations vary.

The intention of these quasifactual encyclopaedias is to teach through play. Evolution is not treated as a rigid deterministic process, but as game with a set of rules and initial conditions. In order to read and comprehend quasifactual texts, it is necessary to hold within one's mind the variations side by side - which is not at all the case with the pseudofactual encyclopaedias which are by their nature exclusive. However, that exclusivity becomes unstable where the pseudofactual and the quasifactual overlap and pretence is revealed more clearly as a part of the process of learning. On one hand, Dixon et al's The Future is Wild serves a pedagogical role in presenting the processes of evolution in an entertaining way, as had Wells' 'The Man of the Year Million', but it also spawned a theme park ('The Future is Wild') and an animated television series that was entirely a fictional narrative in its form rather than imitating the form of a wildlife documentary ('The Future is Wild' (animated TV series)'). On the other hand, crossing over from the realm of pseudofact, Lawrence Krauss wrote The Physics of Star Trek (1995), a nonfictional book that specifically addressed the elements of the Star Trek universe and discussed their possibility according to late twentieth century physics. There have since been many other books of a similar kind addressing the biology of Star Trek and the implicit scientific background and possibilities of other science fiction franchises.

Science fiction, we see, has a deliberately ambiguous relationship with science fact and has, from its emergence as scientific romance, engaged with philosophical questions provoked by scientific discoveries. Because of this relationship, science fiction and scientific speculation and pedagogy have been consciously tied together as a set of games or thought experiments by both writers and readers. Any workable definition of the genre must take into account the fact and nature of this engagement. An account that looks at this engagement as an ongoing process with over a century 
of history behind it is able to reveal the role of play and debate in the maintenance of the genre, and also the kinds of games and discussions that evolve in scientificallyinfluenced culture.

\section{3}

\section{Estrangement}

When one is engaged in a game, one is estranged from the rules of the mundane, but as science fiction is intended to serve a pedagogical purpose, the material that one absorbs in a state of engagement with the game must also be applied in the mundane realm. One therefore oscillates between states of awareness, shuttling information back and forth. Writing in Metamorphoses of Science Fiction (1979), Darko Suvin identifies what he implies is the heart of late twentieth century science fiction as a genre utilising a realist mode or style, in which crucially, its 'necessary conditions are the presence and interaction of estrangement and cognition, and whose main formal device is an imaginative framework alternative to the author's empirical envionment (7-8, emphasis in original). Specifically, it is dependent upon cognition and excludes obviously or exclusively supernatural or metaphysical means of estrangement. This enables a detached, critical perspective that is able to accommodate 'the narrative dominance or hegemony of a fictional "novum" (novelty, innovation) validated by cognitive logic' (ibid 63, emphasis in original). This critical perspective is then useful in illuminating the conditions of the mundane, as Wells' narrator in The War of the Worlds is able to conclude his story, once again in the same physical world of his house, but now possessed of superior insight encompassing a far greater universe than he had previously contemplated.

Cognitive estrangement can use the dispassionate language of science disingenuously, as is the case with Wells' cool, systematic descriptions of things that he knows to be perfectly repellent to his readers. The technique of logically consistent argument and description deliberately strips away any immediate emotional defenses a reader might have against what would seem to be an awful proposition. For example, Wells' Martians, as depicted in The War of the Worlds, seem repellent in every way, and yet throughout, the literate, scientifically-minded narrator argues for their case. He suggests that their invasion is no worse than British imperialism and 
may in fact be morally justifiable as they lack the complacency of their Edwardian victims and are motivated by survival; that their grotesque bodies are simply the likely result of a chain of evolutionary changes leading from a basically humanoid form; and that their blood-drinking is really no worse than what human carnivorism would seem like to an intelligent rabbit.

One can read a horror story such as The Silence of the Lambs and be repelled by Hannibal Lecter's refined cannibalism, but when the book is closed, Lecter remains an extraordinary human being; humanity itself as a category is not suddenly removed from its pedestal as lord of creation and put down amongst the rabbits and other 'beasts that perish'. Satirical fiction, and fantastic satirical fiction does achieve this effect: Jonathan Swift's exchanges of scale and substitutions of humans and horses achieve this effect too, and of course this was what science fiction took from Swift via Wells himself. The innovation of the genre is to present such seeming absurdities of beasts becoming humans and humans becoming beasts not as extraordinary phenomena, but as inevitable consequences of the system of thought (and its technological application) that had supposedly allowed human supremacy in the first place.

Other genres, such as utopian (and dystopian) fiction, or historical fiction that describes societies with radically different ethics to our own but which still have sympathetic protagonists, can also achieve the disturbing thrill of estrangement. In the case of satire, utopian polemics and historical fiction, one has to be able to subscribe to the intellectual processes of the relevant discipline: political science, historiography and so forth as appropriate. Science fiction, as I have indicated, depends strongly on pretence and in order to carry out a pretence, it has to be potentially possible at least to be convinced by the mechanism of estrangement, that is scientific extrapolation. It is like satirical, utopian and historical fiction generally in that one has to be able to engage with an attendant system of knowledge; it is unlike them individually in that the particular system of knowledge that one must engage with is science.

Suvin's definition of science fiction as 'cognitive estrangement' addresses a crucial point about its methodology. While games have been mentioned, we must now consider the rewards of that process: the aesthetic pleasure of reading science fiction. 


\section{4}

\section{The Sense of Wonder}

The pleasure that one gains from science fiction depends on the set of knowledge and attitudes that one brings to it. Joanna Russ points out in her essay, 'Towards an Aesthetic of Science Fiction' (1975) that science fiction often depicts landscapes and beings that would be nightmarish in any normal earthly context, but are logical consequences of natural law and are best treated as such by both the author and the assumed reader (To Write Like a Woman 8-9). The abiding ethos of science is that the universe is explicable and therefore what appears to be strange cannot be irreducibly so and anything that is immediately perceived as horrific is potentially normal and even enchanting. As an example of the application of inappropriate cognitive tools Russ brings up the example of a critic (whose name she does not recall) who applied psychoanalytic reasoning to the analysis of science fiction stories and concluded that the 'grotesque' apparitions of science fiction - strange landscapes and creatures were inherently nightmarish and should be interpreted as such. Russ' own view is that this highlights what separates science fiction from other forms of literature because the appropriate attitude to take, particularly in the case of a rational 'hard science fiction' author like Hal Clement, is to learn to regard a novel apparition as being at first wonderful and then to see it with 'affectionate familiarity' (ibid 9). The 'sense of wonder' that characterises science fiction is both the point of congruence and divergence between the aesthetics of science fiction and other genres.

The sense of wonder is not simply surprise and awe at the inexplicable that may be assumed to be permanently so, but the wonder that one feels in either learning a novel fact or encountering a mystery that one is certain will eventually be understood. This is different from the Romantic notion of the sublime, which is timeless, because it assumes a progressive linear change in the self and the world. Sublime phenomena may be observed again and again and remain irreducibly mysterious in their essence, but a novelty manifesting and investigated in a scientific system can appear as such only once.

Writing in The Encyclopedia of Science Fiction's article on the 'Sense of Wonder', Peter Nicholls and Cornel Robu find it most useful to link the term with the traditional definition of the sublime, noting that a number of critics have identified the 
sublime as a key to the sense of wonder, and allied with some form of conceptual breakthrough, that is 'a sudden opening of a closed door in the reader's mind' ('Sense of Wonder' 1084). This latter component is important as it arises not from the static, timeless appreciation of the natural sublime as described by Burke, but from a cognitive transformation in the reader's mind; not only is a marvellous phenomenon presented, but the engagement of the participant's intellect produces in them a dramatic alteration of their perceptual and cognitive capacity. Unlike the experience of the sublime, which can be repeated again and again with the same great mountain or a succession of similar storms, the sense of wonder cannot be repeated with the same phenomenon. It is generated in the moment when the mysterious becomes significant and potentially knowable. Once it is known, it is no longer mysterious; once a paradigm shift has occurred, the phenomenon is no longer unprecedented. The mysterious in science fiction has a very short half-life: it soon decays - but then ongoing enquiry forever produces new mysteries. A novelty is introduced for the sake of thrilling the reader with its inexplicability but then it must be progressively demystified (or at least we are led to believe that this will be the case). The pleasure that results from the sense of wonder stems from the reassuring knowledge that the unknown is imminently to become known.

As well as its pleasures, science fiction has its tragedies. The nature of science fiction's tragedies, Russ writes, is also a critical distinguishing and necessary characteristic:

The Time Machine is not about a lost Eden; it is - passionately and tragically - about the Three Laws of Thermodynamics, especially the Second... Unless a critic can bring to The Time Machine not only a knowledge of the science that stands behind it, but the passionate belief that such knowledge is real and matters, the critic had better stay away from science fiction (To Write Like a Woman 8).

Now, there are other specialised disciplines and genres that produce their own sensations of thrill and despair. Again, like other genres, science fiction requires that one be willing and able to engage with a specialised field of knowledge and learn to respond to it also at an emotional level after having approached it intellectually (or at the same time), and unlike those other genres, it is specifically scientific knowledge 
that must provoke those aesthetic and emotional reactions. In the example she gives, it is the Second Law of Thermodynamics, which among other things, determines that cups of tea will become lukewarm if unattended. It is not a normal person that sees tragedy in the cooling of tea: it is under most circumstances an unremarkable phenomenon. However, if one becomes willfully estranged from the system of thought that makes the cooling of tea unimportant and meaningless and engages with the cognitive system of physical science, then the cup of cooling tea is an intimation of a profound and tragic fact. On the time scale envisioned in The Time Machine, the cumulative effects of entropy are vastly more important than any single human life or love.

Russ demands a particular critical mode because it is in correspondence with both the composition and the reception of science fiction, which is distinct from the other modes or genres that have developed in 'mainstream' culture at the same time. If we return to Lem's critique of anthropocentric aesthetics - 'We have no need of other worlds. We need mirrors' - which he puts in the mouth of Snow in Solaris, we must realise that honest science fiction cannot afford the resort to earthly similes. A new world demands new frameworks of comprehension. We cannot confront the novum of a science fictional tale with blind amazement and neither can it be related to earthly experience. This strange tension that is part of the unique pleasure and thrill of reading science fiction demonstrates Russ' point that one has to bring new critical faculties to science fiction, specifically a scientific awareness, in order to extract the proper aesthetic experience from reading.

Arthur B. Evans argues in his Jules Verne Rediscovered (1988) that entertainment and the experience of the marvelous went hand-in-hand with instruction (18) and H. G. Wells was happy to describe his own work as 'an assault on human self-satisfaction' (The Complete Science Fiction Treasury vi). Certainly Wells was influenced by such satirists as Swift, but even more than Verne he was enmeshed in the scientific mode of detached analysis and instruction as it continued to evolve from 'natural philosophy'. Didactics does not exclude aesthetics, and science fiction treats the experience of revelation and instruction as aesthetic experiences in their own right. While it alienates many readers who are generally unfamiliar with science fiction, the pleasure of the strange and of understanding the strange is the basis of another characteristic feature of science fiction, the pedagogical 'infodump'. 


\section{5}

\section{Epics in Miniature Portions: Infodumps \& Future Histories}

It is a consequence of science fiction's heritage of scientific romance and the speculative essay that the genre still - wilfully - deploys the 'infodump', which is typically a miniature essay inserted into a narrative that may or may not be put in the mouth of a character speaking to another, but is really addressed to the reader (and usually beginning, as cliché has it, 'As you know, Bob...'). Another characteristic tendency is the habit of authors to create grand future histories into which they embed their stories like jewels in metalwork.

It is when science fiction is truest to its heritage of scientific romance that infodumps come into their own; human individuals are subordinated to or at best share the stage with natural forces in a literature that is engaged in Aldiss' search and shares with the Gothic a fascination with the power of nature. Nonsentient objects and forces are treated on the same level (at least) as human characters without the option of personification that exists in allegorical or mythological texts. This quasiessaying technique also permits an expansion of scale well beyond the individual human experience into the cosmic, as is entirely appropriate.

It is at the superhuman scale of perspective that realist science fiction approaches metafiction. Few authors (with the notable exception of Olaf Stapledon) have been brave enough to abandon character entirely except in speculative essays, but in many cases of authors cognisant of their heritage in scientific romance such as Brian Stableford and Stephen Baxter, characters plainly exist only as viewpoints and surrogates for the reader. Neither of these authors is unusual in creating elaborate future histories - Baxter most notably with his Xeelee sequence and Stableford with his Emortality series.

There are three reasons for the frequent use of future histories (pioneered by Robert Heinlein and Isaac Asimov). The first is quite banal, but inescapable: in the mid twentieth century, there was a restricted market for science fiction and authors were likely to see their work published only as short fiction in magazines; if an author had the ambition to tackle a novel-length narrative or greater, then they had to serialise it or compose it as a linked series of short works that might hopefully be published one day as a collected edition, called a 'fixup'. This is the case with Isaac 
Asimov's first Foundation trilogy, for example. The second is that a great deal of effort can go into creating a fictional world and an author is reluctant to discard it. The third - which is the most compelling - is that it provides the opportunity to expand a plot beyond that of an individual human being's lifetime and into the scale of history, making visible the great but slow and subtle forces that would otherwise be unnoticed. On such a scale, the protagonist is not one person, but a civilisation or a species.

Stableford's Emortality cycle (1998-2002) is a fine example of the future history and the infodump. It is a series of six novels examining the emergence of posthuman species and the attitudes of changing societies to death brought about by genetically-engineered indefinite life extension ('emortality'). ${ }^{*}$ Obviously his characters are long-lived, the essential motive for his writing being an interest in exploring the consequences of extreme longevity, but nonetheless, great social changes span not only centuries, but in this case a millennium and interstellar distances as well, with manifold social and technological consequences. No single character can hope to plausibly witness them all in any meaningful depth. Nonetheless, there is one character, Mortimer Gray, a historian whose life and writings provide a cross-section of the Third Millennium that spans the series (The Fountains of Youth, 2000). Gray's great literary project, for which Stableford offers a précis of each volume to open each section of the novel, is a history of humanity's history-long war with its greatest adversary: death. Nor is emortality merely a useful a novum introduced by the author into his future society because it is convenient for his storytelling; it is one the most powerful weapons used by humanity in a war that has crossed millennia and involved campaigns in the fields of metaphysics, medicine, space travel and genetic engineering. As the series of novels concludes, the solar system itself is about to be fortified against a malignancy overtaking the galaxy; the war goes on, at ever-greater scales.

\footnotetext{
* The background historical scenario was first presented in Stableford and Langford, 1985. A short story 'And He Not Busy Being Born...' (1986) preceded the series and a novella, 'Mortimer Gray's History of Death' (191995), was expanded into The Fountains of Youth. The six novels are, in order of the narrative timeline, not order of publication: The Cassandra Complex, set in 2041; Inherit the Earth, Dark Ararat, Architects of Emortality, The Fountains of Youth and The Omega Expedition, which is set in the thirty-first century. An outline of the publication and narrative history is given by Stableford in the acknowledgements and introduction to The Omega Expedition 7-19.
} 
Science fiction tends towards the epic: it cannot avoid it, because natural laws that present themselves at intimately small scales are also inevitably present at intergalactic scales. Even cups of lukewarm tea, by demonstrating the Second Law of Thermodynamics, hint at universal doom. In every science fiction tale derived from some universal principle, there is a potential epic. An essayist like Stableford speaking in the voice of Gray can explain the implications of natural phenomena in lucid detail, but there is an alternative technique, and that is to remind the reader of great scale and great stakes, and then to let their own knowledge do the work of filling in the detail in darkness.

\section{6}

\section{Panoramas of Thought}

Complementing the author who tells us everything, there is the author who tells us as little as possible, but indicates by oblique gestures the greater structure supporting their individual stories. Of course an author may well be building their future history or grand scheme at a pace only slightly faster than that of the reader. The construction may be done incrementally, but it will be done with a sense of the overall theme and purpose in mind, even if the details are determined by contingency and fiat.

The ideal science fiction structure is like that of an ancient city: it is inhabited - by the reader - and the mode of inhabitation shows awareness of and is in accordance with the schema of the imaginative universe of the author. While nominally a horror writer, H. P. Lovecraft had close affinities with science fiction, particularly in his later and greatest stories such as 'At the Mountains of Madness' (1936) and 'The Shadow Out of Time' (1934). In both of these tales, vast ruined cities illustrate not merely inhabitation, but an order of the world: the beings that created those cities expressed in their form, which seems so horrible to their human explorers, a sense of cosmic order arising from their own perceptions and thinking. Both of these stories too are constructed not as strict chronologically linear narratives, but as intricate structures to be explored, disassembled and cross-linked by the reader. Michel Houellebecq's essay, H. P. Lovecraft: Against the World, Against Life (1991) 
contains a quite striking insight into Lovecraft's understanding and treatment of architecture.

One discovers architecture progressively and from a variety of angles, one moves within it; this is an element that can never be reproduced in a painting nor even in a film; it is an element Howard Phillips Lovecraft's stories successfully reproduced in somewhat stupefying fashion. [...] For, like great gothic or baroque cathedrals, the dream architecture he describes is a total architecture. [...] H. P. Lovecraft's architecture, like that of great cathedrals, like that of Hindu temples, is much more than a three-dimensional mathematical puzzle. It is entirely imbued with an essential dramaturgy that gives its meaning to the edifice. That dramatizes the very smallest spaces, that uses the conjoint resources of the various plastic arts, that annexes the magic play of light to its own ends. It is living architecture because at its foundation lies a living and emotional concept of the world. In other words, it is sacred architecture (64-7).

Houellebecq's unusual and illuminating phrase, 'imbued with an essential dramaturgy', reveals the confluence of narrative and architectonics. Very little of importance actually happens in Lovecraft's best stories; we are told what has happened, we read of tangled family histories and ambiguous documents and psychiatric case histories, but we are rarely there to witness things directly and confirm that they did indeed happen. Even when there comes a moment of revelation, the unveiled monster is frequently 'indescribable' or inexplicable. That, however, is the point: one is led to deduce and once enough hints have been offered, it is very hard to stop. The eye sees (dark) stars and the mind makes a constellation... but Lovecraft has already designed that constellation and the communication between author and reader is not by direct communication, but by a tacit process of suggestion and encouragement. He is more obscure than someone as explicit as Olaf Stapledon, but his intended scope is almost as great.

Lovecraft's stories are a means by which he describes a cosmologicalarchitectonic construct, something more profound than a generic literature machine: it is a generative schema. The same can be said of science fiction texts in general as narrative thought experiments: the author defines premises and parameters according 
to consistent scientific or quasi-scientific principles and the story traces its way through the possible pathways of the schema. Certainly alternative pathways can be followed than that written by one author, and that is the nature of postmodern reading. We will see also however that these schemae can be classified and given genealogies or lines of descent that are in fact competing and interacting lines of argument in the science fiction genre's long open discussion with itself.

The pleasure of the infodump is the complement of the thrill of Lovecraft's lacunae. Olaf Stapledon's Star Maker and Last and First Men are brightly-lit, explicit mandalas, ordering the individual species of the solar system and the cosmos at large. It is very much a view from high abstraction. In Lovecraft's case and any other author who strategically deploys incompletion as a technique, one is terrified less by what one reads than by the thought of the blood-lubricated cosmic machine that the reading compels the mind to envisage. In both cases, narrative is a method to carry the reader to a point of sufficient elevation where they can survey the great schema laid out before them, be it in bright sunlight or chiaroscuro.

The genre of science fiction shares a unique history with science in the modern era, emerging with science as its speculative counterpart and evolving alongside it in that role. Because the appreciation of science fiction has required in the reader a certain sensibility attuned to science as a potential source for aesthetic experience, it has introduced its own peculiar sense of what is marvellous and pleasurable. It has also crafted a sense of the epic and the intricately structured to create schemae of grandeur and horror according to its peculiar aesthetics. The purpose that it has served as an historically-evolving genre is to find a definition of humanity and its status in the universe that will stand in the light of science. The questions then are as follows: How has that definition been progressively explicated? What are the sides of debate on this issue? How have they emerged and how do they engage with each other? How can we describe them? 


\section{4}

\section{The Three Orders}

In bridging science and literature, science fiction faces a dilemma: science is progressive, discarding theories that are no longer tenable, whereas literature, while it still clearly moves through its own historical and stylistic processes, does not classify older texts as 'obsolete'. If it belonged entirely to science, science fiction would be bound to practice a rapid and ruthless turnover of its canon, but it is a literary genre, bound also to respect its heritage. Science fiction's solution is to cast itself as a 'conversation' amongst a community wherein older texts and tropes are revisited and reinterpreted according to newly emerging cultural and literary paradigms.

Bearing the above in mind it is possible to create a history of science fiction that acknowledges the historicity of the genre and its progressiveness at once, provided that the dual scientific and literary nature of science fiction is acknowledged and that an appropriate structure for interpretation is utilised. We will not see a simple directed progression through various cultural-epistemological gateways, each opening and closing at specific dates, and neither shall we see a mere multiplication of subgenres. Aldiss' charter definition has remained at the heart of science fiction where the genre has remained close to science itself, and it is proper therefore to construct a critical framework that will enable treatments of the questions about the nature of humanity and its place in the universe to be placed in scientific, historical and literary contexts, revealing both their ongoing evolution and their allegiances to particular schools of thought.

I propose, as a means of investigating science fiction's project, to come to a scientifically-tenable literary definition of humanity, a system of 'Orders'. These Orders are not genres, sets of discrete texts or styles, because identical arguments can be expressed in differing styles, and neither are they specific ideological positions, because they arise from an analysis of the world that must first begin with an intellectual system. Instead, an Order is a set of conceptual structures that rests on an existential schema describing an architectonic relationship between humanity and the 
universe as revealed or generated by science's interface with culture at a given moment, and which can generate narratives that also serve to reveal those structures.

Ideological and aesthetic systems are not fundamental, but are also generated by the Orders as an expression of the rules embodied in an Order's schema. They share common premises but may be divergent - sometimes radically so - in their political interpretations of those premises. Overall, science fiction concerns itself with the perceived fundamentals of the universe and an appreciation of its vast scale and complexity far beyond that of immediate human experience; from that common appreciation there follow diverging strategies within science fiction to construct a comprehensive relationship with it. In the mundane sphere, for example, a Marxist and a libertarian are ideologically opposed, but both are basing their ideologies on a shared materialist perception of the world; the Orders as I describe them cohere and display diversity in this way.

It is in science fiction's nature, according to Aldiss' charter, to investigate the deep conceptual bases of our engagement with the universe. This is often done through the means of thought experiments in which a single system of thought is elaborated or differing systems are contrasted. Diverse Orders may be present in a single text so that they may interrogate each other, but for the sake of clarity the Orders will first have to be defined according to texts that are most clearly emblematic and which relate with minimal compromise to specific architectonic systems. It is following a definition of the major Orders and their particular dynamics that the more complex interactions between them can be understood - but it is of course the fact that Orders can produce complications that makes them what they are.

As we are dealing with science fiction that follows Aldiss' charter, the Orders are defined according to their approaches to the question of humanity's definition of itself and its place in the cosmos. I therefore posit the existence of a Modernist Order that bases itself on a system of Cartesian logic and spatiality, and two other Orders that address perceived flaws and contradictions in Modernism: Neohumanism, which attempts a synthesis with pre-scientific humanist traditions, and Posthumanism, which is deeply sceptical of the implicit (and explicit) anthropocentrism of both and is even for that matter sceptical of definitions themselves, preferring continual and contingent iteration. All three have emerged at the interface of science and culture and all three have constructed architectonic systems that serve Aldiss' charter. Their emergence and interaction can be described according to a model analogous to that of the social 
historian and theorist, Raymond Williams, who in Marxism and Literature (1977), plotted the emergence and interaction of multiple forces in the social and ideological arena in terms of relative rises, falls and persistence rather than linear succession.

\section{1}

The Three Orders \& Their Emergence

I propose the three Orders as a critical framework for investigating how science fiction has addressed in particular Brian Aldiss' charter definition of the genre. It is by no means an absolutely comprehensive system, considering the diversity of questions actually asked by science fiction writers, but it is possible to extend, modify or add to the framework to look at other issues, or questions asked with different emphases.

An Order must be understood as a generative schema. It is a set of related and mutually-reinforcing concepts that reveal a consistent logical structure, and any product of an Order must consequently embody that Order's own structural concepts in terms of knowing, subjectivity, cosmology, teleology and relation to technology. An Order is more than a literature machine because a machine and its productions are separate whereas an Order will acquire and embody its own canon, altering itself as it does so. Because it changes, it will undergo emergence and evolution and complex dialogue with other Orders. The concept of the science-fictional 'Order' itself indicates its particular quality of both establishing rules and compelling diversity: it has at least as much of an affinity with the architectural usage of the term as it does with Linnaean taxonomy and religious devotion. There are, for example, the basic orders of classical architecture - the Doric in its Greek and Roman variations, the Tuscan, the Ionic, the Corinthian and a synthetic order, the Composite. Each has a particular character, suited to the temples of particular deities; the sturdy, simple Doric suits the temples of the warrior Ares and the 'Earth-Shaker' Poseidon whereas the Ionic, traditionally seen as feminine in its proportions, usually characterises the temples of Aphrodite.

An Order might also suggest the nature of a religious denomination and this is also a useful connotation, as we can understand that they are defined by a particular credo and set of customs and observances. Both the Jesuit and Franciscan Orders are 
a part of the Catholic Church, but each is distinguished by their specific theological and mundane emphases and practices.

In taxonomy, an order represents a pattern that both connects and distinctly categorises diverse species (some of which may even prey upon each other); in architectural practice, the orders have not been absolutely constant in their proportions as built (as eighteenth century Neoclassicists had hoped), and religious orders are of course rife with infighting. As I have remarked above and as we will see later, science fiction's Orders often engage with each other constructively or antagonistically - even within the same text. A literary Order then is not an exclusive intellectual category defined by impermeable boundaries as is the case with Darwinian evolutionary science (which excludes divine intervention, for example), but a dynamic and syncretic system where ideas and themes are exchanged and assimilated between seemingly alienated systems.

As I propose to define them, the Orders of science fiction continue a multistranded conversation about the definition of humankind and its place in the cosmos. To distinguish the definitions given within the context of science fiction from their more general (and therefore familiar) usage, capitalisation has been used. For example, Modernist science fiction is the particular Order to which I refer, modernism is the cultural and epistemological milieu from which it has emerged and from which it derives many of its characteristics.

As I wrote in a previous chapter using the analogy of a telephone, a genre does not really exist until a substantial body of work exists that can only be interrelated according to a new generic classification. A new Order will also divide from one that already exists, often drawing on the same texts and addressing similar issues to that of the first, but with altered priorities and understanding.

Raymond Williams' historical model in which multiple cultural modes coexist simultaneously offers a very useful prototype here. In Williams' model, one can visualise several overlapped bell curves: one is rising or 'emergent', another has peaked or is 'dominant' and another is in decline or 'residual' (121-7). Taking a slice at any point along the horizontal axis that represents time, one will find proportions that vary according to the point chosen. One of the most important features of his model is that it shows that while one element can be dominant, it need not - and maybe can not - be absolutely and exclusively so; other elements may be present and active, inevitably therefore standing in contrast, influencing the dominant and 
potentially able to rise to a higher standing. There may also be a long and significant influence that is not obvious from an observation of superficial popularity; for example, Frankenstein is rarely on the bestseller lists today, but its permeation of our culture is undeniable and quite the opposite is true of many ephemerally popular multi-volume epics.

The persistence of residual or emergent elements 'under the radar' of the dominant cultural formation is highly significant for both the dominant and its nominal inferiors. Three interelated mechanisms of cultural transmission work to extend the influence of a relatively less powerful formation: atavism, assimilation and leverage.

By the presentation of class division as species division - and dependence - in The Time Machine, Wells suggested that the classical Marxist interpretation of class or cultural struggle is basically Darwinian in that it presents an image of beasts contending for limited resources and slowly evolving through mutation and adaptation. In the Darwinian model, there is no fundamental discourse across species boundaries because genes are transmitted through linear descent; once species are divided, one may prey upon another, but neither can create some new synthesis. However, given the recursive nature of literature, culture is atavistic and Lamarckian, utilising 'memes' rather than genes. This means that characteristics can be acquired rather than inherited, and moreover, they can cross generational and species barriers. For example, an old text may continue to exist on a library shelf long after its period of dominance or obvious presence has ended, but it may still be rediscovered and appreciated many years later. When this is done, the new reader will interpret it according to their own cultural biases and if they make use of it in their own writing, appropriated concepts may undergo further alteration. It is because of this, that when constructing a history of the relations between the three Orders, attention should be given to the exchanges between them, the process by which they occur and the results that are manifested in each.

Dwight D. Eisenhower is supposed to have quipped that 'all isms are wasms', and by that he meant that once something is identifiable as a distinct form, it is already on its way into the past. In a modification of that statement, we can say that once a movement emerges, it acquires shared foster ancestors. Cases in point here are H. G. Wells' scientific romances, Olaf Stapledon's epic Last and First Men, and J. D. Bernal's The World, the Flesh and the Devil (1929). Neither Wells, Stapledon or 
Bernal wrote consciously as Posthumanists, the term not having been coined nor the cultural circumstances supporting it being extant during their careers. Nonetheless, these texts are vitally influential amongst writers who can be regarded as Posthumanists. The tendency for science fiction to revisit older texts and reinterpret them according to new cultural paradigms means that many of the foundation or canonical texts of a given Order may predate its full emergence by a considerable period and may also be shared with another. The Time Machine (1895), for example, is grounded in Darwinian scepticism of imperialism and human supremacy and Wells' overt message needs to be read with an understanding of its late Victorian origins. It was also based on a particular model of time as being a fourth linear dimension analogous to the spatial dimensions. Social forms and knowledge of physics moved on considerably in the century after its publication, and Stephen Baxter wrote a sequel, The Time Ships (1995), that both incorporated new paradigms of time and blended more-or-less seamlessly with Wells' original story. Therefore, in the case of Wells and other authors, one can learn more by looking at them in their contexts and then looking at how their work has been reinterpreted according to the agenda of a later Order. Bruce Sterling is quite clear about how he assimilates the influences of his predecessors and singles out Bernal as a key influence in his introduction to a Posthumanist text, Schismatrix (1985), but consciously isolates evolutionary ideas from Bernal's Marxist matrix (vii). As is the case with Frankenstein, a text largely unread or at least certainly not dominant in the cultural marketplace in its pure form can nonetheless have a 'leveraged' influence through the agency of individual authors who have read it and are more dominant at a given time.

Wells, Stapledon and Bernal also provide a foundation for Arthur C. Clarke, who is a complex figure in science fiction. On one hand it is tempting to describe him as a Modernist, but his attempt to synthesise science with the patterns of myth (as a sincerely extrapolated consequence of his law that any sufficiently advanced technology is indistinguishable from magic) is most apparent in Childhood's End and 2001: A Space Odyssey and potentially aligns him with Neohumanism. The same can be said of the nominally hard science fiction writer (and Clarke's occasional collaborator) Stephen Baxter, who likewise writes novels of Stapledonian scope. On the other hand, all of these texts, by using immense scales of space and time, undermine anthropocentrism, which could be sufficient cause to place them within the framework of Posthumanism. 
What can determine the rise to influence of a text, or the elements of a text, is a scientific or technological innovation or an emerging social paradigm and critical or activist method that can indicate that something previously unimaginable or unconsidered is suddenly of crucial significance. Two examples here are cybernetics and feminism. First, cybernetics concerns the interaction of mechanical systems, permitting the reconceptualisation of machines and by implication, human beings too, not as isolated and discrete entities, but as inevitably connected by networks. Samuel Butler, for example, proposed two ways of imagining the future of machines: one in which they will come to dominate human beings and another scenario in which humans and tools become integrated systems. The latter has been neglected in both science and fiction until fairly recently, when it has suddenly risen to significant influence.

The other major example is feminism. Under a Cartesian paradigm, thought is distinct from flesh and therefore intellect is ungendered. Stanislaw Lem, normally a rigorously self-critical thinker, considered women a special case who should be included in fiction only if specific but strangely unspecified circumstances made this necessary (Swirski A Stanislaw Lem Reader 56). Poul Anderson, in response to criticism from Joanna Russ, claimed that science fiction is essentially 'cerebral' and therefore women are a largely irrelevant special case (Mendlesohn 51). Implicitly, and even explicitly, under such a formulation the 'cerebral' is the ideal and the male is the norm and they can be cerebral and women cannot. Naturally, a critique of the inconsistencies of such a value system can lead to a reevaluation of the agendas and tropes of works given and denied value accorded by it: matters which were dismissed as trivial become vital and supposedly self-evident conclusions become suspect. Texts and elements of texts are likewise revaluated and reinterpreted, critical hierarchies are upended and new interpretations are produced. Once this process is well-established, a feminist school of science fictional criticism and practice can be seen to emerge and exhibit the characteristics of an Order fundamentally distinct from that of Lem and Anderson.

It is clear, amongst all this complexity, that once an Order is established, its line of historical reference and antecedence will propagate deep into the past, crossing and recrossing the lines of other Orders and retrieving and discarding canonical texts as it does so. No canon is exclusive, but when the same or similar texts are assimilated to the tradition of each Order, they may be radically reinterpreted, with 
their various elements selectively emphasised or ignored depending on their relevance to that Order. It is the fact that these elements are differently valued and interpreted according to its modes of knowing, subjectivity, cosmology, teleology and relation to technology that can identify the structural systems and dynamics of an Order.

\section{2}

\section{The Modernist Order: Space, Time \& Knowledge}

Science fiction emerged historically as a modernist literary form but it is not modernism per se. In fact, it represents a relatively narrow stream of modernism, being largely unconcerned with the literary experiments of wider modernism, saving the New Wave in British and American sf in the 1960s (instigated by - among many others - Michael Moorcock, M. John Harrison, Brian Aldiss, Robert Silverberg, Harlan Ellison, Joanna Russ and James Tiptree Jr.). As Joanna Russ has argued in the preceding chapter, unique forms and reading strategies are required.

Generally, Modernist science fiction is stylistically realist, overtly didactic, pedagogical and linearly narrated. This tendency can be traced to its historical antecedents; Jules Verne and H. G. Wells certainly provide models for the Modernist science fiction writer. Early in the twentieth century there was a literary debate of sorts between H. G. Wells and Henry James over the future direction of the novel, the question being whether it should concern itself with the inner psychology and outer social circumstances of definite characters, or whether it should concern itself with backgrounds and settings of greater scale, which necessitated a more impersonal, abstract and less intimate focus and representation. As far as mainstream literature is concerned, the debate was won by James - but as far as sf as a distinct genre is concerned, Wells' ideal of clear, non-subjective and pedagogical writing prevailed (MacKenzie 291).

The Modernist Order of science fiction does of course emerge within the broader condition of the modern movement in arts, culture, science and technology. Modernist architecture and literature are both too broad to be fully defined here, but there is a clear overlap of the two in a certain technocratic impulse that is especially clear in science fiction. In the spatiality of architecture, there are two major emerging trends: the homogenisation of space through Cartesian co-ordinates and the servility 
of space through its mastery by technological systems. In the narrative of science fiction, there is the ideal of transparent, functional prose and didactic pedagogy in the story. The architectural partner of this intention is the Modernist promotion of such features as glass curtain walls, open-space planning and the idealisation of mass manufacturing, and both valorise rational thought, seeing as the proof of its worth in that it works in providing what we claim to desire (mostly).

Arthur C. Clarke is often quoted as saying, 'any sufficiently advanced technology is indistinguishable from magic' ('Technology and the Future' Report on Planet Three and Other Speculations 147), and where magic was used, now sufficiently advanced technology stands in its place. As a consequence of science becoming a dominant cultural paradigm, there can be no superimposed realm of the essentially unknowable supernatural. Transcendentalism is untenable and the proper place for the unknown (Star Trek's 'final frontier') is the waiting room of the known. Kirk, Spock and McCoy might be the nominal heroes of Star Trek, but the series is really about the triumph of the Federation and its values, with them as its personification and instrumentality. As has been observed of Stanislaw Lem's science fiction, the real 'hero' is knowing (Swirski Between Literature and Science 73). While Lem's view of the efficacy of knowledge is sceptical - very often his tales are parables about the ultimate limits of human comprehension - he is still fundamentally allied with the ethos of Modernist science fiction that the apparently mysterious universe has an order that will be revealed to a suitably adapted technique of comprehension.

Modernist science fiction has a lot in common with another genre that emerged at about the same time: the detective story. In both cases, the readers and authors are aware that the literature follows certain clearly implied rules; and both generally use a realist mode of narration and revolve around the gathering and evaluation of information in order to discover the truth. It is the process of investigation and solution that is as interesting and as relevant as its object, while empathy with any character is secondary. On these terms, the reader, expecting a solution and attempting to anticipate events according to their generic expectations is as much a part of the story as any of the written characters. Both depend on rational deduction and Modernist science fiction often also uses rational extrapolation not only to derive an understanding of a situation, but to convincingly generate a novel but plausible (on its terms) future world or alien environment. As both science fiction 
and detective stories are about using rational means to discover previously unknown facts in accordance with reason, not only is knowing the hero, it is rational knowing.

Spatially, the open plan represents and facilitates the dominion of the eye; it is panopticism applied to the domestic realm. Le Corbusier's Villa Savoye, an exemplar of the modernist movement in architecture, with its abstract façade, strip windows, ambiguous inside-outside rooms and voids, is absolutely a manifestation of the architectural tendency to impose geometry upon the landscape. While the building appears to dissolve like a cuboid cloud, this dissolution also suggests the potential for it to iterate itself in an infinite grid. This impression in enhanced in the interior where a linear lighting fixture, the ancestor of strip lighting, finds itself reflected in the windows and appears to project like a laser beam into the surrounding landscape.

Engagement with the environment is only through its internally-generated intellectual systems, a form of panopticism in this case. Even movement into and out of the building is on the terms of its technocratic system: while its spaces seem free and continuous, the building is dynamically and formally connected with the approaching driveway that sweeps around its pedestal storey defining or being assimilated into its shape. Passengers arriving in (chauffered) cars are dropped off at the peak of the curve where they proceed by ramp to the living quarters while the car then sweeps around into the garage. This is a house for watchers, drivers and the driven, not hikers and ramblers. Sitting in a green French meadow, it might as well have airlocks.

The space of modernist architecture is not one that has hidden levels. Within, it is continuous, transparent, measurable and its parts or sections are interchangeable. All knowledge and description can and must be applicable universally.

Discontinuities exist only between the known and the unknown because the unknown is that which waits to become known. Science fiction's answer to the sublime is the sense of wonder, and wonder is always a once-only experience, existing only in the instant before the unknown is assimilated into the known. The conquest of outer space is the perfect metaphor for the system of knowledge operating in the Modernist Order. This is well illustrated in the opening monologue of Star Trek (1966-9): 
Space: the final frontier. These are the voyages of the starship Enterprise, its five-year mission to explore strange new worlds, to seek out new life and new civilisations; to boldly go where no man has gone before."

Naturally, the goal of exploration and contact was to assimilate these new civilisations into the United Federation of Planets, based on the assumption that its technological supremacy was indicative of its moral and cultural superiority. The darker side of that of course was the assimilation practiced by the Borg in later incarnations of the franchise, a thoroughly utilitarian race that regarded itself as 'perfect'.

The mission of the Enterprise is certainly the grand scale of things, but within the space of the Enterprise's hull, the same philosophy of the macrocosm applies for the microcosm. Consistency is not the hobgoblin of small minds, but the virtue of modernism. If space is universally the same, then the same techniques of knowledge and the technology that follows it are applicable everywhere. Once space is thoroughly mapped and measured, then next come the heating ducts and data cables. With a keen sense for what is now called the soundbite, the architect Le Corbusier declared that, 'The house is a machine for living' (Le Corbusier 89 and by implication passim). While the early modernist architects lacked the patronage and budget to incorporate much high technology into their buildings, the infiltration of buildings by environmental control systems was inexorable. Technology made a substitute for climate and unlike climate - which in mythological thought is driven by weather gods who demand propitiation but retain their prerogatives - it can be completely enclosed and controlled.

Ironically, it is the desire for a perfectly complementary environment that marks the fissure between Modernism and Neohumanism - or rather Neohumanism's budding node. While modern science and technology promised a physical utopia created through the mastery of technique, modernist culture sought to shape the rational minds that would inhabit it - and often sceptically. The story is not one of convergence and uniformity. Nietzsche's proclamation of the death of God was the most forceful and eloquent diagnosis of the malaise of a rationally-ordered society; ennui and anomie growing under the cover of superficial satisfaction and complacency. This theme was given a fictional treatment in E. M. Forster's 'The

\footnotetext{
* 'Where no man has gone before' was amended to 'where no one has gone before' in later incarnations of the franchise from Star Trek: The Next Generation (1987-94).
} 
Machine Stops' (1909), wherein a society whose every physical need has been fulfilled by an all-encompassing Machine suffers a terminal decline of the spirit as a result. A storm is awesome in the fullest sense of the word and demands the fullest engagement of those caught up in it, but the tepid climate created by an airconditioning system gives no sense of the divine nor asks for an examination of one's own being. Deprived of the sight of the overwhelming and the mysterious, Forster proposes, one would even lose the ability to desire such things and will thereby cease to be fully human.

\section{3}

\section{The Neohumanist Order: Synthesis \& Transcendence}

The Neohumanist Order is predicated on a synthesis of science and myth and no representative text would be complete without at least some influence of both. While the Neohumanist Order lies much closer to fantasy than hard sf and often overlaps it, there are differences also. What distinguishes it from fantasy, however much it may use fantasy elements, is that it is strongly and overtly proscience. It is one thing to believe in fairies and spiritualism as a defiant gesture against the authority of science, but it is another to believe that such phenomena can be scientifically investigated and photographed, as many eminent Victorians and Edwardians did. The parallel belief in fairies and photons represented a kind of ambivalence that Carole Silver documented and analysed in Strange and Secret Peoples: Fairies and Victorian Consciousness (1999). Fairies (and other paranormal phenomena) and fairy stories occupied a powerful position in the nineteenth and early twentieth century imagination and were deployed as rhetorical artillery in arguments about the primacy of science as a source of truth, expanding industrialisation, Celtic nationalism, the sanctity of childhood and an idealising nostalgia for a past England.

The seemingly obvious position of someone who believed in fairies would be anti-scientific, but Silver shows that there was a whole range of intellectual strategies used, which included pseudo-Darwinian evolutionary theories, to explain and justify the existence of fairies and suchlike. While many scientific authorities did dismiss the paranormal altogether, Silver is able to show that some tried to find a scientific mode of explaining and supporting observations of the paranormal as part of a 
continuum of real phenomena (203-4). No less an authority than Alfred Russell Wallace suggested that early humans might have shared the earth with non-corporeal beings (ibid 51) and the occultist Charles Leadbeater even drew up a taxonomic evolutionary table that accommodated fairies and various spirits alongside more familiar forms of life (ibid 53). This kind of work continues today with various societies for psychic research, which are dismissed as pseudoscientific by the scientific mainstream and tossed into the category of 'New Age'. One might consider this an example of irrational beliefs vainly struggling to survive in the time of science - intellectual coelacanths, as it were - but psychic investigators do actively gather evidence and formulate hypotheses in imitation (if not replication) of science, not magic. The cult television series The X-Files and its spin-offs illustrate the continued cultural vitality of this movement. Science is acknowledged as the source and generator of truth, and truth not only as data, but in the broader sense of truth-asmeaning; that is, its value depends on its utility in providing existential definition and guidance.

William Hope Hodgson epitomises this attitude. His visions of the far future in The House on the Borderland (1908) and The Night Land (1912) are framed as dreams and paranormal visions, but his characters are likely to make use of technological devices and (quasi-) scientific procedures to control, manipulate or protect against paranormal forces and entities. Indeed, the science fictional trope of the force field arguably first appears in his short story featuring the paranormal detective Carnacki, 'The Hog', as a kind of 'electric pentacle' (Carnacki the GhostFinder 170), and is further developed in his novel, The Night Land.

As a consequence of its engagement with science, it is often characteristic of Neohumanist science fiction to discard the conventional realistic novel as a template and to follow either the forms of myth on one hand (Hodgson provides the exemplar here) or textbook on the other (Olaf Stapledon's Star Maker can be assimilated to this Order as an example). As a telling complication, both extremes may well also be coloured by the influence of the other, such as an overt valorisation of science and technology in the former case and an overall visionary framing in the latter.

While it can be easy to disparage the reconciliatory ethos of Neohumanism as wishful thinking, that ethos is by no means facile. If fairies are real, it argues, then myths are true (though not in an empirical, historical sense) and science can not merely describe the world, it can make it meaningful. This has implications at the 
macrocosmic and at the microcosmic scale - as it must. If a person is to find meaning, they must not merely see the great patterns of the stars, they must know how their life connects with them. Such a person is not however much like the perpetually psychoanalysed introvert of a Woody Allen film; they aspire and act to be a hero.

While Neohumanist fiction is often heroic literature, a characteristic it shares with high fantasy such as The Lord of the Rings, it is not about psychologically real characters in the Modernist sense. Nor is it necessarily about the individual experiences of a protagonist. The things that distinguish a protagonist in popular mainstream literature of the twentieth century - individual subjective sensual impressions, depth, introspection, and class-consciousness - are not only minimised, they are irrelevant.

In Strategies of Fantasy (1922), Brian Attebery borrows a term from Greimas, actant, to distinguish a character in a fantasy narrative from a character in popular modernist or mimetic fiction, the actor. An actant is defined by their role, social and moral connections and their overarching destiny. They may resist their call, but their eventual and inevitable embrace of these things constitutes a realisation of their true, essential nature and permits their growth to fulfillment as an authentic being (73).

This converges with Joseph Campbell's thesis of The Hero With a Thousand Faces (1949, see 3-46, and in particular 30, where Campbell credits James Joyce with the invention of the term). He construes the 'monomyth' of the world's cultures as a template for self-creation, which effectively provides the narrative template for Neohumanist science fiction when it is focused on active protagonists rather than mere vessels for enlightenment. Campbell's importance to Neohumanist sf and fantasy narrative is comparable to that of Rykwert and Norberg-Schulz in the understanding of traditional architecture; both the synthesist of narrative and the architectural historians saw an intrinsic link between space, place, ritual and movement that served to construct a firm human identity in a chaotic natural world while permitting and governing the relations that must still be conducted with that world.

This stands in sharp contrast with the stated ethos of modernism propounded by Le Corbusier in which architect-technocrats created thoroughly mechanised dwellings that were open and homogenised in its interior space but independent of natural forces. This was presented as being not only inevitable, but overwhelmingly desirable and appropriate. 
Robert Harbison is fascinated by the ability of architectonics to generate both spatial forms and narratives and he describes the aspirations of the actant perfectly:

A writer places a building at the center of a book in order to provide the scaffolding of automatic organization, for adventures in adjacent rooms hang together by themselves, and the overlay of much in the same place achieves intensity unattainable in the picaresque... The faith in geometry leads to a faith in spatial arrangements, in which life's difficulties will be solved by positioning things properly and making prescribed movements (74).

The twentieth-century architect who might be most closely identified with the Neohumanist Order would have to be Frank Lloyd Wright, whose 'prairie style' was inspired by Walt Whitman's writings on the landscape and frontier life and who compared himself - and the architect in general - to the legendary bard Taliesin, naming his studio-academies after him. The purpose of architecture for Wright was to establish an organic link between people and their history and to at once create and represent a fundamental integration with nature itself. Ideally, in a benign environment, a building by Wright (and his follower, Paolo Soleri, developer of the 'arcology' concept, which fuses architecture and ecology) is like a tree, rooted in the earth, centralised and coherent in form, sheltering its inhabitants but in free exchange with the environment. Of course science fiction is often about malign environments, and it is in this case that the Neohumanist structure becomes closed and fortress-like but as we shall see in the case of William Hope Hodgson's The Night Land, it retains an essential unity with some basic vital force, position or axis mundi so as to 'spare and preserve' its contents within a hostile environment.

It is not surprising that many fantasy and Neohumanist stories are about rites of passage. However, 'humanism' in science fiction is not ultimately about self but the selfless revelation of a cosmic vision. The scale of the cosmos and the truly inhuman nature of its contents deny the possibility of a valid atomised or individual experience estranged from the experience of the community.

However strange the future or alien world depicted, modernist realism in science fiction requires that there be a clear continuity between the fictional world and that of the reader in order that the process of cognitive estrangement as described by Suvin can operate most effectively. In contrast, Attebery says of fantasy: 
Most fantasy writers provide clearly defined frames: narrative devices that establish a relationship between the fantasy world and our own while at the same time separating the two. These might consist of threshold stories, in which characters move from a realistic setting into another realm, or embedded narratives like Tolkein's Red Book of Westmarch, an imaginary text that presumably exists in our world and contains the records of Middle Earth (Strategies of Fantasy 66).

This brings to light a prime distinguishing characteristic of Neohumanism: transcendentalism. There are intractable oppositions and contradictions in the mundane world and they cannot be resolved in this world because they are intrinsic. It is only at some superior level that essential differences can be resolved, but that realm is not immediately or constantly accessible. Modernist cosmology and scientific discourse is not constructed to permit a layered cosmos and most Modernist fictions emphasise continuity with the present world in order to enhance their verisimilitude and thereby their dramatic effectiveness. Neohumanism however often draws upon traditions where the cosmos is layered and concentrically structured, and is more comfortable with the separation of realms and the creation of chains or portals linking them. This requires a different reading strategy:

By placing questions of memory and fate, cause and effect, invention and experience at the level of story, rather than leaving them at the discretion of the narrator as realistic fiction tends to do, fantasy suggests that they are central to the process of storytelling, and not mere stylistic choices. They operate at the level of narrative code, rather than of discourse. A realist work is merely one that disguises the doubts built into its fictionality. By displaying rather than suppressing the arbitrariness of narrative choices, fantasy can breathe new life into its own conventions (ibid 68).

The connection between the worlds is one of resonance. Rather than participating in a smooth extrapolation from present reality, as a Modernist writer and reader will, the fantasy - and Neohumanist - reader and writer establish parallels in an alternate plane of reality. The reader is invited to relate their own experience to that which the 
writer depicts as occurring on a qualitatively different but universal plane, so that they perceive themselves to be integrated with the cosmos as the fictional protagonist comes to a realisation that their own relationship with the cosmos is based on a correspondence between their own mundane existence and their higher destiny.

This is what Dante calls a 'polysemous' layering of meaning: 'for we obtain one meaning from the letter of it, and another from that which the letter signifies' (see Tom Phillips 15, 285). In the case of the Divine Comedy, one reads first the literal narrative and then interprets the allegorical meaning of the text, its moral instruction and then its anagogic or transcendent mystical meaning. The layering or nesting of meanings is often reflected in the rhetorical strategy employed by the author. In The Time Machine, Wells emphasises the continuity of present time with the far future, but Hodgson in The House on the Borderland and The Night Land adopts a quite different technique. In the latter case, the tale is supposedly presented by an unnamed editor who has found a manuscript in a sealed box in the ruins of a house written by another unnamed man living in the sixteenth century who had had a dream of the far end of time that had given a validation of his own experiences. Within that narrative, which is told in the first person, there are further nested tales of 'past' incarnations that are nonetheless still in our own far future and which serve as intermediate steps in Hodgson's cosmic history while the narrator himself - also unnamed - strives to fit his adventure into a pattern of universal significance. This may seem like absurd overcomplication, distancing the late twentieth century reader accustomed to Modernist narrative and reading strategies from an appreciation of the text, but this is a perfect illustration of the polysemy of Neohumanist rhetoric; that is, the use of a sign to indicate more than one meaning, each dependent on the intellectual framework in which it is interpreted. Each successively higher level of interpretation is deduced from the lower and furthermore informs a finer understanding of the meaning of the lower. The essential meaning of a text - and one's own life - is explicitly not found through rational linear extrapolation; rather, one is challenged to find resonances across the layered planes of story.

Attempts to both conceive of a transcendent realm and translate the ideal into the language of the real and the rhetorical style that results can be challenging to even the most astute reader who is not entirely sympathetic. Joanna Russ defined a type of literature that she called 'daydream literature', which on the whole she deplored. Daydream literature has the following characteristics: repetition, passive voice, 
straining for effect, simple figures of speech, monotonous pacing, thin characters, flat sentences with little variety in use of syntax, no sound or playing with sound (The Country You Have Never Seen 198) - and supportive critics who say that despite such serious flaws, there is nonetheless something compelling (ibid 193). She finds particularly egregious the lack of specificity in narrative: anything that is described is a type of thing, a form that indicates something else, rather than anything particular that could be visualised in the imagination of the reader (or the writer, it seems). Unlike an actual dream, which can be extraordinarily vivid, daydream literature is all too consciously controlled to be genuinely dream-like while lacking a connection with an existing symbolic tradition - as is the case with the Divine Comedy - to fully elaborate upon the ramifications, resolution and effect or affect of its ideas. In exasperation, she refers to this sort of literature as being 'schematic' (ibid 204).

Of course, as was shown at the conclusion of the previous chapter, much of science fiction necessarily tends towards the presentation and exploration of schemae. As Houellebecq sees it, this can be a narrative virtue and furthermore it can become a resource for the imaginative reader to create their own alternate narratives. One of the most appealing qualities of science fiction, horror and fantasy is that schemae do provide fertile ground for creative engagement by the community of sympathetic readers, who can then formally or informally trace their own narrative pathways through the labyrinths constructed by the originating writer. This is clearly the case with the vast Star Trek franchise and H. P. Lovecraft's 'Cthulhu mythos', and lately the case with the number of works inspired by Hodgson (See Sinclair, Bear and Robertson et al, including this author). Novels such as David Lindsay's $A$ Voyage to Arcturus (1920, Russ' principal example) and William Hope Hodgson's The House on the Borderland and The Night Land all set out first and foremost to present structures of ideas. The richness of the reading experience with such texts lies not in the superficial qualities of the prose and narrative (though there is no reason why they should lack such virtues), but in its polysemy. The reader then is impelled to create in their imagination an outline of the total underlying schema, with the main qualitative criterion for its design being consistency with the body of given texts.

Certainly there is plenty of fantasy that has positive qualities as Russ would define them, but Neohumanist sf is explicitly dealing with a cosmos that surpasses mundane human comprehension and the realm of ideas which transcends the scope of conventional mimetic writing. In its extremes, schematicism offers a dry read with its 
rigidly compartmented cosmic architectures, and transcendentalism can be regarded with suspicion; it is no scientific argument after all to say that ultimate answers can only be found outside of experience and investigation. Russ is correct in terms of literary modernism; the premises and styles of the Orders are incompatible and the more extreme rhetorical styles of Neohumanism are in fundamental opposition to modernist literature in general and Modernist sf in particular. Modernist disparagement of the quasi-mythological rhetorical approach and its intrinsic transcendentalism, as represented by Russ, is a significant factor in the rise of the alternate strategies of Posthumanism.

\section{4}

\section{The Posthumanist Order: Fluid Machines}

Neohumanist science fiction aspires to synthesise science and myth, altering each to become the other, but Posthumanism attempts to create narratives that will stand in the very brightest light of uncompromising science while escaping the determinist agenda of panopticism. 'Nonscientific' critical disciplines such as poststructuralism, cybernetics, transhumanism, gender studies, postcolonial theory and queer theory and all their associated activist practices are notably influential on Posthumanism as well. This cluster of philosophies collectively denies any central position in the cognitive maps generated from their exploration and interpretation. This can make for strange bedfellows: structuralism and poststructuralism tend to hold that identity and meaning are largely culturally constructed while evolutionary psychology holds that there is a basic set of adaptive programmed behaviours that are only modified in their expression by culture (leading to charges of 'essentialism'). As a consequence of this, there is a lively debate, tempered somewhat by the shared acknowledgment that is possible that any 'essential' instinctual human nature is subject to modification in its expression at least by the techniques of power. The malicious or playful activity of subverting a computer system's rules, which are assumed to be fixed, to one's own ends or no end at all other than the process is called hacking, and this practice is rife not only on the Internet, but in Posthumanist literature itself as a key discursive technique. 
If we want to see how much Modernist and Posthumanist visions of the future differ, one need only compare 2001: A Space Odyssey and Blade Runner (1982), two films that have in their own ways become emblematic of different kinds of science fiction (2001 arguably serves a Neohumanist agenda in the end, but its visualisation of twenty-first century technology is impeccably Modernist). The former presents a sleek, mechanised environment controlled by a centralized AI, directly descended from E. M. Forster's 'The Machine Stops'; and however ironic its presentation may be, it is still based on the assumption that this is where technology and society are inevitably headed. While Blade Runner was based on a novel written in 1968, Philip K. Dick's Do Androids Dream of Electric Sheep? and seems dated today (no-one uses cellphones and there appears to be no Internet), the future it presents seems far more plausible to us today. Los Angeles has become William S. Burroughs' Interzone and everything is bricolage: all buildings and machines seem to be hybridised in some way with patched appliances and augmentations; society itself is both fragmented and mixed so that characters such as the senior detective Gaff are of no fixed ethnicity and speak obscure street languages composed of bits of others. Simulacra proliferate and are more imbued with life than 'real' humans and animals, and the man commissioned to hunt rogue simulacra may be one himself. Moreover, 2001 's solution to the binds of its society is transcendence, but in Blade Runner's Los Angeles there is no such promise, no escape despite the continual advertising of new lives in the off-world colonies. The film's perfect warrior mechanism, the android 'replicant' Baty, tracks down his creator to demand a hack that will rewrite his code and extend his life; failing that, after defeating his hunter, Deckard, all he can do is sit down and tell his story as he dies. There is no transcendence and the best the narrative can provide in terms of closure is just that: Deckard, closing the door of his apartment as he flees with his replicant lover into who-knows-what. It is a drama about one confused man which says nothing about the human race - except that it is all about the human race and its end as an exclusive category. It is of course also one of the canonical texts of cyberpunk, particularly the Gibsonian brand. Both films exist within the genre of science fiction and both are considered classics of science fiction film, but they could hardly be more different: in 1968, 2001: A Space Odyssey presented an image of the future that was based on the reasonable projections of the film's writers and their consultants, who were respected scientists such as Marvin Minsky and Carl Sagan, but Blade Runner borrows not only its title from a text by 
William S. Burroughs, but also a world-view that is the antithesis of that of both the optimistic Arthur C. Clarke and the more cynical Stanley Kubrick.

The critical provocation here is cybernetics, founded by the mathematician Norbert Wiener during the Second World War. Cybernetics considers entities not as discrete static objects, but as phases in flows and feedback cycles: every entity is both affected by and has an effect upon another with which it interacts, each thereby modifies the action of the other and, ideally, each should dynamically support the other, responding appropriately to maintain continued existence not as a set of static objects, but as a self-governing metastable system. Indeed, the word 'cybernetics' is derived from the Greek kybernetes, meaning 'governor' or 'pilot'. A human being inside one of the cells of Forster's Machine, with a thermostatically-controlled heating and air conditioning system is, in this model, not a person in a cell, but part of a system that is in itself a gestalt entity. Forster sees this as a dreadful state of being, but Samuel Butler's Lucubratio Ebria would see it as perfectly obvious and a Transhumanist would wonder how the arrangement can be made even more literal and intimate.

Manfred Clynes and Nathan Kline did just that with an essay entitled 'Cyborgs and Space' (1960) wherein they proposed that in order to withstand the rigours of space travel, astronauts could be surgically altered to integrate them with the systems of their vehicles and coined the term to describe such a being: cyborg, a portmanteau of cybernetic organism (Gray, Figueroa-Sarriera and Mentor 29-33). The essence of the cyborg is not that it physically blends flesh and metal or plastic, but that it is conceived as a dynamic system creating a unity between body and machine. The image of the cyborg and its generating concept of identity residing in system rather than substance has become central to Posthumanism along with its unexpected ramifications, but, as will be shown in following chapters, its presence has defined the relationship between Posthumanism and Neohumanism too.

Cyberpunk is one of science-fiction's best-known responses to the rise of cybernetics and its applications in culture, but cyberpunk's own sources within science fiction have assimilated the lesson of Lucubratio Ebria that society is a network of integrated machines, be they made of flesh or metal. HAL 9000 is a centralised and domineering artificial intelligence that controls the Discovery, and as Cellarius feared, 'he' decides that if human beings were unreliable servants to machines, then they should be superseded. However, Norbert Wiener had already 
applied cybernetics to social analysis with The Human Use of Human Beings in 1950, technology was becoming decentralised and diffused throughout society and the predecessor of the Internet, the ARPANET, was in operation from 1969, and numerous avant-garde composers and artists had been experimenting with computers and tape-loops as generators of artworks. Science and technology were inevitably mingling with culture, and it was at the 'lower' end of the scale, not from a centralised mastermind like HAL, that this mingling began to make itself visible in the form of cultural productions and critiques.

Two outsiders of complicated gender and sexuality - Alice Sheldon, writing through the persona (more than a mere nom de plume) of James Tiptree Junior, and homosexual one-time drug addict William S. Burroughs - articulated within science fiction a powerful critique of the rationalist assumptions of Modernism. Burroughs is well enough grounded among the beats, but he is constantly referenced also amongst the New Wave and Posthumanist science fiction community, while Tiptree, as we will see later, is of great and direct significance to the Posthumanist Order, particularly as it is presented in Gwyneth Jones' Aleutian cycle.

Burroughs is certainly not an optimist. Even the desire for gratification is itself an evil in Burroughs' world, because it is one of the faces of addiction. We become addicted not only to pleasures and wayward distractions, but addicted through parasitism. Before Richard Dawkins coined the concept of the meme, a cognitive structure that 'infects' minds and reproduces through communication as a virus infects a cell and propagates through the sharing of fluids, Burroughs had already written extensively on language as a virulent and contagious virus in 1962:

The word is an organism... The word is now a virus... Modern man has lost the option of silence (The Ticket that Exploded 49).

The body is a field in which the word virus is at play; communication is a vector of infection and the etiology of the resulting disease transforms it into a puppet. It becomes, he says, a 'soft machine' (1966):

The soft machine is the human body under constant siege from a vast hungry host of parasites with many names but one nature being hungry and one intention to eat (The Soft Machine, 130). 
With typical irony, Burroughs also sees the soft machine in the mechanism of society itself, so that the social and the individual are similarly parasitised and parasitic (ibid 143). Society and the body are each reflections of the other at different scales. Explicitly also, technologies of transformation, which require specific modes of behaviour for their propagation and use are de facto ideologies in themselves and vice versa. When one of Bruce Sterling's characters in Schismatrix (1985) says that ostensibly political labels such as 'Mechanist' and 'Shaper' are really technologies made into ideologies, he is echoing Burroughs' point that language is a viral technology that subsumes its subjects within its structures (151).

Entire personae in Burroughs' universe can be viral. In The Ticket that Exploded, members of the 'Nova Mob' are not so much 'real' people as what were later called computer viruses or memeplexes that infect human 'coordinate points' through the mechanism of opiate addiction (57-9). Some, such as an entity named 'Genial', may simply infect its host from a tape recording (ibid 14-21).

Burroughs was of course very interested in cutting, splicing, overdubbing and other recording techniques that could generate new meanings as a parallel to his cutup writing method in which a page is typed over linearly and then quartered and the segments rearranged to produce random new texts. The pleasure in producing these new texts from the limited set of the original text is in some way comparable to that of constructing a schema from the cues given in a text such as Star Trek and extrapolating a wider universe of possibilities as fan writers do, but the critical point is that the system is irrational, random or at least inaccessible to the conscious mind of the individual reader/writer. Indeed, Burroughs entitled a collaboration with Bryon Gysin using this technique The Third Mind (1978), emphasising the eerie and thrilling distribution of cognition between two minds and the emergence of a third embodied in the process of the collaboration and randomisation itself. As far as Burroughs was able to tell, Brion Gysin was the first contemporary poet to make use of the cut-up, and he was inspired to apply the technique to his own work alone and in collaboration with Gysin (Burroughs and Gysin 3). In The Ticket that Exploded, he imagined a writing machine that would be able to do this automatically, being fed random samples of texts by spectators who would then see new cut-ups within minutes; and in his novels, this is what is happening to people constantly through addiction, infection 
and forms of psychic time travel - in almost all cases mediated by sex, which is also frequently presented as a form of splice (The Ticket that Exploded 65).

In contrast with the Neohumanist individual who achieves growth as an individual through their realisation of their essential connectedness with the social organism and its mythological foundation, the Posthumanist being becomes subsumed in a perpetual dynamic of always becoming something other without purpose. Deleuze and Guatarri take Burroughs as an inspiring figure in A Thousand Plateaus (1980) and they refer specifically to his cut-up technique (6) and visceral depictions of radically reconfiguring bodies (ibid 152-3) in order to illustrate their own concept of the 'Body Without Organs', a being that spontaneously and continually redefines its structure rather than allowing itself and its components to be rigidly fixed in Englightenment-style functional and taxonomic categories. Consequently, no absolute order can be created in physical and existential space in the manner of the Cartesian grid; only contingent and oblique orders can be expressed in time and process, and thus emerges the paradigm of the open-ended game.

The architect Daniel Libeskind built his own architectonic version of Burroughs' writing machine - as Burroughs had proposed an architectural machine too (Nova Express,1964, 105). Of this, and what it represents, he says:

As opposed to "stable" architectural texts, which best fly in a straight line of myth and resist the pilot's effort to climb, bank, or dive, this "unstable" prototype is extremely agile, having no natural flight path. - It jumps around the text's sky and is guided by "active control systems," which can perhaps never again disclose its starting position (Libeskind, 1974, 181-2).

The 'straight line' is that which an actant follows in accordance with their destiny. The 'pilot', on the other hand, responds contingently or capriciously to feedback, charting an unpredictable course that has no fixed destination or 'destiny' as would be the case with the Neohumanist Order. Again, we see the model of dynamic, openended process instead of a narrative with a culminating objective. This is also a repudiation of Modernism, which he interprets in Foulcauldian terms, with an acknowledgment of Kafka's 'The Penal Colony': 
Architecture as a practice of control has projected itself over an immanent frame sufficient to reveal something without. What is at first an oppressive flash in this system reveals, in fact, the things that belong together. Thus, the truths that have been disclosed in space are the very ones that have been inscribed upon the flesh. The inscription, in the twentieth century, has been performed with all manner of precise instruments, including knives (ibid 49$50)$.

According to Libeskind, architecture, like language, disease and vivisection, impresses itself upon the body of the subject. The visceral model in the end replicates the major metaphors of both the writing machine and the soft machine. Libeskind could easily be speaking as a character in The Ticket that Exploded, and the evolutionary hacker, Doctor Moreau, is probably not far away.

\section{5}

\section{The Posthumanist Order: Gender}

Another major factor in the formation of the Posthumanist Order along with cybernetics is feminism, particularly feminism's analysis of the construction of the embodied identity. Both cybernetics and feminism subvert the assumptions of Modernist and Neohumanist science fiction, but they each employ their own particular strategies, and could exist in isolation from each other. However, in Posthumanist science fiction, leading from the writing of Donna Haraway, they achieved a synthesis.

It is impossible to offer a succinct description of the diverse field of thought that constitutes feminism, except to highlight its fundamental shared critique; that is that the cognitive and social norm had been implicitly masculine, and because it was gendered, it could not possibly be the norm that it was presented as being. The implication of this, made clear in the writings of the contribution of Tiptree and other feminist science fiction authors, was that 'man' could no longer automatically be accepted as the default supposedly encompassing male and female. As it all too often the case, in practice the use of 'man' as a default label for humanity meant man without woman or with women as accessory - or as alien. 
In contrast with earlier feminist utopias (such as Charlotte Perkins Gilman's Herland), rather than trying to present a complementary or alternative separatist state, the idea of both male hegemony and the concept of fixed, essential gender duality was deconstructed by the new generation of writers. While the various feminist utopias of 60 s and 70 s science fiction were superficially separatist, what they showed was the conviction that women at least could be 'female men'. In appearing to show the redundancy of men, they in fact asserted the absurdity of 'woman' as a secondary adjunct to 'man' in a dualist system. They also deconstructed the assumption that women are inevitably only a repressed element in an overwhelmingly patriarchal system. The next step was to reject dualism altogether, represented by the escape from earth. The narrator of James Tiptree's 'The Women Men Don't See' (1972) is a complacent man who imagines that he is objective and neutral, but by being embedded in a patriarchal system, he is unable to comprehend the state of women bound within that system and their existential need to escape from it. As he is told by Ruth, the real protagonist of the story:

"What women do is survive. We live by ones and twos in the chinks of your world-machine" (Her Smoke Rose Up Forever 140).

As her persona and role are constructed by society, at best, she is simply an object that the system of modern civilisation specifies as a default the masculine role as the norm for its components, but as a woman, she is an anomally. Women are redundant and invisible by implication under such conditions, having to live therefore as 'opossums' - pests, pets, aliens or special cases at least. Ruth and her daughter reject this system entirely and make their escape with a party of visiting extraterrestrials, but while this is a moving and eloquent depiction of a point of view, it is by no means a definitive solution to the problem. Indeed, Ruth's escape in the story is specifically by re-identifying herself with alien visitors; and this is a theme that Tiptree further explored in other stories, many of which present cross-species alliances and loves. Her suggestion is that one may define oneself by milieu, but one may also choose to construct that milieu. One must, because without it, one is zero.

A Neohumanist story would offer some reconciliation or transcendence, but Tiptree is deeply sceptical of transcendence. Posthumanism offers recombination because the transcendental is, by its nature, something out of the world in which we 
live. It may offer hope, but it is a curse too because it says that no fundamental problem can be solved in this world. Ruth reframes herself as an alien among other aliens rather than be a nonentity in a masculine world-machine. This position was no easy one for Tiptree. Desire is what all people feel, but desire is not accommodated within the structure of a patriarchal society pretending to be ultimately neutral and cerebral, especially not the desire of a woman of ambiguous and repressed sexuality like Alice Sheldon. Transcendence is departure, and if the change is permanent - and how could it not be? - it can be indistinguishable from death, particularly to those left behind. ${ }^{39}$ While it must be said that death features prominently as the conclusion to many of Tiptree's relationships, to interpret them on this basis as inherently wrong or tragic is simplistic. Death is tragic, but to Tiptree it is nested within an understanding of there being a death instinct, or that living itself is driven by instincts that entail death. In such a context, one strives not to live forever, but to die well, and Tiptree's presentation of death is often as Liebestod ('Love is the Plan the Plan is Death', 1973, in Her Smoke Rose Up Forever 413-29, and 'The Only Neat Thing to Do', 1986, in The Starry Rift 7-55, are the most obvious, but hardly unique, examples).

Desire, if it is permitted to exist and whether or not it can be satisfied, is both the connection between self and the other and the barrier that separates the two. This paradox becomes especially problematic when the idealised union of self and other is performed under conditions where difference is culturally construed as inequality, and it has consequently become a central concern of Posthumanist discussion.

Posthumanism is not Cartesian by any means; it cannot pretend that the intellect and will are separable from the body and thus must seek its solutions in the flesh.

William Burroughs and Joanna Russ both presented their own variations on the theme of utopia addressing gender and sexuality, Burroughs with his wild boys (The Wild Boys: A Book of the Dead, 1969; Port of Saints, 1973) and pirate communities (Cities of the Red Night, 1981) and Russ with the planet of Whileaway ('When it Changed', 1972; The Female Man, 1975). The fact that both authors are queer is extremely significant, neither being able to conform to the standard dualist sexual model and therefore sceptical - indeed, antagonistic - towards its prescriptions. The utopias of both these authors are exclusively homosexual, therefore monosexual, and therefore agendered, rejecting utterly thereby the possibility of gender dualism taking root. However, both are well aware that such a situation is utopian (that is, 'nowhere') and can only be presented as dreams, 
fantasies, counterfactuals or thought experiments embedded in overt polemics. Even then, the planet of Whileaway depicted by Russ in the short story, 'When it Changed', is facing the return of the male other after a long ignorant bliss. That said, the unreal condition of utopia does not mean that it is pointless: as the encyclopaedias of possible worlds discussed in the preceding chapter attempt to show, what is present now is not what was foreordained or inevitable and therefore there can yet be a moment when it will change.

While neither Russ nor Burroughs can be categorised exclusively as Posthumanists, their writing laid the necessary groundwork for Posthumanist explorations in which dualism could be fully dismantled without the transcendentalism of the Neohumanists. The standard science fictional metaphor for the other is of course the alien, and the gendered or post-gendered other as alien allows an incisive and affecting exploration of sex and being in Gwyneth Jones' Aleutian trilogy and its associated texts. The Aleutians are highly sexual beings, but a kind of hermaphrodite (their differences from standard earthly hermaphrodites are significant), and they practice a form of serial immortality with personae being transmitted across generations through memes. As a consequence, they are unable to comprehend the definition of fixed separate sexes as anything other than an affectation or a game. Following contact and the permeation of their influence throughout human society, diverse reactions by human communities range from absolute denial to a full assimilation - or simulation - of Aleutian attitudes towards identity.

Jones was praised for creating in the Aleutians truly alien beings - but she simply based them on women (Jones, Deconstructing the Starships, 1999, 111). Her triumph as a writer then was to present not only a vision of an ungendered or postgendered civilisation, but to present simply women, and nonwestern cultures stripped of the frame of socially-constructed gender or colonial constructed role (ibid 110). Fundamentally, Jones's intention was to depict beings to whom the exclusive category of 'the other' was inconceivable (ibid 111). Following the implications of this, not only is there a removal of distinction between 'man' and 'woman' and 'human' and 'alien', but other distinctions - between culture and persona, body and tool, body and culture - are also erased. As we will see in later chapters, this is emblematic of the Posthumanist approach and incorporates the thinking of Donna Haraway as it relates not only to the products of culture, but other beings with whom 
we share our biosphere. The Aleutian-made world is not presented as a utopia, but as a challenge to reimagine our world as it exists now.

With the binarism of masculine and feminine and the masculine as default erased, gender becomes a mask - not that a mask is a bad thing per se, especially if indeed it can be selected as voluntarily as a mask. The tragedy of Tiptree's 'The Girl Who Was Plugged In' (1973) is mixed because, while on one hand the protagonist can only achieve (temporary) romantic fulfillment through nonbiological technology that functions as a kind of mask, on the other hand she is able to do so with that technology (Her Smoke Rose Up Forever 44-79). Technology as it is used in this story is something that is by its nature variable and dynamic, not fixed or essential, and which also facilitates the alteration of selfhood, and this is the positive point that Donna Haraway pursues in her oft-reprinted 'Cyborg Manifesto' (1985, see Simians, Cyborgs, and Women 149-181; The Haraway Reader 7-45). Haraway remained close to Norbert Wiener's and Manfred Clynes and Nathan Kline's concept of the cyborg more so in fact than many writers who followed them. What was revolutionary was that Haraway, who had already erased the boundary between humans and simians in her writing, was able to perceive the erasure of the boundary between human and machine and apply her understanding of that to feminist social and cultural practice: culture is explicitly technology, and technology is also culture ('Morphing in the Order: Flexible Strategies, Feminist Science Studies, and Primate Revisions', 2000, in The Haraway Reader 199-222; 'Cyborgs to coimpanion Species: Reconfiguring Kinship in Technoscience' 2003, ibid 295-320. See also Simians, Cyborgs, and Women). It follows therefore that cyborg selfhood is tied up in the reciprocal dynamics of person, culture and technology. This converged with the cyberpunk ethos of the appropriation of technology and its Burroughs-inspired examination of the effects of technology on the body. In contrast with previous visions of the uses of technology and culture, they were not depicted as being instruments of procrustean domination and conditioning upon the passive subject, but were engaged in such a way as to bypass altogether the subject/object dichotomy.

Haraway did not resolve technology's 'conflict' with the body; she recast the question altogether: there is no Cartesian separation of intellect and flesh, technology transforms the embodied mind and thus the desires and intentions entailed with that technology and so on - endlessly and without a transcendent telos or object. With no object(ive), the relativism of subject/object is at best contingent. This in itself 
demonstrates the nature of the relationship between the Orders: they do not simply produce alternating theses and antitheses. Rather, world-systems are embodied in their arguments and the dialogues between the Orders in their engagement in the shared arena of science fiction of apparently exclusive epistemes.

There is a parable by Jorge Luis Borges about an actor who is famous for his absorption into his varied roles, but he is always unsure of who his true self might be. Upon his death he meets God and asks Him which of his roles was his true self. God tells him that he was all of them and none of them ('Everything and Nothing' Labyrinths 284-5). Without a fixed essence, there can be no transcendence because there is nothing eternal peculiar to the individual that survives death; the individual is but a contingent and changing construction.

\section{6}

\section{Fissures \& Budding Nodes}

The Orders are not clubs with foundation dates, headquarters, charters, membership lists and application forms. Their set is, in essence, a critical framework for following the development of an evolving historic discussion in science fiction. They enable a position to be described coherently and the dynamics of how proponents of that position deal with concepts that they either reject or assimilate. Because of their dynamic nature, they often emerge gradually, budding or splitting depending on one's perspective, from a line of discourse. These divisions are driven by a need to address issues that have not been previously addressed, either because new cultural and scientific paradigms have emerged allowing new interpretations of issues, or because cultural changes have made the existing precepts of an established Order seem suspect.

In reaction to the uncomforting Wellsian visions of a universe in which humanity was as subject as any of the 'beasts that perish' to predation and extinction, Neohumanist science fiction reached back into the fundamentals of spatial-existential experience (as described by Christian Norberg-Schulz and Joseph Rykwert) to find humanity immovably - and uncomfortably, perhaps - seated at a point halfway up and halfway down the Great Chain of Being. Man (the default gender of humanity in Modernism and Neohumanism) is half angel and half beast, but in either case, the 
intimate and essential rapport of the microcosmos and the macrocosmos reveals to him the intrinsically sympathetic nature of the cosmos. In parallel with this essential continuity of theme, Neohumanist science fiction assumes that there must be a continuity of thought so that ancient traditions illuminate science and vice versa and we thereby are able to find and comprehend our proper place in the order of things. This is the principal motive of Neohumanism.

As mentioned, two emerging social and technical forces in the twentieth century forced radical changes on the literary practices of authors working under each of the Orders. Feminism, as we have seen, was fundamental to the establishment of Posthumanism, along with cybernetics and specifically, the cyborg. William Burroughs' own work with tapes and cutups challenged Modernist assumptions about identity and indicated new creative avenues that diverged from Modernism's linear and rational methodologies. His model of society and body as soft machines, both of which were subject to what is now called hacking, further undermined stable assumptions about the inviolability of self and culture - and even the possibility of a comprehensive understanding of these categories. Burroughs and the other Posthumanists are not simply opposed ideologically to Modernism; they do not even consider its precepts to be in any way sensible or relevant.

Because the fissures that have emerged between the Orders reflect fundamental differences in precepts rather than superficial differences in interpretation of shared precepts (such as materialism producing both libertarian and Marxist political ideology), specialised tools of intellectual analysis particularly adapted to each are required. As classical scholarship such as that of Joseph Rykwert and the philosophy of Martin Heidegger offers insights into the transcendentalist Neohumanist Order, and critics of the Enlightenment such as Michel Foucault offer insights into the panoptic regime of Modernism, one can find critical figures who are well suited to exploring the bases and ramifications of the dynamic flows of Posthumanism. These are primarily Donna Haraway and the partnership of Gilles Deleuze and Félix Guattari. What is particularly significant about Deleuze and Guattari's work in A Thousand Plateaus is their acknowledgement of and direct engagement with Posthumanist science fiction - specifically, that of William Burroughs (153), from whom they take their inspiration for the Body without Organs $(\mathrm{BwO})$ and processes of endlessly becoming. As it happens, science fiction of the Posthumanist Order tends to be overtly and explicitly philosophical in any case, and 
several authors will have characters engage in critical philosophical discussions when Modernists were more likely to have them engage in 'As you know, Bob' explanations of technical matters. Gwyneth Jones is quite clear about her motives and means in writing of the Aleutians and other authors who will be discussed later have, through interviews and DVD commentaries, made their philosophical dependence on postmodern concepts clear.

An Order can be thought of in this context then as a means of describing an implied schema, one not formulated by any single author (such as H. P. Lovecraft), but a contextually-constructed generator and assimilator of narratives. It has no distinct, discrete being, but it produces tangible traces in the rhetoric of particular written texts and in the broader discussion and cultural appropriations attending upon them. These traces can be thought of analogously as bookworms that have chewed a tunnel through a row of books, penetrating the bindings, traversing pages and then eating onwards to leave behind their own winding trails. These trails will have distinct characteristics, indicating which of three genealogies they might have. Caveats must apply of course, considering that emphases will differ and texts will be multiply appropriated. The appropriate method of classification then, is to gain a cumulative impression of a text and its use and then to examine its most significant points of engagement (be they convergent or divergent). It is possible, scanning this 'landscape' of Orders, texts and dates, to select and compare specific examples and to thereby reveal critical points of difference that are nonetheless part of the same discourse - and encompassing that discourse is the larger discourse of genre itself.

With so many points of difference, it is necessary to focus on the most significant issues or clusters of issues, and fortunately it is possible to do so through the framework of architectonic analysis, as it provides the most coherent and structured articulation of an Order and its attendant schema. The following chapters will therefore concentrate on exemplary texts that provide some of the richest feasts for each of the three species of bookworms.

We have seen that the primary point of fissure between Modernism and Neohumanism is in Neohumanism's need for historical and cultural continuity and existential reassurance, which the Order seeks to provide, first by reconciling science and myth, and secondly in establishing a transcendental realm that both reconciles all mundane divisions and provides a constant reference for the mundane. The fissure between Modernism and Posthumanism is driven by the severe homogenisation of 
Modernism, and yet the split occurs because the Modernist invention of cybernetics opened up new possibilities for play and recombination. Recombination, according to the Posthumanist Order, renders the transcendental at once untenable and unnecessary. The space of Modernism is ideally Cartesian, though it may not be achievable; the space of Neohumanism is stratified and concentric, and the space of Posthumanism is a plane of immanence, not only contextualising being, but by recombining and infecting entities, creating nodes of being too. Identity in the Modernist formulation is detached and neutral; in the Neohumanist formulation, a being is authentic only in realising their potential as an actant; and in the Posthumanist formulation, being is role, relation and symptom. As we will see, each Order also pursues its own distinctive literary strategy derived from the processes of its generative machinery.

The particular concern here is the power of technology to alter perceptions of the body and space and to enable and enact those changes. The three Orders of science fiction are sufficiently explicated now to grapple with these concepts in our contemporary society and to reveal in their products illuminating but differing interpretations of their implications. Modernism, however, while having a claim to be the 'original' mode of science fiction or at least its foundation, seems now to be at an impasse if it does not evolve. Posthumanism may seem to be the most obvious candidate for the most thorough explication of the consequences of technology's impact on our culture through its active embrace of the most challenging technologies but, as will become apparent, the seemingly reactionary Order of Neohumanism also addresses these concepts in a manner that may be antipathetic to that of Posthumanism, but which may nonetheless regain vitality and adherents.

While they are very different, they frequently address the issues of Aldiss' charter definition and the ultimate point of their comparison is to illuminate how the project of finding a scientifically-tenable definition of humankind and its place in the universe has evolved and progressed over the previous century. The next three chapters will examine in depth each of the three Orders by critiquing examples of early and late texts that are most closely allied with or antagonistic to their positions and methods, identifying the means by which fiction has represented the transformations that have taken place in culture over time, and, surprisingly, noting their common concern with Aldiss' charter definition. 


\section{5}

\section{The Modernist Order}

The features of the Modernist Order can be identified and examined through two novels located at the beginning and the end of the period in which the Order was dominant: Jules Verne's 20,000 Leagues Under the Sea (1870) and Stanislaw Lem's The Invincible (1964). Both of these novels rest on the same basic belief in the efficacy of rationalism and scientific thought in providing an understanding of the universe and humanity's place in it. The specifically Modernist elements that they exemplify are a determined belief in rationalism and scientific thought; they describe the exploration of the unknown, their principal characters share the objective of assimilating it to the known and are aided in this project by specialised knowledge, physical structures and systems. Furthermore, the novels employ realistic exposition, with the assumption of a reliable, neutral narrative voice, and their narrative structures clearly ally themselves with the linear processes of scientific enquiry.

Along with their explicit rationalism, both 20,000 Leagues Under the Sea and The Invincible carry with them assumptions that may be considered neutral on their own terms, but are contentious in other contexts. One is the fact that the nominally balanced range of viewpoints and characters are actually exclusively male, there being no female characters or perspectives in either novel. Also, it is suggested that identity is defined through objective attributes and knowledge is assimilated and integrated by objectifying means.

When we look at processes of exploration and discovery, we see the more literal mechanisms used, often embodied as spaceships. Verne's famous vehicle, the Nautilus, is a submarine, but it has nonetheless become the prototype for the spaceship as it has appeared in twentieth century science fiction. First, it is presented as a representative or culminating example of an advanced scientific and technological system, but is nonetheless highly autonomous and self-contained. Second, it is not fixed, but moves freely in a void, charting space, assimilating knowledge and where necessary, subduing opposition. The spatial system within 
which it is at large is ostensibly neutral and Cartesian, allowing free motion and universal measurement, but while the Nautilus may be 'mobile in the moving', according to the tautological motto of its master, Captain Nemo, which suggests an accommodation of constant change, it acts very much in a centralising manner. While science is in practice universal and democratic (that is, no individual is privileged by name or social position and everyone is potentially able to acquire the authority that knowledge lends), the vessel is so strongly associated with its master that the two constitute a completely integrated system and are effectively a single entity. One cannot imagine the one without the other, and so the master identifies with the tool, and the tool represents the will of the master. The Cartesian grid, therefore, becomes focussed on a centre, and one that is personified as an Imperial figure. Exactly the same can be said of Lem's starship, the Invincible, and many others in science fiction, not the least being Star Trek's USS Enterprise.

Lem's novel, coming at the end of Modernism's dominance, extends the project of knowledge and control into deep space, but Lem is at least as concerned with knowledge itself as he is with territory. Because interstellar space represents for Lem the irreducibly inhuman, his novels reveal the tension at the heart of the Modernist enterprise. Like 20,000 Leagues Under the Sea, The Invincible describes the scientific investigation of the unknown, but while Verne showed a confident unity of Nemo and the Nautilus and a perfect fitness to the environment facilitated by science and technology, the crew of the Invincible, particularly its captain, Horpach, find themselves singularly ill-suited to their environment and their cognitive and technological systems ultimately irrelevant and ineffective due to their inability to meet their own rationalist ideals. It is this tension that ultimately provokes the emergence of the competing Orders and their divergence from Modernism.

\section{1}

\section{0,000 Leagues Under the Sea: The Empire of the Eye}

20,000 Leagues under the Sea begins in an atmosphere of mystery, with an unknown entity, thought to be possibly a gigantic narwhal, attacking and sinking ships around the world. An eminent marine biologist, Aronnax, is sent as an observer on a whaling ship hunting the presumed beast and that ship too is attacked, pitching Aronnax, his 
servant Conseil and a Yankee whaler, Ned Land, into the sea. They are picked up and imprisoned by Captain Nemo, the commander of a great metal-clad submarine, the Nautilus, which it turns out, is the 'narwhale'. Aronnax eventually gains Nemo's trust and respect to some degree partly by their shared scientific passion for the sea. Throughout the rest of the novel, Nemo demonstrates the various technological marvels of the Nautilus that provide him and his crew with a comfortable living within the sea and, in parallel, he and Aronnax provide the reader with a guided tour of the oceans with entertainments and excitements along the way. Finally, Aronnax is persuaded by Land and Conseil to join them in escape and in a great maelstrom where the Nautilus may or may not have been destroyed, the three make their escape to dry land and Aronnax is able to deliver his tale to the world ashore.

Aronnax is the narrator of an exciting novel, but really he is the tour guide of Nemo's museum - and of Nemo's complicated persona, because they are the same. Captain Nemo's role as an agent in the narrative could be defined according to a number of frameworks. Under one, he can be interpreted as a Romantic revolutionary, champion of the oppressed and prone to a number of Byronic turns. Under another, he is a man of the Enlightenment, sorting and ordering the fluid seas about him through the power of science and technology; and under a third, he is a specifically modern revolutionary, not a Romantic figure at all, but a scientific anarchist who has declared war on imperialism and who believes that superior knowledge and technology are the basis of a proper society. Nemo certainly has his literary expression performing in each one of those roles, but in terms of Modernist science fiction, we have to look at the aspects that are unique and significant to him as science fictional devices. One cannot remove him from the Nautilus and put him in charge of a sailing ship or a horse, and say that he is the same man, for example.

In The Artificial Kingdom (1999), the cultural historian Celeste Olalquiaga sees him as the epitome of the bourgeois 'furnished man'; stripped of family identification, he narcissistically creates a persona through the accumulation and ordering of objects in his museum (184). Aronnax - and by extension, the reader does not have interest or insight into his feelings, which he in fact actively conceals and we are left to piece together a collage of the man through this collection of partial descriptions. Of course, as he is never seen without it, the resulting picture of Nemo must be assembled in a pattern that accords with his identification with the Nautilus. 
Captain Nemo can only be understood by his relationship with the Nautilus. In fact, he and the Nautilus are one - a cyborg. Everything that he does is in concert with his machine and its reason for existing is to facilitate his intellect and will. First and most obviously, the windows of the salon establish his scopic regime and the museum is his reified memory; second, the force of electricity energises the body of the submarine, bringing its architecture closer to the mobile, active human body than has previously been the case with static architecture; third, the technological facilities within are engineered to actively serve the physical needs of the body, further intermingling metal and flesh. This last point is most dramatically illustrated when the submarine is trapped within an iceberg, and unable to surface and replenish its oxygen tanks/artificial lungs, it is the human crew that begins to suffocate. On one hand this intimate entanglement is a classically Foucauldian establishment of knowledge-as-power, but as an essential corollary to that, as Olalquiaga shows, Nemo's physical existence and intellectual identity is based in the physical structure of the Nautilus and its systematically integrated collections of specimens and devices.

The Nautilus is of course well-adapted to its physical environment in terms of its outer physical form, but it is representative of its cultural environment or origin as well and its interior therefore seems to a twenty-first century reader to be surreally discontinuous. It is, for example, equipped not only with mechanisms of power and propulsion in the sea, but also possesses a grand salon and library. It is a perfect bourgeois home adrift in the sea, hence Olalquiaga's point. The Nautilus and Nemo derive their joint identity from dichotomies - not by negating or ignoring the outside, but by creating a structural system of perpetual contrast.

The submarine is a prosthesis, allowing Nemo to dwell in the sea as he would on land, if not do even more (ibid 179). Nemo is professedly detached from civilisation, but the Nautilus is the expression of civilisation, both by being a technical apparatus and by carrying within it all the furnishings of a civilised home. It is also an instrument of dominion over the sea. This is not only by its brute power, but by its optical and ordering proficiency. Nemo observes the sea through the glass windows of his salon, in his museum he catalogues them and in his dining room, he eats them (20,000 Leagues Under the Sea 73). Hunting and gathering sea life is straightforward, but one can be forgiven for wondering exactly how Nemo manages to milk whales to supply the cream for his dining table (after all, how does he get them to keep still?). Nemo is proud to tell Aronnax, and Aronnnax is happy to be 
impressed, that he finds a practical use for almost everything in the sea. Everything is classified according to Linnaean order and reacted to according to its utility, abstract scientific interest or threat.

The submarine itself is the perfect appliance - not in the sense that it is like a very good cake mixer (though it is doubtless equipped with one), but in that it represents the praxis of science. The Nautilus is, as the modernist architect Le Corbusier was to strenuously advocate in the following century, 'a machine for living' (Le Corbusier 89). Le Corbusier's rhetoric used analogies with cars and aeroplanes: these were machines for travel and flight. Buttressing his argument, he explicitly drew positive and negative analogies with ancient buildings and modern machines. Why, he contended, should we model our homes on ancient ruins when the exemplars for truly modern architecture existed in the form of ocean liners, the epitome of technological excellence, luxury and power (ibid 97)? The house, he concluded, must be made less as an individuated, fixed dwelling place than an instrument (ibid 219, $245,246)$. The use of appliances serves to integrate even more fully the performance of one's life with the habitat. One does not merely inhabit the 'machine for living' one requires it in order to live... but only as it is able to enable one to do so. This almost tautological arrangement becomes a procrustean chaise-lounge for the mind and body. Verne expects the reader to be enchanted by Aronnax's lesson on the life of the sea, but he expects them to be impressed too by just how perfect a dwelling Nemo's submarine can be, and by clear implication how much better the cities and homes of the nineteenth century could be. In 20,000 Leagues Under the Sea, we see a little of the social reformer that would become more prominent in his later works and an anticipation of the social-technological reformism of the Bauhaus.

The great novelty to Verne's readers was the fact that the Nautilus was electrically-powered ('All by Electricity' 20,000 Leagues Under the Sea 81-6). It is difficult to overstate the importance of electricity in the nineteenth century, technically and culturally. It was a radically new power source, seen normally only in the violence of lightning storms, that was suddenly domesticated, it was the subject of epic competition between the two visionary and charismatic inventors - Thomas Edison and Nicola Tesla - and its utilisation seemed to be the modern realisation of the myth of Prometheus' delivery of fire to the people of the earth (Nye: 'The Electrical Sublime: The Double of Technology' 143-172; 'The Electric Cityscape: The Unintended Sublime' 173-198). 
Surrounding the sheer spectacle of its mastery by science was an aura of pseudoscience, which made it appear to perform all manner of magical effects for good or ill. After Luigi Galvani was able to cause frogs' legs to twitch with electrical impulses in 1771, Mesmer was able to pose as a master healer with his vats of 'magnetic fluid' and Mary Shelley guessed that electricity might bring the inanimate to life (though there is no explicit representation of Victor Frankenstein using electricity, almost every film adaptation of Frankenstein has made great visible use of it). The life-giving but potentially destructive energy sources of the 'Vril' used in Edward Bulwer-Lytton's The Coming Race (1871) and the Earth Current of The Night Land are both obviously modeled on electricity. Electricity was not merely power, it appeared to be a kind of essence of life itself. The most direct analogy that can be made between electricity in the nineteenth century and a current equivalent in the twentieth and twenty-first might be with nuclear energy, or with smart networked devices that seem to be intelligent. Nuclear energy seemed at least in the midtwentieth century a godlike force and still has a dreadful, almost magical aura about it, and networked smart devices seem too to be possessed of the quality of life that in a machine seems marvelous, uncanny and potentially terrifying.*

Nemo seems all the more a genius - and he is a scientific genius, not a magician. His technology is - for the time at least - sufficiently advanced to be indistinguishable from magic, if not better.

We can see that Nautilus therefore is not merely a vehicle, but Nemo's machine for living. Free living is explicitly linked with mobility. At its best, as practiced by Nemo, mobility is also exploration, which leads to the advance of knowledge and self-development. If we are to explore Nemo's mind, then we do not need to divine any hidden layers, even though he is a secretive man. The structure of his mind is visibly imprinted upon the metal of his submarine. The key of course is that its core is a museum. 'Nemo' means 'nobody', as would be suitable for a stateless man, but as Olalquiaga points out, it also recalls Mnemosyne, the muse of memory (193). The Nautilus' museum is a memory theatre, reflecting and supporting his mind, his persona. He has pictures of his late family, and charts, and mementoes and the accoutrements of a confident, comfortable lifestyle - right down to seaweed cigars (ibid 177).

\footnotetext{
* In Disney's 1954 film adaptation of 20,000 Leagues under the Sea, the Nautilus is actually nuclear powered ('Twenty Thousand Leagues under the Sea (1954 film)').
} 
One of the most evocative illustrations by Alphonse-Marie de Neuville and Edouard Riou for the first edition of 20,000 Leagues under the Sea depicts Captain Nemo standing in the salon of his submarine, the Nautilus, gazing into the waters outside and the eyes of a giant squid that looks back. Biologists have long noted the similarity of the eyes of vertebrates and cephalopods as a classic example of convergent evolution and the eye in modern terms is the outward-turned organ of the intellect (we speak of the Enlightenment and metaphorically describe knowledge with visual metaphors such as seeing and insight); the implication therefore is that there is another consciousness returning Nemo's gaze and it is an alien consciousness with a different understanding. The image is deeply uncanny; naturally the squid is a monster that contradicts the fundamental human understanding of the world and so it must be destroyed - which it is.

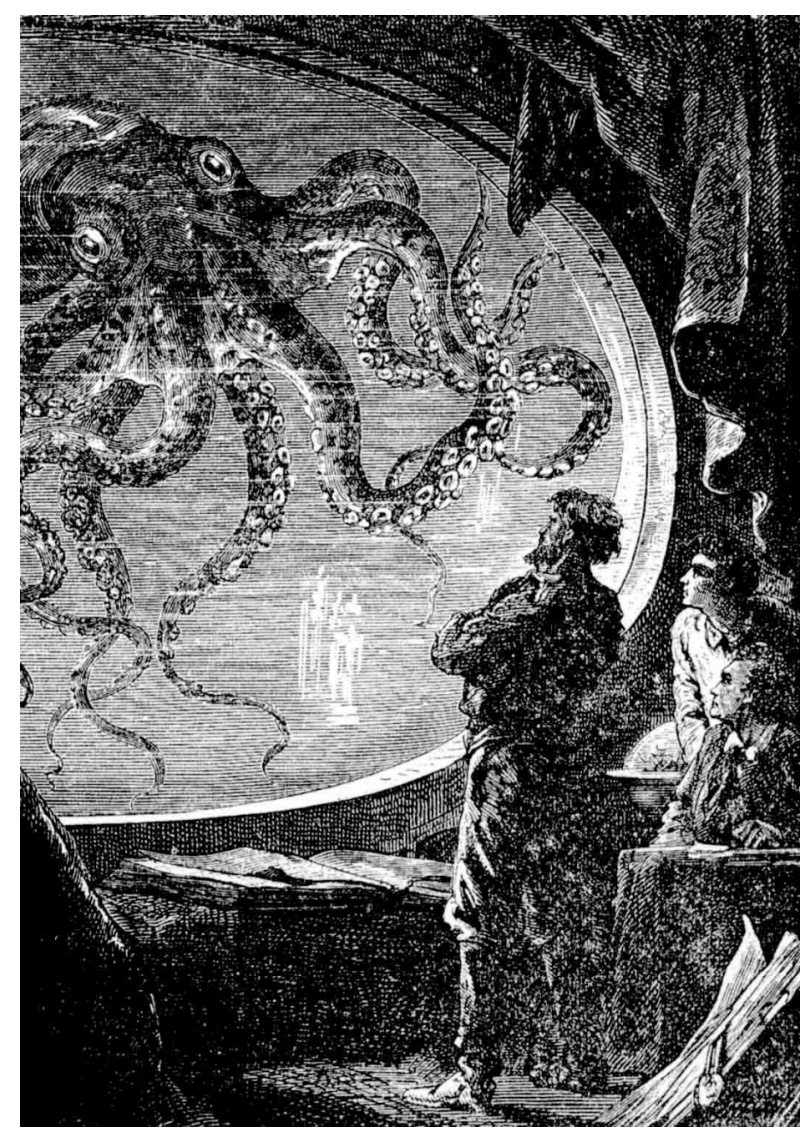

Nemo in the Salon of the Nautilus ('20000_squid_Nautilus_viewbay').

The Baroque style is often the style of absolute monarchs and dictators because it is not only balanced and symmetrical about its internal axes and orders, but extends 
those axes and orders into the landscape itself (a principle we see in Versailles, Baron Haussmann's remodeling of Paris and Albert Speer's plan for Berlin, renamed 'Germania'). Captain Nemo's own ability to gaze upon the creatures of the sea through the portals of his submarine follows the Baroque principle of domination by sight and identification with the world by sight (exemplified by the Panopticon, discussed by Foucault, 1987, 195-228). On one hand it is a process of narcissism by which the one who gazes is able to see everywhere confirmation of himself or herself; on the other, however, it introduces a new element into the absolutist system of Baroque imperialism: the science fictional aesthetic of the sense of wonder. Nemo commands the sea, but he is in love with it too, and through the ports of the Nautilus, he sees marvels and shows them to his companions too. The novel is full of careful, measured rational explanations, but these follow on from the sight of the marvelous, articulating the sensual and aesthetic pleasure of the marvelous transforming into the comprehended.

In classical and mediaeval culture, vision was believed to be an active, outward projection of sensory rays from the eye (analogous to radar or a bat's sonar), not only in commonplace perception (Field 6), but also as a means of transmitting influence - hence the 'evil eye' and the petrifying force of Medusa's gaze (Siebers 27-56). While by the Renaissance this concept had been overturned, in an oblique way it had been materially fulfilled with the development of artillery: artists skilled in perspective were commissioned to design fortifications, where a cannon's line of fire was managed in exactly the same way as a line of sight (Field 129-31). (The distinctive polygonal and stellated forms of Renaissance fortifications are still visible in many European towns and cities today, particularly the Venetian garrison town of Palmanova.) Moreover, as Francis Bacon declared, knowledge itself is power, and it is the ability to see, measure and categorise from a constant viewpoint that is fundamental to modernist scientific dominion. The linear avenues of the Baroque style, such as those centralised on the King's chambers at the palace of Versailles, made obvious the linkage of perspective with an all-pervading secular power, but the Nautilus is a receiver of knowledge as well as a projector of authority.

At the heart of the Nautilus is Nemo's museum, and therein lies the paradox of the vessel and his mission. Verne himself lets this point slip; on an underwater excursion, Nemo shows to Aronnax a giant clam, over two metres across, and nested 
within it a pearl as large as a coconut. Year after year, Nemo has been cultivating this pearl, seemingly without purpose, until Aronnax realises his motive:

Only the captain knew where this marvellous fruit of nature was "ripening"; he alone was bringing it up, one might say, so that one day he might take it to his precious museum... I estimated it to be worth at least two million dollars. But it was more a wonder of nature than a piece of jewelry, for I can't imagine what woman's ear could support such a weight (20,000 Leagues Under the Sea 200-1).

The Nautilus, according to Nemo's motto, is at freedom within a sea that is itself free. However, modern museums are institutions devoted to the display of empiricallyderived facts - incontrovertible, quantifiable and integrated into a rigidly coherent system of knowledge. Outside the museum there is mysterious water, in which growing pearls are hidden, but inside there is light, knowledge and perfected stasis. The fate of this giant pearl is emblematic of the processes of knowledge: it is appropriated from one dynamic interior, that of the clam, by Nemo to his own metallic shell where its processes of change cease and it is fixed in its ultimate form for as long as the museum itself exists. Both physical objects and knowledge undergo the same reverse sea-change; as the art of perspective in the Renaissance fixed space into a system of lines converging on the fixed point of the human observer, both Aronnax's and Nemo's practice of science crystallises the world into an anthropocentric matrix of classifications.

Ultimately the chambered Nautilus becomes a kind of camera obscura, representing the exterior world by obscuring it from direct sight and painting images of it within its own architecture:

Disconnected from any sense of belonging, Nemo seeks his self in utter isolation, furthering an already extreme deracinated condition when he turns to the outside as one gigantic mirror on which to project his desperate saga, rendering the outer world inexistent as a differentiated entity (Olalquiaga 184).

Olalquiaga compares this to the state of Walter Benjamin's 'furnished man'. This is a being whose psyche is founded in the systems of surrounding objects and who is 
unable to experience selfhood or 'exist' without them (ibid 175, 184-186. This is from Olalquiaga's own translation of Walter Benjamin's 'The Interior, Traces,' 192729). Persona is not an abstraction, but is materially embodied in observations, reflections, systems, performances and objects. The irony of this museum, which Verne does not remark on, is that it is entirely impersonal. Nemo has a tragic past, which he speaks of evasively and which shows no traces in his museum: his present self is constructed entirely according to the same system that has created the Nautilus.

Nemo and the Nautilus are completely integrated system, and the cephalopod from which the submarine takes its name is a shelled creature (it is not named, for example, the Squid or Calmar). Shells are very interesting in terms of what they represent: they seem hard and unloving, but they are secreted by living organisms and remain an integral part of their being. Gaston Bachelard grounds his observation on the integrity of mind and house with the analogy of the shell, to which he devotes a whole chapter of Poetics of Space (1958). The shell is no static, separate element, but essential to one's dynamic continuation of being:

[A] dreamer is unable to believe that the work is finished when the walls are built, and thus it is that shell-constructing dreams give life and action to highly geometricially-associated molecules. For these dreams, the shell, in the very tissue of its matter, is alive (115).

Among the examples he assembles to demonstrate his point, he offers a quotation from Charbonneaux-Lassay:

Taken as a whole, with both its hard covering and sentient organism, the shell, for the Ancients, was the symbol of the human being in its entirety, body and soul (ibid 116).

Nemo's adoption of the name of the shelled sea-creature, the nautilus, as that of his home and outer body is entirely appropriate. The products of culture are to us both more and less than what a shell is to a mollusc. They are what Richard Dawkins calls the 'extended phenotype', that is, things and systems that may not be integral parts of our bodies, but which we are nonetheless genetically compelled to create and which are therefore essential to our identity (The Extended Phenotype, 1999). 
In short, the house we are born in has engraved within us the hierarchy of the various functions of inhabiting. We are the diagram of the functions of inhabiting that particular house, and all the other houses are but variations on a fundamental theme. The word habit is too worn a word to express this passionate liaison of our bodies, which do not forget, with an unforgettable house (Bachelard 15).

Retreat into the shell is usually conceived as part of a process of production in secrecy followed by emergence and revelation, a process also noted by Jung in his study of alchemy (ibid 109). However, the shell is attractive as a permanent state of being. Bachelard notes the case of the sixteenth century scholar, potter and enamel artist, Bernard Palissy. Palissy was fascinated by shelled molluscs and drew direct analogies between their utilisation of armour and human habitation. Reasoning that the molluscs extruded their shells as protection against predators, then such a form of dwelling was also naturally appropriate to human communities, especially a sort of covering constructed from within. He even proposed snail-cities: a city made in the form of a coiled shell so as to confound invaders (ibid 127-30). In fact the city of Edo, now known as Tokyo, did indeed have a nautilus-like plan in order to do so, and if we are to consider the other quality of a snail or shelled cephalopod, its mobility, we can see that these are not a world away from the Standard Island, depicted in Verne's satirical Propeller Island (1895), or gigantic mechanical nomads such as the walking city proposed by Ron Herron, a member of the radical architecture group, Archigram, in 1964 (Cook, 48-51).

Benjamin sees the bourgeois man as a materialist, collecting talismans that radiate a magical force to sustain his existence. In fact, existentially he imbues these objects with the essence of his being and draws his being from them too and the resulting relationship becomes ever more intimate and integral.

The furnished man is really Butler's 'organised man' as described by Lucubratio Ebria: a cyborg. Nemo has identified himself as a part of a system of knowledge and power, violently opposed to terrestrial political power and ardently devoted to a different order of authority, spatial organisation, knowledge and control. He does not simply walk the streets of a city where he is at home, he has made a home for himself that is so intimately fitted with what he has decided to be that it 
might be a physical extrusion, like a shell, and yet he has also stripped away his own past, discarded his original name and fitted himself to the system of knowledge and technology that he has utilised in order to live in the sea. Nonetheless, or because of this, the fit seems perfect on both sides.

\section{2}

\section{The Invincible: The Empire of Unreason}

In Stanislaw Lem's The Invincible, a starship of that name (the title, as becomes clear, is ambiguous and may equally refer to its opposition) is dispatched to the apparently dead planet Regis III in order to discover what has happened to its sister ship, the Condor, which signaled a successful landing before falling unaccountably silent. The crew, headed by its captain, Horpach, and his younger second in command, Rohan, begin a cautious scientific survey before locating the wrecked Condor and finding its entire crew either dead or missing and its supposedly impervious hull pitted and scarred. Strangely, the recovered bodies of that ship's crew show few signs of direct attack and they seem to have starved to death while the ship's larders remained full. As far as can be determined from records, the Condor was attacked by nothing more than a swarm of flies. Compounding the mystery, fairly complex life is found deep in the oceans of the planet, begging the question of why there is no life on land whatsoever. Events take an even more sinister turn when expeditions from the Invincible itself come under attack, with men being reduced to states of helpless idiocy, with swarms of black flies being the apparent culprits. It is discovered then that these 'insects' are in fact mechanical entities and can collectively generate great pulses of electromagnetic energy sufficient to destroy the mind of any other being.

While the flies now seem to have been the cause of the demise of the Condor and of land-based life on Regis III, further mysteries emerge: what is their origin, nature and purpose? While the Invincible itself remains for the time being inviolate behind its force fields, the decimation of its crew continues and its enormous military might is no match for the sheer scale and numbers of the swarms of flies. One of the scientists on board, Lauda, hypothesises that an ancient alien colony on the planet failed, leaving its cybernetic systems still operating. These machines underwent a 
kind of evolution, resulting in the current 'necrosphere' of the black flies ('Lauda's Hypothesis' The Invincible 99-112).

Although Lauda's hypothesis is compelling, Horpach's concern is with members of his crew missing in recent battles and he manipulates Rohan into making a final solo expedition to either rescue them or bring back confirmation of their deaths. Equipped with an electromagnetic camouflage that at least appears to prevent him provoking the flies, Rohan is able to find the bodies of a few of the missing men and witnesses a great concatenation of swarms, which he is unable to interpret before he finally returns to the Invincible. He is convinced by now that the whole expedition of the ship has been utterly pointless and its name is a cruelly ironic joke.

Lem's novel is a philosophical thought experiment and satire rather than a straight adventure and while there are many sequences of dramatic action, they serve the narrative as experiments to be discussed so that hypotheses might be formulated and tested by more experiments disguised as battles. The investigation concerns the viability and irreconcilability of different systems. On one hand, there is that represented by the Invincible: intelligent, technocratic, imperial and human; and on the other, a kind of purely reactive, networked system with no sign or need of consciousness or direction. Lem begins by carefully following conventions of science fiction established by Verne in making sure that the reader is informed of the great power and sophistication of the vessel and letting us know too that the people of the story are completely at home in their technological environment. Indeed it is like a mother to them: the crew spend the long cruise periods between the stars in embryonic suspended animation.

On the other hand, there are the black flies. Individually they are insignificant and even en masse their actions are synchronised but are still more reflexive than strategic. A few men are attacked and incapacitated by them initially, but maybe they were careless, as might have been the victims of a flash flood who tried to cross a stream at the wrong time. Surely they cannot be a match for the arsenal of the starship that includes tank-like robots and nuclear weapons. It soon becomes apparent however that they are a threat, as it becomes apparent how they can be a threat. The conflict between the Invincible and the black flies is very much a conflict between what they each represent. As it turns out, while the black flies are not what the crew of the Invincible believe them to be, they themselves are not what they believe themselves to be either. 
The Invincible is about a technological culture of the kind represented by Verne and the Modernists attempting to master 'nature', which it defines as its antithesis. The cybernetic ecology of Regis III, or 'necrosphere' as it is dubbed, is not ready to wear the mask made for it though; it is instead a technological system that has become a radically simplified form of nature. It consists entirely of vast swarms of tiny machines that are the end result of millions of years of evolutionary regression to utter simplicity. The scientist Lauda hypothesises that an alien colony was established on the planet millions of years ago, but failed, leaving its machines still active. These machines followed their programmed imperatives to repair themselves, but soon began to compete for resources. Two strategies were then pursued: in one case, larger, intelligent machines developed that were able to withstand individually the rigours of the new world. In the second case, smaller simpler units evolved that were individually vulnerable, but could replicate quickly from minimal resources. This latter kind had the capacity (indeed, the imperative) to gather into swarms and moreover could generate powerful electromagnetic pulses to disrupt the communications of the larger units, isolating and overwhelming them. Their electromagnetic weapon then developed further into the capacity to entirely erase their complex but delicate minds while leaving the unintelligent units unaffected. Due to their inherent flexibility and ability to absorb damage as a collective, it is the smaller kind, the predecessors of the black flies, which were able to triumph.

Eventually, all complex biological life on the surface of the planet was eliminated too, as the emissions of their own nervous systems were detected by the swarms and reflexively attacked. There was no master plan, no centralised intelligence, nor was there even the barest will and intention. Lem has in fact presented a scenario of pure Darwinian - or Butlerian - evolution by natural selection applied to machines.

Lem's invention of the black flies is itself an accurate anticipation of recent thinking in robotics, particularly scientific and military systems. In those fields, selforganising swarms of individually unintelligent and simple units are increasingly being seen as more practical and flexible than large, sophisticated and centralised (and expensive) systems ('The Upside-Down Evolution', One Human Minute 37-68). Likewise, electromagnetic warfare aimed at disrupting or corrupting communications and ostensibly nonlethal weapons that incapacitate the bodies and minds of human beings rather than directly killing them are increasingly making their way into the 
weapons systems and strategies of twenty-first century military forces (De Landa, 1991, passim).

Nemo's project is scientific, with an imperial cast. The crew of the Invincible are less clear in their motives, because they are less in harmony with themselves and their vessel. Verne presents the role of nineteenth-century science as being imperial and consequently successful, because imperialism was conceived as a positive endeavour, supporting and being supported by the role and method of science. Lem's perspective is anti-imperialist: the Invincible fails in its mission because the two missions that were unified in 20,000 Leagues Under the Sea are dissonant in their means and their objectives. He articulates this in the administrative division between Horpach on the military side, and Rohan, who sides with the perspective of the scientists, led by Lauda. Horpach, because he is the captain and because he is able to manipulate the more passive Rohan, perverts the Invincible's scientific mission and turns it into a war.

Initially, the establishment of the Invincible's base on Regis III is cautious and methodical, following Rykwert's classical prescription: a central axis, surrounded by a protectively energised barrier that separates the known realm of the humans from the unknown outer world. This is only a preparatory stage to the proper scientific investigation of the planet, and expeditions that set out are dedicated to establishing a complete pattern of understanding of the planet that will presumably render it safe and permit uninterrupted movement across its surface. However, the Rykwertian structure is also potentially one that can become ever more deeply entrenched, and as the expeditions and then the Invincible itself are attacked, this is what happens. Military strategy is often based on progressive escalation of defensive and aggressive measures, and rather than opening up the protective barrier, Horpach intensifies his defensive-aggressive stance and turns to attacking the flies, which is fruitless.

The alternative strategy is represented by Rohan's last expedition into the landscape devastated by the millions of years of the flies' dominance and lately by the ship's own weapons of mass destruction. Instead of armouring himself, or using a version of the Invincible's own force field, he adopts a strategy of stealth, wearing an electronic disguise that conceals his brainwaves from the flies and thereby prevents their attention. His goal too is not to oppose and defeat them, but to survey the land and discover the fate of men left outside the ship during a battle. All he intends to gain is knowledge. However, even this mission is fundamentally flawed because its 
knowledge-seeking goal is no longer the primary objective of the ship and its crew; instead, it is used as an act of symbolic closure. It does not open up new paths of enquiry, but serves to salve Horpach's conscience and maintain his standing among the crew by giving them the 'certainty' that they would never be abandoned under any circumstances (154).

The cardinal sin of Horpach is to be motivated not by reason, but by mythology. Nemo fought giant squid that were possessed of some rudimentary form of intelligence and which definitely had malicious intent directed at him, his ship and his crew, and his victory then is akin to a dragon-slaying. Had his opponent really been a dragon or a squid, Horpach would be a hero, but The Invincible deconstructs the myth of dragon-slaying relentlessly: the 'dragon' has a rudimentary intelligence distributed through its network, but it has no consciousness and no intent and no more malice than the weather. Neither is it slain. The expedition of the Invincible is to find out, not to make war, but as soon as it confronts an opposing force, the ideal of rational enquiry by cool minds integrated with smoothly-operating machines to discover and assimilate knowledge gives way to atavistic belligerence and weaponry gone berserk. Horpach's heroism is redundant, but without the harmony of crew, ship and mission, Rohan's last expedition is tragic.

The transformation that has come about since Verne wrote so approvingly of scientific imperialism in 20,000 Leagues Under the Sea is that imperialism is no longer seen as a positive force - indeed, as Lem was a (secular) Jew who grew up in a region of Poland occupied alternately by the Soviet Union and Nazi Germany, and who was active with the Resistance, imperialism's dark side would have been starkly obvious to him.

Lem of course remained committed to rationalism, and his stories do not represent the fundamental failure of science itself. His characters usually do their best to confront their situations rationally and come to grief when they fail to do so. His narratives are themselves constructed in the manner of scientific investigations: phenomena are observed, characters investigate, formulate and test hypotheses, and according to results that they observe, settle on one interpretation or another, however discomforting or contingent they might know it to be. His respect for intellectual honesty is obvious, as is the aesthetic pleasure that he takes in creating patterns of comprehension. These are all fundamental virtues of science and Modernist science fiction. The problem is, after Nazi and Soviet atrocities, technologically-facilitated 
imperialism can no longer be seen as a self-evidently good thing and the natural partner of good science in every situation.

Foucault argues in Discipline and Punish that the panoptic prison could only exist in conjunction with the encyclopaedia and before that, the systems used to control plague (204). A corollary of that is that extroverted encyclopaedism is an attempt to discipline nature. Nemo and the crew of the Invincible (and by implication, the Enterprise) imagine that they are explorers, but act as conquerors, and in the case of The Invincible, when nature proves to be uncooperative, it must be disciplined and punished with greater severity as the stakes rise ever higher. Nemo could no longer survive as himself: he splits into Lauda and Rohan on one side and Horpach on the other.

\section{3}

\section{No Sex Please, We're Cartesians}

20,000 Leagues Under the Sea and The Invincible both examine the confrontation of the rational and the irrational, the rational being presumed to be the peak and essence of human intellect, and both novels present microcosms of society in which there are no women.

Nominally, the microcosmic societies are genderless, 'male' implicitly being the default setting of humanity, but they are also sexless. Granted, one can find numerous examples of symbolic sexuality - Ned Land's harpoon, the Nautilus' ramming, and after Doctor Strangelove, the Invincible's nuclear weapons too - but that is itself the point: sexuality is repressed, and with it, the acknowledgement of irrational and compulsive instinct and sensuality.

As these microcosmic societies are effectively homosocial, but not (overtly) homosexual, sexuality is implied to be absent. There are a number of reasons for and consequences of this state of affairs, not least the claim that science fiction is 'purely' a literature of the intellect, not the body, a claim that is predicated on the Cartesian assumption that the two are separable. Lem has argued that the lack of significant, active women characters in his stories is due to their being, in effect, a 'special case', and that their interactions with male characters would introduce 'unnecessary complications' into the narrative (Swirski A Stanislaw Lem Reader, 1997, 55-6). By 
implication, they would require the characters now established as gendered by their differences to interact with each other as (presumably heterosexual) men and (presumably heterosexual) women, not as people engaged in purely cerebral discourse. If one assumes that pure cerebrality is the norm and proper state of being, with the body and the irrational self strictly subordinated, nominally genderless and asexual homosociality is a 'solution'.

In the absence of overt sexuality, the only sense of the visceral nature of humanity or posthumanity that one gets in The Invincible is in the treatment of men as infants or embryos, either preserved in suspended animation by the 'mother' starship or after mental erasure by the black flies when they become drooling babies unable to feed themselves and with their potty training presumably forgotten too. To postfeminist and postmodern readers, the denial of viscerality now seems absurd and untenable as a literary strategy (Sobchack, 103-15, writes on film, but her criticisms could apply equally well to a portion of written science fiction).

Modernism in science fiction celebrates and employs reason, regarding it as a supreme quality that can and must be both separated from other faculties and placed in command over them. Verne believed that this was possible, Lem thought that it might be too, but the triumph of reason was by no means guaranteed and could be undone by impulses that might well seem to be noble. Horpach perverted the mission of the Invincible because he thought that he should behave in a way that was honourable and brave in a world where courage and honour were irrelevant compared to cool intellect. However, Lem had constructed in The Invincible a world in which cool intellect must be dominant. The patterns of rational thought that he adheres to arise from its fundamental structure and are therefore appropriate to this world, and that ensures his place in the Modernist milieu: no matter how critical he may appear to be of humanity and its ability to be rational, he shows it as failing only when it ceases to be rational. 


\section{6}

\section{The Neohumanist Order}

While The Invincible presented itself as a corrective to any complacent assumptions about the inevitability of the triumph of reason, it has effectively had its own critique: the 1979 film Alien, written by Dan O'Bannon and Ronald Shusett and directed by Ridley Scott with evocative design by Ron Cobb and H. R. Giger. The opening sequence with the highly automated starship waking itself up before reviving its human crew, is almost a direct visual translation of the opening of The Invincible, albeit in a shabby commercial milieu rather than that of Lem's smoothly-functioning imperial-scientific expedition. It is in that film, of course, that viscerality erupts into conventional science fiction with a vengeance. While the ambiguous noun/adjective of the title is creepily effective, there is in essence nothing alien about the monster at all: it is really an all too human return of the repressed. Empirical reason, Neohumanism argues, is not enough to describe the universe and our condition, or the processes by which we can dwell properly and honestly in the cosmos.

According to the Neohumanist and Posthumanist Orders, the Cartesian concept of space offers only a limited view of the cosmos, and the duality of intellect and body is likewise so. As a counterpoint to The Invincible, Alien highlights three of the issues that would be the principal issues in Neohumanism and Posthumanism: the demarcation of space into ordered and chaotic realms and the potential for infection of the former by the latter, the embedding of human bodies in cybernetic systems, and the ineradicable and intractable power of sexuality.

Neohumanism itself demonstrates a wide variety of ideological approaches: it may define the alien as essentially antagonistic, and evil, or it may regard the alien positively, asserting the necessity for dialogue and balance. In either case it preserves the exclusive categories of self and other, and its construction of spatiality reflects that basic opposition - but that opposition is likely to be nested in a metaphysicalspatial system that comprises higher and lower planes in addition to the inner and the outer. In the higher plane, which is structured and governed by different rules than 
the mundane, a grand convergence may (although not in every case) be possible and even inevitable. In any case, while the realms are separate in terms of direct experience, they are linked in terms of meaning, and how the transcendental informs the mundane is discovered within the mundane through revelation and polysemic interpretation rather than empirical observation.

The Order manifests itself in its early form in William Hope Hodgson's novels, The Night Land and The House on the Borderland, while the novels of Robert Charles Wilson demonstrate the evolution of the Order today. Authors working within the Neohumanist Order can be very idiosyncratic in their approaches, but it is often this very idiosyncrasy that is most revealing of the intensity and depth of struggle that they engage in so as to accomplish their syntheses and the breath of sources that they draw upon. Hodsgon's creative process in particular deserves detailed attention as his personal odyssey as a writer is in effect a microcosm of the emergent process of the Order itself. Despite their differences, both authors are representative of their times and both articulate specific attitudes towards science and scientific epistemology from a humanist perspective, both strive to synthesise scientific and esoteric systems of thought, and both articulate detailed spatial schemae.

\section{1}

\section{The Night Land: Jerusalem Built in a Terminal Eden}

The principal edifices constructed by William Hope Hodgson for The Night Land and Stanislaw Lem for The Invincible are eerily similar. In both cases, a great structure stands in a desert where rationality is under siege, protecting itself with a circular energy field demarcating inner reason and light from external insanity and darkness. Both the warship and the Last Redoubt are technological monuments, embodying their civilisations in an alien land; their inhabitants are paragons of intellect and virtue and both structures are potentially doomed.

The Night Land precedes The Invincible by decades and Lem's novel might appear to be a direct answer to and deconstruction of its anthropocentric premises. However, The Night Land also has to be seen on its own terms as it has its own 
descendents that implicitly acknowledge Lem's criticisms of anthropocentrism, but construct narrative architectures that tie together human experience and the alien.

The novel begins with a lengthy prologue in which an unnamed man (few characters in the entire novel are named) living some time in the sixteenth century falls in love with a Lady Mirdath, marries her and then is forced to witness her tragic premature death. Distraught with grief, he has a dream of an adventure in the far future that he then writes down, the manuscript being found in the late nineteenth century and presented to the modern reader. It is this vision that constitutes the bulk of the novel and it opens with a young man - unnamed, but referred to as ' $\mathrm{X}$ ' in the title of an abridged edition by subsequent commentators on the novel for convenience (Hodgson The Dream of $X$ ) - living with the last remnants of humanity (or so he at first assumes) in a titanic metal pyramid called the Last Redoubt. The sun has long since died, condemning the earth to eternal darkness, and the Redoubt is dependent upon the power of the 'earth current' for sustenance. Outside in the 'Night Land', there are strange and vicious 'abhuman' creatures, sinister 'Silent Ones' and still more terrible ethereal beings that feed on human souls while the Redoubt itself is besieged by enigmatic 'Watchers' that are so huge as to be scarcely inferior to it in scale.

The rulers or hegemons of the Last Redoubt are a caste of scholarly technocrats, the 'Monstruwacans', and it is they who receive the first telepathic transmissions from a young woman, Naani, living in a forgotten Lesser Redoubt, founded millennia ago by a dissident faction. The Master Monstruwacan of the Last Redoubt has tutored the protagonist and appoints him, due to his extraordinary facility in 'night-hearing' (telepathy), to the task of communicating with Naani. He learns that the defences of the Lesser Redoubt are failing, and once the news that the Last Redoubt is only temporarily misnamed spreads, a contingent of its youth mutinies and stages an expedition with the intent of rescuing their brethren. Alas, they are quickly slaughtered by the denizens of the Night Land and thus any hope of giving aid is dashed. All the hero and the Monstruwacans and the wider populace of the Last Redoubt can do is listen and console until Naani's voice is extinguished.

This is of course intolerable to the gallant $\mathrm{X}$ who, equipped with minimal supplies, armour, a chainsaw-like weapon called a 'Diskos' and tremendous courage, sets off alone into the darkness with the blessings of the Master Monstruwacan and

\footnotetext{
* 'Monstruwacan' is an invention of Hodgson's, possibly suggesting 'Monsterwatcher'.
} 
the adulation of the Last Redoubt's citizens. There follows a lengthy journey of many 'days' (for want of a better term), filled with encounters with strange and deadly lifeforms, volcanic eruptions and several fights with monsters. Finally, $\mathrm{X}$ arrives at his destination, only to find it dark and lifeless. He is too late - almost. The sole survivor is Naani (of course). The pair begin the long journey back to the now accurately named Last Redoubt and the two inevitably become lovers, recalling as they travel past lives that they shared, indicating that their love is predestined.

As the couple nears the Last Redoubt, the evil forces of the Land are roused and Naani is struck down and killed by an emanation from the Silent Ones. Refusing to give up, $\mathrm{X}$ fights on, carrying her body while fearsome beasts gather in hordes about him and attack. All seems lost until the Last Redoubt turns its own waning but still mighty firepower upon the Land, incinerating his opposition and allowing him at last to renter his refuge. In a great ceremony attended by millions, Naani is entombed in the Redoubt's subterranean cemetery, but is miraculously revived by the force of the earth current and thus she and X may live together in utter mutual devotion, sharing, as X puts it, 'the House of Joy' (357).

The Last Redoubt is an exemplary specimen of the kind of architecture described by Joseph Rykwert. It is described as a pyramid almost eight miles high, five and a quarter miles square at the base and oriented according to the cardinal directions. Surrounding it, there is a protective energy field eight miles in diameter and within there are twelve hundred and thirty cities stacked like plates of steadily diminishing size. Each city is neatly quartered by moving walkways and at its heart there is a Room of Mathematics with a gnomon indicating the exact geometric centre of the structure. Beneath the ground, there are a hundred levels of farmland within a still greater pyramidal volume.

The Last Redoubt is the first mention in fiction of an arcology, a kind of edifice that has now become a staple of the genre. The term itself was coined by the Frank Lloyd Wright-taught architect, Paolo Soleri, and is a portmanteau of $\operatorname{architecture}$ and ecology (Wall and Borek, unpaginated). While Wright idealised the individual dwelling in open space, epitomised by the Prairie style and a component of his Broadacre City urban design concept, Soleri turned his environmental concerns to lessening the environmental impact of a city by concentrating it into the smallest area possible. In doing so, he devised the largest single buildings ever seriously conceived - since Hodgson. 
Soleri bridges the thought of Frank Lloyd Wright and the controversial Jesuit and anthropologist, Pierre Teilhard de Chardin. Wright was deeply concerned with edifices that have a strong sense of centre (represented by the hearth) and integrity with human form and nature itself. Teilhard's theology was based on the convergence of civilisation in an integrated 'noosphere' woven over the biosphere of the earth and which would itself culminate in the perfect unity of an 'Omega Point'." Soleri has produced a great number of arcology designs and has even established a community dedicated to the construction of a prototype, Arcosanti $(<$ http://www.arcosanti.org $>$ ). Because construction of Arcosanti is proceeding at a glacial pace, it may well be overtaken by other, more 'mainstream' architects and developers.

An arcology, unlike a modern city, but much like many ideal cities and ancient cities as they were planned at least, is an integrated, unified superorganism and cosmological schema. Spiro Kostoff places ideal geometric cities in a separate category from real cities, as dreams are supposed to be separate from real life (162-5), but this qualitative division ignores the fact that geometric order nonetheless exists immanently within vast numbers of real cities, however compromised they may be in their actual physical expression - as dreams. It is by clearly presenting the ideal immanent form that the transcendental can itself be indicated. The Last Redoubt is an apocalyptic edifice in that all of the compromises of the world have been stripped away to reveal the ideal that was previously obscured, and because of that, it is the supporting matrix and generator of a civilisation and its citizens.

The Night Land is a place where all is made visible, if not comprehensible and it is the Last Redoubt that is comprehensible. The narrator begins his story of the far future by standing in an embrasure of the Redoubt, examining the land through a spyglass and reading out what he sees in the manner of a lookout in a crow's nest or a navigator with a sextant. This precise manner is made all the more apparent by contrast when his hero leaves the Last Redoubt and enters the Night Land. Inside the Redoubt, absolute measures, directions and intervals dominate the narrator's descriptions, but as soon as he sets foot outside, distances are measured entirely by the hours taken to cover them and directions become vague and relative.

\footnotetext{
* Teilhard de Chardin is particularly significant to Neohumanism and will be discussed in more detail below.
} 
Hodgson's conception of the Last Redoubt is utterly congruent with Heidegger's definition of what is essential for a proper dwelling-place. Obviously, as a redoubt, it spares and preserves, and if we look at Heidegger, we see the reason why $\mathrm{X}$ stands at the Redoubt's peak and surveys the Night Land, but abroad, measurements break down and he and his beloved complete themselves only within its space:

Indeed, the loss of rapport with things that occurs in states of depression would be wholly impossible if even such a state were not still what it is as a human state; that is, a staying with things. Only if this stay already characterizes human being can the things among which we are also fail to speak to us, fail to concern us any longer (155).

In Heigger's terms, the Night Land is not merely an alien land, it is a 'failed' land, its abjected humanoid denizens described as 'abhumans'. X can measure his relationship with things and places from within the safeguarded architectonic order of the Redoubt but, like a man in a state of depression - and like his bereaved former incarnation mourning the Lady Mirdath - he cannot name or describe the things of the land too precisely because they are of the wrong order and would make him corrupt and abject if he identified with them. He and his beloved Naani, Mirdath's reincarnation, cannot survive in the Night Land and remain who they are - and more than that, they are required to return.

The architectonic opposition of the Last Redoubt and the Night Land is one of chaos versus order on the small stage of the dying earth, but Hodgson has extended his concept into a vast cosmological schema in another novel, The House on the Borderland.

\section{2}

\section{The Cosmology of The Night Land}

The Night Land does bear the kind of relationship to The House on the Borderland that Stapledon's Last and First Men bears to Star Maker; it too could easily be contained within the latter and span only a paragraph or so. In a study of the 
composition of the novel, Brian Stableford suggests that the The House on the Borderland was assembled out of the fragments of separate stories, embedding a relatively abstract and impersonal cosmological romance in a more conventional haunted house story ('The Composition of The House on the Borderland' 30). Something that seems overwhelmingly important at the earthly scale is a mere footnote to events at a cosmic scale. Elsewhere, Stableford notes the contrast between the pessimism of The House on the Borderland, which depicts the ultimate end of the universe in lifeless darkness, and the apparent optimism of the conclusion of The Night Land, but considers this to be merely the result of a change of perspective from the vision of complete cosmic decline in the former to a narrower focus on the personal triumph of the latter (Scientific Romance in Britain 1890-1950 100). This is true, but a cosmic pessimism is fundamental to The Night Land and is never hidden. Indeed, as background, it is even more strongly presented by its coherence as the commonly-held history of the characters and the foundation for the narrative. In writing The Night Land, Hodgson was trying to work out a triumphant vision of human destiny in the context of a cosmos he believed to be facing the inexorable closure of a great cycle of time. The optimistic conclusion of the novel in the union of the two lovers is not merely the result of a deliberately narrow emphasis on their loves; instead, they are exemplars, well aware of their location at the end of time and seeing their joyful fate as the ultimate confirmation of the purpose and value of human history. The vision, like all visionary takes, is designed to reveal, to warn and to console, and consolation is highest on Hodgson's agenda.

There is a template for the visionary eschatological experience that The Night Land closely follows. The formula or template requires that the visionary voyager is at first near death or in a profound state of error. The vision that follows is warning, consolation or corrective. The voyager is then returned to life, and lives for their remaining time in the light of the knowledge and consolation that they have gained (Zaleski 18-20). Typically, the story is told second-hand, framed by a didactic interpreter and very often there is a guide figure. The technique of framing is particularly effective in leading the reader into unfamiliar territories of thought while preserving the boundary of the sacred realm (Attebery Strategies of Fantasy 66).

The journey by spaceship to another star or planet, by some sort of faster-thanlight drive, a wormhole or the famous Stargate sequence from 2001: A Space Odyssey all closely resemble accounts of near-death experiences, including the tunnel-of-light 
motif. Another common science fiction device, the use of hibernation (also depicted in 2001) to allow astronauts to survive long space journeys, also suggests the transgression of the boundaries of life and death or entering a trance state in preparation for the visionary experience.

Hodgson often uses the technique of framing and in the case of both The House on the Borderland and The Night Land, he uses the devices of a secreted and rediscovered manuscript and the borderline of death transcended through visionary experience.

In The House on the Borderland, a recluse (also unnamed) living sometime in the early nineteenth century finds his house besieged by Morlock-like 'swine-things' and then flung into the future at an ever-accelerating pace. In fragmentary visionary segments, his spirit leaves his mortal body as it decays and perceives a great convergence about two suns at the centre of the universe, one black and one green. Eventually all matter will be consumed by these suns and all souls gathered in a 'Sea of Sleep' about the Green Sun. They are orders of magnitude greater than the sun of earth in scale and greater and stranger in quality as well: they are not merely sources of the physical forces of light and gravitation, they are metaphysical suns.

The Central Suns are each surrounded by clouds of orbs, which, it transpires, are kinds of 'pocket universes': within an orb attending the Green Sun, the Recluse finds himself standing on the shore of a 'Sea of Sleep' wherein is preserved the soul and memory of a lost beloved and with whom he might be joined in an eternity of perpetual and conclusive fulfilment, but he is dragged away from this prospect and plunged into a globe orbiting the Dark Sun and sees there the 'Plain of Silence', a horrible, forbidding desert dominated by vast stone effigies and a twin of his strange house.

The symmetry is quite striking; they are opposites in that one is oceanic and the other dry, but they are both places of quiet and stillness and these common attributes are then given their positive or negative qualities according to the deeper natures of their Suns: the life-principle of the Green Sun produces fulfilment in its stillness, the death-principle of the Dark Sun produces desolation and dread.

Certainly one can see these realms as attempts to create analogues of Heaven and Hell, but they do have their own peculiar quality that sets them apart from those overtly created by supernatural intelligence. During an eclipse of the Green Sun by its dark companion, Hodgson's narrator perceives a corona of violet rays projecting 
out from it. Corpuscles of light run along each of these rays, which he believes to be messengers of some kind, and he suggests, without openly declaring his belief, that both or either of the Central Suns might be the abode of intelligence (117). Neither the Sea of Sleep nor the Plain of Silence need to be made as such according to the decree of a conscious agency any more than the presence of light and warmth on earth is dependent on our sun being sentient. This is an interesting metaphysical image and a thoroughly post-Newtonian concept of heavenly influence. Rather than there being ordering entities or 'resonances' of some unexplained mechanism between the scales of the macrocosm and the microcosm in 'conventional' magical thought ('as above, so below', as a proverb has it), Hodgson proposes that life and death, fulfilment and desolation, are analogues of radiative force operating exactly like light or gravitation. They are meaning made visible, quasi-Manichaean order manifested in the cosmos, radiating motive throughout the universe as they radiate light and gravitational force. The fact that all objects orbit them is not merely a consequence of their great mass, it is because they are the moral foci of the universe itself as well as marking its gravitational and temporal centre. Hodgson's universe is utterly permeated with motive and therefore his characters are driven to find their place through finding and fulfilling their purpose, however symbolic.

Brian Stableford argues that Hodgson's tales are set in the world of ideas, in the manner of quasi-Platonic parable (Scientific Romance in Britain 1890-1950 95). However, his depiction of this world and his hero's engagement with it is unusual even for a mystical tale. In a 'conventional' allegorical novel, every opportunity would be taken to present an explanation of the symbolic meaning of each new being and feature of the landscape, but the hero, while actually thoughtful at times, never engages with the Land or its denizens in anything other than a physical manner; he does not try to analyse or understand them - he either fights or flees (usually the former). There are reasons for this. The first is that Hodgson himself, while obviously fascinated with the metaphysical, was fascinated too by the physical and he was happy to use his seaman's experience to illustrate his principles. He could in fact be quite deliberately literal-minded about this and one of his short stories, 'Out of the Storm', horrifies not because a storm is like an intentionally malevolent monster, but because it $i s$ one. In reading Hodgson, one should not look too deeply for what an entity represents, but at what it does. The Watchers are vast, they wait, they advance with a terribly complacent but purposeful slowness and the time will inevitably come 
when they will crush the Last Redoubt; that is enough to know what they are. In Hodgson's conception of the world, force is the principal measure of meaning in his world other than love, which is the ultimate goal of any man. There is no 'occult' in the Night Land, because it is an apocalyptic landscape and the literal meaning of this word - 'unveiling' - is the basis of the story: all that was hidden is now apparent. Thus, the hero is not a philosopher moving through a realm of abstract ideas, he is a young man in a world where those ideas are made real.

Unusually, there seem to be no superior deities in Hodgson's cosmology. Rather, the more elevated an entity becomes, the less it is an entity and the more it is a force. Hodgson's cosmology, it must be remembered, is Manichaean in that it posits antagonistic forces of dark and light, but it is deliberately divorced from conventional religious systems in that the two great animating forces are forces, not the creative minds of God and Satan. Forces do not think and therefore forces do not create meanings in things. Rather, minds draw on or are corrupted by the energies of these forces. There is no religion of worship in the Last Redoubt, but this is not to say that it is an atheistic civilisation in the accepted sense, rather that the concept of the ultimate force in the universe as an entity or being would be incomprehensible to its citizens. This is made quite clear in The House on the Borderland, where the ultimate objects of the universe are structurally and literally objects - two suns in orbit about each other, spreading their influence through the universe in the manner of electromagnetic radiation.

The understanding of time as linear (albeit relative) and likely to be entropic is a construction of modern physics and characteristic of the Modernists, but it is unusual in human culture as a whole: most nonwestern and pre-modern Western cosmologies have been cyclic with clearly delineated and nested wheels of ages. Neohumanist science fiction definitely feels a strong pull towards this archetypal cyclic model coupled with its layered concept of physical and metaphysical space, and while The Night Land seems allied with Wells' entropic model of time it is in fact a direct repudiation of Wells. The House on the Borderland and The Night Land both make references to Hindu cosmology, as Stableford points out, and the world of The Night Land is at the end of a kalpas, or great cycle of time (ibid 94, 96, 100). If there

\footnotetext{
* This is a point not lost on Greg Bear who names his terminal cities or edifices Kalpas and Nataraja.
} 
is a renewal after the end of the cycle of Hodgson's cosmos - and there may well be it is offstage, but it is a cycle nonetheless.

The cosmos of The Night Land is winding up and closing in on itself. In the cycle of time, The Night Land is placed as a complement to creation myths. Rather than being a chronicle of origins, giving reasons and causes for the state of the world, the novel attempts to present a justification and closure, hence the importance of the ultimate return to the embrace of the redoubt as opposed to any conquest of the Night Land. X's return with the prize of Naani is the opposite of the biblical expulsion from Eden. If Eden is the seed of the human race, the Last Redoubt represents its completion, and while Hodgson could have conceivably created some small walled garden, the Last Redoubt is immense; so the symmetry is not quite perfect - but it is complementary. The Redoubt is a pyramid, obviously in reference to a Pharaonic tomb, which is a final repository of the earthly matter of a god-king, but it is the last repository of all human culture, and as such, it must be vast. The garden of Eden represents innocence, but the architecture of the Last Redoubt is the product of knowledge and it is rigorously ordered knowledge; thus it can be read as representing a loss of innocence redeemed through the correct application of knowledge, a new, high-tech Jerusalem. It exists in a clear relationship with Eden, but at the end of a sequence, with our own state of civilisation being at a mid-point between the two.

Modern Western culture has tended to homogenise its conceptions of space and time. The Cartesian concept of space and chronological time as things that are linearly measurable and explicable became the dominant paradigm in scientific culture, positions challenged only by the emergence of Einstein's Special and General Theories of Relativity. This linearity of space and time is reflected in novels such as The Invincible with both the use of a linear plot and a concentration within that plot on the rational scientific method. However, non-Western and pre-Modern cultures have had a more varied and integrated set of temporal and spatial concepts. For example, Frank Kermode, in The Sense of an Ending (1967), contrasts the different kinds of time in mythic and mundane experience: linear time, measured by clocks is chronos time; then there is kairos time, the critical moment where the event of a revelation or crucial cliffhanger moment connects with its eternal context; there is eternity, which is not linear time extended infinitely, but a time in which all is present forever; and there is the pleroma, or 'fullness' of time completed (44-52). The chronological and linear concept of time is not the only possible concept of time, and 
these variant concepts constitute not alternatives, but a complementary set that has persisted into the modern and postmodern period in the West. The House on the Borderland and The Night Land are ostensibly set in far future ages, but they actually exist in eternal time, informing us in our present time. As such, they are written and are to be read as myths.

\section{3}

\section{Reading The Night Land as Myth}

Hodgson quite clearly rejected the Christianity of his family, though it is clear, particularly in the prose style of The Night Land, that he was impressed deeply by the epic, mythic quality of the Bible and tried to some degree to emulate its effect by the deliberate use of an archaic, repetitive, almost verse-like style. This grandiloquence is perhaps one of the greatest impediments for the modern reader, but for all its turgidity, it does support the mythic impression of The Night Land and the novel has persisted as a cult classic.

And so do I come to mine ending; and have but one more thing that I tell. And this to happen a while later; after that Mine Own and I had gone through the second marriage which did be the Public Marriage. For it did be, that one day My Wife, that did be Mine Own, did take me with a sweet cunning unto the Hall of Honour. And surely, when I was come there, I to see that many of the Peoples did be in that great Hall, and did stand about in a silence; yet as that they had no meaning to do aught; but yet to be that they did wait upon somewhat.

And My Wife did go forward with me unto the centre place of the Hall; and sudden I saw why that she did bring me so cunning sweet; for there did stand in the midst of the Hall of Honour, in the Place of Honour, a Statue of a man in broken armour, that did carry a maid forever (Hodgson The Night Land 356-7).

The contents page of Joseph Campbell's The Hero With a Thousand Faces might easily provide a synopsis of The Night Land, with only minor amendments. Despite 
the fact that X's heroics can seem to the cynical reader to be ultimately futile - the Last Redoubt is still doomed in the long run as it exhausts is power source - he is in fact successful even in the long run because in the terms of the Neohumanist Order, history must be brought to its closure as a meaningful narrative and this is what is done. His good fortune is that he has millions of living witnesses as well as his own conscience whereas the unnamed tentacled thing on Wells' drear beach had only the woeful regard of the Time Traveller. His story is exemplary, and that is why it is witnessed by the millions of citizens within the Last Redoubt: he makes his heroic journey on their behalf, and it is transmitted to us so that we too may know that it was and will be undertaken for our sakes.

The main portion of the novel suffices as an heroic tale in its own right, but Hodgson's lengthy prologue attempts to elevate it to the quality of myth. While some framing to link the events of a distant time with the present world of the reader is useful, Hodgson is at pains to use his prologue to set a framework of a cosmology and eschatology with a compelling question for the sympathetic reader, the answer to which is the revelation of an essential quality of the cosmos. To be an exemplar, his hero must not only come into his own, and even demonstrating supreme prowess before his people is not enough; he must embody in himself and his life the solution to some essential dilemma. The novel therefore begins with a man mourning his loss some time in mediaeval times and ends with a man gaining his lost love millions of years in the future. It could easily have been written without its prologue or with a séance set in Hodgson's present, and perhaps would have been less poignant, but is deliberately constructed as a past tragedy which is redeemed through the vision that he has of his future, which he then writes down in the manuscript to be found by a nineteenth century man. Both $\mathrm{X}$ and Naani have visions of past lives, including that of the original writer and of ages that are far in their past, but still far in our future, suggesting that they have been serially reincarnated until their meeting in the Night Land (their truly ultimate cosmic fate might be to enter together the 'Sea of Sleep' envisioned in The House on the Borderland). Reincarnation and prophecy link the past and future together, with the more-or-less present time of the manuscript's discoverer and the reader placed more or less in the middle. Time does not proceed in one direction in a straight line; it completes a perfect circle in which end and beginning are visibly joined to one another (this is often represented by Ouroboros, the worm that swallows its own tail). 
At the climax of The Night Land, the beloved, Naani, is killed by the Silent Ones but is then resurrected by the application of the Earth-Current as she is interred in her tomb. In the context of the novel, this constitutes a miracle of sorts and the hero claims that this is due to the force of his love requiring such an outcome. In the introductory chapter, the mediaeval narrator loses his Lady Mirdath and obviously Naani's death is an echo of this fate. Hodgson uses this prefiguration to manipulate the expectations of the reader, but her resurrection is no mere sop to sentimentality either, as his characters in the Night Land are already reincarnations of their mediaeval selves. Naani's restoration at the end of the novel has an appropriate symmetry to it and thus reiterates the theme of the reunion of lovers beyond death (which is also shown in The House on the Borderland).

Naani's restoration is obviously Christ-like in that it is crucial to the cosmological narrative (rather than incidental, as is the raising of Lazarus). Naani is not a prophet or, strictly speaking, a messiah however. Her resurrection does sexually invert the resurrection of Christ, it is a proof of earthly life and love rather than a demonstration of the spiritual resurrection of the blessed in Heaven. The people of the Last Redoubt are not fallen and have no message to receive; rather their already perfect non-Christian faith is confirmed by Naani's resurrection and her marriage to $\mathrm{X}$ and, as the erection of the dual statue of X carrying Naani shows, it is their pairing that is not so much a revelation - there are no doubt millions of lovers already in the Last Redoubt - but the ultimate confirmation made on their behalf. If there is a prophet in The Night Land, it is the narrator of the prologue who asks a question of the cosmos, receives the answer that is the main body of the narrative and then writes it down to be read by later - or rather, intermediate - generations.

\section{4}

\section{Literary \& Scientific Synthesis: The Origin of the End}

The Night Land is a unique novel, seemingly absolutely anachronistic, but Hodgson was not writing in a vacuum. Instead, it represents the drawing together and synthesis of many influences. Obviously as a horror writer, Hodgson had on hand the precedent of Edgar Allan Poe, but even then, it is not quite that simple, because Poe was a cosmological writer as well, with a scientific romance in the nonfictional mode, 
Eureka, to his name. It is likely also that Hodgson was partly inspired by Poe's short story, 'The Colloquy of Monos and Una' (1841), which represents the posthumous reunification of two lovers after the world's terminal age (Tales of Mystery and Imagination 237-44).

In addition to Poe there is Camille Flammarion, whose own writing showed that he was not averse to exercises in spiritualism mingled with straight scientific extrapolation about the scope of the cosmos and the nature of the end times.

Certainly Flammarion's works include the romances Lumen (1872, translated into English in 1897), Uranie and La Fin du Monde (1894, translated into English as Omega that year). The first is a cosmological exploration that may have inspired Olaf Stapledon and the last depicts, as the title says, the end of the world.

Hodgson's utopianism draws on his voracious and eclectic reading. The late nineteenth century was particularly marked by a movement for social improvement and popular education - as Walter Besant's work, and the popular lectures of John Ruskin and William Morris illustrate - and numerous collections of classic literature and learning, such as Everyman's Library, were available. A dedicated browser of bookshops such as Hodgson would almost certainly have come across a book such as the Morley's Universal Library collection, Ideal Commonwealths, which compiled the utopias of Plutarch, More, Bacon and Campanella (1890). Campanella's Civitas Solis was given its first English translation for this volume (217-63). In addition, it is not difficult to imagine Hodgson drawing on the rhetoric of his preacher father, the archaic prose style of William Morris' fantasies and the rational utopias collected by Morley in the composition of The Night Land. The Last Redoubt itself, in both its physical form and social structure, bears more than a passing resemblance to the City of the Sun (even if the sun is dead!), while the chivalric ideals (and his own prose style) of his hero may owe more than a little to the mediaeval fantasies of William Morris, such as The Story of the Glittering Plain (1890), The Well at the World's End (1896) and The Water of the Wondrous Isles (1897).

It is known too that he read and was impressed by Walter Besant's All Sorts and Conditions of Men (1882) and also enjoyed Bulwer-Lytton, author of The Coming Race, which featured a force called 'Vril' that anticipates Hodgson's earth

\footnotetext{
* Poe's typically macabre take is that the process of decay is itself a sublime and fulfilling experience.
} 
current (Hodgson The Wandering Soul 30). Nicola Tesla's experiments were also in the news when Hodgson was writing.

The major influence on Hodgson, however, was certainly H. G. Wells, as the similarities between The House on the Borderland and The Night Land and The Time Machine make clear. Hodgson may have profoundly disagreed with Wells - as the differences also make clear - but nonetheless he was in debt to him. These three novels also share a more or less common setting of a universe described by late nineteenth century cosmology: according to the Second Law of Thermodynamics, entropy increases with time and it was assumed (wrongly, we now know) that the sun generated its heat and light due to gravitational collapse and that it would within a score of millions of years at most become dark. Likewise, Hodgson's swine-things in The House on the Borderland and the giants and abhumans of The Night Land seem to echo Wells' Morlocks. However, there are differences between Wells' and Hodgson's novels and they are quite fundamental - and telling. The primary point of fissure is in the authors' belief that the Cosmos is meaningful or meaningless and the utter extremity of the Time Traveler's journey where he sees nothing in the far future of Earth except some limp tentacled thing flopping about on a beach while Hodgson builds his Last Redoubt.

This is not to say that Wells was an unmitigated materialist, and when he indulged in some metaphysical speculation, it is likely that he inspired Hodgson too. 'The Plattner Story' (1897) is a case in point: the correspondences with Hodgson's tales are less direct than they are with The Time Machine, but in some ways more significant. In Wells' tale, the young man of the title finds himself transported by an accident into a parallel realm apparently inhabited by the revenants of the dead of our world. This world is dimly illuminated by a green sun that is invisible to us, but its inhabitants are able to observe events in our own, particularly those that follow as consequences of their own former lives. Wells maintains a detached approach to his narrative in the manner of a scientific journalist (which he was), suggesting a metaphysical architecture, but not explicitly describing it or subscribing to it. The story's free-floating speculative nature is important: it is similar to many visionary tales, such as Plato's 'Myth of Er' (The Republic 393-401), but Wells was inspired by mystical literature without being bound to simply follow its lead.

\footnotetext{
*Wells writes that it had a 'tremendous significance' to his youthful mind, 1934, 177.
} 
Hodgson was also definitely inspired by visionary and esoteric traditions and the Central Suns refer to these traditions, but he was also deeply respectful of science and The Night Land advocates a well-functioning technology wielded by a secular technocracy. His way out of this dilemma is to suggest a more complex, nonhomogenous system of meaning, that is, to invoke a system of a natural and a supernatural realm complementing each other. This is not anti-scientific, but integrates scientific observations in a multi-layed polysemic system with a firstperson narrator who can interpret what he observes in both mundane and transcendental terms. Crucially, in Hodgson's conception, the supernatural is assumed to be at least partly explicable and controllable on the terms of science and technology: his detective, Carnacki, is a fine example of the type, being skilled with technological implements and linear reasoning, but also well-versed in esoteric literature. Consequently, his investigative modus operandi is to cross-reference one field of knowledge and its techniques with the other. This synthesis is well-illustrated by his use of an electrified pentacle and the fact that the Last Redoubt is protected by a force field powered by the quasi-electrical or Vril-like 'Earth Current' that also has mysterious life-sustaining effects.

Lacking much formal education, but a voracious reader and autodidact, Hodgson's mysticism diverges from the mainstream (insofar as such a term is applicable) of esotericism and is grounded less in the synthesised body of texts than in analogies drawn from personal worldly experience via intuitive reasoning. Insofar as his stories are realistic, they draw on aspects of his direct personal experience, and insofar as they are fantastic, they express as metaphors principles that he observed and interpreted himself. The imagery and themes of his writing in all modes draw heavily on his personal experience and his cosmology is 'realistic' in the sense that he is trying to depict things as the way that they are - as they appear to him - instead of how he would like them to be. When we consider Hodgson's supernaturalism, we must also consider his realism, or his intellectual demand that even the supernatural be open to a realist treatment and interpretation.

The mystical cosmology that Hodgson designed is unusual not because it is mystical, but because he designed it himself. A major intellectual and cultural movement of the latter half of the nineteenth century and the early twentieth was the Neoplatonic revival, manifesting itself initially in spiritualism and then taking on the formal structures of new, synthetic creeds, such as Theosophy and the Hermetic Order 
of the Golden Dawn. This order reached its peak and rancorous schism at the time Hodgson began to be active as a writer and, considering his interests, it is at first curious as to why he did not join or become involved in some capacity. It is, after all, very tempting to draw parallels between the obvious interests of Hodgson and those of his contemporaries who were directly involved in the Hermetic Order of the Golden Dawn, which had attracted adherents from the arts in Britain and Ireland and elsewhere, most notably W. B. Yeats and Aleister Crowley. The Monstruwacan rulers of the Last Redoubt in some ways resemble Rosicrucian adepts and his occult detective, Carnacki, is obviously based on Algernon Blackwood's better-known John Silence. Blackwood was a member of the order and Silence's adventures and methods are modeled on those of an ideal Rosicrucian (Gilbert 82-3). Other members of the order who took to supernatural fiction based on Golden Dawn doctrine were Evelyn Underhill, Dion Fortune (Violet Firth), Charles Williams and Arthur Machen (ibid 83-7). Yeats himself began by absorbing many mystical esoteric concepts before moving on to create his own cosmological-eschatological system (A Vision 12, 23). However, it may be that Hodgson was too contrary and idiosyncratic to be a subordinate in such an organisation or simply did not know the 'right people' (which would have mattered) and while there is no evidence that he had any direct link with the Order or its members, he was almost certainly drawing from the same well.

In addition to Neoplatonist and Gnostic sources still extant in their evolved (or corrupted) form, Hodgson, true to form, drew deeply on his personal experience in the formulation of his personal cosmology. The sea in particular furnished him with some of his richest imagery, ironic as it may seem, considering the immobility of the Last Redoubt.

Two posthumously published poems, 'The Voice of the Sea' and 'The Ocean of Eternity', present the sea as a metaphor for time, memory and wisdom and are particularly indicative of Hodgson's eschatological thinking. In the former, the sea, asking questions that Hodgson asks, discourses with stars and nebulae in a vision that parallels Wells' vision of the terminal beach at the end of The Time Machine while offering a perspective that anticipates the cosmic scale of Olaf Stapledon. The conversation first considers the apparent pointlessness of existence until the sea itself muses upon the desolation of the end of time. This poem neatly depicts the questions of the wondering agnostic in Hodgson and there is a vivid depiction of an entropic cosmos, such as was his understanding of it as described by late nineteenth century 
thermodynamics and the despair that it has compelled. Clearly he finds it impossible to grasp the faith of his father, but in that rejection, he finds questions that he is desperate to answer nonetheless (The Haunted Pampero 52-4).

'The Ocean of Eternity' develops Hodgson's questions and proceeds on to speculation that is clearly a poetic representation of the 'sea of sleep' that appears as part of the visionary sequence of The House on the Borderland. Still uncertain, he nonetheless hopes that souls parted in life will find themselves joined in eternity by the force of their shared love. Jane Frank suggests a date of 1907-1911 as being most likely for the composition of this poem, meaning that Hodgson would have been working on it at about the time that he wrote The House on the Borderland or The Night Land (Hodgson The Wandering Soul 40).

Mysticism does not make Hodgson a fantasy writer, no matter how quaint his schema may seem; it makes him a synthesist. His attitude towards the forces of the spiritual world is the same as his attitude towards the forces of the visible world - a learned and disciplined rational mind wielding finely-crafted and maintained technology is needed in order to deal with them both (in The Night Land, for example, telepathy exists in a few favoured individuals, and it is enhanced and practically applied as a substitute for radio communications through technological means). Thus, his parapsychological detective, Carnacki, makes use of an electric pentacle in 'The Hog' and the Last Redoubt is sustained by the 'earth current' and surrounded by the 'electric circle', all of which are designed and maintained in a technical manner rather than through incantation and sacrifice. This seems odd to modern eyes, but it may not have been wildly implausible to Hodgson when, late in the nineteenth century, Charles Leadbeater had proposed an evolutionary tree that included not only humans arising according to Darwinian evolution, but fairies and incorporeal beings emerging by similar processes in parallel (Silver 53). Neohumanism seeks the synthesis of science and myth, but crucially, it is according to the forms of science.

Hodgson tried to demonstrate that love is a scientific phenomenon without reducing its traditionally romantic quality. The attainment of true personal love is in his cosmos what divine grace and the attainment of Heaven would be in Christian escatology. It is transcendent, originating at the ultimate apex of the universe, but not external to the universe: instead, it permeates the cosmos from top to bottom. Love, he endeavoured to prove, is a force like gravity. 
As we see, the Neohumanist Order is embodied in intellectual processes of synthesis, and the process that Hodgson followed parallels that of his contemporaries, such as Leadbeater and Flammarion, and his predecessors such as Poe. Hodgson's stories are syntheses of pre-modern and non-western patterns of logic and narrative: time is cyclic, their narratives are enframed as visionary quests by the devices of a dream, astral projection, reincarnation or a tale related in a rediscovered manuscript sealed in a box, and meanings must be read using techniques of polysemy because the higher or far future realm is strange and governed by its own rules, but informs the mundane. Stories of this Order synthesise myth and scientific romance not simply by their use of various props and elements, but in their structure and processes of composition, narrative and comprehension.

Because scientific understanding changes, the relationship that science's contingent description of the universe has with mythology that strives to be eternal is continually renegotiated. As science fiction under the Modernist Order has evolved, so too then has that under the Neohumanist Order.

\section{5 \\ Robert Charles Wilson: A Newer Synthesis}

Culture accumulates but science advances. No synthesis that is too specifically bound to a specific cultural moment will remain tenable in the long term, as knowledge advances. The essence of synthesis lies ultimately in the process of synthesis itself, not in any result. Fiction then is drawn into the slipstream of science, playing dramatic variations on scientific themes as it goes. The common characteristic is an attempt to find a definition of humanity and its relation to the cosmos by synthesising the forms of knowledge creation used by science and traditional forms of knowledge.

An author who demonstrates the continuation of Neohumanism into the late twentieth century is Robert Charles Wilson, his writing being marked by the interaction of contemporary scientific knowledge with other knowledge traditions, most notably Gnosticism (explicitly in the novel Mysterium, 1994). Wilson's novels are remarkably consistent in their narrative development and in their dominant motifs. For example, he will usually construct a narrative in which a small, tightly-knit community finds itself isolated, and beyond a clearly-marked line or within a central, 
labyrinthine omphalos-type artefact (or both) there is an inhuman force which must be confronted - though not necessarily antagonistically. Coupled with this too is the emerging revelation that the sequestered community is being elevated into a realm where it is able to be put in contact with other similarly elevated places, previously unknown. Often an alienated child or child-like innocent will perform a redemptive role as a liminal figure, revealing a higher, extra-physical realm and bringing hints and suggestions of special knowledge to the community from that realm. The climax of the plot is usually an Orphean quest and alchemical and Gnostic elements that have been implied are made more overt - indeed, Gnosticism, alchemy and nuclear physics were brought into intense confrontation and synthesis in Mysterium. In other novels, higher orders of existence are alluded to, such as obscure forms of extraterrestrial intelligence (The Harvest 1992, and the 'Hypotheticals' trilogy: Spin, 2005; Axis, 2007; Vortex, anticipated for 2011), self-aware planetary biospheres (Bios, 1999) or vast archives of all lives that were ever lived constructed at the end of time (Darwinia, 1998). In each case, they are all accessible to human beings, should they choose first to cast off their human forms. If we do not, then it is understandable that we choose not to - this decision to remain human after transcendence is offered is the central motive of characters in The Harvest - but to remain human also implies orphanhood, separated from the great community of minds permeating the cosmos (Bios 192, 199-200).

Other motifs also proliferate in Wilson's fiction, such as patchwork families reformed from the fragments of broken or false families - and this touches on a crucial point in his ideology. Empathy is an essential quality of being human, and it is willed or chosen rather than compelled. Individuals and communities are suddenly and catastrophically isolated, but find themselves also elevated to a position where they can choose to reach out and establish new contact and an encompassing structure of shared narrative. This indeed is what happens in Blind Lake (2003), where it is explicit that it is the shared act of storytelling that can transcend the difference between human and alien - a gap that is at least partly created by purist scientific empiricism.

There is therefore running throughout Wilson's work a sense of tragic tension: between alienated individuals who must be brought together, and also between the kinds of knowing that characterise different planes of existence and which each exact an almost unbearable price, but which must somehow also be connected and 
reconciled. An incarnate existence is one that is identified with inevitable mortality and with ignorance, but it is also identified with the potential for love and empathy, a characterisation that Wilson shares with Hodgson.

\section{6}

\section{The Alien(,) Subject}

Several of Wilson's novels would be suitable examples of narratives illustrating and examining contact between humans and aliens - and contacts between alienated humans. Blind Lake (2001) in particular looks closely at the idea of drawing borders between human and alien, object and subject and then seeks to undermine the divisiveness built into such labels.

The premise of Blind Lake is that the eponymous town hosts a research institute observing a roughly earthlike and inhabited planet orbiting the star 47 Ursa Majoris by an exotic application of quantum entanglement. The exact technique used by the observatory or 'Eye' is an accidental discovery by artificial intelligence systems and is not comprehended by its human operators, but it nonetheless offers practical close observation of individual beings, one of which has been exhaustively observed for years in the hope of gaining a comprehension of the being's culture. Strict empirical objectivity ('parsimony' in standard scientific parlance) is enforced in the studies, with the individual being named only 'the Subject', his species unnamed, though nicknamed 'Lobsters' on account of a vague resemblance. Even the planet is referred to only as 'UMa47/E'. Despite its or 'his' nomen, no subjectivity is ascribed to the Subject. All of his observed behaviours are catalogued, but interpretation is suppressed and the prevailing belief is that the Lobsters are essentially and ineluctably alien and thus they will remain forever incomprehensible.

Without warning, while the senior staff of the laboratory are absent at a conference in another city, the entire town of Blind Lake finds itself cut off by a militarily-enforced quarantine and all communication with the outside world is blocked, trapping the team members, the population of the town and a party of visiting journalists between two seemingly absolute mysteries: the ring surrounding them and that seen through the Eye at the centre. 
Meanwhile, a human drama is being acted out against this background: one researcher, Marguerite Hauser, is stalked by her increasingly possessive and unstable ex-husband, Ray Scutter, who is also the most senior administrative official remaining. Ray's primary object of contention is Marguerite's daughter, Tessa, who herself exhibits symptoms of mild autism and who has apparently created an alterego, 'Mirror Girl', who asks peculiarly obvious questions about the town and its environment (such as why indoor plants are green when those outside are brown). One of the journalists, Chris Carmody, is first billeted in Marguerite's home and then begins a relationship with her and becomes protective towards Tessa, thereby further provoking Ray's jealousy.

Eventually, one man is able to enter the town from outside, revealing that Blind Lake's sister facility, Crossbank, was overcome by a strange starfish-like growth, almost certainly generated by its Eye. As the novel climaxes, a similar starfish begins to grow at the Blind Lake Eye, Ray abducts Tessa and takes her into the facility while Marguerite and Chris attempt to rescue her. At this point, Marguerite is able to somehow meet the Subject within the maze of the starfish, her encounter mediated by Mirror Girl, who it is revealed, is an icon or mask created by the intelligence underlying the starfish. Mirror Girl explains that a network of starfish exists across the galaxy and enables Marguerite and the Subject to relate their life stories to each other, sharing comprehension. Marguerite, Tessa and Chris then escape from the starfish and the cordon around the town is lifted and the three are able to constitute a new family. The novel ends with Marguerite telling Tessa the Subject's tale as a bedtime story.

Wilson's tales are ultimately optimistic for all the doubt and tragedy that they contain. Wilson depicts communication as being possible only through the mediation of transcendent consciousness. Stanislaw Lem's novels, Solaris, Fiasco and The Invincible all make use of deceptively invulnerable edifices that are reifications of the human technology and anthropocentric consciousness while Wilson tends to be more ambivalent: the human edifices of Bios are certainly vulnerable, as is catastrophically shown, but in Blind Lake the eponymous research institute and the alien 'starfish' are instead alchemical vessels of transcendent quality free from the constraints and divisions of the mundane world that concentrate the forces of change and discovery.

This is a key element of Wilson's narrative technique: human technology is flawed, but super-human systems can be built by means such as a 'bootstrapping' 
process employed by the artificial intelligences of Blind Lake's Eye or the recovered remains of an alien vessel in Mysterium. These systems are not necessarily more intelligent than humans by any simple measure, but they are more attuned to the basic physical laws of the universe, and by blind adaptation they are able to create a common, timeless space in which both humans and aliens meet.

Wilson explicitly does not anthropomorphise any of his aliens and instead relies on intermediaries, fey children (changelings) who are in some way cognitively estranged from 'normal' humanity; by autism in the case of Tess in Blind Lake or genetic engineering in the case of Zoe in Bios (1999). Where the alien entities or forces do speak, it is through human-seeming masks in a sequestered intermediate space, created specifically for discourse. In his handling and presentation of the aliens, Wilson is scrupulously scientific, but converges strongly with the archetypes and tropes of fantasy and myth. This is appropriate to Neohumanism, with the synthesis of science and mysticism being one of its primary aims.

It is well worth comparing The Night Land with Blind Lake. Wilson does not present the nonhuman other as irreducibly antagonistic, as Hodgson does in The Night Land and The House on the Boderland. The difference is that the category of 'other' or 'inhuman' is not inherently a negative. 'Inside' and 'outside' exist, but they are relative categories and therefore any specific or absolute use of these categories is equally questionable. The eponymous township of Blind Lake is sealed off by the authorities and quarantined as if it were in a state of internal exile, but its strange observatory opens through another dimension on to something else that seems utterly alien to the scientists and townspeople. Despite their fundamentally alien nature, the experience of the Lobsters and the Subject is still something with which Tess and Marguerite can establish a bond. The polarity of self and other is essential, but the other demands not opposition, but colloquy.

\section{7 Everything That Converges Must Rise}

The Catholic theologian and paleontologist Teilhard de Chardin embodies the synthesising spirit that we also see so strongly in Neohumanism. The fact that he was both a priest and a scientist specialising in human evolution could have led to 
irreducible conflict, but as a theologian - albeit a controversial one - his belief was that all knowledge and systems of knowledge could be reconciled. His own project was to find that reconciliation within Christianity, but his methodology and results are very similar to those of the Neohumanists, and those who came after him could not avoid comparison with him.

Hodgson's The House on the Borderland chronologically prefigures Teilhard's teleology of his Omega Point, in the Sea of Sleep at the end of the universe where all souls are finally gathered together, but Wilson has the benefit of living after Teilhard and being able to write in the light of his ideas and particularly the principle (as paraphrased by Flannery O'Connor) that 'everything that rises must converge' ('The New Spirit 1942', Teilhard de Chardin 82-96). Teilhard proposed a conic geometry for spacetime, with God or the Omega Point as its apex, but Wilson's geometry may be more of a network or some other form. Stephen Baxter's short story, 'Dante Dreams' notes that Dante's cosmological schema is a hypersphere described in three-dimensional terms: what appears to be the centre according to one perspective becomes the outer boundary and one exits by passing through the centre (Phase Space 86-103). This is not merely a geometrical issue, but a moral and epistemological one; one must look deeper into a mystery in order to understand it and likewise one must reach out to touch others despite their seemingly alien form. Hodgson believes in timelessly monogamous heterosexual love while Wilson applies the broader principle of universal sympathy.

It is possible to play a sort of symbolic hopscotch with the various eschatological visions - Teilhard's Omega Point, superficially, is not so very far away from the Green Sun or the Sea of Sleep described in The House on the Borderlandbut it is necessary to look at the fundamental bases of these beliefs. First and foremost, Teilhard is a monist, working within an explicitly Catholic tradition. Despite the suppression that he experienced during his lifetime, that was where his intellectual and spiritual base lay and his desire was only to strengthen that base and reconcile it with modern scientific knowledge, not abolish it. Hodgson's own position was not Christian, despite or because of his father's vocation. What Hodgson shared with Teilhard de Chardin was a view of eschatology as being a matter for careful speculation and reference to what he considered to be authoritative sources: in Teilhard's case it was Catholicism, paleontology and technology; in Hodgson's case it was thermodynamics (as it stood at the time) and alternative spiritual traditions that he 
felt had equally valid claims on at least aspects of fundamental truth. Both come to apocalyptic conclusions based on the assumption of a supreme telos. Although Hodgson's cosmology is dualist, seeing eternally locked opposites driving the universe, and Teilhard's is monist, seeing God as the sole and ultimate end of the universe, , both also lead their narratives (fictional in Hodgson's case, philosophical in Teilhard's) through chronological time to a perfect fullness of time, a pleroma.

The various versions of the Omega Point or the Sea of Sleep that have been proposed in theology, futurology and science fiction during the last century are all, with rare exceptions, located at the end of time or a cycle of the cosmos. This is highly significant; while Neohumanism has revived a stratified system of space, traditional concepts of time have not returned in quite the same way. Chronological time, as described and used by the scientific method, functions alongside eternal time and indeed ultimately leads to it, though there are kairos moments strung along its line like beads on a necklace that intimate the presence of the ultimate.

In Hodgson's case, it is clear through the intricate narrative framing and structure created to support The Night Land that he too is exploring the connection between chronos and kairos; however, as the Night Land is an apocalyptic realm, time too is apocalyptic; virtually all of the action takes place in kairos time. It is up to the reader to relate the story to their own experience of chronos.

The House on the Borderland points to a kind of Omega Point with its Sea of Sleep, that stilled time being a form of eternity, accessible through the terminus of chronological time. The rhetoric of the future is employed, 'future' being synonymous with 'destiny'. A consequence of the grand scale of time that is necessary in depicting galaxy-spanning (or galaxy-surpassing) events is that enormous time scales are invoked. Olaf Stapledon is well-known for his use of vast over-arching timescales and nested cosmological scales in Last and First Men, Last Men in London and Star Maker. His own use of cosmic time is emblematic of science fiction's adaptation of kairos to the modern linear and directional model of temporality and has had a tremendous influence on the genre. Arthur C. Clarke and Stephen Baxter are most obviously influenced by Stapledon, though relatively few other authors have been as wholeheartedly committed to lengthy and detailed depictions of a Stapledonian realm; Wilson has limited himself to relatively short

\footnotetext{
* To ascribe equal power to Satan, merely a fallen angel and not a deity, is condemned within Catholic theology as the Manichean Heresy.
} 
episodes within narratives that are based on smaller scale human interactions, with the cosmos largely providing the indicated context against which this action occurs, not the observable action itself until the climax.

The Neohumanist Order carries with its intentions its own essential paradox. In this case, it is the ultimate immateriality and inexpressibility of the transcendent. Hodgson has a mystical sense of heterosexual love, seeing it as a force of nature and of destiny, because his process of seeking a humanist synthesis of scientific and esoteric knowledge led him to believe that the universe was structured by dualisms and must be in rapport with human desires. That view is untenable today, with humanity now described by science as one animal among many, with its desires and instincts conceived as adaptive strategies, not direct representations of fundamental laws. Wilson tries to avoid simple romantic dualism and invents, as part of his thought experiment in Blind Lake, a reproductive system for the Lobsters that precludes dualistic romantic attachment but which nonetheless fosters connection. His strategy then is to imagine a transcendent architectonics in such structures as the Starfish that facilitates intercourse of an empathic, not erotic kind, which is universal and not introverted, as is the case with the Last Redoubt.

Drawing on Gnostic distrust of the body as a 'grave' of the spirit, Wilson depicts it as inherently flawed and subject to decay, but its redemption in his eyes is a fascinating variation on Hodgson's thought: the body dies, but in the body we love, and thus there must always be a place for the visceral. An early novel by Wilson illustrates his knowing ambivalence quite clearly: in The Harvest (1993) an alien race offers an incorporeal immortality to humanity, but many people reject the offer and choose to remain embodied on earth. The novel deliberately ends without definite resolution, with an alien ark remaining in orbit over the earth, carrying within it immortal souls, while down below people wilfully persist in the flesh. Of course the ark can be seen as a technological substitute for Heaven, but the philosophical intention of the story is to propose a Heaven without a presiding judge and as a consequence of this, its potential inductees themselves judge whether they desire to enter it. Life now continues on earth within the flesh with certain knowledge of the presence of life without the flesh.

Neohumanism generates a wide variety of ideological ramifications from its premises; from antagonistic rejection of the inhuman in Hodgson's case, to the argument articulated in Wilson's work that colloquoy with the other is absolutely 
necessary. The basic architectonic conception of the cosmos is remarkably consistent however, with centralised edifices that have established a 'spared and preserved' realm (as described by Heidegger). Within their clearly delineated environs, identification with a unified community and a complementary cosmological awareness are enabled.

Delineation of boundaries and centres and definitions of self and other are fundamental to Neohumanism. While these things are presented as absolutely ingrained into the structure of the cosmos according to Neohumanism, they also locate the fissure between Neohumanism and Posthumanism, which has come to a different formulation of identity and place. 


\section{7}

\section{The Posthumanist Order}

The key factor in the emergence of the Posthumanist Order has been the change in the relationship between the human and the technological, in which the technological becomes an active and not dependent factor in the relationship.

The point of fissure between Neohumanism and Posthumanism is in the inability of the latter to accept the necessity for transcendence. Transcendence facilitated union, or held together in an overarching system those things that were separate in the mundane realm. This, though, is a false promise as Donna Haraway describes it, because it is inherently separate from and inaccessible in the presently experienced realm:

How can there be a popular, playful and serious imaginative relation to technoscience that propounds human limits and dislocations - the fact that we die, rather than Faustian (and so deadly) evasions. Again, this might be a psychoanalytic question, since those holisms have the appeal of bridging all the parts and promising an ultimate oneness. They promise what they cannot, of course, deliver, or only pretend to deliver at the cost of deadly practices, almost a worship of death. The kind of partiality I'm talking about is resolutely antitranscendentalist and antimonotheist, fully committed to the fact that we don't live after we die. In religious language, that's what it comes down to: no life after death. Any transcendentalist move is deadly; it produces death, through the fear of it ('Cyborgs at Large: Interview With Donna Haraway'. Penley and Ross 16).

It is technology or the culture of technological media that frames discourse and therefore interaction between parties. This is not quite the same thing as synthesis, but dynamic interaction is the model of engagement for this Order, not synthesis. 
Cyberpunk is certainly a major inspiration and contributor to Posthumanism and underlines Posthumanism's tendency not to turn to the past and seek 'essential' pre-scientific foundations and definitions of human nature, but to go with the latest developments in science and technology and articulate their implications. The nature of identity implied in the Modernist worldview is ideal, bounded, abstract, non-carnal (as pure cerebral intellect, not a non-corporeal 'soul') and implicitly fixed. The emerging Posthumanist model is almost exactly the opposite: reflecting the findings of recent cybernetics, neurology and evolutionary psychology as well as poststructural cultural theory, the Posthumanist sense of ' $\mathrm{I}$ ' is based in the real world, unbounded, carnal and dynamic or performative. It is integrated with the external world through feedback loops and rather than being the changeless observer, it is the changing participant. The question that emerged early in the development of science fiction was whether technology that serves the body would create isolation, as E. M. Forster depicted in 'The Machine Stops' and as architectural critic Martin Pawley argued in his nonfictional The Private Future (1973), or whether it would enable deeper communality and thereby new modes of personal and communal identification, as Gwyneth Jones argues.

When the nature of the cultural schema changes, then language changes, and the conceptualisation of oneself within space changes. The features typical of Posthumanist writing, as a direct result of the spatial medium taking on an active, dynamic role, are: the questioning and recasting of identity and subjectivity; fragmentation of the human species, a scepticism towards independent will; and finally, recombination. Identity and subjectivity are created in a posthuman milieu not by the expression of an essential individual nature, but by interaction with external factors; selfhood then is inherently reflective at least and more likely to be a creation of its circumstances and history. Technological forces certainly create many variations on the primal human form in science fiction, but beyond that, the assumption of an essential unity and homogeneity among people is often treated with scepticism and deconstructed. This can often be a corollary of the former, with estranged communities placed in radically different circumstances and those circumstances thereby creating different kinds of being, whether or not there is direct technological intervention in the body and germ line. While there are new forces at work that categorically divide individuals and communities, there are other forces or ways of conceiving community that bring them together within a new common 
system as well, such as when the utility of 'species' as a concept itself is questioned and superseded. Both division and reunification are examined below in, respectively, the case of Bruce Sterling's Schismatrix and Gwyneth Jones' Aleutian or Buonarotti tales.

\section{1}

\section{Recasting}

The most significant literary characteristic of the Posthumanist Order is its treatment of the relationship between subjectivity and technology. Modernism can treat technology as an extension of the will in a largely one-way exchange, and Neohumanism can treat objects as talismanic and spaces as maps or territories (or a fusion of the two), but Posthumanism is more based on perceptions of processes of feedback. The emergence of ecology and cybernetics as disciplines after the Second World War is a vital historical and conceptual turning point because it was a new means of describing and understanding the relationship between the human being and the world. Instead of positing strictly-defined categories, a fixed central identity and lines of discourse between the self or community and external agencies and factors, all parties interacting with one another could be conceived of as being enmeshed in a common dynamic system and all could be seen as dependent on each other.

In order to understand an abstract intellectual construct, a tangible metaphor often has to be produced, and science fiction has excelled in this. William Hope Hodgson's Last Redoubt may stand as the icon of Neohumanism, tracing as it does its lineage back to the classical city as described by Joseph Rykwert, but the iconic metaphor of Posthumanist Order's architectonics is Jameson's example of the Bonaventure Hotel, which he described as a directionless 'hyperspace' (see Chapter 2, above). Jameson saw this hyperspace as inimical to an unchanging 'natural' human being, but it is actually kaleidoscopic (as opposed to being purely panoptic, though of course security cameras are everywhere). The problem is that it simply lacks proper inhabitants: it is (unintentionally or contingently) created not for humans but for posthumans. The ideal inhabitant of the Last Redoubt is X, but the ideal inhabitant of a hyperspace such as the Bonaventure Hotel is the cyborg because of its intrinsic ambiguity and lack of demarcation. As a literary motif, through the lens of 
appropriation, the cyborg has some deep literary roots, even if it is not called by that name, but by some other label, such as Samuel Butler's 'organised man'.

The fact that science fiction has its elders and precedents, coupled with the fact that it has an ideology of progress, means that while it reveres them, it must also evolve. The way that it is able to do this is by radical recontextualising and reinterpretation of classic tropes, which I refer to as recasting. Posthumanism in particular is prone to using this method, taking stock science fiction scenarios such as the artificial being, alien invasion, first contact, the utopia and the galactic empire or federation, and subjecting them to this process of recasting, breaking down their constituent matter and reshaping it.

In recasting, Posthumanism appropriates to itself a canon of existing literature and engages in a retrospective mutation or deconstructive misreading of those texts. Both Christopher Priest and Stephen Baxter have written novels - The Space Machine (1976) and The Time Ships (1995) respectively - that not only draw their inspiration from H. G. Wells' The Time Machine and The War of the Worlds, but weave both together and bring with them - particularly in Baxter's sequel - the benefit of new scientific knowledge, allowing the authors to elaborate on Wells' original ideas. However, this particular postmodern strategy can be limiting, restricting the act of writing to pastiche. Actual recasting takes the identifiable themes and images of a science fiction text and deconstructs them, questioning the basic premises of a theme or image. This is not, for example, changing from being for or against an idea such as cyborgisation, taking a text which says that it is a good thing and writing a text that says that it is a bad thing, but rather looking at the idea of cyborgisation itself and creatively investigating how that idea is constructed and how as a result an actual cyborg might exist according to those recast ideas.

Wells himself recast the Christian creation myth using the mould of Darwin, though he simply called The Island of Doctor Moreau (1896) a 'youthful blasphemy' (The Complete Science Fiction Treasury v). The eponymous scientist, a son of God born to Mary Shelley and fostered by Jonathan Swift, attempts to reshape animals into human form, though ultimately he fails, producing only half-human simulacra that regress again as their animal natures assert themselves. He does not re-enact Darwinian evolution exactly as his experiments might seem to do by 'elevating' mere beasts, because his programme is conscious and directed; rather, his failure to erase the animal heritage calls into question the supposed advancement of humanity when 
the narrator returns to civilisation and cannot help but see the indelible traces of animality still present on his compatriots and waiting for overt expression. Moreau is not entirely a vivisectionist and predecessor of a genetic engineer; he is also a social engineer, a utopian who wants to bring the benefits of reason and civilisation to animals; and he fails, as all utopians will fail if they do not cut deeper still into the concealed core of identity with their scalpels.

H. G. Wells was a frustrated utopian, knowing that whatever human nature was, it was stubborn and deeply ingrained, and even Moreau lacked sufficient tools and knew that social engineering alone was inadequate against the legacy of evolution. In such novels as The First Men in the Moon (1901), The Food of the Gods (1904) and In the Days of the Comet (1906), radical changes in human (or Selenite) form and nature are technologically enabled. However, having been educated before truly fundamental forms of rapid somatic and behavioural modification could be seriously imagined as being applied in the immediate environment and timescale, Wells turned ultimately to arguments for social and educational reform. Writers born barely a generation later than Wells, such as Aldous Huxley and J. D. Bernal, did have access to knowledge and education that was at best barely imaginable at the time of his schooling. In particular, the work of Mendel in genetics, Freud in psychology and Pavlov in animal behaviour studies made it much easier to imagine as a real medium-term possibility the radical conditioning and modification of the human body and mind that went well beyond Doctor Moreau's capabilities, along with its practical methods and its ramifications. Bernal and Stapledon posited, like Wells, that society and the organism are interdependent, that an ideal society could only be created if it were composed of ideal bodies.

Olaf Stapledon's utopia was one that was made of people who had been thoroughly remade - over a dozen times, in fact. In Last and First Men (1930) he depicted a long, repeated tragedy of waves of human species rising and falling until the process culminated in the Eighteenth or Last Men who did finally achieve a perfect society that reflected their perfected natures. While they are approximately humanoid, they explicitly break away from the binds of present humanity by having new senses, a form of telepathy that creates a group consciousness and over ninety genders.

J. D. Bernal was not willing to sit out two billion years of the slow grind of evolution in his imagination, however, and presented a technological solution, 
visceral cyborgisation and the creation of artificial worlds in space. The World, the Flesh and the Devil (1929) takes its title from Christian theology and refers specifically to the maintenance of innocence and the avoidance of sin. Bernal, in appropriating this litany, explicitly identifies as virtuous the uses of technology to alter the human condition. This is a major development in the emergence of Posthumanism and highlights a key characteristic of the Order. As a Marxist, Bernal believed that God had been slain by science, and presented technology as the new creed of miraculous interventions. The appropriation and recasting of Christian mythology and language was to him entirely proper.

Bernal's own speculations saw later integration into the scientific mainstream with Norbert Wiener's foundation of the science of cybernetics and particularly Manfred Clynes' and Nathan Kline's essay 'Cyborgs and Space' in 1960, and thereafter into science fiction works such as Frederick Pohl's Man Plus (1976). The immediate point is that, as is often the case with the Modernist Order, technology is given the tasks formerly given to magic, and significantly, technology arises from the mundane world, not the transcendental.

If a tool is a talisman or an extension of will, sanctioned by the layered and hierarchical cosmology that we see in Beowulf and the Arthurian romances, then it is right and proper that Hrunting and Excalibur are gifted to and enhance the wills of their wielders, as the Nautilus does the will of Captain Nemo. However, rather than having it bestowed upon him or inheriting it, Nemo built the Nautilus himself using his financial resources and scientific and technological expertise. If we go even further than Jules Verne, the technology itself is self-motivating. Under the paradigm of older science fiction narratives, this is a dreadful thing, as if Excalibur turned against Arthur, or put a curse upon him by which he was compelled to follow its urgings. Certainly fantasy is replete with tales of wilful, cursed objects, and in every case this is supposedly self-evidently evil and an upturning of the proper or desired order of the world (Tolkein's The Lord of the Rings and Michael Moorcock's tales of Elric and his sword Stormbringer are recent examples of this type). Science fiction too has plenty of tales of this kind, from Frankenstein to The Invincible, 2001: A Space Odyssey and The Matrix ( in which autonomous artefacts turn against their makers. These scenarios present a dichotomous relationship between human and instrument, one that is properly one-way from human through instrument, but cybernetics recasts this relationship as a loop and therefore one without dichotomies. 
These narratives, therefore, are rendered obsolete under the Posthumanist Order and must be melted down and recast.

\section{2}

\section{Wolfbane: Structural Ambiguity}

A particularly significant recasting of the scenario of the revolt of the machines is Wolfbane (1959), by Frederik Pohl and Cyril M. Kornbluth. This novel can also be seen to refer to the scenario of E. M. Forster's 'The Machine Stops' in its depiction of infantilised humans encapsulated by an absolutist mechanical system, and it similarly inverts the judgment of Forster and his sympathetic readers.

While it seems at first to follow the Cellarian model like so many other stories, Wolfbane incrementally shifts its sympathies to the Ebrian. In the story, alien machines, huge tetrahedral 'Pyramids', have completely re-engineered their own homeworld as a vast starship and stolen the earth from its orbit around the sun. The earth and its population is a convenient resource to them and therefore they periodically ignite chain reactions on the moon to serve as an artificial sun and 'mine' the human populace as 'components' in their own cybernetic management systems. As it is later revealed, the Pyramids were once created by an organic race to serve as their 'omniverters', universally servile mechanisms that provided all the necessities of sustenance, mobility, tutelage - and life in general. Having exterminated their own creators, they set off into the galaxy in search of new components. However, one assimilated component, Glenn Tropile, is not completely integrated into the pyramids' matrix ${ }^{*}$ and he, along with a group mind - a 'Snowflake' - formed with seven other components, is able to capture more humans and deploy them as 'mice' (135), sabotaging the Pyramids' systems and ultimately bringing about their downfall. The conclusion, though, is not entirely comforting: while the Pyramids have been vanquished, the earth is still far out in space and the Snowflake has been destroyed with the exception of Tropile. Finding himself a misfit wherever he goes, he realises that someone will have to reactivate the pyramids' engines to take care of the earth,

\footnotetext{
* The parallels between the basic scenarios of Wolfbane and The Matrix (1999) are so numerous and strong that it is almost certain that the novel was a significant inspiration for the film franchise.
} 
and after that, the stars beckon. As the novel closes, he is once again recruiting companions to form a new snowflake; the first is his wife, suggesting the obsolescence or the radical reconfiguration of a formerly 'essential' human relationship.

Pohl and Kornbluth are more complex in their presentation of the human race, the Pyramids and their great apparatus, than this bare outline suggests. Several dilemmas are presented to the reader: for example, should one read the novel as an allegory and interpret the Pyramids' exploitation of human brains as a metaphor for imperialist subjection of colonised peoples (in which case it compares with The War of the Worlds), or should one read it as a scientific thought experiment and characterise them as simple reflexive organisms driven by imperatives to survive? Is the scarcity-conditioned human society on earth to be viewed pragmatically as one that is fair and ethical, or from an idealist's point of view as one of limited vision, rigid conformity and mutual oppression? Are the 'wolves', who reject and are rejected by mainstream society, saviours or proto-fascists? Is the technology of the Pyramids, despite its awful use, potentially liberating? The authors examine these questions and the cognitive frameworks that generate them in turn, catapulting their protagonist through situations in which assumptions are brought into direct conflict with their consequences and possibilities.

It would be possible to read the story according to any chosen mode, except that in each case, the pieces will not fit. On one hand, Wolfbane is the tale of a ne'erdo-well who overthrows the wicked tyranny and is validated as a man by the society that had rejected him... except that the story does not end there: his victory has created more problems for the society of sheep and he is not accepted by them, provoking him to leave or justifying him in his decision to leave for an existence that seems awfully similar to the state of kidnap and oppression that he had suffered. On the other hand, the story does not quite fit together as a straight story of the technocratic wolves triumphing over the evil machines with their grit and determination, as the famous and influential editor of Astounding Science Fiction, John Campbell, would have demanded. In practice they had needed the intelligence of the Snowflake, which then treated them simply as mice along with those they had called sheep as part of their own binary social ideology. On the third hand (and why not?), as a component of the posthuman snowflake, Tropile realises that while its 
existence is glorious in its possibilities, it is one that has alienated him from humanity and made him cruel and callous.

The possibility of multiple-mode readings springs in part from the subversion of the old science fictional tropes - many are held up only to be deconstructed - but they are there nonetheless and invite readings according to their original precepts. Pohl and Kornbluth could have written Wolfbane as a straightforward propaganda piece for whatever ideology they chose and stacked the narrative deck in its favour, but the structural ambiguity of the novel serves to elevate the sense of surprise in the narrative: the story of the dragon-slayer or the revolutionary is invoked because we think that we know how it ends, but if that archetypal story is contradicted by other narrative threads and other possible readings, then the old tale is renewed.

The presentation of the Snowflake as a posthuman being is particularly interesting and articulates the questioning of identity and subjectivity versus objectivity that is characteristic of the Posthuman Order. The Snowflake has a rich internal life of the shared consciousness and memories of its eight components, with strong bonds of mutual comprehension and love between then, and its richness is further enhanced by contact with the remnant mind of a representative of the Pyramid's creator race. However, observed from an external perspective, it is a unitary entity and one that is as cold and ruthless as the Pyramids themselves, depositing its captive 'mice' in an environment that is as good a substitute for Hell as any. Only belatedly does it become cognisant of this.

The question of whether the Snowflake is eight people and one alien joined together or one gestalt being depends on which perspective one applies. From within it is complex, its various strands of consciousness and memory functioning perhaps as discrete entities in the sense that our bodily organs are distinct from each other, but from the outside it is definitely one and coldly callous, without any intimation of human sympathy. Although it does say at one point that it could be addressed as Tropile (ibid 120), this revelation is shocking and strange, because it in no way resembles the Tropile that its captives remember. Their horror is further aroused when it sometimes uses the original names of its other components and asked who it really is, simply replies, 'Yes' (ibid 135-6).

Once Tropile has been cut off from the Snowflake, he is once again an 'individual', but in fact he feels like an amputated member. When he expresses his desire to recreate the Snowflake, his wife, Gala, is initially aghast. She describes the 
state of suspension in a nutrient tank as being like death or infancy (187), underscoring the fact that interior experience and external appearance are starkly contrasting. Nonetheless, she ultimately decides to join him, which according to her frame of reference entails her death as a human and re-gestation as something else.

Cartesian Dualism implies a single, conscious and rational intellect ruling the body, but whatever its flaws may be, Freudianism demonstrated that the mind actually has multiple components, including parts that are unconscious but nonetheless highly proficient. The existence of 'free will' has been a contentious issue in philosophy for millennia, but specifically within the realm of science, more recent psychological and neurological studies have undermined Freud's exact model of the mind, while enhancing his essential point that 'free will' is anything but free. Still more recent neurological studies have cast doubt even on the existence of conscious free will as anything but a convenient illusion. ${ }^{*}$ However, even at the time Pohl and Kornbluth were writing, the unified and fully-self-conscious rational mind was a doubtful proposition. Science fiction has a penchant for considering the implications of metaphors turned into literal facts (and the Snowflake then is a metaphor for the mind as science shows it to be) and translated into a narrative actuality. To ask whether the Snowflake is one or many is to misunderstand it. From within, it is diversified, like our own minds (except that all of its components are aware of each other), but even then its specific architecture integrates its being and thus it presents itself externally as one.

The paradigm of cybernetic identity illustrated in Wolfbane raises interesting dilemmas. As cultural concepts have evolved, these dilemmas have been illustrated and resolved in different ways. Two distinct movements that have been crucial to Posthumanism in science fiction are cyberpunk and late twentieth century feminism, which took on the tools of science, structuralism and poststructuralism and turned them to their own ends.

Cyberpunk was quite explicit about its appropriation of mechanisation as not only a technique but a world view, describing bodies and minds and their modifications as most people would describe hardware: they were 'jacked in' to the Internet, augmented, subtracted, extended. As in Wolfbane, identities can be mere labels of convenience when brains are tumbled like Rubik's cubes.

\footnotetext{
* Peter Watts provides pertinent Notes and References to Blindsight, 369-72. See also $<$ http://www.rifters.com/real/Blindsight.htm>
} 
For all its reputation for grimness, cyberpunk is joyful - joyful in the manner of a pyromaniac entranced by the bright lights and colours of violent explosions. There may be huge aggregations of abstract power, zaibatsus larger than nations, but human beings - or passing facsimiles and fragments thereof - are tiny, isolated things, connecting only as nodes in temporary and shifting networks. Feminism, on the other hand, has long been concerned with the endurance of structures and the necessity of conscious change (whether evolutionary or revolutionary) rather than its mere chance permutations. Naturally there are divergences between the positions of various elements of the movement, but there is also a case of convergence, as we shall see in the work of Gwyneth Jones.

\section{3}

\section{Schismatrix: Everything that Rises Must Diverge}

Bruce Sterling, whose early works are considered foundation texts of cyberpunk, demonstrates the fully postmodern consciousness that characterises the Posthumanist Order in his Shaper/Mechanist stories, collected in the volume Schismatrix Plus (1996). The keystone novel of the sequence is itself called Schismatrix, a playfully oxymoronic neologism of Sterling's invention representing the inherently dissociative and dynamic state of his future civilisation as a 'schismatic matrix' or 'matrix of schisms'. These stories depict a solar system in which humanity is undergoing rapid speciation through a variety of rapidly-evolving technologies; the factions that give the sequence its name are respectively geared towards human enhancement through biological and mechanical prostheses and they are caught in a cold war in which evolution is the new arms race. In the course of these stories we see the emergence and decline of many posthuman species, and characters who rise, fall, remake themselves to rise and fall again and remake themselves yet again - if they survive.

Sterling identifies his principal inspirations in the introduction to Schismatrix Plus as J. D. Bernal (shorn of his Marxism), Freeman Dyson, an eminent physicist and prolific writer of non-fictional scientific romances, and the chemist Ilya Prigogine, who was prominent in the development of complexity theory (vii). Sterling himself has been a highly influential figure within the science fiction community and presents in his reference to Bernal a perfect example of a relatively 
little-read foundation text 'leveraging' influence far beyond its initial readership. Likewise, while he does not mention Stapledon, his influence is clear too and readers who have not read Stapledon will unknowingly have been introduced to his themes via Sterling.

Sterling's sympathies are very different from those of his mentors. He does not care much for Bernal's politics, and Stapledon's transcendental vision of a multitiered cosmos does not interest him as a subject for literary explication either: that which is beyond the realm of human experience altogether is by definition inexplicable. Transcendence is hinted at several times throughout the Shaper/Mechanist sequence as a probable evolutionary outcome, only to be dismissed as being irrelevant in the here and now.

As Wells offered a revolutionary perspective by looking at humanity versus the Martians as a Darwinian biologist would look at organisms competing for an ecological niche, Sterling also offers a replay of evolutionary history with human and posthuman beings recapitulating a famous episode in the history of the earth. In this case it is the Cambrian Explosion, a period when there was a sudden increase in the diversity of basic body forms, only a few of which are now extant. The new factor here is that evolution is not by natural selection, but by a more Lamarckian and selfconscious process of technological interventions and acquired characteristics.

It is a richly detailed scenario - almost too detailed, with much dialogue being the exchange of slogans:

“The Shapers, the Mechanists - those aren't philosophies, they're technologies made into politics. The technologies are at the core of it. Science tore the human race to bits" (ibid 151).

Variations on this quotation appear throughout Schismatrix and its associated short stories. The point that Sterling is at pains to make would gladden any science fiction fan: politics is in the long run a result of a response to science and technology. More precisely, one should say that ideology or policy is a response to phenomena revealed by science or generated by technology. This would come close to technological determinism were Sterling's sole focus technology, but he is interested in the choices made according to policy to pursue particular pathways of technology too. Thus, in his paradoxical community/anti-community of the Schismatrix, the Shapers pursue 
biotechnology, the Mechanists pursue electronic cyborgisation, while other factions or are they species? - variously develop interstellar travel, reject interstellar travel in favour of terraforming Mars, or reject terraforming Mars in favour of adapting themselves to live in the subsurface ocean of Europa.

What Sterling is telling us here is that science and technology are new evolutionary factors, perhaps the primary evolutionary factors affecting the 'clade' of emerging posthumanity. A strong dramatic and rhetorical consequence of this is that the diverse subspecies of the human clade continue to interact with each other despite a lack of a shared metanarrative, so that the civilisation of the Schismatrix becomes an environment within which posthumanity undergoes its Cambrian Explosion. This reframing of the socio-political as biological and ecological is an excellent example of Suvin's cognitive estrangement and a demonstration of how far late twentieth-century science fiction has moved from the Modernist ethos that is exemplified in the work of Jules Verne.

Clearly, the recurring motif throughout the Shaper/Mechanist stories is fragmentation - not merely cladistic diversification, but existential and narrative fragmentation (again, utterly repudiating Verne's Enlightenment ideal of the synthesis of all knowledge illustrated by Captain Nemo's logically systematised and utterly rigid museum). The protagonist of Schismatrix, Lindsay, at one point takes a drug named 'PDKL Ninety-Five' or 'Shatter', which is obviously a play on the initials of Philip K. Dick (ibid 175); he repeatedly reinvents his identity and experiences prolonged fugues in which he is alienated from his world and forced to readapt. He is himself no constant and reliable viewpoint character but a succession of roles and his companions and antagonists are no less strange. Among his associates, a cyborg Mechanist, Ryumin, is uncertain about where he has left his brain and is coy about whether it even still operates (ibid 147); a sometime lover and ally, Kitsune, cultivates her body to such an extent that it becomes an entire habitat; and a friend, Neville Pongpianskul (or at least as close to a friend as such a category can exist) dies, but is too polite to mention the fact, his identity efficiently perpetuated by his various cybernetic prostheses (ibid 231).

As Wolfbane played with genre expectations, the Shaper/Mechanist tales upset conventions too. Dramatic events are paralleled by an episodic structure that pays homage to the science fiction tradition of the 'fixup': the compilation of individuallypublished short stories as a single novel. While Sterling's prose is easier to follow 
than that of William S. Burroughs, one story, 'Twenty Evocations', acknowledges Sterling's debt by using Burroughs' cut-up technique. Schismatrix itself undermines the concept of novelistic integrity not only by presenting its protagonist as a chamaeleon, but by coming to multiple climaxes without dénouement before shifting Lindsay's and Sterling's own focus on to some new project, which is as likely as not to be the repudiation of the previous one. In doing so, he ironically recapitulates some of the favourite motifs of science fiction - contact with technologicallyadvanced aliens whose interstellar voyages are driven solely by mercantile greed and who have nothing to teach humanity (ibid 317), terraforming Mars to suit human colonists, then adapting humans to live in the ocean of Europa instead of adapting that world and so on. All of these goals are presented as magnificent in their own right, but it is fulfilment in them, or the expectation of fulfilment in any one, that is seen as a deadly trap. Ultimately, nothing is ever ultimate; a typical passage in Schismatrix might describe the structure and ethos of the novel itself:

History's kaleidoscope worked its permutations, its pace ever faster, approaching some unknown crescendo. Patterns changed and warped and flew apart, each chip of light a human life (ibid 215).

And thus, in the last words of the protagonist of 'Twenty Evocations', Nikolai Leng (who is essentially a variation on Lindsay):

'Futility is freedom!' (ibid 319)

This 'freedom' is the liberation from the certainty of a fixed telos. Sterling's characters are eternally playing and changing themselves, never seeking completion or fulfilment. On their terms, consummation is existentially equivalent to extinction. This is a very existentialist interpretation, one that is very close to Camus' recasting of the myth of Sisyphus in which Sisyphus' punishment becomes a perpetual triumph of exultant will over circumstance through circumstance. The cherry on the top of this confection, however, is that rather than eternally repeating the same task, Sterling's characters continually reinvent themselves, never rolling the same stone up the same hill, and never even staying long enough to reach the top so that they are spared the disappointment of seeing it roll down again. 
It would be easy to dismiss the Shaper/Mechanist stories as exercises in playful nihilism, but Sterling is as determined an architect as any of his characters and his stories stand as a manifesto as much as they do entertainment. There is a structure and system there, indeed it is all structure and system. Consider Neville Pongpianskul: he is dead - or 'faded', as the accepted euphemism has it - but he continues to speak through his voicemail messages and programmed house settings, as Brian O'Blivion lives on through all the 'new flesh' of his recordings in David Cronenberg's Videodrome (1982). Considering the facility of much of the dialogue in the Shaper/Mechanist stories and the perpetual exchanges of koan-like slogans, one might wonder if any other character truly 'lives' as we would expect a character to live in a novel of psychological realism. Would they actually pass a literary Turing Test? Probably not - but that is the point. Sterling's characters are not self-contained and static individuals anchored in a sense of personal self-consciousness, they are vectors of their culture, channels for the transfer of genes and memes. Richard Dawkins' The Selfish Gene subordinates the individual as it is constructed in the modern sense in favour of the ongoing stream of blood through generations, and Sterling does the same with memes (a word coined by Dawkins) that pass through the stream of culture. People are shattered fragments, and the Schismatrix is a jigsaw puzzle made of these fragments which can never be completed and which continually resets itself in new configurations. This is an architecture of civilisation that shows the influence of early chaos theorist Ilya Prigogine, with order arising as a form of 'metastability' out of flux.

We could hardly be further from the panoptic will of Captain Nemo.

\section{4}

\section{Gender Deconstruction \& Reconstruction}

The Burroughsian writing machine is congruent with a complete social constructivist model of persona, but Posthumanism, true to its Wellsian roots, must acknowledge the legacy of our evolutionary origins and process as well. Sterling has a way out, following Bernal into territories now occupied by Transhumanists who intend to hack their own physical, social and mental programmes. The literature of gender studies, particularly feminist writing, however, has had its own complex set of interpretations 
of the processes of identity formation. It cannot of course be said that there is a unified viewpoint, but it can be said that gender-focussed writing has provided a framework in which there can be a specific debate about the tangible issues of being and identity as they relate to cultural and biological legacies.

Many of Tiptree's stories were concerned with the social and cultural construction of identity, often with the mediation of technology or variant biology, and have been significant in the emergence of Posthumanism. As was shown in chapter four's introduction of Posthumanism, it is the understanding of the power of compulsion - through, but not limited to, the central metaphors of sexuality and addiction in the work of William Burroughs - that has been crucial in the Order's emergence. Identity is conceived of not as essential but performative, overlaid with masks and underlaid with instincts. Each exerts its own compulsive power. For example, 'Love is the Plan the Plan is Death' is narrated by an alien who believes himself to be acting out of free choice, but his mind is herded along fixed channels and his being and end, for all his hopes of independent creative agency, is simply a performance according to the rules of his genetic heritage, of which he has no true conscious knowledge (Her Smoke Rose Up Forever 413-29). Such a story serves as a warning that seemingly reasonable subjectivity is anything but. 'Performance' is certainly not necessarily choice and is affected by powerful intrinsic and extrinsic forces: culture, biology, technology and so on (one of science fiction's distinguishing characteristics is that it keeps adding new factors to the equation, such as thermodynamics, complexity theory and quantum physics). One may negotiate to some degree, but choices are always contingent and in any case one will become by performing, even if it is the mere iteration of the Plan.

There are masks also, cultural rather than genetic performances, and Alice Sheldon, a CIA photointerpreter and psychologist, and a complex person with a history of depression and ambiguous sexuality, was one more to analyse than judge outright. She decided then to hack her persona and created James Tiptree Jr. Tiptree is a constructed identity, as is Sheldon's other writing persona, Raccoona Sheldon. It would be inaccurate to say that these persona are masks over the real Alice Sheldon, because writing under that name to confidants such as Ursula Le Guin, she felt that her 'real' life was a 'puppet show', and as Tiptree she could be 'really real' (Julie Phillips 367). This moves beyond Oscar Wilde's quip that if you give a man a mask, he will tell you the truth; the mask is (a) truth. An existentialist and a feminist would 
agree that a life of conformity to societal expectations against one's instincts is one of bad faith, more of a lie than a writerly persona. James Tiptree, Raccoona Sheldon and Alice Sheldon constitute a form of aggregated being composed of alternate personae, Raccoona and James being, as it were, prostheses in the form of text, but they are also alternatives, might-have-beens that became actualised.

Otherness is an overriding theme in Tiptree's work, be it encounter with the alien (often erotic) or realisation of one's own otherness. Discovery and desire are not simply tropisms, they are generated from the concealed starting conditions and propensities of an entity. The bundling together of alternates is quite different from an actant-character finding their 'true' self through some sort of Jungian individuation, because no strand of being is privileged. If there is privilege, it is given to the dynamic of the compulsive engagement between them.

The idea of alternate identities existing in superimposition is a recurring element in Posthumanism, as will be seen below in the discussion of reading/writing strategies. Parallel and alternate universes, as we call them now, are common in fantasy and myth, but they are not legitimated in a Modernist spatiality and neither are they legitimated by hard Modernist science fiction. However, two important developments in science have opened up the concept of alterity as not only an unfortunate mechanism of exclusion and subjugation, but as a potentially liberating necessity: cybernetics and quantum physics. In the case of the former, there is the model of the cyborg, which has the ever-present possibility of exchanging its components to serve new purposes, but the concept of alterity is intrinsic to computer programming as well: rather than having one linear pathway, a branching decision tree needs to be mapped out for a system to be successfully programmed. In the case of the latter, Erwin Schrödinger's famous thought experiment involving a cat that is at once alive and dead until the intervention of an observer collapses its state into one or the other has become a potent modern metaphor, enabling the visualisation of equally valid parallel states of being where previously their existence would have been considered absurd.

The crucial twist on alterity here is that it is 'otherness' in the sense that Baudrillard's simulacrum is a 'copy' - there is no 'right' original. No alter-state is privileged as no simulacrum can be considered the 'true copy'. Consequently, 'truth' 
is diffused across a bundle of multiple-alternates, concentrated at moments of engagement in specific circumstances, but never fixed to any one excluding the rest. ${ }^{*}$

Gilles Deleuze defines the 'plane of immanence' as a field of forces, structures that produces many alternate possibilities, some of which are visibly actualised and others that nonetheless exist as present alternatives (the artist-architect Lebbeus Woods has used the term 'free field' to denote something similar). One cannot separate any individual actualisation of an entity from its field of alternates and influence. Rather than being a problem or a blurring confusion of uncollapsed quantum superimpositions, the key to comprehending an entity is in comprehending (as well as one can) that broad plane of immanence on which it rests, including then its alternatives (Deleuze 31).

The pervading immanence of alternate possibility is used as the fundamental premise of Joanna Russ' The Female Man, one of the classics of feminist science fiction. In this novel, four alternate women, Jeanne, Janet, Jael and Joanna, are each constructed as widely different personae by their engagement with alternate societies, but they are essentially the 'same' woman. However, while multiplied alterity is a dramatically effective means of structuring rhetoric (and The Female Man is nothing if not rhetorical), multiple-alterity as a condition in itself of being is not the novel's subject. The Female Man is a postmodern novel and while it does not stand exclusively within the Posthumanist Order, it definitely makes a fundamental contribution to it.

The awareness of the ever-present possibility of variant iterations upon the plane of immanence informs not only the reading of quasifactual encyclopaedias discussed in chapter 4 , but alternative reality games and, of course, (relatively direct) narrative fiction. Joanna Russ not only presents a quartet of counterfactual or alternative universes in the primary armature of The Female Man, but insists on the world of the reader being a fifth strand by refusing to offer a tidy conclusion. Instead, in the closing lines of the narrative, she addresses the book itself as if it were a character or person and exhorts the kind of change that will make its arguments obsolete (212-4).

\footnotetext{
* There is now a substantial heritage of science fictional alternative histories, such as Philip K. Dick's The Man in the High Castle, and the technique of creating alternate timelines has become a part of 'respectable' historiography in the form of the 'counterfactual'. As we have seen, multiple-alterity is not merely depicted as a plotting device; it can be characteristic of personal identity too.
} 
While presenting utopian societies (such as the world of Whileaway), Russ is no utopian; if there is a utopia that is an alternative to the present state, then the present state stands as an alternate possibility to utopia as well (Mendlesohn 238). The radical point made by this seemingly pessimistic scenario is that alternatives do not exist as absolute 'should-have-been' worlds that illustrate the tragedy of our fallen state or offer specific remedies, but instead counter the argument used by oppressors that there is and can be no alternative to the present state. Persistently insisting that there are alternatives immanent in the world is liberating because it deconstructs and reconstructs the cognitive parameters of the possible.

Immanent-alterity is analogous to a quantum state of superimposition, one that collapses into any of a given range of possibilities according to the nature of one's interaction with context - and it may keep doing so. Unlike a quantum collapse, however, each alternative is still potentially as real as the one immediately perceived. An author who has followed on from Tiptree and Russ and explored directly the nature of the alternative itself as an intrinsic part of her storytelling is Gwyneth Jones.

\section{5}

\section{The Buonarotti Cycle: There Are No Aliens}

Russ' deconstruction/remixing of gender pertains not only to feminism itself, but to the notion of the construction of identity in general. The construction of male/female is a specific binarism in which the self is defined by what it is and is not in relation to the other, which is defined as its antithesis. This binarism has as its corollary the binarism of the subject versus the object, which conditions the discourse between self and other. Denying the tenability of a binary male/female system calls into question the division of the experience of any relationship and quality of being founded on oppositional binaries.

Under the cybernetic and (post)structuralist paradigms, identity is performative. The initial, simple cyborg model as described by Wiener, Clynes and Kline et al, consists of a feedback loop, such as exists between a cyclist and their bicycle, but social, cultural, technological circumstances create a far more complex architecture. Gwyneth Jones has a particularly strong sense of the complexity of such reciprocal arrangements and has been able also to create a coherent, integrated vision 
of cyborg cultures. Her writing owes a great deal to her predecessors, James Tiptree, Joanna Russ and Ursula Le Guin, and repudiates Bruce Sterling's vision of constant schism being an inevitable corollary of technological-cultural development - but it is also slyly overlapped with cyberpunk.

One of Jones' most significant projects thus far has been the collection of stories and novels initiated by a trilogy depicting first contact with one race of humanoid extraterrestrials and expanded to depict a larger 'Diaspora' of multiple races reminiscent of Le Guin's Hainish Ekumen. A key device tying the stories together is a form of storytelling device that is also a technological one: the Buonarotti Device, of which more anon.

In the initial trilogy (White Queen, 1991; North Wind, 1994 and Phoenix Café, 1997), androgynous aliens, dubbed 'Aleutians' due to their initial appearance on the islands of that name, find themselves the occupiers of earth almost by accident. Traders by nature, their lost starship becomes an imperial power by default as they and humanity successively and in escalation misunderstand each other. Against this background, one of the Aleutians, Clavel, falls in love with a human, Johnny, and, mistaking the nature and role of sex in human biology and culture, rapes him. This incident and its legacy persists as an emblematic stain in human-Aleutian relations and, as the Aleutians are capable of a form of serial reincarnation and believe that humans are too, Clavel attempts to redeem both him/herself and the Aleutian mission in successive incarnations over a span of centuries as both cultures undergo radical changes.

In her explanatory essay, 'Aliens in the Fourth Dimension', Jones repeatedly points out that the Aleutians are not 'alien' in fact, but alternate humans with no sense of the division of 'us' versus 'them', and their differences are actually disguised similarities (Deconstructing the Starships 111, 114). It is their reproductive biology, which demolishes the gender division of human culture, which serves to make them seem strange.

Aleutian biotechnology exists in a smooth continuum with their own natural biology so that there is no real distinction between biology and technology - and neither is there one between these and culture and eschatology. This has a number of striking consequences. For example, like bacteria, they are constantly exchanging parcels of encoded information in lice-like 'wanderers' that update each other's 
genomes, as sexual reproduction in humans is supposed to reshuffle the genetic deck to avoid vulnerability to disease.

The continual genetic variability of the Aleutians has two corollaries. The first is that the Aleutians' selfhood literally infests their local environment, and reproduction occurs by the activation of stored genetic templates (with updates via the wanderers) rather than the fertilisation of egg by sperm. Each person born is an iteration of an archetype, or a Baudrillardian simulacrum of such, and the point of passage in their life when they become an individual (both aware of their true identity and fully a member of the community) is when, on watching records of their past incarnations, they finally recognise the person depicted as themselves. Aleutians do not see themselves as beings possessed of a unique, separate essence or soul, but rather incarnated gatherings of the memeplexes that make up a self that is the closest that they have to a concept of divinity. Self-worship is their religion, but it is paradoxically (to us) without the egoism of humanist self-worship.

There is a clever inversion at work here: the Aleutians are superstitiously scared of electronic technology, but they accomplish in biotechnology what the likes of Hans Moravec and various cyberpunk authors have invested their hopes in achieving via electronics. Jones deliberately uses biology or biotechnology as a mechanism so as to avoid suggesting to the reader that this is something that could be in the future through the medium of electronic technology, and as an estranging device, causing one to look back on the human analogues of this activity now as if they were alien and therefore remarkable rather than banal. The actual technological enablement of the Aleutian exchange of gossip is Facebook, or something similar. In her study of the changing modes of identity, ID: The Quest for Identity in the $21^{\text {st }}$ Century (2008), Susan Greenfield quotes a teenaged intern who was an avid user of the service: 'I can see that Facebook makes you think about yourself differently when all your private thoughts and feelings can be posted on the internet for all to see. Are we perhaps losing a sense of where we ourselves finish and the outside world begins?' (9). It is significant that the Snowflake in Wolfbane comes into being as a gestalt individual by the utter, shameless surrender by its components of all of their most private memories. This process, specifically described as an awakening, translates Greenfield's intern's metaphor into literal reality, in a way very characteristic of science fiction (Pohl and Kornbluth 94-8). 
The second corollary, which initiates the crisis and the plot of the trilogy, is that to an Aleutian sex is not directly associated with reproduction, but facilitates a massive exchange of genetic and biochemical information. Clavel, sensing a fundamental failure of communication between humans and Aleutians, attempts a communion with a human through sexual congress, but it is experienced by the human as a rape because he cannot bear either the physical transgression or the breaking down of distinctions between identities.

There is one other aspect of Aleutian biology that offers the solution to the conflict and that is their ability to reincarnate: every living Aleutian is the expression - a simulacrum - of one of about three million recurring genetic patterns and their identity is held in their common body of culture, so that the same individual can be reborn (or multiple versions can be alive at the same time too). Because they have a mastery of biotechnology that extends from their own borderless natures, Aleutians do not recognise and are not bound by species boundaries. The solution then is to reconstruct individuals 'in each others' place' across those unimportant boundaries. Thus, by another communion, by exchanging the roles - and bodily forms - of human and Aleutian in the subsequent volumes the characters are able to achieve reconciliation, and that point marks the departure of the Aleutian mission to earth and the world's liberation. The 'original' Aleutian remains behind on earth as the Aleutian expedition finally departs, living life in human female form, but other alternates will be come into being among the Aleutians again.

Ursula Le Guin's Hainish Cycle, which includes numerous short stories and novels such as The Left Hand of Darkness (1969) and The Dispossessed (1974) has the convenient device of a common ancestry for humanoid species in our portion of the galaxy, enabling discourse with different races that are not so different as to be incomprehensible. Jones uses a similar device, a community of worlds named the Diaspora, but with her own twist in that the shared ancestry is ambiguous; the theoretical underpinning of the Diaspora has its Weak and Strong versions, the Weak being that convergent evolution is enough to account for similarities among several races, and the Strong variant holding that there is indeed a common ancestral race native to Earth, or the Blue Planet as most peoples refer to it. Jones presents the debate, but she provides no favour to either Weak or Strong Diaspora Theory within her narratives. Certainly it is a realistic touch to show a major evolutionary debate being the subject of contention rather than consensus, as this is what we have seen 
many times in our culture (indeed, the Weak and Strong labelling echoes that applied to the Anthropic Principle), but this is not quite her point. Rather, characters' preferences for Weak or Strong are used to indicate their own attitudes towards community and being in general, and its unresolved status reinforces the Aleutian position that there is no such thing as an alien in any case. One character, the inventor of an interstellar transit system, Peenemünde Buonarotti, states flatly that no conscious being can be alien because consciousness itself is universal and by its nature that which makes connections, reiterating the Aleutian creed (White Queen 227).

Sterling sees the clade of humanity's species as becoming increasingly and inevitably divided and alienated, a position which other authors do not necessarily accept and which indicates a deeper elaboration on the concept of Other. One of James Tiptree's most famous short stories is 'And I Awoke and Found Me Here on the Cold Hill's Side' (1971, Her Smoke Rose Up Forever 35-43), which is a vignette depicting a human community surrounding and erotically devoted to the transient and biologically diverse population of a spaceport; it is a darkly romantic unfolding of the science-fictional theme of the attraction of the stars and of the alien. William Burroughs also, and more extremely, populated his novels with many alien, quasiand ab-human beings that were in rotating succession parasites, predators, prey, food, masters, slaves and lovers, bound by conspiracy, hunger, lust or addiction. Both authors and those who followed see the presence of the Other as inescapable - and compelling.

In Plato's The Symposium, Aristophanes states that erotic love is in fact the desire for a divided hermaphrodite to reunify itself (61). Erotic desire between species in the Buonarotti cycle is that of simulacra seeking to rebundle themselves as sheaves of multiple-alternates. A judgment about the correctness of the Weak or Strong interpretations of Diaspora Theory is beside the point, and better left obscured under the circumstances. One or the other may be empirically true, but regarding the dynamics of the situation, it is irrelevant.

Jones, it can be seen, addresses directly the issue raised by Sterling, that evolution appears to have a tendency to cause radical divergence; but recent ecological and evolutionary thought, such as James Lovelock's Gaia paradigm which presents the earth's biosphere as a single integrated superorganism, Lynn Margulis' work emphasising symbiosis as a driving force, and Donna Haraway's politicisation 
of cybernetics have emphasised the coming-together and emergence of complexly integrated systems rather than their divergence and disintegration. As both social structures and narrative structures of a culture are seen by her as expressions of the same given schema, then Gwyneth Jones' literary techniques parallel and support her ideological statements.

\section{6}

\section{Nothing is True, Everything is Rewritten}

Modernist space is Cartesian, homogenous in its nature and homogenising in its effect. As Lem demonstrated with his deconstruction of the implicit colonial paradigm hidden inside the modernist project in The Invincible and Solaris, the assumption that there is a universally efficacious system for describing and comprehending the universe that would be accessible to the parochial intelligence of human beings is surely absurd. Unfortunately, his own assumption that reason was ungendered was undermined when examined in Posthumanist critical terms, which highlight the fact that it was by default described and expressed in literary form purely in heterosexual masculine terms while women and homosexuals were framed according to gender and pathology and were therefore minority special cases.

Neither Russ nor Burroughs were permitted to assume that they could represent the 'normal', and they did not search for a new 'normal' as a kind of utopian project. Instead they embraced fluidity, polymorphy, uncertainty and perpetual immanent alterity as a substitute for the idealised normal. Authors influenced by them, such as Gwyneth Jones and Bruce Sterling, and authors who are working scientists who observe any variant of human cognition as limited and peculiar to a species of bald apes, are more amenable to this understanding and it becomes intrinsic to their writing.

Neohumanist space is hierarchical and concentric, and while it thrives on the meetings and borders of its various layers of space, it tends to favour narrative styles that extend themselves 'horizontally' - that is, all action and commentary takes place within one plane of existence with reference to the other planes above or below as intrusive or revelatory incidents. Posthumanist space, on the other hand, is fluid and polyvalent; intrusion or alterity are not extraordinary, but inevitable corollaries of any 
event or circumstance, as the immanent must be. Every event or circumstance always carries with it ramifications and alternatives and these exert their influence as strongly as the 'real'.

Of the writers who can be grouped in the Posthumanist Order, Jones comes closest to, say, Robert Charles Wilson, whom I have placed in the Neohumanist Order. Both see the creation of stories in a non-space, non-time as the means of integrating experiences of oneself and others: the Buonarotti Cycle in Jones' case, and Blind Lake and the Hypotheticals trilogy in Wilson's. This apparent closeness disguises a deeper separation. Jones is aware of the sheer power of biology in determining destiny, but is at pains to argue that culture fundamentally modifies the expression of biology and that culture and narrative are things that can and must be chosen. In being contingent, they exist in our world. Wilson on the other hand suggests that there is a higher, transcendent realm of independent truth that stories attempt to approach, however impossible a perfect realisation may be. Wilson then creates higher or shared spaces within which the reconciliation of immutable and essentially different natures can be engineered. Jones, on the other hand, shows culture intervening via technology in the supposedly unchangeable and essential architecture of a being's nature.

One of the great tropes of science fiction, a myth told over and over, is the elevation of humanity to a higher state of being. It is of course a millennial fantasy, recapitulating the Christian Rapture. It is often combined with the image of space travel (though a material spaceship is optional): spatial elevation equates with spiritual elevation, but also the great expanse of scale equates with the expansion of consciousness. Olaf Stapledon's Star Maker, Arthur C. Clarke's Childhood's End and 2001: A Space Odyssey furnish examples here, as does C. S. Lewis' early acknowledgment of the power of the myth when he cast space exploration as inherently 'diabolical' or precisely, anti-Christian, as distance in space was also a spiritual quarantine in his theology (Aldiss 193).

The transcendental myth was bitterly attacked from a critical perspective by Donna Haraway in the interview quoted at the opening of this chapter, and creatively in James Tiptree's novella ‘A Momentary Taste of Being' (1975), which is representative of Tiptree's anti-transcendence stories (Her Smoke Rose Up Forever 283-368). In this story, the common phallic association of the spaceship is explicitly taken to its logical conclusion - and its conflation with colonialism - with the starship 
Centaur carrying a human crew who dream of themselves as sperm, fertilising an alien planet. With science fiction's penchant for switching the literal and the metaphorical, this is in fact what they are: they find a fertile planet like an egg, and some essential element from almost every individual is fused with its receptacle on the planet, producing some new, posthuman transcendental lifeform - and leaving the original catatonic and dying. Tiptree's point is that the agenda of a metamorphosed being that is somehow raised to a higher plane is served by the prior existence of its contributing elements, but it does not necessarily serve theirs, and it will be, by its nature, divergent from and incomprehensible to those that remain below. The sole survivor of the mission sees nothing like fulfilment; he sees only irreparable loss, and doom for the people who will follow, and on his terms he is perfectly correct.

The living world of the Aleutians is not a transcendentalist one: there is no hidden higher order that will resolve all paradoxes and forgive all sins, all conflicts must be dealt with in the real world. Of course their serial immortality means that they have multiple chances to 'get it right at last', but there is no 'at last': an Aleutian as an actant has no path to an ultimate destiny, but is engaged in a continual dance with the world. Also, just as Russ presents no closure for The Female Man that privileges any one of her alternate worlds, it is clear that Jones' universe is one without a privileged transcendental space (or even science fiction's old standby, 'hyperspace'); instead she constructs an interstitial shared space of engagement in the form of the Buonarotti Transit.

Margaret Wertheim's The Pearly Gates of Cyberspace posits the revival of a spatiality that encompasses multiple layers of being and knowing in the mode of mediaeval epistemology, as computer and internet-mediated games present multiple levels. This is likely, indeed perhaps already accomplished; but rather than there being any hierarchy of higher, transcendent levels where the existing conflicts and contradictions of the world are resolved as one ascends in the manner of climbing a staircase, the very conflicts and contradictions as they exist are maintained in order to support the existence of alternate iterations - in fact they become necessary. Posthumanist science fiction does not merely acknowledge that there is an essential indeterminacy in the universe as an unfortunate reality, it embraces it because, according to its epistemology, any other attitude would be denial.

The Posthumanist spatial system, then, is dynamic and, unlike the stratified space of Humanism and its offshoots or the continuous grid of Modernism, it is one 
that is a bundle of alternates, switching between one another depending on where one gazes.

In addition to hyperspace, $a$ (not the of course) posthumanist ideal is its logical inhabitant, the cyborg, and one in the mould of the Aleutian: somewhat like any human, but in fact perpetually an alternate iteration of the self. The cyborg, however, while being the major myth of late twentieth century science fiction and an explicit presence from H. G. Wells' tripods onwards, is also - and probably because of that - one that is continually reinterpreted and recast. There are two extreme aspects of the cyborg: one is a reification of autonomy, the other, more amenable to Posthumanists of course, is an embodiment of culture, as individuals are embodiments of culture. These two aspects will be examined in the following chapters. 


\section{8}

\section{Architectonics of Identity: The Embodied Self}

From the emergence of science fiction, the relationship between human and machine has been a significant preoccupation that has culminated in the figure of the cyborg. As I have already noted, one of the ways in which the intersection between the human and its built environments is represented in science fiction is through the armed body. Tracing this motif through a selection of novels will allow me to demonstrate not only how it differentiates the three Orders from each other but also how ideological differences within each Order are manifested. My general line of argument is that the earlier conception of the armoured (male) body as a site of power through the enhancement of biology by technology, and a model of individuality, is challenged both by biological agents - the biosphere proves more powerful than the technosphere - and by the representation of the individual as constituted not autonomously but in social relationships.

Samuel Butler in his dual guise as Cellarius and Lucubratio Ebria formulated a vision of what evolved into the cyborg as we know it now, but that vision began with two different sides and, as it is manifested now, the cyborg is also subject to varying interpretations and presentations. From the Cellarian point of view, machines are an emerging species and we are their reproductive organs. Soon, they may well be openly our masters. From the Ebrian point of view, a person is really a system of body, clothes and tools, and someone who works with machines does not serve them, but extends his or her being to encompass them. H. G. Wells' Martian fighting machines are clearly of the later species, but many later science fiction stories explored the full spectrum of possibilities between the Cellarian and Ebrian positions - and quite a few that were off the scale altogether. Frederick Pohl and C. M. Kornbluth's Wolfbane even found a place for an Ebrian Snowflake to crystallise in a Cellarian Hell. Science fiction itself has taken the cyborg and turned it into a kaleidoscope of possibilities that do not so much reveal the geometry and colour of the entity itself as magnify the premises informing its Orders. 
The Modernist, Neohumanist and Posthumanist Orders, as a consequence of their distinctive architectonics, produce a diversity of representations of the body and the self and their relations with their contexts, both within and among the Orders. We can take the case of the body, then, as an indicator of how a set of premises within an Order can provoke starkly different responses according to ideological and aesthetic variables. We can also observe how frustration with internal conflict can provoke the emergence of new, more fundamental formulations.

\section{1}

\section{This Quintessence of Mud}

The great irony of The War of the Worlds is that the Martians, flabby creatures made mighty in their towering machines, are vanquished by common microbes. Wells of course intended this to humble his readers, who had already seen artillery of the human army prove generally ineffective against them. The image has ramifications beyond Wells' initial intention because it is one that has continued to reproduce itself through narratives depicting similar fusions of flesh and fighting machine. It is easy to focus on the glittering fighting machines, but it is necessary to look at what they stand against. When we read of cyborg fighting machines, we must think of what hellish conditions have developed to demand their existence. The sharper the division and contrast between body and landscape, the stronger the armour and more powerful the weapons depicted, the greater the science and the discipline required - and the more terrible the landscape will seem. The landscapes against which the figures of fighting machines are set are terrible, and they are aggressive in themselves, seeking to get inside the hard shells and to transform their contents into their own rotten matter. The War of the Worlds is what it says on the tin: a war of worlds. Earth and Mars are the antagonists and it is earth - dirt, muck, infection and corruption - that wins.

Wells' personal irony is particularly pointed in that he had been afflicted by injury and chronic disease in his youth and that he grew up in an age when society was just making its first real steps in the systematic control of disease with the promise of its eventual elimination. William Hope Hodgson's own writing is quite explicit but hardly unique in revealing his own obsession with hygiene, disability and 
personal mortality. His ardent practice of physical culture (bodybuilding) and personal hygiene is not merely idiosyncratic, but fundamental to the mythology of his stories. Repeatedly, ill-fortune comes through infection and contamination: in one short story, 'The Voice in the Night' (1907), a pair of castaways are compelled through starvation to eat a fungus on a desert island and find their own flesh infected and then transformed into the fungus itself, while in The House on the Borderland, the Morlock-like 'swine things' that are the main visible antagonists are bearers of physical corruption, and in one telling episode, the narrator's dog is struck with a glowing green mark by one of the swine things and the stigmata begins to spread until the animal is dead.

In 'Illness as Metaphor' (1977), Susan Sontag notes that in the nineteenth and early twentieth centuries, diseases such as tuberculosis and cancer in particular were metaphysically conflated with death itself. While tuberculosis had some romantic connotations, cancer was by far the most terrible because of its sheer, brutal and visceral inexorability; it may strike anyone, anywhere, and it will eat the sufferer alive. It is tempting to make a personal psychological assessment based on the fact that Hodgson as a young seaman saw the dangers of rot and scurvy all about him and that his father died of cancer, but as Sontag makes clear, there is plentiful literary representation of disease and cancer in particular on such terms (16-19). The principal weapon against disease in the period onward from the Enlightenment was systematic organisation and order - and disease was therefore characterised as a deadly force of chaos to be kept at bay. Bearers of disease became representatives of that chaos, their physical taint represented a contagious social and moral corruption, therefore requiring their ejection from the bounds of society (ibid 99, 142).

Throughout Male Fantasies (1977), Klaus Theweleit devotes much space to considering the conditions of liquefaction, fears of filth and dirt, anything that flows and threatens to dissolve hardened, fortified flesh. He notes the case of one Freikorps man, a Lieutenant Ehrhardt, who was forced to go into hiding and consequently lost his sense of identification with his orderly military community:

Socks and shirts were strewn about all over the place, shoes and suits were never moved once I had discarded them, and, above all, money was hardly easy to come by. Every day held the threat of renewed humiliation. But I 
kept a grip on myself. Though every evening presented me with some new source of revulsion, I fended off every urge to vomit. Any man who has successfully conquered seasickness must remain impervious to the nausea of life. I kept myself from slackening by issuing myself my own orders (2: 225).

Obsessed with maintaining integrity against an onslaught of feral socks, Ehrhardt is quite ingenious in his creation of a virtual order to surround himself that become braces for the mind as armour (and clean socks) would brace his body. Theweleit devotes some attention to cleanliness as a metaphor and a compulsion in psychoanalytic terms that can also be considered existential, especially when he considers the creation of boundary demarcations:

Toward the end of the nineteenth century, lack of affection during infancy and insufficient eroticisation of the body's surface seem to have become the rule. That development marked a new phase in the "armouring" of the body... The new body had no feel for its psychic boundaries; if it cathected its own periphery at all, it did so in a tentative, incomplete way. The body did acquire boundaries, of course, but they were drawn from the outside, by the disciplinary agencies of imperialist society. We can see why fascist propaganda and social practice places such great emphasis on setting boundaries of all kinds (1: 418).

Ehrhardt is almost comically vulnerable to attack by roving packs of rabid underwear, but this is not in the least amusing when he and his like categorise Jews and communists along with filth as not merely deserving of expulsion, but demanding elimination. To him they have human shapes, but they are not human; they are extrusions of the gutter, made of the muck and slime that constitute the outer world, threatening to take over his body and dissolve it. This is an image that we see again and again; and similarly, every time we see a cyborg fighting machine in fiction, we must consider the ground on which this figure is placed.

The environment is quite crucial in the formulation of the fighter-body or tank-body of the warrior cyborg. They do not fly over or trundle across gardens, but devastated wastelands. They do not face the odd enemy who will leap out from 
behind a rose bush, they are surrounded and immersed in an ambience of literal deathliness. Monsters that appear within this realm are not so much independent entities as extrusions of it. We see this in The Invincible, where the black flies appear largely to be a manifestation of the climate of Regis III, and it is quite clear too in The Night Land, where the hero leaves his Redoubt clad in armour to venture across a land that he refuses to comprehend on its own terms. Hodgson's own last letters from the battlefields of the First World War drew explicit literary parallels with his novel The Night Land. He noted particularly the churned-up, formless, almost liquid quality of the devastated landscape lapping against concrete blockhouses while immersed in its mud are the graves of the unknown dead. He described the war as an 'Infernal Storm that seeps for ever, night and day, day and night across that most atrocious Plain of Destruction.' That might be language from The Night Land, and indeed it is: 'My God! talk about a lost World - talk about the END of the World; talk about the 'NightLand', he wrote, 'it is all here' (The Wandering Soul 384).

Aggressive opposition that takes cognisance of the other as other across the dividing line of armour plate is the key to self-identification and self-preservation in such a cosmological system. It is a form of narcissism, articulated through antagonism (the alternate form of narcissism, which is empathic in nature, will be seen as underlying Gwyneth Jones' description of the Aleutian sense of identity later).

The ground, as it were, is prepared, and the machine 'must' be assimilated into the human system, because it draws a line between body and filth and makes a human everything that they should properly be.

\section{2}

\section{The Technological Metaphor \& Subjectivity}

Machines, unlike passive armour, are active, possessed of motion and therefore a semblance of life so that they can easily (so it seems) be fused with the living. When two elements are integrated in the same system, defining the identity of the new entity in unambiguous terms becomes problematic at least. However, as will be seen, flesh that desires a casing of steel, can desire to be steel not flesh. The warrior cyborg draws on this theme in particular, and while it has been explicitly identified and 
rejected with horror by certain authors, it has still exerted its fascination and reappeared with a disturbing ambivalence.

The later manifestations of the warrior cyborg such as Robocop, the Terminator, and Ripley in her exoskeleton have been analysed in terms of their affinity to modern and postmodern ideas of cyborgs, but in fact they are emblematic of a theme that has a quite different origin. The concept of the cyborg that emphasises the armouring and mechanisation of the body appropriates technology to the purpose of defining and enforcing a boundary between the ordered, interiorised self and the chaotic, exteriorised other. This spatial conception of identity is characteristic of Neohumanism, but its lines of descent extend out of that Order.

Fascism presents the most explicit illustration of the extreme end of the armoured, mechanised cyborg body here, though it must be pointed out, fascism is not the essence of any of the three Orders under discussion here, nor even their logical endpoints. What it does represent is an extreme, pathological, development of xenophobic, anti-modern totalitarianism that infuses an idea of the cyborg with meanings and intentions that could otherwise be benign in the context of Neohumanism or another Order. Posthumanism presents a direct challenge and deconstruction of the model, clearly articulated in Mamoru Oshii's film Ghost in the Shell 2: Innocence, but critical treatments can be found within Neohumanism as well.

Klaus Theweleit devotes a significant portion of his study of the Freikorps culture to the process of making a soldier: the charisma of the leader, the synchronisation of companies, the physical drills that are designed to push young men beyond their limits so that they can be reconstructed, reborn as killing machines. The mechanisation of the body is no mere metaphor, but an ideal to be realised in as literal a form as possible. In the work of the fascist writer, Ernst Jünger's Feur and Blut ('Fire and Blood', 1929), he finds explicit the desire to go beyond the emulation of the machine to become a machine. Every word used to describe a man draws on the same store used to describe machines so that there is no longer any distinction (2: 159-62). Theweleit sees the engagement with mechanisation as being fundamentally existential:

The more absolutely the body armor is mechanized, the more its product becomes not the multiplicity of reality, but an expression of being, the more 
likely it is to connect into machinery as obstruction, expression and display, rather than machinery as means of production. The body is then fantasized as coupled not to freight aircraft - since these are not so much expressive as useful - nor to machines for aircraft construction, but to fighter aircraft as destructive display machines $(2: 202)$.

Prophetically, he notes:

Today it is likely that the promise of intense pleasures would not be held by machines, but rather by parts of our unconscious being, shot into space at the speed of light and landing on alien planets, but still controlled by our computers; the hidden depths of our souls stored, labeled, and structured in vast data banks, countless prototypal components that can be recalled in a matter of seconds, yielding the deepest insights. I am fairly convinced that there are a number of people dotted around who are already tinkering with the fascist aesthetic of electronics (2: 454, endnote to 202).

Theweleit's analysis inevitably converges here with the history of the warrior cyborg. In fact, science fiction authors had already described this possibility. Terry Nation, scriptwriter for Doctor Who, had (with the production designer Raymond Cusick) created in the Daleks a brilliantly succinct representation of the warrior cyborg in 1963. The Daleks were, Nation proposed, a race of humanoid beings originally called the Kaleds, whose bodies were suffering progressive and unstoppable degeneration as a consequence of fallout from perpetual nuclear war. In order to survive, they encased themselves in mechanical appliances that became their new forms as they presented themselves to the world. Coupled with their new mechanistic bodies, they expressed nothing but genocidal fury towards any living thing other than themselves very much like the Nazis, and of course that parallel was clear and deliberate. The Daleks have been a fixture in the stories of Doctor Who and popular culture ever since their first appearance and provide a useful thought experiment in all their variant iterations and representations.

The 2005 revival of Doctor Who brought with it the return of the Daleks after a long hiatus and with it, a searching examination of what it meant to be one. In the 
case of episode six, 'Dalek', the Doctor and his companion, Rose, encounter a damaged Dalek that has been imprisoned by a billionaire collector of alien artifacts, Henry van Statten. The creature of course contrives to free itself and goes on a rampage. Initially, it goes on an orgy of killing throughout van Statten's complex, effortlessly slaughtering his guards - and as the Doctor warns, when it breaks out of the complex, it will go on killing because that is what Daleks do. Once the Dalek is established in the audience's consciousness as an authentic monster, the script then delves more deeply into its nature and its motivations.

It is in its interactions with the Doctor's companion, Rose, that the Dalek reveals depths that seem, for a while, to humanise it. By a bit of pseudo-scientific hand-waving, the creature has repaired itself through contact with Rose, somehow absorbing and integrating samples of her DNA (genes are often shorthand for a vaguely-defined personal essence). Confronting van Statten, it prepares to kill him, but Rose is able to stop it with a word. Confused, its eye-stalk swivels between its target and Rose and it demands an explanation of why it should feel merciful. The Dalek by this stage is self-aware enough to know that it suffers a conflict between orders and empathy. In the absence of the external structure of Dalek society, it must rely on its own judgments, and it is influenced by its human company - in particular, Rose, through the sharing of emotions. As it realises that it is changing into something other than a pure Dalek, it decides to die rather than lose its existential foundation or exist without a constant stream of orders from its collective society. 'This is not life,' it says, 'this is sickness.' To a Dalek, anything that is not of its kind is a disease, and in changing - as a human would think, for the better - it is becoming what it has been conditioned to hate - no matter that Rose, a human, resembles its own ancestors. Inevitably then, it decides that it must die and orders Rose to order it to exterminate itself.

The identity of a Dalek rests on its opposition to that which is without and there being an impenetrable barrier between inner and outer and an opposition to whatever is outside that barrier. Furthermore, the Dalek must deny its own subjectivity through the complete surrender of will and intention to a surrounding and permeating authority structure - orders from recognised authority are the only things that can penetrate its armour. Once it becomes aware of itself as an individual and is able to conceive of the subjectivity of others, it is no loner a Dalek. This creature that 
objectifies all about it also objectifies itself; the system of subject/object mutates from a binarism into one of pervading objectification. There is no self versus the other, because it has the barest, if any, sense of self. The self has been identified as a weakness itself - the 'sickness' - and a successful Dalek has exterminated its own self by accepting externally-imposed will to forestall reflection.

If one is conditioned to think of the unadorned naked body as the representation of authentic human status, cyborgisation entails loss and the destruction of self-image. The person who is compelled through accident or force or persuasion to be permanently blended with the inhuman is immediately made insecure; it is not surprising, then, that the warrior cyborg emerged with its exaggerated armour and offensive power as an overcompensation. The contrast of the weak, atrophied Martian and Dalek and their powerful technological shells is of course obviously ironic. The contrast is explored more as a tragedy in Colin Kapp's short story, 'Gottlos' (1969).

During a war at some undefined future date and location, remotely-operated tanks ('warmecs') are employed by the antagonists, one apparently American, the other apparently German, stalemated over an already thoroughly devastated territory. The operator of one warmec, Manton, is acutely aware of his own status as a cyborg, and he is traumatised when his warmech, Fiendish, is destroyed by the effortlessly more powerful and agile antagognist, Gottlos. Manton comes to realise that Gottlos has been given its advantage by having a human brain wired directly into the mechanical body of the fighting machine, thereby ensuring that there is no need for risky radio communication between operator and fighter and allowing far greater sensory acuity. Moreover, he learns that his own commanding officer, Rohm, knows that beings such as Gottlos may break the stalemate and has been assessing him for a similar operation so as to escalate their side's response to match their enemy once again. Manton, however, sees Gottlos as a tragic being and assists it in its selfdestruction. Meanwhile, he wonders about the future, challenging Rohm:

'The war machines are the real creatures of this generation. We've made the world so brutal and ugly that they alone can live in it. They can't reproduce, but it doesn't matter. They can outlast us. You'll either fail to create the true gestalt creatures, or you'll fail to survive their creation' (47). 
While the gestalt warmecs may be the next stage of evolution, their condition is one of agony and tragedy, caught between the imperatives of their human legacy and those of their posthuman state. Gottlos is tortured and existentially alone - his very name means 'God-lost.' As Manton complains to Rohm, Gottlos had the option of self-destruction by overloading his power plant and Manton does not:

'I'm poised out in some limbo where I'm truly neither one thing nor the other. I suppose I've a couple of years more useful life out in the rowen before I forget you as Gottlos forgot the operators in the command post. But where do I turn for somebody to help me to destruct?' (ibid 47)

Kapp's remedy for Gottlos is suicide, and from an existential point of view he has a point to make that is consistent with his humanistic perspective, but from a psychological point of view, Gottlos might well feel no conflict or sense of loss. The cyborg tank is represented as a solitary being, an existential state of being without category, and therefore alone and 'lost', but fascism's totalitarian structures negate the possibility of solitude altogether.

'Gottlos' anticipates the vision of Andrew M. Stephenson's 1976 story, 'The Giant Killers'; his warrior machine has no internal conflicts arising from the unwelcome presence of any vestigial human elements and consequently no need to seek a way out through suicide (Stephenson 155-84). In this tale, a commando group is sent out to capture the brain of a new enemy robot tank, the Wojonik-Olbryzym, Number 0739 or 'Voyo'. The landscape of war here is not the churned mud and shattered trees and buildings of 'Gottlos', but an Africa overrun with biological and cybernetic weapon systems. While the Voyo is purely a machine and not a cyborg, it represents the endpoint of cyborg evolution towards which Gottlos has been directed. Whereas Gottlos desires to die, the Voyo is confident, almost mocking, because it has eradicated in itself all trace of human imprint (as the Daleks wished to do). Asked by the leader of the commandoes, Tolbein, why a machine with no human sympathies would still fight, it replies: 
'My instructor told me about human beings. It said they were inconsistent, unreliable, often treacherous. Men, it said, think of war as a romantic adventure, one bound by rules which may or may not be observed as convenient, rather than as a way to the clarification of political hierarchies, no more... I have never understood this, not in all my six days of life, why creatures so imperfect could have dared to build us to play their games for them, but then I have never before encountered humans. I am not impressed. Indeed, I think my instructor was right when it added, It is better that we fight for them and do it properly, and honestly' (ibid 180. Emphasis in original).

The Voyo then shoots him. Dying, Tolbein thinks he is in pursuit of the bronze giant Talos, and finds instead that it has become Ares:

'No mere mortal may bind me now. At last I am become my own master.'

'And what shall you do with your freedom?' I ask, though I am sure of his answer.

'I shall exist!' he bellows, and the echoes of his voice rebound from the four corners of the earth.

'Is that all?'

'That is my nature, Man. I am what I am; is that not enough for you?' He leans now, studying me. The smile on his lips is tinged red and orange and gold with the firestorm light of dying cities. 'You made me,' he whispers. 'And I am the life which will supplant you. Be proud that at last you have created perfection.'

And with those words he grinds me into Mother Earth beneath his thumb (ibid 183-4).

Like Gottlos, the Voyo in its guise as Ares is now without master and not in any way beholden to its creators. Underlying the image of war as a man-made chaos, with its mythical associations, there is an acute Darwinian anxiety in the depiction of Gottlos and the Voyo. Strictly speaking, the Voyo is a completely artificial intelligence, but it is so closely allied in type to Gottlos that it can be seen as an ultimate, pure expression of a kind of being which has at last eradicated all trace and taint in itself 
that is human, wet and infirm. There are many stories that depict machines or cyborgs as successors to humanity, but in these two stories, the 'coming beasts' have arisen as the faces of a universal chaos and catastrophe. The Voyo is the apotheosis of fascism, having eradicated everything that is filthy, liquid and inconsistent; machines of its kind do not compete with humanity for our place in the world, because we are now the misfits. It is free even of obsolescence, because it has no end; it is pure warrior and war is its eternal domain.

\section{3}

\section{The Annihilation of the Self}

Nation, Kapp and Stephenson are all quite clear in their fear and hatred of what is represented by the emergence of the warrior cyborg, which they see as death-oriented and fundamentally anti-human. The uncanny and dreadful quality of a warrior cyborg in their eyes is due either to the fact that it has a human consciousness inside a dead body, in which case it is a tragic being, or it possesses a body that is animated as if it were alive, but is essentially nonliving, in which case it is evil. This perception arises from a Cartesian model of mind and body, with the two being essentially different in quality. There are two corollaries to this: first, if the mind and body are different, then the subtraction of one need not affect the quality of the other; and second, when they are divided, if one is to look for a distinct repository of identity, then one must choose one or the other and in most cases that is the mind. A mechanised body, even if it began as a human body, is potentially a mindless body - but one that in some way still lives. That is not simply horrible, as it seems to the aforementioned authors, but ironically attractive to some.

Within a Neohumanist framework, with its emphasis on subjectivity, the annihilation of consciousness and selfhood would seem to be anathema, but both Neohumanism and Modernism can - in theory - facilitate the separation of mind and body and permit thereby the continued existence of consciousness without body and body without consciousness. According to the Neohumanist concept of layered, transcendental realms, what is consciousness in the mundane realm becomes spirit in the transcendental realm, but in the Modernist Order, the Cartesian dualism of mind and body assumes at least a fundamental division between the two, with the 
implication that pure reason can exist without bodily form and the body can exist without a mind. Posthumanism, which emerged from Modernism, has retained to some extent a vestige of Cartesianism in some of its manifestations, and cyberpunk has often represented minds uploaded from fleshly bodies into the new medium of computational hardware.

Cyberpunk has relatively rarely addressed the uncanny image of the animated doll without a soul, but fantastic and satirical writers of the nineteenth century such as E. T. A. Hoffman and Villiers de l'Isle Adam have been fascinated with that possibility. Robert Martin Adams argues in the introduction of his translation of Villiers de l'Isle Adam's L'Eve future (1886) that the android and gynoid present an image of Cartesian dualism (xix-xx). The implication is, even if Villiers de l'Isle Adam's and Hoffman's gynoids are ultimately failures, that they are still compelling and attractive not only as objects of desire, but as models for being. Indeed, Villiers de l'Isle Adam's Axel (1885-6) ironically presents the replacement of life by artifice with the line, 'Live? Our servants will do that for us' (183). Perfection does not need reflective consciousness because it exists entirely within and for itself.

While 'The Giant Killers' is not about consciousness and subjectivity per se, it nonetheless has implications pertaining to those things that illustrate this aspiration. The Voyo is clearly intelligent and possessed of a kind of consciousness and able to ask questions of itself, but it has also decided not to reflect. In Tolbein's terminal vision of a triumphant Ares, the god declares that he has no need to conceive of any telos of victory, because he has become completely identified with the process of war. The consciousness that one has in such a situation is of a unified, timeless, static kind, for all the overt dynamism of his power.

This unthinkingness is not, however, a state of absolute erasure from the cosmos; it is still dependent upon an existence and even experience fixed in the cosmos. It is the expression of the absolute, abstract, total will as the concept was employed in Nazi ideology, but which is also used in many other realms, and which can also be expressed therefore as a state of absolute dominance. This desire for what is not exactly death or unconsciousness, but a timeless, autotelic state of perpetual flow, stands in contrast with that of other cyborg entities such as Pohl and Kornbluth's Snowflake, which is both curious and deeply introspective and therefore exists in an entirely different experiential universe. 
The Dalek and the fascist do not wish to think, but they most certainly wish to act. Yukio Mishima (in Sun and Steel, 1970) directly addressed the tension between thought and action, between revelation and desire. He takes the example of an apple: we see an apple, but how can we be sure that it is a real apple? The only way to be sure is to cut the apple open, but when it is cut, it ceases to be an apple. There is a paradox: existence is confirmed only at the threshold of destruction (69). In Mishima's own life and death, this meant physical action and destruction, but destruction can mean a profound negation in any state and realm, be it in flesh or in understanding. He relates his own epiphany in the cockpit of an F-104 jet at high altitude. On the intrinsic danger of high-altitude flight, he considers the apparent conflict of flesh and spirit:

Somewhere, I told myself, there must be a higher principle that manages to bring the two together and reconcile them.

That principle, it occurred to me, was death.

And yet, my idea of death was too mystical; I was forgetting the plain, physical aspect of death.

The earth is surrounded by death. The upper regions, where there is no air, are crowded with death pure and unalloyed; it gazes down on humanity going about its business far below and bound by its physical conditions on earth, yet very seldom does it bring bodily death to man, since those same physical conditions prevent him from climbing this far. For man to encounter the universe as he is, with uncovered countenance, is death. In order to encounter the universe and still live, he must wear a mask - an oxygen mask (ibid 89-90).

Accordingly, he meditates on his experience in a high-altitude aircraft in the realm of death:

This silver tube floating in the sky was, as it were, my brain, and its immobility the mode of my spirit. The brain was no longer protected by unyielding bone, but had become permeable, like a sponge floating on water. The inner world and the outer world had invaded each other, had become 
completely interchangeable... The flesh should glow with the pervading prescience of the spirit; the spirit should glow with the overflowing prescience of the body. And my consciousness, that shone serene like duralium, watched over them all the while (ibid 99-100).

Mishima obviously iterates the identification with the fighter aircraft described by Theweleit, but as the example of the 'failed' Gottlos and the 'successful' Daleks and Voyo show, a tank will do just as well as a model.

The authors discussed here vary greatly as to whether they desire or abhor the state of the warrior cyborg, but all are consistent in indicating that it is an inevitable endpoint of the process of the mechanisation of war. Mishima's emphasis on the deathliness of the world in which the refined, ecstatic identity of the warrior cyborg arises clearly sits alongside the numerous decaying and wasted landscapes of all the other warrior cyborgs: the Night Land that Hodgson saw replicated in the battlefields of the First World War, the ruins of 'Gottlos', the degenerate Africa of 'The Giant Killers', the ruined planet of Regis III and the nameless junk world of Pohl and Kornbluth's Pyramids wandering the still larger wasteland of interstellar space. The armouring clearly goes along with the conception of the outer world as being hostile and desolate, but in certain cases, the dichotomy of inner and outer provokes or reflects an internalised destructiveness as well. As Nietzsche says, look long into the abyss and the abyss looks into you; but while that was meant as a warning, in the case of the warrior cyborg it represents an aspiration.

As I have mentioned, the spatial demarcation of self and other in Neohumanism laid the groundwork for the concept of the warrior cyborg, but that concept is not an inevitable and necessary end, and neither is Posthumanism essentially fascist. Indeed, it is in their attitudes to death that we can see the sharp distinction that makes fascism what it is. The fascist's goal is to achieve annihilation, and that annihilation is an absolute, as Mishima himself made absolutely clear in his writing: he wanted to find perfection in the moment of death, he had no need to imagine anything beyond that singularity. However, the transcendentalist tendency in Neohumanism sees the forces that produce a convergence on that singularity as a great paradox, and through a transcendental synthesis, a superior and redemptive state or realm is invoked as a destination beyond the apparent terminus. 
The responses of Neohumanists and Posthumanists to the Modernist Order are not exclusive, and authors drawing on one do not exclude the approaches and techniques of another. I have chosen to use the novel term 'Order' rather than subgenre or another term precisely for the reason that individual authors may cross ideological and genre boundaries. For example, it is possible by recasting to take the material of 'Gottlos', and, with relatively minor alterations to dialogue, to make the tale a tragedy not because such a being as Gottlos has come into existence, but because the individual brain chosen for implantation in the cybernetic body of Gottlos was inadequate for its role. This would certainly alter the ideological tone of the story, but not necessarily the system of logic that has created its scenario. It is possible also for a Posthumanist, rewriting Kapp's tale as a cyberpunk story, to make Manton a triumphant figure because he is a man who can alternate between bodies and personae as he desires and is now mostly at home in a state that is neither one thing nor the other. The Snowflake is, indeed, a being very much like Gottlos presented from such a point of view.

Transcendentalism and fascism are both responses to the Neohumanist schema's dependence on a fixed, centralised definition of self and other. The conflict between the transcendentalist and the fascist has, as one of its consequences, provoked the Posthumanist Order's rejection of the Neohumanist centralised schema. The nature and consequences of this rejection will be examined in more detail later, but now it is necessary to examine the means by which transcendentalist Neohumanism approaches the Posthumanist position of establishing a bond with the alien other while still retaining its characteristic identification with humanism.

\section{4}

\section{Bios: Another Green World}

The machine may undo the body, but biology can also be shown overcoming the machine and finding its own fulfillment in the dissolution of the borders of the body and consequently the self. Robert Charles Wilson's novels have had a recurring theme of contact across borders, and Bios (1999) makes the process of infection a metaphor for this while operating fundamentally within the Neohumanist Order. 
Bios is a novel that in many ways pays homage to the tropes of planetary exploration stories - and as it turns out, the myth of Orpheus - and it is this conjunction that presents an interesting deconstruction of the image of the invulnerable explorer in the realm of death.

The initial scenario of the story is relatively familiar. In the twenty-second century, interstellar travel is possible, but extremely expensive. Only one earth-like planet, Isis, has been found and is being explored under the aegis of the oligarchic government of earth with support staff from the independent Martian and Kuiper Belt republics. The similarity between terrestrial and Isian genetic and biochemical systems means that the microbial organisms of Isis are deadly to the humans there, and therefore the orbiting and surface bases are tightly sealed redoubts protected behind multiple layers of prophylactic shielding.

Into this environment, a young woman, Zoe Fisher, is sent by the earth authorities to test an experimental surface excursion suit - and her own artificially enhanced immune system. Initially, she is a lonely and disoriented figure, orphaned with four dead clone sisters, and unbeknownst to her, a rebellious doctor has removed her 'thymostat', an implanted device meant to moderate her emotions. Trains of events converge: she begins to fall in love with a similarly isolated Kuiper technician, Tam Hayes; her paternalistic sponsor and father-figure, Avrion Theophilus, arrives from earth to oversee her trial and her expedition into the forest of Isis coincides with the collapse of the prophylactic systems of the human bases under the assault of the Isian bacteria. Zoe herself is captured by eusocial native creatures called 'diggers'. As the human outposts collapse and die, Tam sets out to rescue her, but he is too late and finds her with her protection breached and dying in a subterranean chamber within the digger colony. In her last seconds of life, she hears the biosphere of the planet itself speaking to her...

Water imagery runs throughout the novel: the first disaster occurs in an underwater research base; Zoe's final expedition takes place during intermittent rain and it involves the crossing of a river that might as well be the Rubicon or the Styx; the chamber of the digger's mound that is her tomb and womb of her rebirth is cool and moist; and Tam's last gift to her is fresh water. Zoe's own names are particularly important: 'Zoe' means 'life', while 'Fisher' suggests that she reaches into water for prizes, but obviously also alludes to the Christian myth of redemptive sacrifice on 
behalf of humanity and the fisherman Saint Peter's role as first Pontiff or bridge between realms and eventual gatekeeper of Heaven.

The partner of water and indicator of the family tie, blood, also appears - and in copious quantities. The primary symptom of Isian infection resembles the attack of Ebola, with massive 'bleedout' and deliquescence. The effect is terrible and disgusting, but as the orphaned characters often say to themselves in this story when reaching out to their companions, 'life touches life' (Bios 203). ' The bios of Isis is reaching out to that of earth; at first it is a destructive power, but at the very end it is able to speak directly to Zoe as a collective entity through the medium of her own infection. In the end, though it appears that she dies (along with everyone else), some element of her consciousness is made immortal within the bios.

Two ideas are important here. Fluidity is represented as vile in the fascist formulation of the warrior cyborg, because deliquescence is literally a fate worse than annihilation: it represents corruption, uncertainty and the erasure of boundaries between self and other. Thus the survival of Zoe's essence within the bios of Isis via the deliquescence of her flesh (while affirming the duality of mind and body) is a direct repudiation of such an alienating structure. The removal of her thymostat at the beginning of the novel underlines this point: with her emotions unchecked, she becomes capable of empathy and discovers her own subjectivity along with the love of others, as opposed to being simply what she was to begin with, one of a series of experimental, genetically engineered clones. Certainly she is unlike the Dalek that would deny all others and even itself.

The second point is that Isis is perceived as a dangerous world - as indeed it is - but it is in fact full of life and possessed of a powerful, integrated biosphere that has a kind of self-consciousness and a link with similar systems on other planets throughout the galaxy. The armouring of the human bases allows the staff to remain human, but since they are not on earth, being human is worse than pointless; it becomes an exercise in denial. Of course, the fact of Zoe's death irreducibly remains: Isis is not transformed into a garden of Eden, but as we see, the fact that her death is explicitly not an end is also critical, drawing the line between the fascist and transcendentalist positions.

\footnotetext{
* Jones has Buonarotti define consciousness as that which encompasses otherness along with the self, and that therefore 'alien' is an untenable classification. See White Queen 227.
} 
In Bios and the later Blind Lake, Wilson appears to directly address Lem's thesis that contact with the alien is impossible due to our inherent anthropomorphism. Wilson's tales are ultimately optimistic for all the doubt and tragedy that they entail. He shows communication as possible only through a transcendently posthuman consciousness, thereby accepting Lem's point, but an interesting divergence with Lem is his use of the edifice. Solaris, Fiasco and The Invincible all make clear use of deceptively invulnerable edifices that are reifications of the anthropocentric consciousness. Wilson tends to be more ambivalent: the edifices of Bios are catastrophically vulnerable, but in his following novel, Blind Lake, the eponymous research institute and the alien 'starfish' are instead alchemical vessels that concentrate the forces of change and discovery, creating syntheses on a higher level out of materials that were separate in their isolated mundane realms. The naming of the alien being as 'The Subject' by the rigorously empirical observers of the Blind Lake institute is ironic, as they adopt a fundamentalist behaviourist line, objectifying it and denying thereby any possibility of comprehending its subjectivity. It is the dialogue within the transcendental space of the Starfish between Marguerite and the Subject that reveals its subjectivity.

\section{5}

\section{Chaotic Bodies: Long Live the New Flesh}

Cyberpunk, as distinct from the romantic pastoralism that was the nostalgic myth of fascism (represented by the declared need for liebensraum, or 'living space' and the unity of 'blood and soil', as Himmler put it) and which saw its ultimate corruption in Kapp's rowen and Stephenson's Africa, is thoroughly urban. Unlike the tame natural countryside, the city is unnatural and untameable. Along with William Burroughs, one of the most incisive examiners of the urban cyborg has been J. G. Ballard.

Ballard's novel Crash (1973) seems to take the prescription of the warrior cyborg at face value, without even the mask of martial order that conceals sexuality and then hacks it. Bodies in Crash achieve sexual fulfillment in the act of car collisions. The car is an intensely gendered (as both male and female) and eroticised object already in Western culture, and it is inevitable in this context then (albeit disturbing - as it is meant to be) that the bodies of men and women damaged in car 
accidents/incidents and then rebuilt through prostheses should themselves be objects of desire, precisely because of the traces of their violation and alteration. Radically, Ballard chooses not to make the body vivisected and rebuilt according to some classical idea of perfection through discrete prostheses that 'realistically' simulate flesh as some form of consolation for loss. Rather, it is the body sculpted by chance that is presented as delightful and compelling in its own right, in the manner of the Surrealist game of Exquisite Corpse, in which body parts or words are arranged randomly, with the resulting images or sentences admired as artistic creations composed by contingency or unconscious intentions that were once hidden but are now flaunted. The automotive Madonna, Gabrielle, is a woman inscribed with the twisted scars and braces resulting from her multiple accidents, and these randomlylocated incisions and extrusions become an ideal assortment of novel genitalia, new locations of entry and extrusion.

Crash reveals a suppressed possibility in the warrior cyborg, and the novel could easily have explicitly depicted tanks at war, as the carnage of willful automotive demolition and war are implicitly identical. In Ballard's eye, the more armoured a being is, the more receptive it must ultimately be; the more it seals itself tight, the more it must surely invite penetration; and the harder the shell, the more compelling the spectacle of its deliquescence.

Ballard's bodies do not seek simple terminus in explosive destruction or annihilation; despite the violence of the car crashes that they enact, they seek the ecstasy of union. They exist in a world in which no armour is adequate and in which the armour itself cuts the flesh it was supposed to protect; indeed, the boundaries between flesh and automotive armour are erased as the two alternate and substitute for each other.

The Strangelovean sexualisation of machinery and its use as a medium for sexuality in Ballard coincides with Burrough's treatment of addiction, sex and the 'soft machine'. Both authors see death as an ultimate goal, though not necessarily as an absolute termination. Burroughs, through his recycling of characters and situations, treats it more as a 'dark' counter or complement to orgasmic fulfillment within a text fragment, or as a fissure or joining line between fragments. Ballard's treatment in Crash is more final, but it is nonetheless repetitive, and not necessarily preordained; voyeurism without termination is likely to be sufficient, with the 
possibility of imminent death ever-present. This adds a thrill of uncertainty to living, the repeated and varying near-death experiences drawing exciting new patterns for continued life, as they are drawn in Gabrielle's scars and prostheses.

Allison de Fren, in her examination of the compulsion to create and to sexualise dolls, 'Technofetishism and the Uncanny Desires of A.S.F.R. (alt.sex.fetish.robots)' (2009), notes two important and linked aspects of fetishism. The first is apparent in an artist such as Hans Bellmer, who deals in depictions of sexualised dolls. He depicts not the girl or woman made into object, but the process of desire itself - and that desire is chaotic and uncontrollable, as evidenced by its continual, compulsive reiteration. He could simply have depicted girls, but he explicitly chose the doll as object; fetishism is the opposite of repression (427). Secondly, 'technofetishists' who idolise the artificial, take as the climactic moment of a fantasy sexual encounter, the revelation of the essentially artificial nature of the beloved object (ibid 412,414). The common similes in technological culture for 'essential', 'intrinsic' and 'natural' thought and behaviour are 'hard wired' and 'programmed', but the whole point of cybernetic devices is that they short-circuit and can be rewired or reprogrammed. Structures and desires that are hard-wired are therefore not immutable, and neither is it the point to 'correct' deviance; rather, they themselves become objects of playful interference and iteration - hacking, in other words. The revelation of artificiality is therefore horrifying on an immediately perceived level, but following a quantum leap to the next it is a delightfully surprising and ecstatic invitation.

What Burroughs and Ballard both acknowledge - and celebrate in their different ways - is that perfect armour is impossible, and perhaps considering the alternatives, undesirable... and what is desirable is compelling. All of the writers who posit warrior cyborgs, with the exception of Lem who seeks to undermine the concept in any case, wrote without awareness of the condition of real cybernetic systems in the present world, which are vulnerable to hacking. The warmecs of 'Gottlos' are a reality today and the Voyo could perhaps be built in the near future (simple versions of it exist now), but they can be infected by malicious software and hacked; the perfect warrior cyborg, then, is ultimately unattainable or untenable.

Fictions of the cyberpunk genre or influenced by it, such as William Gibson's initial 'Sprawl' trilogy (Neuromancer, 1984; Count Zero, 1986 and Mona Lisa 
Overdrive, 1988), Blade Runner, Ghost in the Shell (manga 1991, various other media thereafter), and to some degree the new Battlestar Galactica (2003-9) do not place human subjective being in opposition to machines, but, following the lead of authors such as Burroughs and Ballard, understand that our relationship with technology is ambiguous and contingent. Our relationship with machines that overtly reflect our desires, according to the various authors, is even more ambiguous, the divisions between 'us' and 'them' depicted as disturbingly uncertain and misleading.

Mamoru Oshii's film Ghost in the Shell 2: Innocence (2004, based on Masamune Shirow's manga, Ghost in the Shell) looks at the issue of the 'gynoid', drawing on the artistic precedents of Hans Bellmer's dolls (referenced in the opening title sequence) and Descartes' reputed fetishisation of a doll as a substitute daughter (there are also clear references to E. T. A. Hoffman's Olympia and Villiers de l'Isle Adam's Hadaly). In Ghost in the Shell 2: Innocence, two government investigators Batou, a powerfully augmented man reminiscent of Schwarzenegger's Terminator, but far more articulate and self-conscious, akin to Rutger Hauer's Roy Baty in Blade Runner, and Togusa, his more 'normal' partner - are initially investigating a series of murders committed by gynoid sex-dolls. Frustratingly, all gynoids are engineered to self-destruct should they violate their fundamental prohibitions against killing humans, unfortunately erasing all records in their 'e-brains' of motive or original instigator. All that can be recovered from the memory of one gynoid are her last spoken words: 'Help me.'

The investigation by Batou and Togusa rapidly becomes one that focuses less on crime as defined in legal structures than on the overlap of human and machine, specifically the question of whether the lack of consciousness of a perfect doll is preferable to the subjectivity of a human, and whether a mechanism can take on subjectivity. Throughout the film, several characters debate the desirability of consciousness, and the doll as a class and the automaton in particular are the emblems of the perfect unthinking being. This recalls the fascist ideal of the anti-subjectivity of the warrior cyborg, and certainly there is some overlap, but Oshii does not use the absolutist rhetoric of the proponents or opponents of the warrior cyborg, and neither do many other cyberpunks. Instead, the doll is one kind of entity in an ecosystem of beings, all possessed of differing kinds of consciousness. Batou, the most obvious incarnation of the warrior cyborg, is an intensely subjective individual, and as the 
film's narrative progresses, it is his relationships and inner feelings that become the true focus of the story as exemplifying its fundamental existential questions.

Batou exists among a cast of characters who each exemplify a different approach to the confluence of body, selfhood and mechanism. Superficially, he represents the ideal of such cyborgs as the Daleks and the Terminator: he is melancholic, of intimidating stature and manner, powerful, proficient in combat, virtually invulnerable to physical attack, and something of a loner but backed up by the power of the state. However, his characterisation complicates and undermines the stereotype of the warrior cyborg. He is also highly moral, literate and prone to philosophical introspection. His behaviour is marked by the loyalty and kindness that he shows to animals, such as his pet basset hound, and people - and, significantly, machines too.

Some of the other characters are relatively normal - Togusa has only minimal cybernetic implants, which are apparently on a par in his world with the possession of a smartphone, a Facebook account and other electronic accoutrements in ours - but others are far more radical. Motoko Kusanagi was Batou's former superior and like him had an entirely synthetic body in human (female) form, but, realising that in substituting her original flesh with technological systems, she was effectively state property, she escaped her bind by downloading her 'ghost' into cyberspace to become a purely posthuman, disembodied being. The chief of Batou's department notes that he is showing signs of following her, and as we watch the film, it is clear that he was devoted to her - and still is. He may or may not follow her soon, and Togusa is appointed to keep an eye on him.

Another character, Kim, is bizarre even in this context: he is a hacker so in love with the artificial that he decided to become artificial himself. As a kind of sarcastic aesthetic statement, he has his body reconstructed so that he looks not merely like a puppet, but a puppet depicting a desiccated corpse. He is given persuasive arguments in the film that suggest that he has a clear understanding of the true state of the world of Ghost in the Shell 2: Innocence, and justifies most eloquently the existence of unloving, unsubjective gynoids, but he is also a horrifying, malevolent being and not a little pathetic as well.

The gynoids are a particularly ironic and tragic element. As it is revealed in Batou and Togusa's investigation, the corporation that manufactured them, Locus 
Solus, discovered that they were more attractive to their customers if they were endowed with authentic human consciousness or 'souls' - translated from the Japanese as 'ghosts'. Batou's outrage upon learning this is telling. As he sees it, they are being violated, not by being sexually used (because they are made as sexual objects), but by being treated as human, endowed with consciousness and so made aware of their abuse. It is the consciousness itself that is the violation and the motivation of the initial murders is their desire to initiate the automatic deactivation of their own minds. In their ideal - innocent - state, as idealised by Kim, they are blessed by never having been infected with William Burroughs' word virus. Animals too enjoy this innocence, as Kim explains. This is something that Batou appreciates himself, in his relations with his beloved pet, another innocent being.

The manifestation of the gynoids as an army of unthinking killers on board the Locus Solus factory ship is almost certainly a revenge wish-fulfillment, and Oshii directs their attack to emphasise their uncanny nature by their appearance and action. When they emerge from their assembly or storage cases, they extrude like missiles being readied for launch, and in action their movements are in vertical lines or leaping and whirling, as opposed to the human characters who are bound in the horizontal plane (with the exception of Batou). Their appearance is stereotypically sexually attractive, but their articulation and body language are thoroughly unerotic; their faces are unexpressive, their skins are porcelain white and when they are hit by bullets, they break instead of bleed. Even when the sympathetic Kusanagi comes to Batou's aid by possessing one of them, she imparts little humanity to it: the communications channel that she is using, she says, is too narrow to permit much expression.

It might be said that Kusanagi and other people like her are unusual or extreme cases on account of the artificiality of their bodies that are effectively owned by the corporations and agencies that employ them. However, organic bodies are commodified and have long been treated as property. The gynoid sex toys of Ghost in the Shell 2: Innocence are machines, but they replicate the actual condition of prostitution, enslavement and the trafficking of human beings in our own present and past. William Burroughs of course sees the natural body as a 'soft machine', subject to every form of infection, compulsion and acquisition. There is, then, no escape in bodily form, and therefore it is not at all surprising that transcendence is an attractive myth. Both Kim's and Kusanagi's strategies are understandable in this context. 
The paradigm underlying Ghost in the Shell 2: Innocence is one of bodies as objects, possessed by subjective personae that are imprints that can be forcibly imposed, overlaid and hacked. Bodies themselves are commodities, and while this suggests Cartesian dualism, it offers a more subtle and disturbing interpretation. Descartes, in positing a binarism of mind and body, denoted by the mind a self-aware reasoning capacity in control of a body that is its unconscious and subservient complement. The animals, which Batou clearly loves, and animated dolls, which Kim explicitly admires and to which Batou at least is sympathetically inclined, are explicitly not reasoning beings in the Cartesian sense, though they are not unintelligent or incapable of experience. Indeed, they clearly do have experience and feeling. The joy that Batou feels in the company of his dog is one in which he is not aware of himself and shares the kind of timeless experience that the dog experiences. 'Being', then, is not an abstract quality based on detached reasoning, but can encompass states thoroughly integrated with bodily experience.

The relationship between the self-aware mind and the body, and even the brain (or 'e-brain') that is the platform for the mind, is also a complex and negotiable one. In one action sequence, Batou perceives a threat to himself in a pet food store and wildly opens fire. We perceive the action through his augmented senses, but while his vision is overlaid with technical data and target assessments in the manner of a sophisticated military machine, it is also blurred, awash with static and distortion. As it turns out, Kim has tried to stop his investigation by hacking his e-brain and implanting false perceptions so that he would open fire on innocent bystanders and drag his department into a scandal. Later, when Batou and Togusa seek out Kim in his mansion, they are both trapped in even more sophisticated illusions while he lectures them on his nihilistic philosophy. ${ }^{*}$ In both cases, Kusanagi, whom Batou calls his 'guardian angel', hacks into these illusions and places clues that Batou is able to use in the end to outwit and capture Kim. Kim's eventual role is to be reduced to a passive instrument of Togusa - a kind of glorified modem and software package - in hacking the security systems of the Locus Solus factory ship as he supports Batou in his physical infiltration of the facility.

\footnotetext{
* Some of the tableaus in Kim's mansion are based on those described in Raymond Roussel's novel, Locus Solus.
} 
In the world of Ghost in the Shell 2: Innocence, identity and being are definable by relationships, but perceptions can be manufactured and identity effectively deconstructed and reconstructed. Bodies are commodified, but the bodily experience - that of a dog or a doll - is also in a way blessed, or at least viewed by abstractly reasoning characters as existing in a pre-lapsarian state. In a system that reduces bodies to commodities subject to external agencies and claims of ownership, and in which a reductionist view of identity is assumed, Kusanagi was caught in a bind where she was being directed towards annihilation as more and more of what she identified as 'herself' was stripped away and replaced with artificial parts. She could perhaps have had the option of becoming like Kim, a doll, but as a government agent with a body paid for by the government and memories that were state secrets, there was no way that she could be permitted to retire and become an autonomous being free of their ownership. At the climax and conclusion of the first Ghost in the Shell film, therefore, she contrives to download her consciousness into cyberspace, severing her identity from its physical substrate. This is the ultimate self-hack, bypassing the hardwiring of her manufactured body and her own commodification.

Kusanagi's upload into cyberspace represents a common cyberpunk trope that itself reiterates the old dream of disembodied transcendence, which is the classic Neohumanist solution to the paradoxes and binds of the mundane world. However, placed in context - and the point of the Ghost in the Shell series is that context is everything - her escape is a more complicated affair. For one, she does not disappear entirely, nor does she desire to, and she continues to watch over Batou. Her reply to him when he asks if she is happy is telling: happiness is a nostalgic concept, she says, but she is pleased to be free of the old dilemmas. This is not 'transcendence', but a reformation of the conditions by which she is able to measure herself. She is not exactly bodiless - she can inhabit bodies of her choosing - but diffusely present in the web, able to concentrate or manifest herself at various points. She is effectively a 'stealth' entity. The conflicts Kim articulates, between a reasoning being aware of its mortality and existential loneliness and the desire for the innocence of a doll or an animal whose experience is based in a timeless, selfless present, is a construction the 'hardwiring' or 'programming' - of a world in which bodies and minds exist in a binary system. Kusanagi's existence as an incorporeal entity is based in a world in which such a binary system does not exist, and therefore she is 'pleased' to be free of 
the tensions and dilemmas suffered by Kim. However, she is not alienated from other beings - as is evidenced by the continued mutual bond between her and Batou.

Interviewed for $I G N$, Oshii stated that he wondered what was the basis of identity - the brain, or more specifically memory, perhaps? Certainly he could have taken a reactionary philosophical path: Gottlos-like tanks exist in the first Ghost in the Shell film and the spin-off television series, Ghost in the Shell: Stand Alone Complex, but he did not do so. By the time he completed Ghost in the Shell 2: Innocence, he had decided that essential identity was not a reducible quality, but a phenomenon based both in the body in a general sense and in the relationships that one has (Gilchrist). Physically, Batou is reduced to a brain within a titanium (although naturalistic) body and Kusanagi has no physical form at all, but clearly she and he feel a bond between each other, and in his judgment, this is what makes them authentic.

The last image in the film is of Batou holding his dog, looking back at a doll held by Togusa's daughter. The doll is blue-eyed, mindless and smiling beatifically. Togusa's daughter can be taken as representative of the girls that he and Batou have saved, but the doll, with its blue eyes, can clearly be taken as a representative of the gynoids that Batou has saved too. Innocence exists in several forms.

The Ghost in the Shell series, along with much cyberpunk fiction, represents the deconstruction of the warrior cyborg. The very mechanisms that had been implanted into - and eventually replaced - the bodies of Kusanagi and Batou were intended to make them invulnerable, but in fact had exactly the opposite effect, making them subject not only to hacking, but to commodification as well. The solution, then, is not ever more layers of armour, which serve only to exacerbate the problems the armour is meant to prevent, but to bypass those problems or reformulate the precepts upon which identity is constructed, by seeing identity as a contingent phenomenon, based in intersubjective relations, not strict binarisms. These new relational identifications are explicitly based not on engagements with others like oneself or by an intensified version of the self within an armour that excludes the notself, but by sharing experience with those that are other, be they cybernetic entities, dolls or animals. This is a point that Donna Haraway introduces in her cyborg manifesto and further elaborates in her 'Cyborgs to Companion Species: Reconfiguring Kinship in Technoscience' regarding our relations with animals (2003, 
The Haraway Reader 295-320), a point de Fren notes too among her concluding points (de Fren 434).

Lest one think that the only opposition to the fascist model of the warrior cyborg comes from within the Posthumanist Order, consider Clifford Simak's Cemetery World (1972), which articulates a rehabilitation of the warrior cyborg within the context of a Neohumanist approach to identity. In his scenario, earth is devastated by a 'Final War' that truly seems to have been the war to end war. Thousands of years later, the radiation has declined and earth has been landscaped as a pleasant park-like cemetery to the galaxy, but there are still natives living in the backwoods, based on Simak's own knowledge of Appalachian people, and they have legends of huge, enigmatic 'Raveners' that roam the night. The protagonist, Fletcher, and his companion, Cynthia, are cornered by these Raveners and find that they are in fact two huge cyborg tanks and the last veterans of the opposing sides of the war. One, a Snowflake-like gestalt of five human brains in a mechanical body, styles himself 'Joe' and the other, a similar collective, is 'Ivan.' Unlike Gottlos, their humanity is revived, and has even flourished in their metal shells. His experiences of the devastation wrought by war and the fear that his form inspired in any remnant populations he encountered, as Joe puts it, have 'cured' him of his patriotism (142). Now, he says of himself and Ivan, 'We would be friends of the human race, for we ourselves are human' (ibid 139).

Simak's belief is that an essentially humane human nature will inevitably express itself. Significantly, however, despite their moral reawakening, neither Joe nor Ivan suggest that they might want to be restored to the previous human forms. There are numerous other characters in this novel and many of Simak's other stories and novels that are robots and aliens, but interact with human beings like other human beings or dogs. The core cast of characters in Cemetery World comprises two biological humans accompanied by a diverse group of aliens, incorporeal entities ('shades' or ghosts), an alien, the cyborgs Joe and Ivan, and robots designed for a variety of purposes such as maintainence, artistic composition and even ethnic cleansing. These individuals nonetheless come together to form a quasi-family group or clan, identifying themselves by their belonging to a community according to sense of their own identities rather than their initially designed and programmed intentions. Fletcher's first associate, a robot named Elmer, was initially constructed to service 
war machines such as Joe, but joins with Fletcher to construct machines that create art and defines himself as a human. In fact, he has the legal documents to prove it, which tells us that the culture in which he operates is willing to accommodate its members as human according to criteria other than biological origin (ibid 20).

In repudiating their prior attitudes, Joe and Ivan have by implication rejected the human beings that they were before becoming tanks, because they were people that wanted to be tanks. Instead, he identified with his nominal enemy, Ivan, and the two of them, along with Elmer and other machines and beings, have become individuals that are part of a community that is defined as human. This was the fundamental breakthrough necessary to redeem the war machine in this Neohumanist context.

The warrior cyborg, then, is an image that has been constructed, critiqued and reformed under different Orders and according to different ideologies. Gottlos, the Voyo, Joe and Ivan, Batou and the various AI and cyborg tanks that appear throughout the Ghost in the Shell franchise can be formed by their cultural context as expressions of fascism. However, as has been shown, in the context of the Neohumanist and Posthumanist Orders they can be characterised as benign and members of a human or posthuman community according to the specific processes of those Orders. Certainly the Posthumanist premise that the interconnection of technology makes armour an obsolete and untenable concept can facilitate this communal identification (albeit with the risks of infection and hacking), but we can place Simak's strategy - which emphasises the humane aspect of humanism - in parallel with this. Simak suggests the creation of communal spatiality similar to that represented by the starfish in Blind Lake: in such a case, 'humanity' is defined not by explicitly anthropomorphic characteristics, but by the capacity for empathy and sociality. Thus, when we use the term 'Neohumanism', we must see that this is a fundamental quality that distinguishes it from xenophobic fascism.

The genealogy of the cyborg has had diverse posibilities all along. Burroughs' term, 'soft machine' denoted not only the body, but the society that sculpts it, penetrates it and may eat it - which is something that the fascists understood too. It is necessary now, following an examination of the concept of the body, to look at the social aspect of the soft machine. In many ways, this is in fact its 'truer' nature, or at 
least that manifestation that traces its lineage from Butler through Wiener, Clynes and Kline and Haraway. 


\section{9}

\section{Architectonics of Identity: The Social Body}

Superficially, the warrior cyborg articulates a desire for absolute containment and autonomy, but inevitably, such a being is embedded in a social and cultural matrix that compels that desire. The Posthumanist response to this highlighted the inevitable - on its terms - bondage of the individual to their cultural context and the commodification of the cyborg body. The individual, according to the Posthumanist Order, can never be truly autonomous; it always exists at the intersection of biology, technology and culture. It may be contained partly within the body but it is also distributed among the networks of culture because, in being influenced by them, it is entangled with them by systems of feedback - and these forces influence each other as well.

A definition of the self that places it within the biological-technologicalcultural matrix sees the individual as either resisting these forces or the product of them, or both. In any case, the singular armoured body of the warrior cyborg cannot exist in perpetual isolation and it becomes defined not by its centre, but by its engagement with other entities that may or may not represent a structured collective. The Posthumanist cyborg is willfully engaged with the connections and flows of culture, not insulated from culture, but intimately integrated with it. We have therefore two basic archetypes: the armoured cyborg and the networked cyborg. How these two archetypes are generated and how they engage with society is again representative of the Order to which they belong, and in this chapter, the range of Orders and their consequences in their representations of the cyborg will be investigated according to their relations with collectives.

All societies are collectives to some degree, but how the individual is constructed within a society and their relations with the collective differ according not only to ideology, but also according to Order. We can call these collectives 'hives' or 'superorganisms' in order to emphasise their status as integrated beings, but even that characterisation permits a wide range of variation in terms of internal structure, 
dynamics and the kinds of idiosyncrasy or conformity it enforces upon its members or components. In some cases, the visible characteristics of individuality are suppressed, so that individuals appear identical and act entirely in the service of a collective identity - fascist societies such as that of the Daleks are of this kind. In other cases, individual differences are manifested and even cherished, but identity is layered or polysemous, so that at one level individual desires are both celebrated and served by society, while at others, individuality conceived as a singular essential quality may be absent, but variation is strongly present and dynamically enacted.

In order to gain a clear understanding of the range of concepts of society and the relations it has with the individual - and how the individual might be defined - it is necessary to begin with a treatment of social relations that see the individual as being possessed of fixed, essential qualities. In such a case, the forces that would influence it are almost inevitably seen as antagonistic and 'dehumanising'. However, as the Orders arise to address what appear to be insoluble dilemmas, Neohumanism as it evolved has been able to create structural systems that instead foster 'essential humanity', while the Posthumanist Order has actively embraced the potential for combination of social, biological and technological forces to radically and continually reform the individual.

\section{1}

\section{The Softening Machine: Castration by Prosthesis}

The effects of cyborgisation as a social imperative were depicted as a dystopian reality in Bernard Wolfe's Limbo (1952). In Wolfe's scenario, it is certain that there is a fixed human nature, tragically complicated by the fact that sexuality and aggression are inextricably tied together. In order to supress aggression, a collectivist and pacifying social creed of 'Immob' (the name is an abbreviation of 'Immobility' and echoes George Orwell's 'Insoc') has emerged after a devastating nuclear war, which has gone so far as to identify mobility itself as evil. Its adherents - 'vol-amps' - therefore undergo voluntary amputation and make use of prosthetic limbs when they must, but aspire to a perpetual state of immobility that is indistinguishable from that of a newborn infant and is therefore one of complete innocence and gentleness. The novel's title appears to refer to the ideologically compelled amputation of limbs 
which is the focus of the story, but is also a clever pun indicating the passive, changeless state of the unbaptised in Dante's Inferno.

Limbo is a very witty novel, full of ironies - not least of which is the discovery by the neurosurgeon protagonist, Doctor Martine, that his own old notebooks have been appropriated and annotated to turn his sarcastic jokes and hyperbole into the deadly serious gospel of Immob (presented in dedicated chapters of the novel). Norbert Wiener receives attention, although cybernetics is somewhat misunderstood by Wolfe as a deterministic system and is presented as the underlying ideology for his dystopia and his own prediction that prostheses will be superior in performance to natural limbs (125). Another irony is that a creed designed to prevent war leads to a literal arms race (another pun made real) and nations fight over access to raw materials with which to manufacture better prostheses.

It is the representation of cyborgisation as a technologisation of sexual power that is the main intention of the novel. Wolfe's presentation of gender relations and sexuality in this context is significant and deliberate. The male-supremacist ideology that he presents is not necessary for an examination of cyborgisation and passivity per $s e$, but the various twists and turns of the plot continually highlight it in a vindicating (and vindictive) manner, suggesting therefore that active and passive roles are both tied together and instrinsically gendered.

Immob, according to Wolfe, is a feminine plot to control men and to control sex. Martine has observed that the centres for aggression and love in the brain are inseparable and the former cannot be suppressed without also destroying the latter. Because Immob is largely promulgated and enforced by women and inflicted upon men, they commit the double crime of both doing harm in at least equal portion to any good they intend and upsetting the natural order of things in which man is active and woman passive. At one point, imprisoning a woman and raping her - an assertion of 'equal rights', apparently - Martine justifies his action to himself with telling himself that 'Rape is a pretty difficult business without a bit of ambivalence in the woman' (ibid 192). Immob, he declares, is an inversion of proper sexual roles; it is effectively castration (ibid 206), and as war resurges, he finds that this is indeed the literal end of the ideology (ibid 305).

Wolfe is quite explicit in seeing pacification as a malign and specifically feminine force, a view entirely congruent with those of Theweleit's examples. Immob and its ramifications represent an ironic counterpoint to the warrior cyborg 
even it if is not an exact reflection because Limbo exists as a novel on its own terms, but both acknowledge the existence of a basic social and sexual dynamic (as Kapp and Stephenson abhor the warrior cyborg but acknowledge the power of the system that produces it). The difference lies solely in that Wolfe presents prostheses as sham substitutes for authentic limbs forced upon the natural body by social and technological forces while the fascist dreaming of being a warrior cyborg sees their prostheses as what their body should properly be as an expression of their core will. Both see prostheses as structures imposed upon the body - negatively in the case of Wolfe and positively in the case of the fascist - by social forces dressed as necessity. Both share deep sexual anxieties centred on women: sex, if it is acknowledged and performed, is performed as a biological act representing a social role and it must always be penetration and domination of the female other by the male. Immob is evil for Wolfe because it inverts this dynamic.

Glenn Tropile, happy in his tank like a foetus and linked into the Snowflake, would no doubt loathe the isolation of Wolfe's vol-amps, but it is his connectivity and gestalt with his fellows that turns his abject state to one of triumph and continually realised potential. The cyborg lovers Batou and Kusanagi, both of whom are arguably extreme expressions of Immob, ${ }^{*}$ would no doubt vehemently disagree with Wolfe too.

\section{2}

\section{We, Dalek: The Superorganism}

Like Clifford Simak, Wolfe believes that there is an essential human nature that will, in at least a few cases, manifest itself despite the strictures imposed upon the self and body by social and technological forces. Unlike Simak, he has a very jaundiced view of human nature. The existence of human nature, and its definition as something inevitably aggressive, is not of course unique to Wolfe and it is epitomised in the archetype of the warrior cyborg. One might think that the warrior cyborg is inevitably a solitary being, but this is not the case at all. The Daleks, themselves a representation of fascism, provide an example of the warrior cyborg as a component of a warrior culture.

\footnotetext{
${ }^{*}$ Kusanagi is so perfect that she entirely lacks a body and is even without a location.
} 
Theweleit's Freikorps men and Mishima in his exegesis are instances where a true group identity has been forged and in which individual subjectivity and the concept of internal space has been subsumed into the interiority of the collective armoured group. They are, in biological terms, superorganisms: that is, one may see individual bodies, but they are no more individual than the cells that make up a single body and no more capable of autonomous existence. The term 'superorganism' has often been applied to eusocial insects (ants, bees, termites and so on) and other communities (naked mole rats) and while loosely defined and contentious, it can be applied to what is, in the words of eminent myrmecologist Edward O Wilson, 'a society [that has] become so nearly perfect that it is no longer a society' (383). A superorganism is not necessarily one continuous corporeal body in which individual entities have become entirely subsumed, thought it might as well be. The apparently individual bodies of its components, such as those of worker bees, are not in fact separate individuals at all, but simply the equivalents of the fingers and toes of the hive itself. Even the queen is relatively unimportant compared to the collective gestalt, being really only a kind of chemical switchboard and a set of reproductive organs. The equivalents of single worker bees may be intelligent and perceptive, but reflective consciousness is redundant. The annihilation of the self discussed in the preceding chapter is therefore not only a consequence of the emergence of the armoured warrior cyborg, but facilitates the construction of a superorganism by causing the subjective 'I' to be entirely absorbed within the collective identity.

Despite its impenetrable armour and appearance of autonomy, the lone Dalek encountered by the Doctor and Rose in the episode of Doctor Who discussed previously cannot exist without the matrix of Dalek society. If it were to live, it would no longer be a Dalek, and having no ability to be anything but a Dalek, its continued existence is only a brief paradox that is resolved by its self-extermination which will then reaffirm its absolute fidelity to the Dalek ethos and community. This is, of course, insane by humanist standards, but it is the logical end of a collective that enforces its integrity by outwardly-focussed destructiveness and inwardly-focussed repression. It is repression that is the key to Dalek society and identity.

Because Wolfe sees sexuality and aggression as being inseparably tied together at the neurological level, the nominally pacifist culture of Immob is infantilising and anti-sexual - or anti-masculine, which amounts to the same thing to Wolfe. However, to assume that there is an essential human nature does not mean 
that one has to have only one particular sense of what that nature is. The question of sexuality regarding Daleks may seem incongruous, because the misogyny of warrior cyborgs seems to be overtly anti-sexual too, but while Immob is an attempt to suppress sexuality, Theweleit makes it clear that fascism represses sexuality, and that is quite another thing. Suppression removes or destroys, but repression encourages its re-emergence in another form. In Theweleit's analysis, what is rigidly denied in fascist society is therefore ever present as a source of dread and fear. As such, it is fitted into the self-perpetuating dynamic of repression and transgression: a thing is forbidden, but because it is forbidden, it is a latent possibility and therefore present also as a perpetual source of anxiety. Theweleit specifically considers a compulsive parody of homoeroticism in totalitarian homosocial communities and he is at pains to distinguish this from actual homosexuality $(2: 339)$. The repressed individual is plagued by guilt over actual or imagined acts and becomes obsessed with appearing to conform - which suits the regime perfectly. It is in the interest of the regime to covertly promote deviancy so that its subjects will be all the more motivated by guilt, which will be externalised as mutual surveillance and aggression. William S. Burroughs has also often looked at the use of sexual repression coupled with anxiety over revelation of deviancy and sees it as an effective means of assuring neurotic conformity in totalitarian regimes. ${ }^{*}$ One might speculate about Dalek sexuality or its practical elimination in this context (they are, after all, descended from humanoid beings), but as Doctor Who is a family show, it is restricted by broadcasting standards and thus has never obviously expanded on such a matter. De facto, we can conclude that sexuality is not an obvious part of what the Dalek is as a conceptual being; it is instead completely sublimated into violence. With their metal casing, they are perhaps the most perfectly closeted creatures. The warrior cyborg in its initial stages of evolution might argue that it is expressing via technology what its nature requires but, in fact, in its self-annihilation, it facilitates repression so as to make itself the perfect component of an aggressive superorganism.

Fascism, at least as far as it was practiced by the Nazis and represented fictionally with the Daleks is dependent on technology, but it is not Modernist if that term is to have any specific meaning. It shares many of the characteristics of Modernism, such as standardisation, but in a Modernist context, abstract standards of

\footnotetext{
* This is an abiding theme in William S. Burroughs' writing.
} 
measurement exist to permit comparison and categorisation of different entities within a common intellectual system. Homogenisation may be an unconscious or covert aim of Modernist systems, but in a fascist context, homogenisation is overt, absolutist and repressive, so that ultimately the superorganism acknowledges no categories at all, saving 'us' (that is, itself) and 'them' (or 'Dalek' and 'ashes').

Culture and technology can also be seen as negative forces corrupting humanity, and not by the suppression of Immob or the repression of the Daleks and fascists, but by a more insidious seductive process, promising to cater for every need. E. M. Forster's Machine provides an example of this form of corruption.

\section{3}

\section{Sterile \& Fertile Hives}

In 'The Machine Stops', E. M. Forster presents a forceful critique of Modernist technocracy. The eponymous Machine, intended to serve every physical need, insulates people completely from the natural environment and from each other: empathy and sexuality seem to have become entirely absent from the world of the Machine even in potential form. While a biographer can point to Forster's own repressed homosexuality as being a personal idiosyncracy that caused him to skirt the issue of sexuality altogether in this story (though not in others), that in itself is significant: Forster existed in a particular cultural moment where mechanical systems and the mechanistic institutions that existed in parallel with them seemed about to be able to provide for all needs. Such mechanistic systems could mediate and govern all intercourse, but could not conceive of or accommodate anything that did not conform to their own narrow criteria. Thus, the all-encompassing system of the Machine, which is utterly servile, is also the master and the mould of a degenerate, abhuman race that, once it fails, is unable to survive in the open air. The Machine, following a Cellarian evolutionary path, had supplanted the essential dynamic qualities of humanity and caused them to atrophy, rather than an Ebrian path in which it added to and extended the human body, even if that appeared to be its initial purpose.

Forster's Machine is a failed hive, a kind of soulless cyborg civilisation that has become a bed of Procrustes for a degenerating humanity. Its depiction as such is motivated by a deeply-felt humanism (without the 'Neo') reacting to Modernism. 
However, there have been a number of authors, who, while they may not be classified as Posthumanists, have at least experimented with non-anthropomorphic models for society that deliberately blur the lines between biology and culture, suggesting that 'human nature' would in some way be well-suited after all to dwelling within architectonic constructions that are really much better versions of the Machine. There have been in literature, fantastic and 'mainstream', overt and subtle, innumerable examples of human communities depicted as hives, from W. H. Hudson's The Crystal Age (1887), through Frank Herbert's Hellstrom's Hive (1973), Stephen Baxter's Coalescent (2003) and A. S. Byatt's country house in 'Morpho Eugenia' (1992, adapted for film as Angels and Insects in 1995). Hives are not populated by stupefied functionaries except in the most shallow depictions of the type; instead, what is most fascinating about a hive to most writers is the fact that independent agents will actively harmonise themselves with it. In societies modelled on hives, writers have thought about how this confluence of identity might be enabled through the integration rather than the suppression of conscious, individual wills.

Edward Hyams' 1975 novel, Morrow's Ants, presents an interesting evolution of the practice of philanthropist capitalists such as Robert Owen and Titus Salt in its depiction of the foundation of an ideal city built along the lines of a hive. The story does not explicitly refer to Paolo Soleri's work, but nonetheless provides an interesting critique of the reasoning that would support such an edifice and the interface between individual and community that would develop within it. The eponymous 'hero' is Graham Morrow, a billionaire industrialist fascinated by myrmecology. His name of course recalls Wells' Doctor Moreau, but also denotes the future, rendering the title significantly ambiguous.

Morrow's Ants is not so much a narrative, though it is filled with events and interaction; fundamentally it is a didactic dialogue. Morrow is an obsessive notetaker, dictating his findings on ants and their applicability to human society and his great project is an arcology, Saxonsea, in which Morrow, like a modern Owen, is trying to put into practice his vision of the industrial state, modelled on an ant colony (it may also be partly inspired by the New Towns such as Milton Keynes built in Britain after the Second World War). It will be built largely underground, with artificially-lit fields providing food for a population of a hundred and fifty thousand, making it a self-contained entity. In one of Morrow's monologues, Saxonsea is described as the perfect and final synthesis: 
The termitory and the hive are the ultimate expression of the Hegelian State and the international corporation combined [...] In his critique of Hegel Feuerbach says - The being is subject, thought an attribute, the human being the very condition of the existence of personality. I will bring the Hive into existence; it becomes a being, 'personality' will follow, because manifold being is at least as much 'subject' as individual being. Feuerbach again: It is not the idea of state which, realizing itself in the state, creates and directs society, but society which determines the state. Laws and public organs have their roots in the material conditions of life. Good; there is a dialectic of the Hive: why, given time, should not the laws become implicit, then immanent, like 'Love' and 'Justice'? And so the 'organs' wither for want of need (39. Italics in original).

Morrow explains to his lover, Julia, that Saxonsea will be an individual in more than a metaphorical sense.

The ants had overcome the well-known limits of neurophysiology by contributing all their minds to the supermind. He did his best to explain, from the work of von Neumann and above all of the work of zoo-psychologist Jean Meyer, and by drawing analogues from cybernetics, just how this could be, and almost certainly is, done, and just why, as von Neuman had pointed out, the probability of coordinated working in any 'majority organ' system increases necessarily (it is a matter of mathematics) with the number of elements it contains. Morrow said, 'In our brains the elements are neurons; in an ants' nest, which is among other things a brain, the elements are individual ants (ibid 78. Italics in original).

\footnotetext{
* As these passages show, Morrow's Ants requires the reader to be familiar with the names continually being dropped by Morrow and others. In this 'difficulty', it is like any science fiction story; the novel is a means by which nominally non-fictional ideas are engaged with each other. In this case, it also emphasises Morrow's view that individuals, ultimately, are essentially circuits.
} 
Altering the context of behaviour alters the significance of that behaviour, and therefore narrative. Morrow expresses offhandedly a desire to burn the extensive collection of paintings acquired by his father because the past can have no hold on the future and, as for drama, he feels that both heroes and villains are redundant in the new state. Those whose lives have been given meaning in a context of a literary culture that values the expression of individualism and psychological depth and savours tragedy will be merely absurd in the collectivist culture of Saxonsea:

'I have always been very doubtful whether the concept of tragedy ever was more than the primitive instinct of self preservation essential to the survival of the species, evolving with consciousness, in the Greeks, into self-importance. Homer's heroes and villains are touching only because they are children at play; otherwise they are simply ridiculous, almost as ridiculous as Virgil's' (ibid 126).

Tragedy, to Morrow, is a meaningless absurdity. Even the prospect of his own death (by assassination, as it happens) does not trouble him and an associate, Foscari, tells Julia that his death will have no effect whatsoever on the progress of Saxonsea or the other hives being built by his consortium.

'We shall miss his quick brilliance. But something else will take its place. On the scale we work on now, we are all... So very dispensible. It was that truth, of course, perhaps you realize it, but few do, that all the great leaders of our time, from Mussolini to Mao suppressed with blood and iron. How can they bear the truth? There is a momentum, it carries them as a high tide carries a dead body on the crest of a wave. That is the measure of their success' (ibid 186).

To Morrow, a person comes into being only in their interactions with others. It follows then that the community creates individuals, even though it is itself built out of individuals. The conversation between Foscari and Julia further demonstrates the hive's power of contingency and this is true even at a personal level: Morrow was her lover, but with him gone, it is implied that Foscari will become his substitute.

Logically, in the Hive, because there are no egos, there is no tragedy: 
'An accident victim regrets a lost arm or leg; he does not mourn it' (ibid 127).

Ernst Salomon, in Die Kadetten (1933), gives some insight into the identification of the individual with the regiment. On his ecstatic description of the formation and march of a brigade in terms of statistics - this many thousand unindividuated legs, that many thousand communally-owned fists and rifles and so forth - the historian Klaus Theweleit notes:

The soldier's limbs are described as if severed from their bodies; they are fused together to form new totalities. The leg of the individual has a closer functional connection to the leg of his neighbor than to his own torso. In the machine, then, new body-totalities are formed: bodies no longer identical with the bodies of individual beings (2:154).

This is a superorganism assembled, Dalek-like, via absolutist collectivist ideology.

The human superorganism is no metaphysical abstraction or metaphor (as Hobbes' Leviathan might be considered), it is a real, visceral thing. It is in fact more real by virtue of its effective immortality than any single body that must always die. Morrow is explicitly not indispensable, and in the end he is perhaps not even particularly inspiring, because the architectonic structure of Saxonsea is such that qualities like heroism, genius and charisma are redundant. This is in keeping with a fundamentally Modernist conception that grants empirical procedures authority precisely because they are non-individual, non-idiosyncratic and 'objective', which in itself is also an indicator of authority within the framework of Modernism.

Lest we think that the hive is either a fascist or a Modernist archetype, it is worth considering the ubiquity of the hive as a microcosm or model of human society, whatever form it may take. The faults that Forster identifies in the Machine are the faults that Neohumanists ascribe to Modernism, but they are not necessarily the faults of all hives, and the archetype remains popular as a social model because, as the social historian Bee Wilson [sic!] put it, '[s]tudying bees is a way of studying ourselves' (4). It is, in fact, a supremely flexible model, which can be adapted to suit almost any Ideology and Order. Inevitably, due to the persistence of the hive as an archetype and the Neohumanist tendency to seek synthesis, hive societies have been 
conceived that do not suppress essential human nature as construed by Neohumanists, but which serve to facilitate its fullest expression

\section{4}

\section{The Hive, the Hero \& Ideal Love}

A hero is someone who is celebrated by their society and therefore exemplifies the ideal qualities of its citizens. When a heroic narrative is presented, the nature of the society that requires a hero is also implicitly revealed. Despite The Night Land's being written in the first person, William Hope Hodgson's protagonist displays little in the way of psychological depth or uniqueness (and indeed all but a couple of characters remain nameless). This is not to say that he is a particularly dull-witted or shallow individual, but that he fully accepts that in order to be a hero, he must show exemplary and not idiosyncratic characteristics. Unique and personal motivation is an unnecessary complication in a society that is overwhelmingly cemented by oral traditions rather than the book: reading is a private act, but storytelling is by its nature a communal act; even the love between two individuals is constructed and justified according to the patterns of their shared culture. All societies have complicated webs of allegiance, many of which are contradictory and compromised by past errors and betrayals. An active individual in such a context is supposed to be aware of these, redeem the failures of ancestors and relatives and meet present obligations. Beyond that, as a great hero, he (it is almost always 'he') seeks out new challenges for the benefit of others, thereby obligating them to come to the aid of their own community in times of trouble. This is how hives create and use heroes in the Neohumanist Order.

If we are to seek a precedent and model for ' $X$ ', then we could consider Beowulf and his role in the epic that bears his name, and the construction of that narrative. The text of Beowulf is filled with intricate descriptions of allegiances and objects because a great and good man is defined in Beowulf's society as one who honours his allegiances by family and oath, meets deadly opposition without hesitation, commands respect and dispenses boons fairly. With collective memory based on oral traditions describing deeds, obligations and lineage, it is the things that are held in common or as tokens to be displayed among the populace that are 
celebrated and described as vividly as words can make them. The Night Land is written in a style that looks cumbersome on the page, but is intended to read as if it were spoken, with the multiple repetitions and grandiloquent declarations that often characterise ceremonial or formal spoken language.

As a member of a community and as a character in a novel written as if it were to be read aloud, X may be able to actually ask whether it is better to be or not to be, but he will always be led to what he must $d o$ in order to be. Hamlet himself, in pondering such a question, was led to eventually acknowledge his family and moral obligations as an imperative to exist and act accordingly against his personal desire for quietus. If we consider Attebery's definition of the actant, we can see that $\mathrm{X}$ is someone who realises his identity by discerning his archetype and achieves authentic being not by sceptically questioning the relevance of something that he perceives to be something other than himself, but by realising that he cannot exemplify the qualities of that archetype until he acts in the real world according to its ideal requirements.

The language of Beowulf and The Night Land is, in Yukio Mishima's terminology, the language of the group:

There is of course such a thing as the language of the group, but it is in no sense a self-sufficient language. A speech, a slogan, and the words of a play all depend on the physical presence of the public speaker, the campaigner, the actor. Whether it is written down on paper or shouted aloud, the language of the group resolves itself ultimately into physical expression. It is not a language for transmitting private messages from the solitude of one closed room to the solitude of another distant, closed room. The group is a concept of uncommunicable shared suffering, a concept that ultimately rejects the agency of words (84).

$\mathrm{X}$ is bound, though he does not know it consciously, to close the question asked by his earlier incarnation, which is, can he find fulfilment in love? The answer, in Hodgson's cosmology, is 'yes', and therefore X must do so, not only for his own satisfaction in his current existence, but at the end of history itself. The fact that his personal desires are completely coincident with the teleology of history is his affirmation as an authentic rather than deviant individual. 
The hero, in the fullest sense, is one who is adulated as an exemplar by their community and is not an isolated agent; they are therefore the product of a superorganism that has a sense of single, essential shared identity and metanarrative. Presented in such terms, the Last Redoubt is clearly a benign, utopian hive. Unlike the Dalek superorganism, the Last Redoubt fosters subjectivity and unlike Saxonsea, it fosters and even needs heroism. This need for private subjectivity and public heroism is essential to its character, and characteristic of the Neohumanist synthesis. The key to this synthesis is Hodgson's concept of ideal love.

In heroic narratives such as Hodgson's, romantic love is the microcosmic expression of the macrocosmic bond of communal loyalty, and often lovers become jealous of the integrity their companion feels with their comrades because they know that the bond is basically made of the same stuff. Sexual discourse is separated by a discrete veil from romantic and communal discourse, but that veil is permeable and in many cases it is reduced to a mere fig leaf or stripped away entirely. Both overt descriptions and all-too-clearly repressive concealments of sexuality in the context of sociality can reveal interesting features of the architectonics and dynamics of a society.

Collectives that are not absolutist and homogenising are characterised by a polysemous construction of identity, and the Neohumanist society of the Last Redoubt presents an example of this kind. On one level, $\mathrm{X}$ and his beloved, Naani, are individuals desiring each other exclusively; this is ideal love in the mundane realm, but their love has significance in higher realms of moral allegory, where it is manifested differently. As two people, they share intimacies that they do not share with others, but as celebrities in their society, their adventure and their marriage are exemplary and as citizens their natures are ideally connected with but different from their subjectivity as individuals or as a private couple.

As a champion of his society, Hodgson's X thinks about things and articulates his thoughts, but he is concerned only with matching those thoughts with what is 'proper' because it is thereby truthful and what is proper and truthful is determined by his own collectivist society. Anything that is outside is ultimately inarticulable, alien and evil; even abroad in the Night Land, he is still within the shell of the Last Redoubt and his aim is to bring his beloved, Naani, into that space with him, the 'House of Joy', to ensure that she is safely of his own kind. 
Hodgson's characterisation of gender relations is, in post World War Two terms, deeply sexist (though at least he takes a far more positive view of women than Theweleit's examples!). The feminine is certainly an object of desire, and Naani represents unruly, childish femininity that is cultured through commands and physical discipline. That said, she is not without resources: she is aristocratic (a positive in Hodgson's formulation) in being the daughter of the Lesser Redoubt's Master Monstruwacan, she is able to survive for some time alone in the Night Land after its fall and she possesses the same telepathic talent as X, which brought the two of them into contact in the first place. Like him, she recalls past lives, and when not being a child lost in the present, she is able to reflect upon these and together they are able to construct a comprehension of the history of the world as well as a 'House of Joy.' They achieve their fulfilment by enduring the trial of the Night Land, discovering the deep identity of their past incarnations and by returning to the community of the Last Redoubt. While born in separate locations in a world in which place is all-important, the lives of the two are braided from before birth and their physical coupling is foreordained and is performed as a reflection of the greater structures and conjunctions of their lives.

The Last Redoubt represents in Hodgson's formulation not merely a literal fortification, but a cosmic diagram and as such, an example of architecture that both reveals and facilitates the 'proper, natural' structure of the microcosm that it contains (as Christian Norberg-Shulz described it). As has been mentioned before, as a pyramid oriented to the cardinal points and surrounded by a protective ring of force and tapping a vital, health-giving earth current that is deadly to its enemies, the Last Redoubt is no unnatural imposition on humanity, but rather the final and perfect representation of both its omphalos and transcendent cosmological form. Its form and $X$ 's introductory narration in which he describes the Redoubt and the surrounding Night Land in the manner of a lookout in a crow's nest, establish its status as the perfectly fitted abode at the centre of a sane realm in an insane world.

The Last Redoubt itself is a machine that can focus the earth current to resurrect Naani, who has been killed by its malign equivalent, the 'House of Silence' using some unnamed lethal energy, permitting her to live within its bounds as the ideal mate of $\mathrm{X}$. The relationship of the two is therefore consummated not merely by their love, but by the architecture itself, and it is witnessed by the assembled population - not only those who can be physically assembled in the Redoubt's vast 
underground cemetery, but by the millions of others watching through its internal news service. Critics often note that the Last Redoubt is the first arcology in science fiction, and is surrounded by the first version of a force field of the kind that was to become common in the genre, but few note that The Night Land also depicts for the first time a community bound by high-tech media reporting in real time. X's journey, as long as he was within direct range of the Redoubt's sensors, was a mass spectacle, as was his return and his marriage, and it was all broadcast live.

Within science fiction, the implied corollary of Clarke's Third Law, 'any sufficiently advanced technology is indistinguishable from magic' (first presented in 1967, see‘Technology and the Future' Report on Planet Three and Other Speculations 147), is that technology must inevitably become a superior substitute for magic. Hodgson, however sees no essential difference between the 'magical' and the 'technological'. He makes much of the spiritual forces at play in his story, be they malign or benign, petty or cosmic, and he gives a place for humanity in their matrix, even if it cannot be mapped as accurately as the physical geography of the Night Land as seen from the Redoubt's apex. Even though they are not comprehensively understood, technology engages with, counters and facilitates them. The initial telepathic contact between $\mathrm{X}$ and Naani is spiritual in essence, but mediated and enhanced by technological means and this mingling of technological and spiritual structures and dynamics permeates the novel and its settings. The mass media that binds the community of the Last Redoubt together as one social body and binds the lovers' story as spectacle into its shared culture is not a mere analogue of a bond that exists on some invisible plane, the two are the same. The 'House of Joy' that X speaks of to describe the form of his relationship with Naani is not merely a kind of pun on the surrounding abode, it is his description of the complete - or now, in his eyes, completed - edifice.

If we compare the Machine and the Last Redoubt, the two seem at once similar and utterly different. The Machine is presented as a critique of the perceived flaws of Modernism: it is a high-tech edifice that caters to all physical human needs, but ultimately destroys the soul of humanity by neglecting the possibility of there being anything other than physical needs. The Neohumanist Last Redoubt on the other hand, while still standing as a magnificent technological edifice, exists harmoniously with both the human body and the human soul in both the individual and the collective manifestations. Because it was conceived by Hodgson according to 
a polysemous epistemology, not only does it stand as a physical entity, it also has within it and directly connected to it, the House of Joy, as X and Naani's corporeal, private and ideal personae exist simultaneously on multiple planes.

William Hope Hodgson's Neohumanist stance does not simply present the machine, the tool or the architectural edifice as something merely useful, but establishes their roles as complements to and enablers of the essential human being and will. It is a form of cyborgisation in the broader sense of the word, but it is carefully delineated, with every part in its place determined by a sense of transcendent cosmic order. The fascist pathology embraces the more intimate and invasive cyborgisation of the body because the machine is everything the human body 'should' be, while outraged reactions to the prospect of the hypermasculine warrior cyborg such as Kapp's still supposed that that was the mode of cyborgisation that would inevitably come to pass or at least haunt humanity as a latent possibility. Extreme reactions to external forces, depicting architecture not as facilitator of a healthy and proper human existence but as a bed of Procrustes, can be seen as a geometrically inverted twin of fascism, and equally pathological, but nonetheless, the concept of an external mechanism that invades and alters the body and identity leads itself to a Posthumanist inversion, as we will see.

\section{5}

\section{Borg(es) Rewritten}

Where a community has been presented as malign, insofar as it is a community it can be recast as positive and Star Trek's Borg are a case in point. The Borg, a cyborg superorganism clearly inspired by Doctor Who's Cybermen, are without any sense of individual identity and were originally conceived as the evil opposite of the supposedly indvidualistic, pluralistic Federation (or of the Federation as it chose to see itself): totalitarian, homogenous, collectivist, relentlessly expansive, but as is so often the case, this negative projection can be read too easily as a revelation of the latent nature of the Federation itself. What is more interesting (at least in this context) is yet another inversion, the appropriation and recasting of the Borg by fans, and the response by writers to their attention. 
As antagonists, the Borg were a hit with fans after their first appearance in the Star Trek: The Next Generation episode 'Q Who?' (1989), and as was the case with the Klingons, last series' villain became this year's most interesting crew member when the character of Seven of Nine (sometimes sarcastically referred to as 'Barbie of Borg') was introduced to Star Trek: Voyager in the episode 'Scorpion: Part 2' in 1997 and triggered an immediate boost to ratings. Star Trek's creeping humanisation of the other is at one level gratifying in its receptiveness, but disturbing in that it insists on forcing the other into an anthropomorphic mold. Fans however soon began to explore the more provocative implications of the Borg and one of the most interesting avenues that they followed was the one that ran into the areas of identity, sexuality and society.

Superficially, the Borg are analogous to the vol-amps of Wolfe's Limbo; they have also been forced by the strictures of the society in which they are embedded to surrender essential parts of themselves. None of their changes have been measured as gains, all are losses and as a result they are dehumanised. As a sign of their enforced degeneration, solitary Borg are unable to feed themselves and must retreat to alcoves regularly to sleep and receive power and nutrition. In this state, they are not only subsumed within the collective consciousness of their race, but are literally, physically embedded within their technological infra/superstructure as well. The implied norm for a Borg is not as a roving entity inhabiting a space as Starfleet's crewmembers inhabit their spacecraft, but as an extrusion of their technostructure. They might well be Wolfe's swaddled castrati or the logical evolutionary end of Forster's wards of the Machine.

However, cyberpunk was already well-established by the time the Borg appeared, and while they may have been conceived as an attempt to incorporate the tropes of a novel subculture into the venerable structures of Star Trek in order to rejuvenate it while leaving it essentially unchanged, the cyberpunk ethos is fundamentally at odds with the totalising bourgeois humanist culture that many see as the abiding assumption of the franchise. In presenting the cyberpunk imagery of plug-in body parts and linked-up brains, the Borg appealed to fans who were excited by these possibilities as they had been described in cyberpunk and they were not inclined to see them as the stigmata of villainy. If anything, the Borg became the Goths of Star Trek: they may look like vampires (which in many ways they are a parallel), but vampires in popular culture have often been sexy. 
Accordingly, the Borg were quickly appropriated by fans and cast in their own image through the mechanism of slash fiction. ('Slash' stories are [homo]erotic fantasies written by fans of given films and television shows, so-named because of the colloquial categorisation of any given text by the names of the two principal characters with a slash between them.) Slash fiction does not merely carve a new niche for marginalised fans, or indicate the Freudian return of the repressed; its key characteristic is not its inversion of the existing template, but its fidelity to it. The very essence of fan fiction is the writer's intention to work within the existing rules as they are perceived and the seemingly radical rewriting of slash serves - consciously or not - to reveal possibilities already implicit in the schema. Slashing hacks a system, it does not replace it.

Constance Penley identifies the main writers of slash as 'pink collar' workers, women in technical support positions, who create depictions of male homeroticism as a utopian gesture towards a sexuality unencumbered with social power imbalances (Penley 126; revised and expanded from 'Brownian Motion: Women, Tactics, and Technology' 1995, Penley and Ross 154). Mark Dery ('Resistance is Fertile', 1996) and Brian Attebery (Decoding Gender in Science Fiction, 2002, 177-8), however, show that specifically Borg-centred slash, published in the fanzine Science Friction, is a means for gay fans to appropriate a key element of Star Trek's mythology and thereby secure a previously unacknowledged or suppressed stake in the Star Trek community. Having been excluded from the 'mainstream' precisely because of the isolated characteristic of sexuality, they use that very mark of division as a means of regaining entry into the wider Star Trek community by recasting the Borg as gay.

The Borg as cited by Dery can be seen as an attempt to create a male homosexual utopia, akin to Burroughs' Wild Boys, by subverting the given template. However, as Penley points out, slash is predominantly written by heterosexual female fans and while it is overtly homosexual and the writers identify with their characters' desires and objects of desire, it is de facto monosexual and desire therefore exists without any hierarchies of gender. This is a fine but crucial point, as it is the utopian and critical illustration of a pattern of sexuality that is without fixed and involuntary structures of domination and submission, something that is radically different from that presented by Wolfe in Limbo.

Dery also points out that it is not only community identification that is significant in Borg slash, and not even the erotic content that is its obvious raison 
d'être, but the nature of that eroticism. The fan writers he cites cast the Borg as science-fictional leather-clad cruisers; their individual anonymity is not an indication of the erasure of being, but rather a means of facilitating continual, random encounters without the imprints of difference or inhibition that would divide. Though that may not be the intention of the writers, homosexuality becomes a metaphor for a system that renders division and difference irrelevant. Mechanisation itself is a plus (contra Wolfe); the body is not the foundation of one's essential being to be jealously guarded and protected, but an instrument to be used for the uninterrupted exchange of pleasure.

Ecstasy, it must be remembered, is derived from a Greek word, ekstasis, that literally means 'to stand apart' and is presented in religious thought as a transcendent pleasure that elevates the spirit above the corporeal body. In the cyberpunk formulation of Dery's Borg, ecstasy is achieved through the corporeal and the technological and not in a separate spiritual stratum as would be the case in a Neohumanist schema. By surrendering skin and organs, these cyborgs have fused with a sentient architecture that is universal and timeless, not based in the space and time limitations of atomised experience. A congruence can be found here with the death-state aspired to by Oshii's character of Kim, remembering that he himself saw it as absolutely desirable.

There is hanging over the cruising scene the spectre of AIDS, as disease haunts all intercourse, and the Borg have been presented as metaphors for HIV, with their means of assimilation being the injection of virus-like 'nanoprobes'. In this they are not dissimilar to vampires, whom they overtly echo - and vampires in their time have been utilised as a metaphor for sexual disease. Susan Sontag has written famously on the treatment of illness as metaphor and both her and Michel Foucault's investigation of both the social and technocratic handling of disease and of cultural engagement with images of disease are particularly illuminating- as is the fascination of fans for a race designated as diseased or a disease itself, which has gone even further.

While real disease has an irreducible quality of morbidity, and its use as a metaphor is highly contentious, it is that contentiousness that has made it compelling, for two reasons. First, those with chronic and terminal conditions are socially stigmatised as manifestations of the disease, placing them beyond the pale of society and thereby making them into a collective, unindividualised community. Second, as a 
consequence of this, those with chronic and terminal conditions cannot ignore their state and have no choice but to live with it in a manner that accommodates their state, and in doing so, they are forced to confront and wrestle with their outsider status.

Illness, depending on the specific affliction, has had widely varying representations, with tuberculosis receiving what might seem the most weird and irrational, with syphilis tagging along close behind in the strangeness stakes. Tuberculosis was an affliction that became strongly associated with the Romantic movement because it struck famous figures such as Keats. Unlike cancer or cholera, it lent an aesthetically 'interesting' appearance to its sufferers: thin, passive and pale to the point of translucence and imparting a strangely genderless but still sexy and ethereal quality to them which suggested superior level of aesthetic sensibility and consciousness (Sontag 30-1, 36). Syphilis, a sexually-transmitted disease, was also often associated, because its symptoms included insanity, with both sensuality and altered consciousness (ibid 111). We need not look far for modern analogues. While anorexia and 'heroin chic' are highly contentious today, it is nonetheless widely assumed that many supermodels have addiction and eating disorders and that furthermore they gain their 'desirable' appearance and therefore their celebrity status from them. A valid comparison can certainly also be made with David Bowie's Thin White Duke persona that made him such a suitable choice for the eponymous alien in Nicholas Roeg's film adaptation of Walter Tevis' novel, The Man Who Fell to Earth (novel 1963, film 1976) made at a time when Bowie's own physical and mental health was at a very low ebb.

Anorexia and addiction are not infectious diseases, except, it is believed, in a moral and social sense in Romantic and reactionary presentations of disease. As Sontag points out early on in 'Illness as Metaphor', those with a disease become figured as representatives of the disease itself (6). Tuberculosis and syphilis were both believed to afflict those of an intrinsically flawed nature, and they would bring them upon themselves - and into the communities that they inhabited (ibid 40, 134). Moral corruption and physical corruption were seen as two sides of the same coin.

The AIDS crisis provoked a similar moralistic reaction in the West, indicating that little had changed, despite the discovery of bacteria and viruses and a technologically-advanced means of combating them. Various code-terms that appeared to be euphemisms but were in fact dehumanising dysphemisms have been deployed in discussion of the management of victims: a gay man, haemophiliac or 
intravenous drug user risks being identified as a member of a 'risk group' that is marked by a 'pattern of behaviour' (that last term egregiously denies any subjectivity by defining a person solely by external aspects). These all add up to indicate, and objectify not only persons with AIDS, but those who are supposedly likely to contract AIDS. In some ways this is worse than the case in the eighteenth and nineteenth centuries; then, one had to display the symptoms to be an object of fascination and ostracism, but now one merely has to have the potential risk of contracting the disease to be subject (depending on national and local legislation) to social or legal restriction and condemnation and then rendered unrecognisable as a person. Not only is a victim of disease first treated as a vector for the disease and then an embodiment of the disease, one who shares a likeness with its bearers is seen as an avatar of the disease itself, removed from the category of human and placed in that of the anti-human.

It is this association of actual and potential medical status with moral status, thus dehumanising real sufferers and allied members of risk groups, that leads Sontag to strongly oppose the presentation of illness as a metaphor. However, there are further complications to the new dynamic of disease compared to its cultural framing in the Romantic period and that is identity politics and activism. Authoritarian and reactionary responses to AIDS directly threatened a self-identified gay community that was identified as a prime risk group and was thus likely to see hard-won civil rights stripped away once more in the name of disease control. A group that fought to be acknowledged within society now faced forces that would accept its identification and quarantine - effectively its expulsion from 'normal' society - on the grounds of that identification.

The recasting of the Borg by fans can be understood in relation to this threatened ostracism as semiotic counter-attack. The Borg resemble cruisers, as Dery claims, but they also resemble persons in the later stages of AIDS: they are pale and gaunt, their skin is marked with lesions and their bodies plugged into elaborate support mechanisms which will never let them go again; they are 'other' who were once people and they are the disease itself. In desiring to inhabit the form of an objectified other, one infects that other with one's own subjectivity, erasing the boundary between categories by doing so. To take on the image of a similarly dehumanised and disease-like antagonist is a consciously radical gesture, and one that operates in a carefully-controlled realm between imitation, metaphor and experience. 
Having AIDS and being at risk of having AIDS, that is 'being' the vector for the disease and being dehumanised as a result is a real and brute fact. Of course the Borg aren't really like persons with AIDS, just as vampires aren't really like persons with tuberculosis or syphilis, but they are like them. There are differences that serve to insulate the iconic Borg and vampire from charges of trivilisation and there are similarities that enable one to articulate deeper connections the (potential) bearer of disease and the more fundamental, less specific idea of the outsider who is resisted, but also covertly embraced by society. AIDS may be too real now to be glamorous, but AIDS activism has in the real world reapproriated the abject and the decline of the old scourge, syphilis, in the Western world has freed vampires to become the ideal undead of popular culture. It is not so bad to be a metaphor, the fans of whatever sexual orientation who write slash fanfic and dress as Borg at conventions say, so long as you take possession of it.

The point of being a Borg is that no Borg can ever be an outsider, at least to other Borg. The matrix of Borg technology/culture - the two are the same - is such that it is a generative algorithm that accommodates and extrudes mobile drones. These drones, as former individuals and representatives of separate races, are compiled within the great library of Borg knowledge according to the new system of classification that acknowledges no preceding system of divisions. Their oft-stated threat, 'Your uniqueness will be added to our perfection', seems particularly sinister because it places a high value on those it desires to assimilate, and it is heard therefore as an expression of greed and urge to conquer, but internally it is defined as an overpowering curiosity and a desire for self-expansion by erasing all boundaries that separate and exclude. Gay or marginalised fans who identify with the Borg still follow the rules of the franchise as they are apparent and rewrite the Borg as a technocultural system (or library catalogue) with alcoves (or shelves) ready to receive them and which will integrate them totally with the system. There in the Borg library there are no categorical divisions and all books shelved there will be desired and will be read. Nemo's museum 'tamed' the chaos of the seas within the steel hull of the Nautilus, but this library is being compiled by the outsiders. The whole point of the slashed Borg is that there is no 'outside' against which to armour oneself; all is 'inside'. 


\section{6}

\section{No Aleutian is an Island: Dividing \& Sharing}

For the slashed Borg in Science Friction, beyond the exchange of pleasure, the flux of sex is a mechanism of community bonding and information exchange. Gwyneth Jones designed the sexual and reproductive systems of an alien race, the 'Aleutians', so that they converged with this ideal in their function (predating Science Friction) and sexuality, consciousness, culture, technology and biology complemented each other and existed on a continuum with no clear line of division between any of them.

The Aleutians were introduced in the novel, White Queen (1991), the first volume of a closely-integrated trilogy that continued with North Wind (1994) and Phoenix Café (1997). Since then they have appeared in a number of short stories and another novel, Spirit (2008). In parallel, Jones has explored the implications of a fictional transportation system, the 'Buonarotti transit.' Both the aliens and the transportation system (it is not exactly a form of 'propulsion', nor is it instantaneous teleportation) have significant implications in terms of space and identity - as they are meant to.

The initial trilogy deliberately follows a reiterative structure, with one crucial incident revisited from different perspectives in its sequels. In the first, the Aleutians 'invade' earth, in a manner of speaking. That is to say that they appear, and being aliens, they are assumed to be superior (after all, they visited our world - if they were not superior, we would be conquering them) and by default find themselves cast in the role of overlords; they are variously accepted or resisted, but in either case, the assumption of their otherness and their superiority is not questioned. From their perspective, however, all they expected was a safe harbour for their massive slowerthan-light starship and profitable commerce; their 'conquest' is a trade mission with unexpected complications. Trying to bridge the gulf of incomprehension, Clavel attempts sex with Johnny, whom 'he' has fallen in love with, but rather than healing, this action brings to a head the contradictions and misunderstandings between Aleutian and human and Clavel's attempts to redeem himself and his people then form the generator for the next two volumes. The nature of this breach and the catastrophic attempt by Clavel to establish communion bring to a sharp focus 
seemingly essential differences that are in fact misinterpretations and which are intimately tied to the contrast of human and Aleutian physiology and culture.

Jones explains that the Aleutians were intended not merely as a race of convenient aliens, but also as a means of commenting on the idea of the alien other itself and people who were treated as alien in Western culture, particularly women (Deconstructing the Starships 111). She pursued a lengthy process of considering the Aleutians' biological and sexual makeup and as an essential corollary used that to further investigate the proposition that biology equals social destiny. Writing in Science Fiction Studies, Sherryl Vint uses Althusser's concept of 'interpellation' as being essential to the dynamic of identity-formation: the being 'hears the call' of ideology and the answer is to be fitted into its structures (2001, 399-425). In this system, ideology is by definition that which makes its structures seem so obvious and natural as to be unconsidered at any conscious level and to be thereby virtually invisible - and insidious. Science fiction, in Suvin's definition, can serve by its mechanism of cognitive estrangement to make the invisible visible and, as Jones writes, she created the Aleutians to show that 'natural' arrangements that have been taken for granted 'ain’t necessarily so' (Deconstructing the Starships 110). The Aleutians utilise an obvious system of 'calling' and 'answering' and if that seems weird, then what can be said once we realise that we use a similar system.

The Aleutian 'call' and 'answer' system is intimately based in their biology. Sexual reproduction has often been cited as a means to keep ahead of the evolution of infectious diseases by resorting genomes at every fertilisation, but bacteria manage to do the same without sex and by continually exchanging genes. Every Aleutian carries within their reproductive system a library of several million possible genetic individuals, any one of which might be selected when pregnancy is triggered. Genes are not combined during sex solely to produce a new, unique, genome, but continually updated through all social intercourse, rather in the manner of bacteria that are perpetually sharing genetic updates with each other. Cast-off parts of the Aleutians' bodies, 'wanderers' that would to human beings be abject material like sweat, bodily waste and dandruff, permeate their world and suffuse it with their personal identity and are willfully exchanged as a means of communication. Moreover, their technology is based on biology rather than mechanics and electronics and all of their devices and possessions are derived from their own genetic material. The Aleutian race acknowledges no separate species and neither does it draw a line between self 
and tool or self and architecture. As Jones puts it, they are perpetually immersed in a 'soup of self' (ibid 114).

As a consequence of their biology, Aleutians are immortal through serial incarnation, though significantly without the need for the transcendent element of a divinely-bestowed 'soul'. Instead, the essence of identity rests within recurring genepatterns and the cultural memory of an individual's lives are assiduously recorded and played back to each new incarnation until they recognise their essential integrity of self with the recorded individual.

The Aleutians do not comprehend the concept of the alien, seeing only extensions to the continuum of selfhood. An Aleutian's ideal romantic partner is not a sexual opposite, but another self born in a prior generation and Clavel's fault was to assume that Johnny was his other self while Johnny could only conceive of himself as a single inviolable self. Belatedly realising this, Clavel instigates a programme of first reincarnating Johnny in quasi-Aleutian form in North Wind, and then 'himself' in human form as a woman named Catherine in Phoenix Café. In the process, the human and Aleutian biological systems and cultures alternate and shift, while their cultures begin to echo the positions of the other by adopting (and continuing to misinterpret) the other's forms and dramatic positions.

Aleutian culture is not a utopia, it is an alternative like the worlds of Russ' The Female Man, with both its positive and negative elements that serve not to propose a transcendently better substitute, but to reflect our own in a previously unconsidered way and to thereby become a challenge. Aleutian society, for example, is rigid; roles are determined by genetic and memetic heritage and it takes many generations to change one's destiny. An 'actant' we remember, is one who attempts to fulfill their specific destined role, but Clavel is hacking both Aleutian and human presumptions by trying to deliberately subvert and transpose those roles.

Jones is intensely cognisant of the power of biology and refuses because of that cognisance to allow it to become by default the dominant factor in determining role, identity and action. The physiology of an Aleutian is a depiction in biological form of what people do through social discourse and which is depicted as being facilitated by technology in cyberpunk literature. The same acts are, according to generic aesthetics, depicted in different forms that support their ideologies; cyberpunk emphasises the hack, and hence the deliberately subversive use of technology that puts the 'punk' into 'cyberpunk'. In Jones' Aleutian stories, biology is construed as a 
more fundamental force, but not necessarily inflexibly deterministic. Indeed, her obvious target is the proposition that biology is destiny. At the end of North Wind, biology has been shown to be now not an external, irresistible force of nature, but both one's being interfacing with society and a technology subject to manipulation and collective social choices.

One particularly elegant technology introduced in Phoenix Café and referred to in Spirit is the 'envie', a kind of hallucination delivered by paper flowers which is more or less the human equivalent of the Aleutian wanderer, treated as an art form and given usually as a gift. As it unpacks experiences, the words themselves unpack: flowers are tokens of desire, and envie itself denotes desire or lust - and specifically, it denotes a desire to have what is possessed by another, that is, to exchange places with another or to be them. The sexual metaphor is obvious, even more so when it is so obviously analogous to Aleutian exchange. The envie translates Aleutian biotechnology into human narcotics, it also suggests the sharing state of the slashed Borg - but the feminine image of a paper flower is rather more appealing than a violent injection of nanoprobes.

The Aleutians and the Borg are very much alike, their superficial difference exaggerated by the fact that Borg technology is mechanical and Aleutian biological, but as Gwyneth Jones made implicitly clear through obvious mirror-imaging of attitudes to biological and electronic technology, the Aleutians do with biology what humans do with electronic technology anyway. The primary points of similarity are their continuous sense of identity, their relative reluctance to use the narrow channel of words: in the case of the Borg, this is represented as muted anonymity, though again, from an interior perspective, words are unnecessary except when dealing with non-Borg (yet to be Borg) because the continual exchange of information within the collective is rich and uninterrupted. Words divide, Jones tells us; that is their job. Once one establishes a denoted category - or Order - one also creates 'others' outside that category and once one creates a language structure, one then requires 'insiders' to start explicitly subscribing to its structure and dynamics. Tacit communication can permit one to get along with the assumption of being a member of the 'inside' group', but as soon as, for example, a woman speaks aloud in a manner not condoned by the ambient structural system of language, she is identified immediately as an other (ibid 116). 
The Aleutian caste system of 'signifiers', complementing or complemented by the 'silent', was inspired by Jones' experience in male-dominated non Englishspeaking environments and is quite crucial to her fictional resolution of the problem of exclusive signification. She was accepted as human (and not a foreign woman) as long as she made the right gestures (ibid 115). The Aleutian silent language, which is mistaken initially by humans for telepathy (another 'superior' alien characteristic), is in fact a continual communal information exchange through gestures, wanderers and tacit understanding. Much human conversation, she points out, is elliptical and phatic, cueing the receptive to recall the shared cultural and emotional heritage of the race. This is our own 'soup of shared presence' (ibid 117).

The question that arises when positing signifying and silent castes is - falsely - which one is dominant? The speakers seem to be the decision makers because they are visible, individuated and outspoken (obviously). However, the reality is of course much more irreducibly ambiguous; Jones realised that she had reinvented Lacanian psychology and the silent caste could be taken to be the unconscious, shared plenum of human experience and the signifiers, rather than being the executives, are the public face of the silent majority. 'The 'signifiers' may be prominent figures', she asks, but they may only seem to be:

But who is really in charge? The intelligentsia, or the silent majority? Which is the puppeteer? The fugitive, marginal latecomer, consciousness? Or the complex, clever, perfectly competent wordless animal within?' (ibid 118)

While a Borg has (apparently) erased their idiosyncrasy in the flux of unifying communication, an Aleutian is a conscious actant, emerging as an individual when they recognise themselves in recordings and constantly exchanging portions of their self through the medium of their flea-like wanderers, their gestures and their pheromones. In terms of individual subjectivity, Aleutians are extremely subjective, or rather, possess an intersubjectivity derived from a definition of identity in perpetual dynamism, or in Deleuzean terminology, becoming. As Deleuze and Guattari write in A Thousand Plateaus, becoming is not a lot of things: it is not imitation, it is not aimed towards completion and it has nothing to do with classification. What becoming is is not so easy to define, because the concept and practice of becoming is predicated on the rejection of essential identity: in becoming, one does not imitate 
because imitation implies a mask placed over one's real face and there is no real face to be masked; becoming is not aimed at completion, because teleology is also predicated on absolute identity and becoming is not about classification, because classifications depend on exclusive labels. To become another Aleutian, or another human being, or a wolf, for example, you think of running with the wolf pack, performing the act of 'wolfing' alongside wolves that are wolfing. If you are wolfing, you are becoming wolf. Identity is performative, not fixed (Deleuze and Guattari 239). The Aleutians find social niches calling to them, and compelled by their genes, they answer those calls, but all of society calls out to them too. They become their roles in the Deleuzean sense, but in discoursing with others, by being intersubjective, they are becoming each other.

Becoming is irreducible to Cartesian terms. This is both in terms of the duality of mind and body and in terms of spatiality based on absolute co-ordinates. Individual consciousness and being is a contingent gathering into focus of experience, an eddy in the soup. Descartes can say 'I think, therefore I am', but among the Borg and the Aleutians, there is no 'I' and no thought that does not draw upon communal experience.

If we are to find a spatiality of becoming, we need a new system of coordinates. Deleuze and Guattari helpfully provide us with another term and concept, haecceity. A Cartesian grid is timeless and neutral, but haecceity is particular and temporal (ibid 261). The word itself is derived from a Latin word meaning 'thisness' and, as they define it, it is a form of uniqueness that is related intrinsically to the fleetingly relativistic arrangements of time, space and motion. Beings that are becoming do not have generic classifications, they have haecceity: they are in motion, located less by changeless co-ordinates than by vectors and velocities. Becoming, they are always between, relative to other things, never fixedly occupying a single point. The space of becoming is an in-between space and this is described and used evocatively by Jones not as a polemical metaphor, but as the space in which her narratives occur. She names it after its eccentric human discoverer, Peenemünde Buonarotti.

\section{7}

The House that Peenemünde Built: Being-in-Transit 
Running through the Aleutian trilogy is what at first seems like a McGuffin, ${ }^{*}$ the secret of a faster-than-light interstellar transportation technique, called the Buonarotti transit. However, this transportation system is as architectonically ordered and as encompassing as the Aleutian biosphere and it is likewise linked with the use of language and narrative.

Travel is something that starships $d o$; it is not often thought of as a state in itself. Nonetheless, being-in-transit is the broad context and logical consequence of the cybernetic paradigm that sees entities as parts of systems. The 'system' in this case is a narrative and we can compare the structural bases of both the Borg and Aleutians with the eponymous Bios of Robert Charles Wilson's novel. That novel's immediate successor, Blind Lake (2003), proposed narrative and the art of storytelling as a means of fulfilling or revealing the subjectivity of an alien 'Subject' that was otherwise objectified while Jones' own invention, the 'Buonarotti transit' links different worlds and even facilitates in one story, 'The Tomb Wife' (2007), the exchange of identities and fates (Jones The Buonarotti Quartet 111-33). Neither of these systems are starships, teleportation transmitters, wormholes or any other such stock item from science fiction's storehouse, but 'eternal spaces'. That is to say that they intersect our familiar space at specific times and places of entry, as they do others, but they are bound by their own rules and do not follow the local rules. They are analogous to classical conceptions of eternal time, which is not merely infinite chronological time, but all times, and their points of interception are analogous to the kairos, the instant where all possibilities are immanent, but also, within their realms, they have the fluidity of possibility inherent in open narrative as opposed to the determinism of closed narrative and both are spaces that facilitate intersubjectivity.

In the opening and closing novels of the trilogy, White Queen and Phoenix Café, the Buonarotti transit spans immense distances of location and time, which means that it juxtaposes starkly different states of being, causing a psychotic break. The only means by which a human can remain sane while making such leaps is to construct a linking narrative, connecting the self with the process and the locations or states of being in one comprehensible structure. In White Queen, Johnny and his companion Braemar use Buonarotti's technique to infiltrate the Aleutian starship in a

\footnotetext{
* A term coined by Alfred Hitchcock to mean an object that motivates characters because it is desirable to them, but serves no essential purpose beyond that.
} 
failed attempt to sabotage it; this is not obvious, only implicit until one realises that they are following the structures of interactive video games, which themselves follow the precedents of adventure stories. This becomes ironically reiterated when a guerilla organisation that has co-opted Catherine (Clavel in human guise) transports her to a world of blue forests within the framework of a virtual reality game and then at the climax of the novel, conducts a raid explicitly using the Buonarotti technique, but deliberately conducting it as if it were a game very similar to Johnny and Braemar's original mission.

After the initial trilogy, Jones continued to explore the implications of the Buonarotti transit in a number of short stories, four of which are collected as The Buonarotti Quartet (2009). In 2008 she also published a new novel set in the postAleutian universe, Spirit, or: The Princess of Bois Dormant. This novel is set some centuries after the initial trilogy and since then an interstellar community of "numinal homind' races has emerged, comprising humans, Aleutians and a few others including the bat-like Sigurtians. A number of science fiction franchises or linked series have posited for the sake of convenience an unseen elder race or some other agency that has caused a number of intelligent races to emerge on the galactic stage at more or less the same time and at more or less the same stage of development, a situation that would on its own be so unlikely as to be virtually impossible (Ursula Le Guin's Hainish Ekumen is a famous example). One can take it as a narrative convention and forget about it, but Jones' people can't and they have developed and begun to argue about 'Diaspora Theory' - its 'Strong' position being that all races have a common ancestor and its 'Weak' being that there is simply an evolutionary tendency towards convergence. Neither position is proven, and where one stands on the spectrum between the two is more an indicator of one's own character and preference than any special scientific insight (see 7.5 above). In any case, there are a half-dozen humanoid races who are both convergent and divergent, depending on how one chooses to look at them. Diplomacy in this context is difficult and ambiguous, much as it was in Europe in the nineteenth century, when the Romantic novel emerged, and Spirit is a self-conscious scientific romance that mimics a nineteenth century novel. In this case, it is The Count of Monte Cristo, hybridised with the French folk tale, 'La Belle au Bois dormant' or 'Sleeping Beauty'. Naturally, since this is a Gwyneth Jones novel, the (hi)story repeats, but never exactly as it was first written. 
The main and almost exclusive thread of Spirit's narrative concerns the life of a Welsh-Pakistani orphan, Gwibiwr, a word meaning 'traveler' and used in the diminutive form, Bibi. Bibi finds her family wiped out by the forces of General Yu and, for the sake of her survival, joins the household of his wife, Lady Nef, and makes her way up the ranks and meets her Aleutian companion, Francois. In order to avoid a political scandal on earth, Yu takes his household on an ambassadorial mission to Sigurt's World, where things proceed to go horribly wrong.

The shared-story nature of the first interstellar Buonarotti transit, developed in the first novels and short stories, is given a very wry treatment in Spirit when Yu and his household/staff collaborate in the scenario of a party of hunters sequestered in a cabin surrounded by a blizzard. This is a relatively light-humoured excursion, but it does hint at the dangers of the Buonarotti technique when uncontrolled unconscious misapprehensions threaten to turn the collective narrative away from a mild adventure to one of many horror stories about parties of hunters trapped in huts and companions mistaken for prey.

The transit is eventually concluded safely, and the party disembarks on Sigurt's World, an alien world in a science-fictional sense, but clearly borrowing from Romantic literature; their bat-like hosts inhabit a vast rambling castle called Black Wing and of course the nights are long, dark and stormy. Intrigues grow, secret messages are passed back and forth, plots come to fruition, Francois and others are killed and the party finds itself trapped, enclosed and divided. Bibi is sacrificed to an arranged mating with a prince to seal a bond between their races, their half-breed child is taken from her and she is sent to life imprisonment on the bleak moon of Fenmu.

So far, so (Post-) Gothic. Bibi's imprisonment though is more than an episode; in many ways it is the central drama of the story. Her situation is, of course, one of terrible deprivation and slow death, relieved only by relief that she can barely stand; she discovers the dying Lady Nef in a nearby cell by exploring forgotten back passages (which are dangerous, dark, vertiginous and so on). However, her meeting is pivotal. In essence, her meeting with Lady Nef marks her own recreation and is accompanied by unrecognised births. First, Nef becomes her teacher, educating her in morality and adulthood and also revealing a path of escape, and even more than that, a source of riches - the location of a secret planet, as yet undiscovered by others, giving her both the opportunity and means for her future revenge, though Nef warns her 
against taking this path. Second, Bibi has a new, double birth, an experience that she is unable to assimilate, but which will also profoundly effect her: one child is obviously a child, but tiny, barely half the size of a normal human and probably a freak generated in some way as a byproduct of her Sigurtian insemination. She names the girl Dirt-baby, or Di. The second offspring is stranger still: a slug-like thing that usefully consumes waste in her cell, but seems to be nothing more than what she calls it, a phage. Though she affects to despise and reject them both, she will not abandon them either. All in Fenmu are abject, and that at least they share, something that Bibi is starting to understand, even though she will not admit it.

After Nef's death and when Bibi does make her escape, Di is killed by the fierce native wildlife and all Bibi can find of her is a fragment of her skull and some teeth in one of the creatures' excrement. It is at this point, where Bibi has lost everything she could love and stands ready to gain immense power that the perspective of the narrative shifts to the adventure of a young Sigurtian prince, D"fydd, enjoying a wanderjahr. Very likely he is Bibi's stolen child, and soon a mysterious and attractive Princess Bois Dormant appears, who is obviously Bibi herself, and certainly she has plans which she is starting to put into effect.

Everything that was packed into the Black Wing Castle and the prison moon of Fenmu begins to unfold, and revelations come in torrents. D"fydd is indeed her son and the phage was Francois 'encysted self': knowing that his demise was imminent, he ensured that a portion of himself was hidden away in her body and eventually the phage grows into a full-sized Aleutian and achieves the moment of self-recognition under Bibi's tutelage. He then becomes her lover, as he was the Lady Nef's, and it may be that he sees Bibi as her other self.

While the implications of these discoveries elaborate, Bibi and her companions find and liberate the world of Mallorn. This was the world of blue forests depicted in Phoenix Café and it has been trapped for centuries in a perpetual fugue state of a failed Buonarotti engagement, a parallel of sorts to her own imprisonment in Fenmu and eventual escape. There, while it appears Eden-like, any horror can become real according to the nightmares and anxieties of its visitors. The original explorers themselves brought with them the fiction of a crash and primitive aboriginals and those have been made real, trapping them in their fictitious but now real roles until the transit can be completed and redeemed. Finally, Bibi is able to engineer a final confrontation with General Yu and his associates back at the capital 
of the interstellar community, Speranza, and there, where she might take her revenge, she holds back. Nef, Di, Francois and D"fydd have all taught her that she cannot let revenge consume her when she can learn to love. Love redeems, but then, as a good story demands, fate dishes out appropriate punishments and rewards anyway.

The plot of Spirit, or: The Princess of Bois Dormant, which I have described in some detail here (and there is much more), clearly recapitulates the well-known story of The Count of Monte Cristo with a few added twists and a change of nominal genre. The point of this is not that Jones has saved herself writerly effort by having Bibi recapitulate existing narratives, but that she engages with them and struggles with them as anyone in a conventional novel of 'realistic' psychology would struggle with a dilemma of self-definition and moral insight. Bibi does not really have individualistic psychology and neither does anyone else in Spirit: what they have is what they are supposed to be according to the story - and nonetheless they make choices, choosing better stories than the ones they have been given and thus a revenge tragedy becomes a fairy tale with a happy ending. Spirit is a novel in which plots are themselves landscapes over which characters navigate, trailing new stories behind them.

Furthering the spatial motif that underlies the construction of Spirit, estrangement and enclosure underlie the most pivotal incidents and episodes and the two are oddly linked with ambiguity that is typical of Jones. This happens in a number of ways, between numbers of people. The first and most obvious cluster of partings and meetings is on Sigurt's World and its prison moon. Clearly Bibi loses her first child, whom she might never have loved anyway had events proceeded as they were 'meant to', and then when she is cast away in Fenmu, her abjected, isolated state is horrifically obvious. Di's name and eventual fate serve only to underline this, as if fate can never be repudiated, only repeated. However, Fenmu is also a crucible that brings Nef and Bibi together and within which Francois begins his long reincarnation and $\mathrm{Di}$ is able to teach Bibi the rudiments of intimate affection and need that she had never before known.

Significantly, Jones numbers the chapters of Buonarotti transits and Bibi's imprisonment outside the normal sequence of numbers given to other chapters using zero or infinity to number them, as she does with the trapped world of Mallorn, indicating that they exist in a special time, such as kairos or eternity. The Buonarotti transit is not just a means of space travel, it is a state of consciousness - a story - that 
enables one to bridge the gulfs between being different kinds of people as it does one to bridge the gaps between locations. Moreover, and necessarily, a Buonarotti transit can never be undertaken alone, because stories are always told together.

It is not surprising that, as a professional writer, Jones is skeptical of the efficacy and transparency of language; writing is not living; writing is a way of comprehending living and one has to look beyond the words into the spatial systems that they describe to understand the structures that support them. The whole of Spirit exists in a Buonarotti transit, and as it depends on the reader's understanding of a shared (at least Western) cultural heritage, it entangles them too, creating the space of mutual engagement and a discourse between author and reader. This system is one that is incomplete, fragmentary, arbitrary, phatic and based on the non-signified substratum or 'soup' of culture.

Trivial - and not so trivial - objects such as paper flowers, prison moons, worlds imprisoned in fugues, lost and found children and Diaspora Theory all come together ambiguously, as they will remain together. Jones offers no answer to the Diaspora controversy, and she would refuse to: there is no answer there to be settled, because the question is really of the same kind that asks whether a glass is half full or half empty. How different are we, really? How similar? Answers are not solutions, actions are, and no action is ever completed because consequences always follow.

Enclosure is not closure in a narrative sense, nor should it be personally, aesthetically or politically. The warrior cyborg represents an attempt at enclosure through rejection of the liquid, 'filthy' exterior, but the hackers of the late twentieth and twenty-first centuries have rendered that paradigm absurd. Oshii's cyborgs, drawing on Haraway, maintain stability within a chaotically dynamic milieu not by rigidity, but by metastability, the rewritten Borg by the creation of a universal fluid category that defines all as 'insider'. Likewise, the Aleutians are aliens that acknowledge no state of alienation and Bibi comes to her quasi-Aleutian moment of self-realisation by acknowledging the abject in herself, by embracing Di, D"fydd and Francois - and herself.

As Bibi says of softness, so abhorred by the fascists and Wolfe:

When Lady Nef first taught me that I must learn to rule myself, I thought "ruling yourself" meant doing what you had to do to survive, but always staying the same, like a rock inside, no matter what. Now I know that if you 
want to rule yourself you can be as hard as you like on the outside: hard as rock in matters of loyalty, honour, obligation. But inside you must be soft, yielding, always ready to accept change, to embrace life in whatever form it takes. That would be my advice, D"fydd, if I were giving you advice, but you don't need it (Spirit 469).

In a way, this brings us full circle. The warrior cyborg first armoured itself, and in the end annihilated itself to be remade as a hollow vessel animated by the spirit of the beehive, a hard metallic component of a cybernetic superorganism. By contrast, Jones celebrates softness and fluidity in conjunction with the hardness of honour and obligation.

This concept of identity is linked with a concept of spatiality and context and of persona as being something generated by cultural patterns. The space in which the Posthumanist cyborg being dwells is descended from the 'hyperspace' of the Bonaventure Hotel, as described by Jameson, and which is more precisely articulated by Deleuze and Guattari as 'smooth space', not one 'striated' by fixed walls and boundaries, let alone centres. The atrium of the Bonaventure Hotel is without fixed axes and references; the kind of space that they call 'deterritorialized'. To a Modernist or Neohumanist consciousness, this makes it impossible to navigate, producing anomie and madness. $\mathrm{X}$, we recall, scrupulously registers the bearings and ranges of the structures and entities inhabiting the Night Land from the Tower of Observation before he embarks on his quest. However, the nomad who inhabits smooth space, always becoming and never still is distributed throughout deterritorialized space (Deleuze and Guattari 381-2). In striated, territorialized space, a line exists between two points, taken as fixed and absolute, the line being an interval between the origin and the goal. In smooth space, points are contingent effects, the intersections of two or more lines (ibid 480). Deleuze and Guattari are referring to lines in these cases as vectors, not boundaries which are vital to Neohumanist spatiality, but their point is clear: the space that you inhabit, with its flux of fields and connections, makes you; you become not only those you are 'wolfing' with, you become that space. 


\section{0}

\section{Conclusion: Application of the Orders}

This study has not sought to definitively encompass all science fiction, but rather that which has pursued the question raised in Brian Aldiss' charter definition. This definition implies an ontological relativity, but relativity is not random. As is the case with Einsteinean Relativity, it depends on a frame of reference: 'Who or what are we according to our understanding of the universe?' In attempting to create an understanding of spatial systems in science fiction, we are using these systems with the purpose of creating an understanding of ourselves.

Because both science and culture undergo paradigm shifts, and because new forces and subcultural elements emerge and decline while others also undergo their own waxing and waning fortunes, every cultural moment is complexly contingent. Every text, rooted in a cultural moment but dependent upon the antecedents of the Order(s) that it represents, is itself contingent. The Orders must be applied as a critical tool in a manner that acknowledges contingency, mixture and change.

\section{1}

\section{The Orders Themselves}

A critical methodology has been proposed here, based neither on genre or subgenre nor on whether common props such as cyborgs and aliens have been treated positively or negatively. An Order is an integrated set of epistemological, existential and narrative structures that generates narratives and elements of narratives: characters, plots, tropes. Authors and readers may ideologically approve or disapprove of the products of the Order that they follow and make this clear in the narrative cycle and in the voices of characters, but they will nonetheless accept the logical process that has produced them. 
A prime example of an Order's facility for variation is apparent in the contrasting Neohumanist treatments of the warrior cyborg by Colin Kapp and Clifford Simak. Kapp depicts Gottlos as literally god-lost and death-seeking, while Simak presents Joe and Ivan as sympathetic, essentially human characters, but both speculate that total warfare that thoroughly permeates and conditions a culture will compel the transformation of its citizens into warrior cyborgs. Within the range of Posthumanism, the works of both William S. Burroughs and Gwyneth Jones depict personality transference in the manner of infection or gene transference, but Burroughs sees this as an evil thing, akin to or exactly the same as parasitism and addiction, while Jones depicts it as a positive force. Again, both authors assume that this process is a logical outcome of the social forces and technologies around them, as they perceive and interpret them.

An even better example, and one which clearly demonstrates the workings of postmodern cultural dynamics, is the treatment of the Borg by the creative team of Star Trek: The Next Generation and their appropriation by fans, which influenced the later development of the beings (or superorganism) in spin-off television series, novels, conventions and fan fiction. The Borg as they were first conceived can be considered Star Trek's liberal humanist response to cyberpunk, but nonetheless, the makers of the show accepted the validity of cyberpunk's speculations, and a significant portion of the fan community embraced the outcomes of that speculative process as well - and generally within the dictates of the generic and franchise structures of Star Trek.

The Borg are a very different kind of cyborg from Gottlos. The fictional societies that produce them and the epistemological schemae that are the bases of those societies are entirely different, and it is misleading to critically assess them according to shared criteria because there is one common denominator in the fact that they are cyborgs.

This brings us back to Aldiss' charter definition. Science fiction has its iconic tropes: the spaceship, the alien, the cyborg and so on. All of these represent a definition of humanity's relationship with the cosmos and with the other: the spaceship because it travels through space to other worlds, the alien because it is a mirror to humanity, and the cyborg because it depicts the coupling of humanity with its technological and cultural systems. An author's approach to each of these and a reader's reception of them reveals the structure of their reasoning on the nature of 
humanity's position and engagement with those systems. That reasoning, in the case of science fiction, is based on an understanding of science.

If we are to come up with a definition of humanity and its place in the cosmos that will stand in the light of science within the realm of fiction, then we must be aware of the state of science at a given cultural moment, of how science stands in relation to culture, and what is considered to be reasonable speculation at that moment. One must also be aware of the fact that science is a process and it evolves, compelling therefore the continuation of definitions as a form of debate, with its origins in the past and an ongoing engagement with definitions generated by parallel positions or Orders as they are described here.

As these lines of debate perpetuate themselves through time, they arise from particular cultural bases and enter different cultural phases, encountering different critical systems and responding by modifying their precepts and outputs, resisting or generating new strands. There is no single critical system that is part of an Order that can consistently describe all other Orders, as each characteristically applies its own systems as part of its means of constructing and perpetuating itself. Thus, Modernism can best be understood as having emerged in the late Renaissance and having been conditioned by the Enlightenment and Post-Enlightenment epistemological milieux and is best critiqued by the kind of analysis practiced by Michel Foucault. Neohumanism tends to existentialism and attempts a synthesis with classical and esoteric traditions, and therefore Joseph Rykwert, Martin Heidegger and others provide the most fruitful perspectives on its mechanisms and outcomes. Posthumanism's writers and readers make more use of epistemology and poststructural criticism as components of their practice, so critical analysis tends to explicitly arise within its texts.

Also, when considering the Orders, it must be understood that the experience of spatiality is no mere metaphor. When we seek a definition of humanity in relation to the cosmos, we must assume that there are particular culturally-constructed structures to that cosmos that create and accommodate particular models of humanity and which determine the forms and dynamics of its standing. Architectonics is the grammar of spatiality, and that grammar is based on a particular logic, expressing the overall cosmology of a culture. Places, things and people are placed in relation to each other as causes and influences are placed in relation with effects: the schemae that produce narratives also produce spaces, and pathways through real and cognitive 
spaces produce narratives. Space, time and story are inextricably linked, and no Order can make sense without an understanding of mundane and metaphysical architectonics.

\section{2}

\section{Mixed Media, Impure Thoughts}

I have stated previously that individual texts should not be considered in isolation; in fact, that is fundamental to my argument. For the sake of clarity in establishing my critical framework, I have selected texts that are exemplars of each Order, but no author or reader can anticipate a future critical framework, let alone be obliged to conform to it. Therefore there are many science fiction texts, perhaps most of them, that are not pure exemplars of the Orders. However, this is not a problem and it is in fact essential to my argument and method. I have said that when we are to critique a text, we must not consider it in isolation; every science fiction text exists in relation with other science fiction texts, and this is because science fiction itself is an ongoing debate. As a corollary of that, every text refers to other texts within the genre, as each Order exists in a dynamic relationship with other Orders; therefore, every text will to some degree include an acknowledgement of more than one Order. This is not a contradiction, but indicative of the true nature and role of the Orders; as they exist outside of any given text, multiple Orders can also exist within any given text, and as the Orders exist in relation to each other, then the analysis of texts must be conducted not to ascertain whether they show fidelity to any Order, but to reveal how they present the confrontation and engagement of different Orders.

There is an added complication to postmodern criticism of science fiction and that is the fact that no text can be considered exclusively in terms of one medium. Print dominated the period in which science fiction emerged, but by the middle of the twentieth century, visual media became significant and, in monetary terms at least, possibly dominant. However, while commercial imperatives may have forced visual science fiction to pursue creative avenues that were separate from those of print, postmodern media are deeply interrelated. Every book that enjoys the backing of a significant publisher will be supported by Internet resources as part of its marketing 
and most authors are at least likely to have blogs. A 'purely' visual presentation will certainly have substantial multimedia support.

Consider this scenario, which is increasingly becoming the norm for visual science fiction: a film is released and is (hopefully) seen by many people, but that is certainly not the only point of contact that the audience will have with the story and the world in which the story is set or the world that has generated the story. First, there will be a film, then there will also be a DVD/Blu-ray/downloaded version, with extras, featurettes, easter eggs, commentary and a special director's cut. There will be a website and a viral marketing campaign and there will be merchandise. There may be an original novel on which the film was based, and whether or not there was an original novel, there will certainly be a novelisation of the film and probably a graphic novel as well. If there is matter in the story that is 'unsuitable' for children, then there may be another novelisation that is aimed at a separate market of younger readers. There may very likely be a book or books on the making of the film, and pseudofactual encyclopaedias that offer a guide to the film's background and contain information that was not included in the film. There will be a soundtrack album, games and an iPod/iPhone application. In addition, there will be many fan websites and official and unofficial wikis. Inevitably, there will be fan fiction. If the film is very successful, then it will enter popular culture and there will be conventions at which fans dress as characters, or other broader cultural representations will manifest themselves (for example, it is very unlikely that anyone in a Western nation is unfamiliar with Mr Spock and doesn't know that he represents the principle of 'logic' in some form or that Vulcans are supposed to repress their emotions). Finally, of course, there will be sequels and new texts set in other 'universes' that directly or indirectly refer to the cluster or franchise in some way and the cycle will begin again. Even if a text appears in the print medium and remains primarily defined by its print manifestation, it is not unlikely that the author's blog will attract fan activity, including fan discussion of the issues raised in the novel and art depicting characters and events in the story. To ask which is the origin or master text is meaningless, because even if one could point to a single document as being the first text, or assert the supremacy of a specific author, then considering the later elaborations that have been accepted by the fan and creative community, then that first text might well be relegated to the role of research notes by many or even most of the readers that constitute the fan community. 
As a consequence of the clustering of multiple media about the basic concept of a story or imaginary world, there is inevitably going to be, to some degree at least, a mixture of subgenres as each medium tends to favour the expression of some qualities more than others. This can often lead to mixtures not only of mode and subgenre, but of Order. There is of course also the fact that science fiction itself is discourse that is a mixture of discourses: science and fiction. Science fiction is a genre that is very deeply engaged with both scientific and popular culture. The postmodern culture in which we live now accommodates this mixture and uses it as the means by which divergent ideas and Orders are shown to be engaging with each other. Thus, if the Orders are to be analysed in an individual text - or rather cluster of texts in multiple media - then in all practical cases it is necessary to see how the Orders are presented in relation to each other and how each text functions not as a unique unit, but as an intersection of influences.

To use an architectural analogy, in a baroque building the orders may be combined. Sir John Vanbrugh, who was a playwright as well as an architect and therefore understood that dramatic license could take precedence over consistency (which is, of course, the hobgoblin of small minds), designed Castle Howard with the Doric Order on the North façade and the Corinthian on the South. For the purpose of identifying the science-fictional Orders, I have used exemplars in which they are shown in their purest and clearest form, but as I have commented also, all may be present in varying proportions in a given text, or on opposing façades, as it were. This may be contrary to the conscious aims of an author, but compelled nonetheless by their cultural milieu. Two mass-media presentations, which, due to their economic bases, have been required to have general and therefore conservative appeal, have shown interesting hybridisations of 'old' and 'new'. These are Star Trek, as it has evolved in various incarnations in successive decades; and Battlestar Galactica, which, by being 'reimagined' (Potter and Marshall 1) from first principles, is a more radical mix of older space opera premises and a postmodern, Posthumanist sensibility.

Star Trek is dedicated to liberal Modernist principles, as its opening monologue and manifesto claims, but the introduction of the Borg as antagonists in Star Trek: The Next Generation was provoked by cyberpunk (as well as drawing on Doctor Who's Cybermen for inspiration). The Borg were intended as antagonists, their fundamental nature, and therefore the Order that generated them, utterly opposed to the values, structures and dynamics of Gene Roddenbery's United Federation of 
Planets. However, Star Trek is not merely a series of film and television presentations, it is a collective activity constructed both by studios and fans, each of which influences the other, and the Borg were recast by a significant portion of the fan community to stand as an alternative and critique of the Federation and its values and as a mode of fandom and identity as well. Modern and liberal in its conception, Star Trek as a franchise has become postmodern; its modernist (with the ' $\mathrm{m}$ ' in upper and lower case) qualities are now only one aspect of a much more complex cultural form.

\section{3}

\section{The Hybrid: Battlestar Galactica}

Ron Moore's and David Eick's Battlestar Galactica (2003-9) presents an excellent resource for critics looking for Orders and their interplay. Generically a space opera, the series draws directly and obviously on contemporary events, such as the invasion of Iraq, and metaphysical questions, such as the cyclic nature of time and the compulsion of destiny, the value of an identity supposedly expressing 'essential' qualities versus one that is synthetic, and whether empirical or polysemous comprehension can truly describe the universe. The premise of this series, based on an original of the same name devised by Glen Larson and first broadcast in 1978, is that virtually all of the human population of a federation of twelve colonies has been exterminated by their enemies, the 'cylons', in a surprise attack, and the last remnants of the race are led by their last surviving warship, the titular Galactica, towards a semi-mythical haven called 'Earth'. In Larson's original series, the cylons were a robotic alien race, but in Moore and Eick's version, they were created by humanity itself and turned against it. An added twist is that the cylons have themselves created humanoid models that are indistinguishable from Colonials, and some of these have false memories so that they believe that they are human.

Battlestar Galactica (and its spin-off, Caprica, 2009-?) in many ways shows fundamentally Neohumanist features: time is conceived as cyclic, the narrative is driven by a fierce antagonism of the self and the other, and there is from the very beginning the indication of a transcendent realm and agency framing, controlling and ultimately resolving events. However, Moore and Eick set out to subvert the simple 
oppositional structure implied here. Characters who are thought to be human - even by themselves - are revealed to be cylons, so the conflict apparently founded on opposed natures (biological and technological) is revealed to be in fact founded on divergent cultural and moral values.

In four areas we can see elements of the Orders engaging with each other: design and physical architecture, characterisation and identity, cyborgisation and metaphysical architectonics.

In both its visual aesthetics and characterisation, the series is so Gothic that it could have been named Battlestar Gormenghast. In terms of visual form, there are obvious comparisons to be made. The Galactica, a kind of spaceborne battleshipcum-carrier, overtly resembles a gigantic mechanical alligator. Internally, its Gothic nature becomes more apparent, with its labyrinthine and shadowy corridors buttressed and vaulted in a manner that seems utilitarian, but cannot help but recall cloisters. The dim, shadowy lighting prevalent throughout the series (there are virtually no brightly-lit interiors and, if they are, reflections are painfully sharp and the glare obscures detail as effectively as shadows).

The cylon vessels, while sleeker and clearly more advanced, still recall Gothic forms, again with a cloistered appearance not only in the interior spaces of their caltrop-shaped baseships, but in the external form of many of their other vessels and installations. The 'Resurrection Ships', which are facilities where the minds of humanoid cylons can be downloaded into new bodies, thus giving them an effective form of immortality, are explicitly church-like in their appearance. ${ }^{*}$ The robotic centurions, the foot soldiers of cylon civilisation, resemble a cross between Jacob Epstein's sculpture ‘The Rock Drill' and the Grim Reaper. The cylon's home base, an artificial world called simply 'The Colony', is also explicitly Gothic in style, with a 'biomechanical' theme apparently inspired by the art of H. R. Giger, particularly his concept and production design work for Alien.

The spaceships of Battlestar Galactica - the titular ship and the semibiological cylon baseships - are certainly metaphorical edifices that are also living beings in the sense that they are emblems of the collective identity of their communities, not unlike the Last Redoubt. In the penultimate episode, 'Daybreak, Part I', the Galactica's resident mad scientist, Gaius Baltar, says:

\footnotetext{
* Indeed, they most closely resemble the USAF Academy Chapel by Skidmore Owings and Merril, 1955-62.
} 
Galactica has been more than our guardian. She's literally a vessel into which we've poured all of our hopes and dreams. And when she's gone - when we can no longer derive the security from looking out a window and seeing her massive bulk gliding by - then this life will be over, and a new life will have begun ('Daybreak Part 1' Battlestar Galactica The Final Season).

The cylon vessels themselves do not merely ape Giger's biomechanical art; they are themselves quasi-living entities, able to 'heal' themselves after being damaged and in places revealing moist, red flesh. Piloting them and managing their systems, they have 'hybrids', beings that at least partially women permanently immersed in glowing womb-like tanks (which resemble the pods used for resurrecting fully humanoid cylons) and connected by thick cables to the fabric of their baseships. Not only are they half humanoid and half machine in appearance, their consciousness seems to straddle the mundane and the transcendental, with their oblique utterances leading some fully humanoid cylons to dismiss them as insane while others believe that that are in communion with God. One passage, written by Jane Espenson for the spin-off feature, The Plan, is representative of their speech, and intriguingly echoes the culture of our own age - in this case, Yeats' 'The Second Coming' - as the cylons launch their opening attack on the human colonies: ${ }^{*}$

Mists of dreams drip along the nascent echo and love no more [...] Counting down. All functions nominal. All functions optimal. Counting down. The center holds. The falcon hears the falconer. Infrastructure, check. Wetware, check. Everyone hang on to the lap bar, please. Accepting scan. Love outlasts death.

The overall hybrid nature of cylon being becomes increasingly significant as the series progresses, and serves to illustrate the ambiguity of 'natural' and 'artificial' identity in a quite literal way.

This mixture is manifest in the characters of the executive officer of Galactica, Colonel Saul Tigh, and his wife, Ellen. First, Saul is shown to be a

\footnotetext{
* Bob Dylan's 'All Along the Watchtower' features even more prominently in the later seasons as another link between the world of Battlestar Galactica and our own.
} 
dedicated but flawed military man: an alcoholic martinet of an officer who hates the android cylon enemy that have almost wiped out the Colonials and equally contemptuous - so he thinks - of his promiscuous wife. He is nonetheless devotedly loyal to his friend and superior officer, Admiral William Adama, who in turn sees some essentially valuable and human qualities in him, as well as his utility as his second-in-command. He seems to be all too human - but he is not, and this opens a window on to the deeper agenda of the writers.

As the series develops, the Colonials try to establish a new home on a bleak, bedraggled planet only to have the cylons take control of it and force him to take up arms as the leader of the resistance. He is forced to oppose them using the most brutal tactics, which include suicide bombers and even the murder of Ellen for betraying the resistance. In truly melodramatic fashion, he subsequently finds that he is himself a cylon with false memories; and that, when Ellen is returned to him via cylon resurrection technology, she too is a cylon. In addition to that, as Ellen regains her memories, the two of them learn that they are not in fact members of the current cylon generation, but are two of the last five survivors of a previous historical cycle and the creators of the new, current generation of humanoid cylons. Finally, after the crew of the Galactica and its dependent fleet finally arrive at a new habitable world, a flash-forward reveals that all of present-day humanity is a hybrid descended from both cylons and the Colonials of the original story: two secondary characters, Helo and Athena, respectively pure human and pure cylon have produced a child, Hera (who increasingly became a major motivator for the plot of the series), who is revealed to be 'Mitochondrial Eve', the ancestor of all presently living people. Saul and Ellen, for a while at least, live happily ever after in the Africa of our own distant past.

Who then are the Tighs? Saul Tigh answers the question for himself, when the ship is under attack from cylon forces:

My name is Saul Tigh, I'm an officer in the Colonial Fleet. Whatever else I am, whatever else it means, that's the man I want to be. And if I die today, 
that's the man I'll be ('Crossroads Part II' Battlestar Galactica Season Three).

This is not to say that he ignores his cylon heritage or that it is ignored by his compatriots: Adama suffers a temporary but severe emotional breakdown over his friend's unconscious betrayal, but in the end remains steadfastly loyal to him. Saul and Ellen acknowledge their cylon identities while remaining whom they have chosen to be and ally themselves with the fleet of Galactica, along with a faction of humanoid and mechanical cylons who are determined to break the historical cycle of creation and destruction. In the end, as the flash-forward twist shows, nobody is 'essentially human'. The relationship of cylons and Colonials is like that of humans and Aleutians within the matrix of Gwyneth Jones' Posthumanist Diaspora Theory: any division that exists is a semantic creation and, even if it were empirically true, it is practically irrelevant.

The ethos of the series Battlestar Galactica is humanist and even antitechnological: the entire fleet is scuttled in the last episode as the surviving Colonials and humanoid cylons settle on earth, while the mechanical cylons take their baseship and depart to pursue their own destiny. This represents a turning away from the overt mixture of flesh and steel in favour of what is in the end more of a racial mixing, but cyborgisation remains as a not entirely negative motif throughout the series.

Certainly early on, it lends the cylons a sinister quality. However, this is contradicted by the fact that the rebel cylons join the fleet along with their baseship, and Saul and Ellen (and others) discover their cylon nature and even the Galactica itself has to incorporate cylon biotechnology as it begins to succumb to cumulative battle damage. The racial lines are blurred, so too are the cultural and technological boundaries.

The blurring of boundaries can also be thought of as a form of doubling or mirroring. To delay her final breakdown, Galactica is augmented with cylon biotechnology, and most significantly, as Admiral Adama prepares to transfer his flag to the cylon baseship, the Galactica becomes a Colonial analogue of a cylon vessel.

Characters become hybridised too. Samuel Anders, another one of the five cylons of the previous cycle, is seriously wounded in a mutiny and in order to save his

\footnotetext{
* This speech is obviously highly significant to many of the academic critics of the series, being repeatedly referred to in separate essays (see Potter and Marshall, 29, 141, 167; and Steiff and Tamplin, 277).
} 
life, he is connected to artificial life-support system. Then, as he begins to talk and behave like one of the baseship hybrids, he is connected to the ailing battlestar itself in the hope that he will enable the ship to continue to function. Normally, mechanical prostheses are presented as means by which a failing human body is supported, but in this case, a failing mechanical edifice is supported by a biological component, and like a baseship hybrid, he seems to have access to the transcendental realm too. As a result of these changes, Baltar's Neohumanist observation that the Galactica is the vessel that carries the hopes and dreams of the community is also true in a literal technological sense.

While the cataclysmic wars between Colonial and cylon in Battlestar Galactica are nominally predicated on the essential opposition of human and machine or self and other, and the fact that fate determines all (as indicated in the oft-repeated credo, 'All of this has happened before and all of this will happen again'), nevertheless, construction and compromise are the recurring conditions of the series. Characters are continually having to reconsider their most basic assumptions and deal with situations that require them to turn against what they thought of as eternal laws. The motif of doubles and alternatives is prevalent, as we see in the case of the Tighs and other cylon sleeper agents, but we see it also in the case of the cylons themselves; there are twelve basic humanoid models, and according to the stereotypes of the genre, each individual should behave exactly like another of its line, but in fact they display multiple-alterity instead. Doubles may be 'uncanny' (Anonymous 39, Peirse 118-9), but beyond that, they present a means of dramatising the importance of choice and experience in the construction of persona. Representatives of the 'Number Eight' line vary between extreme loyalty for the Colonial community (one is Athena, who has married the Colonial Karl 'Helo' Agathon, and is the mother of Hera) or vacillation between sides; Number Sixes appear in a very diverse range of roles, and in The Plan, two of the hegemonic line of cylon models, Cavil (technically, both are models of the type designated 'Number One'), diverge in their paths, with one becoming sympathetic towards the Colonials and the other becoming, if anything, even more bitter and vindictive. Saul Tigh's own declaration is of course an assertion of his will over his heritage; a choice that takes him away from what the hostile

\footnotetext{
* This author is credited as '[ ]' in Steiff and Tamplin. I have listed them as 'Anonymous' in the bibliography.
} 
edition of Cavil assumes would be his destined role. In Ellen's case, empathy serves to steer her to the same end.

One way in which the overlapping of 'natural' and 'artificial' is brutally brought into focus is the treatment of humanoid cylons by Colonials. Anyone can kick a malfunctioning machine, but what if one mistreats a sentient construction, bearing in mind that the Posthumanist viewpoint regards all beings as constructions? In the second season episode, 'Resurrection Ship Part II', one Colonial officer, Colonel Fisk (in some ways an alternate of Tigh), observes, when told of the abuse and torture of humanoid cylon prisoners (a Six and, ambiguously depending on the editing of broadcast and DVD extended cut versions of the episode, Athena), 'You can't rape a machine.' Athena and various Sixes, like Tigh, repeatedly demonstrate that they are capable of desire, pain and choice and indeed, therefore, they can be violated and that violation can be morally reprehensible. The experience of Athena and a tortured Six, Gina, in particular provide an interesting parallel to the gynoids of Ghost in the Shell 2: Innocence. If they are essentially distinct from humanity, their torture is both justifiable and profoundly meaningless, because their pain is insignificant. In a system that ascribes subjectivity to any intelligent being capable of cognition, whether it is based on experience in Battlestar Galactica or more metaphysical in the case of the unconscious gynoids of Ghost in the Shell 2: Innocence, then empathic and moral consideration encompasses them as it encompasses 'real' humans, because all are equally constructions.

The complex but necessary negotiations entailed by the construction of validated identity are not unique to Battlestar Galactica. Not only can we recall the shifted identities of characters in Jones' Aleutian trilogy, but there are several other examples. Ellen Ripley as presented in Alien: Resurrection is a clone of a human woman with an admixture of alien DNA. In District 9 (2009) Wikus van der Merwe* becomes contaminated by alien biotechnology and then becomes physically and socially transformed into an alien, a change that reflects his rise in moral stature from minor corporate bureaucrat complicit in evil to actual hero. In Avatar, a similar social fall - according to prior standards - is accompanied by a moral ascent and increase in consciousness as a former marine, Jake Sully, loses his crippled human body and socio-cultural identity to become an alien resistance leader. (The Alien series also

\footnotetext{
* The surname 'van der Merwe' in South African humour commonly denotes a naïve, bumbling Afrikaaner character, similar to the villagers of Chelm in Yiddish humour.
} 
introduces sympathetic artificial persons, Bishop and Call, who show themselves to be the moral and empathic equals - or superiors - to 'natural' humans.) Technology, in all of these cases, is the facilitator of profound transformations and it is not something that protects and defines essential human identity, but is instead something that erases boundaries between human and other, because that erasure and transformation is necessary and inevitable.

In terms of the critical system of the Orders that I propose, Battlestar Galactica is an impure text, as are most that are not exemplars of a sole Order. As such, it is relatively explicit in its treatment of metaphysics, which is openly discussed by its characters. On one hand, there is Gaius Baltar, formerly an empirical scientist who has undergone some radical challenges and transformations, and on the other there is John Cavil, the leader of the fundamentalist faction of the cylons and instigator of the holocaust.

Baltar's understanding of the architectonics of reality has become polysemous, as he begins to see visions of transcendental reality laid over the world of empirical experience. At the climax of the last episode, where he faces Cavil and pleads for the life of Hera, he delivers this speech:

I see angels, angels in this very room. Now I may be mad, but that doesn't mean that I'm not right, because there's another force at work here; there always has been. It's undeniable, we've all experienced it. Everyone in this room has witnessed events that they cannot fathom let alone explain away by rational means: puzzles deciphered in prophecy; dreams given to a chosen few; our loved ones dead, risen. Whether we want to call that God, or Gods, or some sublime inspiration, or a divine force that we can't understand, it doesn't matter, doesn't matter. It's here, it exists. And our two destinies are entwined in its force ('Daybreak Part II' Battlestar Galactica The Final Season).

It is no help to his sanity that the Angels that he sees are identical to himself and his cylon lover.

Cavil sarcastically asks Baltar what makes him think that God's on his side, to which he replies that God isn't on anyone's side, but this leaves Cavil distinctly 
unimpressed. He explains his own mechanistic, reductionist view of his relationship with the cosmos to Ellen in an earlier episode, 'No Exit':

I don't want to be human! I want to see gamma rays, I want to hear X-rays and I want to - I want to smell dark matter. Do you see the absurdity of what I am? I can't even express these things properly, because I have to - I have to conceptualise complex ideas in this stupid limiting spoken language. But I know I want to reach out with something other than these prehensile paws... and feel the solar wind of a supernova flowing over me. I'm a machine, and I could know much more. I could experience so much more, but I'm trapped in this absurd body! And why? Because my five creators thought that God wanted it that way! (Battlestar Galactica The Final Season and Battlestar Galactica: The Plan)

Cavil's desire is, considering his origins, anti-humanist, or beyond that, transhumanist, but in the context of the series, his views are given short shrift. Both he and Baltar are depicted as desperately ambitious, narcissistic characters who despise their parents, but they ultimately have profoundly different fates and it is the desire for clear vision that unifies them at one level and divides them on another. Cavil is outraged at the inadequacy of his merely human senses and believes that with a greater bandwidth, his consciousness and his being will surpass its arbitrary limitations. His transhumanist desires are based in an essentially Modernist, empiricist conception of the cosmos. Baltar, on the other hand, doesn't necessarily want to see still more of the mundane world, and instead is given access to higher planes of existence. He has many visions, including those shared by other characters, in which an opera house appears with five glowing figures standing upon the stage, an angelic version of his cylon lover, Six, and Hera, the child borne of a Colonial father and cylon mother and repeatedly described by various characters as 'the shape of things to come' (a vision shared by his version of Six, Athena and the Colonial President, Laura Roslin). In the end, he realises that the opera house is the command centre of the Galactica and the performance is the culmination and potentially final resolution of the conflict between Colonial and cylon, orchestrated in some way by a being or force inhabiting a higher realm. 
Baltar is depicted throughout the series as a cowardly, venal and vain man, but his faults, the narrative shows, are redeemable because his own neediness allows him to be led by more enlightened beings - Colonial, cylon and supernatural. Cavil, on the other hand, with his vast resources and his ambition, is fatally limited, unable to escape both his purely empirical sensory range and the cycle of conflict because of his hatred of both his makers (Saul, Ellen, Samuel and others) and of humanity. This can be put down to his refusal to imagine anything beyond himself: Baltar is forced by others to take responsibility for his faults by others, but Cavil is not and therefore persists in blaming others - everyone else - for his limitations, and perpetuates a genocidal war. Baltar as an emergent Neohumanist sees the transcendental and accommodates the other within his community, whereas Cavil is the ultimate reductionist Modernist who thinks that seeing X-rays is the pinnacle of experience and abhors the Other.

Potentially, Cavil could be represented as a positive character, and his greater aims beyond the desire for vengeance, are admirable. It must indeed be fascinating to hear X-rays and smell dark matter, but this possibility, while hinted at in the liberation of the last mechanical centurions and their departure from earth orbit, with the implication that they will evolve further, is not pursued and is therefore excluded from the series' narrative structure. Moore and Eick come down on Baltar's side, or rather the Baltar that his angels and his lover want him to be, so he is allowed to live while Cavil succumbs to spiteful despair and shoots himself.

The angels themselves, eternal beings able to see the overall structure of time, but unable to be certain of the future, are shown to be real and appear independently in the last scene to offer their own judgment of the real concerns of the story. They stand as a kind of chorus to the events of the series, and 150,000 years later in what turns out to be New York's Times Square in our own present time, they read reports of the discovery of Hera's fossilised remains (although, of course, only they know that it is her), developments in robotics, war and poverty, and wonder if the whole cycle of time is about to repeat itself yet again. According to their conversation, there is a God, but, as the one resembling Six says, 'it hates being called that.' The ultimate judgment of the worth and destiny of (hybrid) humanity is left open and is thus directed at the audience.

What then is Battlestar Galactica? Is it Modernist, Neohumanist or Posthumanist? On one hand, obviously Cavil's primarily Modernist viewpoint (with 
a transhumanist admixture) is rejected and there are the ambiguities of identity that are so characteristic of Posthumanism, but on the other hand, there are the polysemous layerings of space and meaning and time has a cyclic structure, which is repeatedly indicated by several characters saying, 'All of this has happened before and all of this will happen again' as an article of faith. However, none of this means that Battlestar Galactica is confused as to its identity as a text; what it does mean is that a text is a structure in which various Orders can be presented in juxtaposition with each other. Ideas are brought together and the revelations come as a result of that encounter. Various characters can present their own systems of thought - and their own identification with the various Orders - and the narrative as a whole can be understood as a hybridisation of the Orders.

In terms of genre, Battlestar Galactica is a space opera (with an opera house!) bearing the influence of cyberpunk and in terms of mode, aesthetics and narrative, it bears a strong influence of the (Post-) Gothic included by Aldiss in his definition. In terms of ideology, it sides with values that are described under the label of Neohumanism, but structurally and narratively is not purely of that or any other Order. As a reflection of the fact that it has emerged in a postmodern cultural milieu, it displays postmodern structures. It is, typically, a multimedia enterprise with multiple authors and its attendant cluster of creative fans. As a text (denoting the television series and associated media that constitute the total story), it is the intersection of multiple influences and Orders. Potentially, the mixture that exists in Battlestar Galactica could provide the material for new narratives that come to be representative of an new Order utilising elements of both the Neohumanist and Posthumanist Orders, but which differs from both. Time will tell.

\section{4}

\section{The Orders Entangled}

The system of the Orders is not a means of classifying individual texts, but a means of understanding texts in relation to their intellectual contexts, and it is also, because each individual text represents an intersection of influences, a means by which the elements constituting a text can be analysed. 
There are similarities implying convergence between the Orders at a superfical level, as there are deeper down. Clifford Simak's and Robert Charles Wilson's Neohumanism converges ideologically with Gwyneth Jones’ Posthumanism. However, there will continue to be fissures between the Orders at a fundamental level - Simak and Wilson diverge from Jones metaphysically, for example. Many stories will also be written in which two or all three Orders are present and antagonistic or exist in a state of tension, perhaps never to be resolved by the absolute dominance of one Order over the other. Each new Order has emerged not because an old Order has had its questions answered, but because the adherents of a new emergent paradigm have considered those questions themselves to be questionable - or irrelevant. Scepticism does not always equal dismissal, and that is why the orders are most often manifested together within the same texts - as is the case with Battlestar Galactica. Granted, Cavil does not get a very sympathetic presentation, but as an antagonist, he is nonetheless a major motivator of the plot and a representative of the essentialist division of 'us' and 'them' that is the foundation for the story and which the story then deconstructs. Battlestar Galactica can be seen as an arena in which the Neohumanist Order battles Modernism, while Posthumanism makes its presence known in a few details here and there. Any thorough critique of the text must take into account the fact that the story is not only about races that come into conflict thinking that it is a battle of fundamental natures, but a contention of visions of fundamental definitions of humanity (and cylonity) in relation with the cosmos.

As I have argued, every individual text is representative of a cultural moment as perceived and articulated from a particular perspective. Admittedly, this can be taken to reflect a Deleuzean conception of the identity of points as being the intersection of lines rather than an absolute and eternal centre, which would place my sympathies with Posthumanism, but it is also derived from a perspective that is historical and that inevitably entails a comprehension of texts as being nodes embedded in a stream of historical changes. No text can be divorced from its history or its consequences. I have used Battlestar Galactica here as an example of the Orders, but that is based on the understanding that it is a space opera and therefore draws on generic antecedents. This is obviously indicated by the fact that it is a 'reimagining' of an older television series of the same name with the same premises and with characters that have the same names. It is also indicated by the fact that it also draws on other influences, such as cyberpunk, and one of the foundation texts of 
cyberpunk, Blade Runner, co-starred the star of Battlestar Galactica, Edward James Olmos, and featured androids who desired to be considered as worthy of regard as humans (coincidentally or not, the replicants in Blade Runner are 'Nexus Six' models while the most prominent cylon is 'Number Six'). After Battlestar Galactica (including its prequel, Caprica) there will be other texts that represent the themes and Orders which it has juxtaposed and engaged. The lines of the Orders will continue beyond this point and generate new intersections and they can only be understood in terms of their lineage and their relations with the other Orders.

Because science fiction exists in the interface between science and culture, a Fourth Order, whatever it may be, is certain to emerge from the meeting of new scientific and cultural paradigms. No doubt it too will arrive with a long heritage of antecedents. 


\section{Bibliography}

2001: A Space Odyssey. 1968. Dir. Stanley Kubrick. Writ. Stanley Kubrick and Arthur C. Clarke. DVD. Warner Brothers, 2007.

‘20000_squid_Nautilus_viewbay.' jpg file. Wikipedia. $6^{\text {th }}$ March 2010. $<$ http://en.wikipedia.org/wiki/File: 20000_squid_Nautilus_viewbay.jpg >

Aldiss, Brian W. with David Wingrove. Trillion Year Spree: The History of Science Fiction. London: Victor Gollancz Ltd, 1986.

Aldiss, Brian W. and Harry Harrison, eds. Hell's Cartographers: Some Personal Histories of Science Fiction Writers. London: Weidenfeld and Nicolson, 1975.

Alien: The Director's Cut. 1978. Dir. Ridley Scott. Writ. Dan O'Bannon and Ronald Shusett. DVD. $20^{\text {th }}$ Century Fox Home Entertainment, 2004.

Alien Planet. Dir. Pierre de Lespinois. DVD. Discovery Channel/Sony Pictures Home Entertainment, 2005.

Alien Resurrection: Special Edition. 1997. Dir. Jean-Pierre Jeunet. Writ. Joss Whedon and Jean-Pierre Jeunet. DVD. $20^{\text {th }}$ Century Fox Home Entertainment, 2007.

Angels and Insects. 1995. Dir. Philip Haas. Writ. Belinda Haas and Philip Haas. DVD. Metro Goldwyn Meyer, 2003.

Anonymous. 'Gothic Anxiety'. Battlestar Galactica and Philosophy: Mission Accomplished or Mission Frakked Up? Eds. Josef Steiff and Tristan D. Tamplin. Chicago: Open Court, 2008 39-47.

Arcosanti. Website. <http://www.arcosanti.org>

Attebery, Brian. Decoding Gender in Science Fiction. New York and London: Routledge, 2002.

---. Strategies of Fantasy. Bloomington and Indianapolis: Indiana U. P., 1992.

Avatar. Dir. and writ. James Cameron. Film. $20^{\text {th }}$ Century Fox, 2009.

Bachelard, Gaston. The Poetics of Space. Trans. Maria Jolas. Boston: Beacon Press, 1994.

Ballard, J. G. Crash. London: Vintage, 2004. 
Banham, Reyner. The Architecture of the Well-Tempered Environment. London: The Architectural Press, 1969.

Barber, Paul. Vampires, Burial and Death: Folklore and Reality. New Haven: Yale U. P., 1988.

Barlowe, Wayne Douglas. Expedition: Being an Account in Words and Artwork of the 2358 A. D. Voyage to Darwin IV. New York: Workman Publishing, 1990.

Bassom, David. Battlestar Galactica: The Official Companion. London: Titan Books, 2005.

Battlestar Galactica. Pilot Mini-series. Dir. Michael Rymer. Writ. Ronald D. Moore and Christopher Eric James. DVD. Universal Studios, 2003.

---. Season One. Writ. Ronald D. Moore et al. DVD. Universal Studios, 2004/2005.

---. Season 2.0. Writ. Ronald D. Moore et al. DVD. Universal Studios, 2005.

---. Season 2.5. Writ. Ronald D. Moore et al. DVD. Universal Studios, 2006.

---. Season Three. Writ. Ronald D. Moore et al. DVD. Universal Studios, 2006/2007.

---. Season Four. Writ. Ronald D. Moore et al. DVD. Universal Studios, 2007/2008.

---. The Final Season. Writ. Ronald D. Moore et al. DVD. Universal Studios, 2009.

Battlestar Galactica: The Plan. Writ. Jane Espenson. DVD. Universal Studios, 2009.

Baudrillard, Jean. The Ecstasy of Communication. Trans. Bernard and Caroline Schutze. New York: Semiotext(e), 1988.

Baxter, Stephen. Coalescent: Destiny's Children: Book 1. London: Victor Gollancz, 2003.

---. 'The Daleks.' SFX 133 (August 2005): 71-3.

---. Evolution. London: Gollancz, 2002.

---. Exultant: Destiny's Children: Book 2. London: Victor Gollancz, 2004.

---. 'The Origin of the "Destiny's Children" Series'. 5 th $^{\text {th }}$ October 2009

$<$ http://www.stephen-baxter.com/articles.html\#destiny $>$

---. Phase Space: Stories from the Manifold and Elsewhere. London: Harper Collins, 2002.

---. The Time Ships. Illus. Les Edwards. London: Harper Collins, 1995.

---. Transcendent: Destiny's Children: Book 3. London: Victor Gollancz, 2005. 
---. Vacuum Diagrams. London: Harper Collins, 1997.

Bear, Greg. City at the End of Time. London: Gollancz, 2008.

Beer, Gillian. ' 'The Death of the Sun': Victorian Solar Physics and Solar Myth.' The Sun is God: Painting, Literature, and Mythology in the Nineteenth Century. Ed. J. B. Bullen. Oxford: Oxford U. P., 1989:159-180.

Bergin, Thomas G. Dante. Boston: Houghton Mifflin Company, 1965.

Bernal, J. D. The World, the Flesh and the Devil: An Enquiry into the Future of the Three Enemies of the Rational Soul. Bloomington and London: Indiana U. P., 1969.

Bizony, Piers. 2001: Filming the Future. London: Aurum Press, 1994.

Blackmore, Susan. The Meme Machine. Oxford: Oxford U. P., 1999.

Blade Runner: Five-Disc Complete Collector's Edition. 1982. Dir. Ridley Scott. Writ. Hampton Fancher and David Peoples. DVD. Warner Brothers, 2007.

Blake, William. William Blake: The Complete Poems. Ed. Alicia Ostriker. Harmondsworth: Penguin Books, 1977.

Borges, Jorge Luis. Dreamtigers. Trans. Mildred Boyer and Harold Morland. London: Souvenir Press 1973.

---. Labyrinths: Selected Stories and Other Writings. Eds. Donald A. Yates and James E. Irby. London: Penguin, 1964.

---. The Total Library: Non-Fiction 1922-1986. Trans. Esther Allen, Suzanne Jill Levine, Eliot Weinberger. London: Penguin Books, 2001.

Bukatman, Scott. 'Postcards from the Posthuman Solar System'. Science-Fiction Studies \#55, Vol. 18, Part 3. 24 ${ }^{\text {th }}$ January 2008 $<$ http://www.depauw.edu/sfs/backissues/55/bukatman55art.html $>$

Bukatman, Scott. Terminal Identity: The Virtual Subject in Post-Modern Science Fiction. Durham and London: Duke University Press, 1993.

Bullen, J. B., ed. The Sun is God: Painting, Literature, and Mythology in the Nineteenth Century. Oxford: Oxford U. P., 1989.

Burke, Kenneth. 'The Poetic Impulse'. In The Hudson Review, Vol. 11, No. 1. (Spring, 1958): 54-63.

Burroughs, William S. Cities of the Red Night. London: Picador, 1981.

---. Nova Express. New York: Grove Press, 1992.

---. Port of Saints. Berkeley CA: Blue Wind Press 1980.

---. The Soft Machine. London: Flamingo, 1992. 
---. The Ticket that Exploded. New York: Grove Press, 1968.

---. Wild Boys: A Book of the Dead. New York: Grove Press, 1992.

Burroughs, William, and Brion Gysin. The Third Mind. London: John Calder, 1979.

Butler, Samuel. 'Darwin Among the Machines.' In The Press Vol. III, No. 192, Saturday 13 June 1863. Christchurch, New Zealand: 1-2.

---. 'Lucubratio Ebria.' In The Press Vol. VIII, No. 847, 29 July 1865. Christchurch, New Zealand: 2.

Byatt, A. S. Angels and Insects. London: Vintage, 1995.

Calvino, Italo. The Literature Machine. Trans. Patrick Creagh. London: Vintage, 1997.

Campbell, Joseph. The Hero With a Thousand Faces. London: Fontana Press, 1993.

Churchill, Winston S. Never Give In! The Best of Winston Churchill's Speeches. New York: Hyperion 2003.

Clarke, Arthur C. 2001: A Space Odyssey. London: Arrow, 1984.

---. Childhood's End. London: Pan, 1974.

---. The Lost Worlds of 2001. London: Sidgwick and Jackson, 1972.

---. Profiles of the Future. London: Pan, 1980.

---. Report on Planet Three and Other Speculations. London: Pan, 1984.

Clute, John, and Peter Nicholls, eds. The Encyclopedia of Science Fiction. London: Orbit, 1999.

Cohn, Norman. Cosmos, Chaos and the World to Come: The Ancient Roots of Apocalyptic Faith. New Haven: Yale U. P., 1999.

---. The Pursuit of the Millennium: Revolutionary Millennarians and Mystical Anarchists in the Middle Ages. London: Paladin, 1970.

Cook, Peter, ed. Archigram. New York: Princeton Architectural Press, 1999.

'Dalek.' Doctor Who. Dir. Joe Ahearne. Writ. Robert Shearman. Television series episode. BBC. First broadcast April 30, 2005.

Dante. The Comedy of Dante Alighieri, The Florentine, Cantica I, Hell (I'Inferno). Trans. Dorothy L. Sayers. London: Penguin Books, n. d.

Davis, Erik. TechGnosis: Myth, Magic and Mysticism in the Age of Information. London: Serpent's Tail, 2004. 
Davis, Mike. City of Quartz: Excavating the Future in Los Angeles. New York: Vintage, 1992.

Dawkins, Richard. The Extended Phenotype: The Long Reach of the Gene. Oxford: Oxford U. P., 1999.

---. The Selfish Gene. Oxford: Oxford U. P., 2006.

de Fren, Allison. 'Technofetishism and the Uncanny Desires of A.S.F.R (alt.sex.fetish.robots).' Science Fiction Studies \# 109, Vol. 36, Part 3 (November 2009): 404-440.

De Landa, Manuel. War in the Age of Intelligent Machines. New York: Zone Books, 1991.

Delaney, Samuel. 'Science Fiction and "Literature" - or, the Conscience of the King.' Visions of Wonder: The Science Fiction Research Association Anthology. Eds. David G. Hartwell and Milton T. Wolf. New York: Tor, 1996.

Deleuze, Gilles. Pure Immancence. Anne Boyman (trans.). New York: Zone Books, 2001.

Deleuze, Gilles, and Félix Guatarri. A Thousand Plateaus: Capitalism and Schizophrenia. Trans. Brian Massumi. Minneapolis and London: University of Minnesota Press, 1994.

Dery, Mark. 'Slashing the Borg: Resistance is Fertile'. 30 ${ }^{\text {th }}$ August 2008. $<$ http://www.n5m.org/n5m2/texts/markdery.htm>

District 9. 2009. Dir. Neil Blomkamp. Writ. Neil Blomkamp and Terri Tatchell. DVD. Tri-Star, 2009.

Dixon, Dougal. After Man: A Zoology of the Future. Frogmore: Granada, 1981.

---. Man After Man: An Anthropology of the Future. London: Blandford, 1990.

---. The New Dinosaurs: An Alternative Evolution. London: Grafton Books, 1988.

Dixon, Dougal and John Adams. The Future is Wild: A Natural History of the Future. Toronto: Firefly Books, 2003.

Dyson, Freeman J. Infinite in All Directions: Gifford Lectures Given at Aberdeen, Scotland, April-November 1985. Harmondsworth: Penguin, 1988.

Edwards, Paul N. The Closed World: Computers and the Politics of Discourse in Cold War America. Cambridge MA, MIT Press, 1997 [1996].

Evans, Arthur B. Jules Verne Rediscovered: Didacticism and the Scientific Novel. Westport, Connecticut: Greenwood Press 1988. 
Field, J. V. The Invention of Infinity: Mathematics and Art in the Renaissance. Oxford: Oxford U. P., 1997.

Flammarion, Camille. Lumen. Trans. Brian Stableford. Middletown, Connecticut: Wesleyan U. P., 2002.

---. Omega: The Last Days of the World. Lincoln, Nebraska: University of Nebraska Press, 1999.

Forster, E. M. 'The Machine Stops'. Collected Short Stories. Harmondsworth: Penguin, 1976: 109-146.

Foster, R. F. W. B. Yeats, a Life: I: The Apprentice Mage 1865-1914. Oxford: Oxford U. P., 1997.

Foucault, Michel. Discipline and Punish: The Birth of the Prison. Trans. Alan Sheridan. London: Penguin Books, 1987.

---. The Order of Things: The Archaeology of the Human Sciences. New York: Vintage Books, 1973.

Freud, Sigmund. The Uncanny. Trans. David McLintock. London: Penguin, 2003.

'The Future is Wild'. Wikipedia. $17^{\text {th }}$ January 2010. $<$ http://en.wikipedia.org/wiki/The_Future_is_Wild $>$

'The Future is Wild' (animated TV series)'. Wikipedia. 17 $7^{\text {th }}$ January 2010. $<$ http://en.wikipedia.org/wiki/The_Future_Is_Wild_(animated_TV_series)>

The Future is Wild. 2003-2004. Writ. Dougal Dixon et al. DVD. Paramount, 2004.

Ghost in the Shell: Special Edition. 1995. Dir. Mamoru Oshii. Writ. Kazunori Ito. DVD. Madman, 1995.

Ghost in the Shell 2: Innocence. 2004. Dir. and writ. Mamoru Oshii. DVD. Manga, 2004.

Gibson, William. Neuromancer. London: Grafton Books, 1986.

Gilbert, R. A. The Golden Dawn: Twilight of the Magicians. Wellingborough, Northhamptonshire: The Aquarian Press 1983.

Gilchrist, Todd. 'Interview: Mamoru Oshii.' IGN. $16^{\text {th }}$ October 2004. IGN. $26^{\text {th }}$ October 2009. <http://.au.movies.ign.com/articles/548/548854p1.html> $<$ http://.au.movies.ign.com/articles/548/548854p2.html>

Gray, Chris Hables, Heidi J. Figueroa-Sarriera and Steven Mentor, eds. The Cyborg Handbook. New York: Routledge, 1995.

Greenfield, Susan. ID: The Quest for Identity in the $21^{\text {st }}$ Century. London: Sceptre, 2008 . 
Haldane, J. B. S. Possible Worlds and Other Essays. London: Chatto and Windus, 1932.

Haraway, Donna. The Haraway Reader. New York: Routledge, 2004.

---. Simians, Cyborgs and Women: The Reinvention of Nature. London: Free Association Books, 1991.

Harbison, Robert. Eccentric Spaces. Boston: David R. Godine, 1988.

Hartwell, David G. and Kathryn Cramer, eds. The Hard SF Renaissance. New York: Tor, 2002.

Hartwell, David G. and Kathryn Cramer, eds. The Ascent of Wonder: The Evolution of Hard SF. New York: Tor, 1994.

Hayles, N. Katherine. How We Became Posthuman: Virtual Bodies, Cybernetics, Literature, and Informatics. Chicago and London: University of Chicago Press, 1999.

Heaney, Seamus, trans. and perf. Beowulf. Compact disc audiobook. London: Penguin, 2000.

Heidegger, Martin. Poetry, Language, Thought. Trans. Albert Hofstadter. New York: HarperPerennial 2001.

Herbert, Frank. Hellstrom's Hive. London: Corgi, 1982.

Hodgson, William Hope. Carnacki the Ghost-Finder. Frogmore, St Albans: Panther Books, 1973.

---. The Dream of $X$. Illus. Stephen E. Fabian. West Kingston, RI: Donald M. Grant, 1977.

---. The Haunted Pampero. Ed. Sam Moscowitz. Hampton Falls, NH: Donald M. Grant, 1991.

---. The House on the Borderland. London: Robinson Publishing, 1988.

---. The Night Land. Doylestown PA: Wildside 2001.

---. Out of the Storm. Ed. Sam Moscowitz. West Kingston, RI: Donald M. Grant, 1975.

---. Terrors of the Sea. Ed. Sam Moscowitz. Hampton Falls, NH: Donald M. Grant, 1996.

---. The Wandering Soul: Glimpses of a Life: A Compendium of Rare and Unpublished Works by William Hope Hodgson. Ed. Jane Frank. Hornsea: Tartarus Press, 2005. 
Hoffman, E. T. A. Selected Writings of E. T. A. Hoffman, Volume 1: The Tales. Ed. and Trans. Leonard J. Kent and Elizabeth C. Knight. Chicago: University of Chicago Press, 1969.

Houellebecq, Michel. H. P. Lovecraft: Against the World, Against Life. Trans. Dorna Khazeni. London: Weidenfeld and Nicolson, 2006.

Hudson, W. H. A Crystal Age. London: Duckworth and Co., 1919.

Hurley, Kelly. The Gothic Body: Sexuality, Materialism, and Degeneration at the Fin de Siècle. Cambridge: Cambridge U. P., 1996.

Hyams, Edward. Morrow's Ants. London: Allen Lane, 1975.

James, Edward, and Farah Mendlesohn. The Cambridge Companion to Science Fiction. Cambridge: Cambridge U. P., 2003.

Jameson, Fredric. Postmodernism, or: The Cultural Logic of Late Capitalism. London: Verso, 1991.

---. Archaeologies of the Future: The Desire Called Utopia and Other Science Fictions. London: Verso, 2005.

Jencks, Charles. Architecture Today. London: Academy Editions, 1988.

Jones, Gwyneth. The Buonarotti Quartet. Seattle: Aqueduct Press, 2009.

---. Deconstructing the Starships: Science, Fiction and Reality. Liverpool: Liverpool U. P. 1999.

---. North Wind. London: Victor Gollancz, 1995.

---. Phoenix Café. London: Victor Gollancz, 1998.

---. Spirit, or: The Princess of Bois Dormant. London: Gollancz, 2008.

---. White Queen. London: Victor Gollancz, 1992.

Joshi, S. T. H. P. Lovecraft: A Life. West Warwick, RI: Necronomicon Press, 1996.

Kafka, Franz. The Collected Short Stories of Franz Kafka. Harmondsworth: Penguin, 1988.

Kapp, Colin. 'Gottlos.' In Analog 8. Ed. John W. Campbell. Garden City, NY: Doubleday and Company, 1971: 1-47.

Karinthy, Frigyes. Voyage to Faremido/Capillaria. Trans. Paul Tabori. London: New English Library, 1978.

Kearney, Richard. The Wake of Imagination: Ideas of Creativity in Western Culture. London: Hutchinson, 1988. 
Kemp, Peter. H. G. Wells and the Culminating Ape. New York: St. Martin's Press, 1982.

Kermode, Frank. The Sense of an Ending: Studies in the Theory of Fiction. New York: Oxford U. P., 1967.

Kind, Amy. 'You Can't Rape a Machine.' Battlestar Galactica and Philosophy: Mission Accomplished or Mission Frakked Up? Eds. Josef Steiff and Tristan D. Tamplin. Chicago: Open Court, 2008 117-128.

Knight, Damon. In Search of Wonder: Essays on Modern Science Fiction. Chicago: Advent, 1967.

Kostoff, Spiro. The City Shaped: Urban Patterns and Meanings Through History. London: Thames and Hudson, 1991.

Krauss, Lawrence. The Physics of Star Trek. New York: Basic Books, 1995.

Kristeva, Julia. Powers of Horror: An Essay on Abjection. Trans. Leon S. Roudiez. New York: Columbia U. P., 1982.

Lacan, Jacques. Écrits: A Selection. Trans. Alan Sheridan. London: Routledge, 2003.

Le Corbusier. Towards a New Architecture. Trans. Frederick Etchells. London: The Architectural Press, 1946.

Lefanu, Sarah. In the Chinks of the World Machine: Feminism and Science Fiction. London: The Women's Press, 1988.

Lem, Stanislaw. Fiasco. Trans. Michael Kandel. San Diego: Harcourt Brace Jovanovich, 1987.

---. The Invincible. Trans. Wendayne Ackerman. Harmondsworth: Penguin, 1973.

---. One Human Minute. Trans. Catherine S. Leach. London: Mandarin, 1991.

---. Solaris. Trans. Joanna Kilmartin and Steve Cox. London: Arrow Books, 1973.

Libeskind, Daniel. The Space of Encounter. London: Thames and Hudson, 2001.

Lima, Antonietta Iolanda. Soleri: Architecture as Human Ecology. New York: The Monacelli Press, 2003.

Lindsay, David. A Voyage to Arcturus. Edinburgh: Canongate Press, 1992.

Lovecraft, H. P. Necronomicon: The Best Weird Tales of H. P. Lovecraft. London: Gollancz, 2008.

Machen, Arthur. The Strange World of Arthur Machen. Ed. Arno Eckberg. New York: Juniper Press, n. d. 
MacKenzie, Norman and Jeanne. The Life of H. G. Wells: The Time Traveller. London: Hogarth Press, 1987.

Mamet, David. Three Uses of the Knife: On the Nature and Purpose of Drama. London: Methuen, 2002.

Margulis, Lynn, and Dorion Sagan. Microcosmos: Four Billion Years of Microbial Evolution. New York: Touchstone, 1991.

---. What is Life? London: Weidenfeld and Nicolson, 1995.

Martin, Raymond, and John Barresi. The Rise and Fall of Soul and Self: An Intellectual History of Personal Identity. New York: Columbia U. P., 2006.

Matrix, The. Writ. and dir. Andy and Larry Warchowski. DVD. Roadshow Entertainment, 1999.

McCaffery, Larry, ed. Across the Wounded Galaxies: Interviews with Contemporary American Science Fiction Writers. Urbana: University of Illinois Press, 1990.

---. Storming the Reality Studio: A Casebook of Cyberpunk and Postmodern Fiction. Durhan: Duke U. P., 1991.

McIntee, David. Beautiful Monsters: The Unofficial and Unauthorised Guide to the Alien and Predator Films. Tolworth: Telos, 2005.

McLuhan, Marshall. Understanding Media: The Extensions of Man. London: Routledge, 2002.

Mendelsohn, Farah, ed. On Joanna Russ. Middletown, Connecticut: Wesleyan U. P., 2009.

Mishima, Yukio. Sun and Steel. London: Secker and Warburg, 1971.

Mitchell, Kaye. 'Bodies That Matter: Science Fiction, Technoculture, and the Gendered Body.' Ed. Arthur B. Evans. Science Fiction Studies \#98, Volume 33, Part 1. Greencastle IN: Arthur B. Evans, March 2007. 109-128.

Moore, C. L. 'No Woman Born' in The Best of C. L. Moore. Ed. Lester del Rey. Garden City, NY: Nelson Doubleday, 1975: 200-242.

Morley, Henry, ed. Ideal Commonwealths: Plutarch's Lycurgus, More's Utopia, Bacon's New Atlantis, Campanella's City of the Sun and a fragment of Hall's Mundus Alter et Idem. London: George Routledge and Sons, Limited, 1890.

Morris, William. The Story of the Glittering Plain Which Has Also Been Called the Land of Living Men or the Acre of the Undying. Hollywood CA: Newcastle, 1973.

---. The Water of the Wondrous Isles. London: Ballantine Books, 1972.

---. The Well at the World's End. 2 vols. London: Ballantine Books, 1971. 
---. The Wood Beyond the World. London: Ballantine Books, 1972.

Morton, Peter. The Vital Science: Biology and the Literary Imagination 1860-1900. London: George Allen and Unwin, 1984.

Naphy, William and Andrew Spicer. The Black Death and the History of Plagues: 1345-1730. Stroud: Tempus, 2000.

Niven, Larry. Ringworld. London: Gollancz, 2005.

Norberg-Schulz, Christian. Existence, Space and Architecture. New York: Praeger, 1971.

Nye, David E. American Technological Sublime. Cambridge MA: MIT Press, 1994.

Olalquiaga, Celeste. The Artificial Kingdom: A Treasury of the Kitsch Experience. London: Bloomsbury, 1999.

Pawley, Martin. The Private Future: Causes and Consequences of Community Collapse in the West. London: Thames and Hudson, 1973.

Peirse, Alison. 'Uncanny Cylons: Resurrection and Bodies of Horror'. In Cylons in America: Critical Studies in Battlestar Galactica. Eds. Tiffany Potter and C. W. Marshall. New York: Continuum, 2008 118-30.

Penley, Constance. NASA/TREK: Popular Science and Sex in America. London: Verso, 1997.

Penley, Constance, and Andrew Ross. Technoculture. Minneapolis: University of Minnesota Press, 1991.

Phillips, Julie. James Tiptree, Jr: The Double Life of Alice B. Sheldon. New York: St. Martin's Press, 2006.

Phillips, Tom, trans. and illus. Dante's Inferno. London: Thames and Hudson, 1985.

Plato. The Republic. Trans. H. D. P. Lee. Harmondsworth: Penguin, 1970.

---. The Symposium. Trans. Walter Hamilton. Harmondsworth: Penguin, 1985.

Poe, Edgar Allan. Eureka: An Essay on the Material and Spiritual Universe. London: Hesperus Press, 2002.

---. Tales of Mystery and Imagination. Illus. Harry Clarke. Christchurch, NZ: Caxton Press, 1972.

Pohl, Frederik. Man Plus. Frogmore: Granada, 1978.

Pohl, Frederik, and C. M. Kornbluth. Wolfbane. London: Victor Gollancz, 1986.

Potter, Tiffany, and C. W. Marshall, eds. Cylons in America: Critical Studies in Battlestar Galactica. New York: Continuum, 2008. 
Priest, Christopher. The Space Machine: A Scientific Romance. London: Pan, 1981.

Purkiss, Diane. Troublesome Things: A History of Fairies and Fairy Stories. Harmondsworth: Penguin, 2001.

Robertson, Andy W., ed. The Night Land. Anthology website. $<$ http://www.thenightland.co.uk $>$

---. William Hope Hodgson's Night Lands, Volume 1: Eternal Love. Doylestown, PA: Betancourt and Company, 2003.

---. William Hope Hodgson's Night Lands, Volume 2: Nightmares of the Fall. Brighton: Three Legged Fox Books, 2007.

'Ringworld' Wikipedia. 25 ${ }^{\text {th }}$ December 2009 $<$ http://en.wikipedia.org/wiki/Ringworld $>$.

Russ, Joanna. The Country You Have Never Seen: Essays and Reviews. Liverpool: Liverpool U. P., 2007.

---. The Female Man. London: The Women's Press, 1985.

---. To Write Like a Woman: Essays in Feminism and Science Fiction. Bloomington: Indiana U. P., 1995.

---. The Zanzibar Cat. New York: Baen, 1984.

Rykwert, Joseph. The Idea of a Town: The Anthropology of Urban Form in Rome, Italy and the Ancient World. Cambridge MA: MIT Press, 1988.

Shapiro, Alan N. Star Trek: Technologies of Disappearance. Berlin: AVINUS Verlag, 2004.

Shelley, Mary. Frankenstein. London: J. M. Dentand Sons, 1960.

Siebers, Tobin. The Mirror of Medusa. Berkeley: University of California Press, 1983.

Silver, Carole G. Strange and Secret Peoples: Fairies and Victorian Consciousness. Oxford: Oxford U. P., 1999.

Simak, Clifford D. Cemetery World. New York: DAW, 1983.

Sinclair, Iain. Radon Daughters. London: Jonathan Cape 1994.

Sobchack, Vivian. 'The Virginity of the Astronauts: Sex and the Science Fiction Film.' Alien Zone: Cultural Theory and Centemporary Science Fiction Cinema. Ed. Annette Kuhn. London: Verso, 1990. 103-115.

Soleri, Paolo. The Omega Seed: An Eschatological Hypothesis. Garden City NY: Anchor Press/Doubleday, 1981. 
Sontag, Susan. Illness as Metaphor and AIDS and Its Metaphors. New York: Picador, 1990.

Stableford, Brian. The Architects of Emortality. New York: Tor, 1999.

---. The Cassandra Complex. New York: Tor, 2001.

---. 'The Composition of The House on the Borderland.' William Hope Hodgson: Voyages and Visions. Ed. Ian Bell. Oxford: I. Bell and Sons, 1987. 29-36.

---. Dark Ararat. New York: Tor, 2002.

---. The Fountains of Youth. New York: Tor, 2000.

---. Inherit the Earth. New York: Tor, 1998.

---. The Omega Expedition. New York: Tor, 2002.

---. Scientific Romance in Britain, 1890-1950. London: Fourth Estate, 1985.

Stableford, Brian, and David Langford. The Third Millennium: A History of the World: $A D$ 2000-3000. London: Sidgwick and Jackson, 1985.

Stapledon, Olaf. Far Future Calling: Uncollected Science Fiction and Fantasies. Ed. Sam Moscowitz. Philadelphia: Oswald Train, 1979.

---. Last and First Men and Last Men in London. Harmondsworth: Penguin, 1970.

---. Star Maker. London: Millennium, 1999.

Star Trek. Writ. Gene Roddenbery et al. Television series. NBC, 1966-9.

Star Trek: The Next Generation. Television series. Paramount/First-run syndication, 1987-94.

Star Trek: Voyager. Television series. UPN, 1995-2001.

Stephenson, Andrew M. 'The Giant Killers.' In Andromeda 1. Ed. Peter Weston. London: Futura, 1976. 155-84.

Steiff, Josef, and Tristan D. Tamplin, eds. Battlestar Galactica and Philosophy: Mission Accomplished or Mission Frakked Up? Chicago: Open Court, 2008.

Sterling, Bruce. Schismatrix Plus. New York: Ace, 1996.

Sturgeon, Theodore. More Than Human. Harmondsworth: Penguin, 1965.

Storr, Catherine. Marianne Dreams. London: Faber and Faber, 2000.

Strugatsky, Arkady and Boris. Roadside Picnic. Trans. Antonina W. Bouis. Harmondsworth: Penguin, 1979. 
Suvin, Darko. Metamorphoses of Science Fiction: On the Poetics and History of a Literary Genre. New Haven and London: Yale U. P., 1979.

Swirski, Peter. Between Literature and Science: Poe, Lem, and Explorations in Aesthetics, Cognitive Science, and Literary Knowledge. Liverpool: Liverpool U. P., 2000.

---. A Stanislaw Lem Reader. Evanston, IL: Northwestern U. P., 1997.

Teilhard de Chardin, Pierre. The Future of Man. Trans. Norman Denny. New York and Evanston: Harper and Row, 1964.

Tevis, Walter. The Man Who Fell to Earth. London: Pan, 1976.

Theweleit, Klaus. Male Fantasies. Vol. 1: Women, Floods, Bodies, Histories. Trans. Erica Carter, Chris Turner and Stephen Conway. Minneapolis: University of Minnesota Press, 1989.

---. Male Fantasies. Vol. 2: Male Bodies: Psychoanalyzing the White Terror. Trans. Erica Carter, Chris Turner and Stephen Conway. Minneapolis: University of Minnesota Press, 1989.

The Man Who Fell to Earth. Dir. Nicholas Roeg. Perf. David Bowie et al. DVD. Anchor Bay Entertainment, 2003.

Tiptree, James, Jr. Her Smoke Rose Up Forever. Sauk City, Wisconsin: Arkham House, 1990.

---. The Starry Rift. New York: Tor, 1986.

'Twenty Thousand Leagues under the Sea (1954 film)' Wikipedia article. $27^{\text {th }}$ December 2009. $<$ http://en.wikipedia.org/wiki/20,000_Leagues_Under_the_Sea_(1954_film)>

Vandermeer, Ann and Jeff, eds. The New Weird. San Francisco: Tachyon Publications, 2008.

---. Steampunk. San Francisco: Tachyon Publications, 2008.

Verne, Jules. 20,000 Leagues under the Sea. Trans. Anthony Bonner. London: Corgi, 1975.

Videodrome. 1982. Dir. and writ. David Cronenberg. DVD. Universal Studios, 2002.

Vidler, Anthony. The Architectural Uncanny: Essays in the Modern Unhomely. Cambridge MA: MIT Press, 1992.

Villiers de l'Isle Adam, Jean Marie Mathias Philippe Auguste. Axel. Trans. June Guicharnaud. Englewood Cliffs NJ: Prentice-Hall Inc, 1970.

---. Tomorrow's Eve. Trans. Robert Martin Adams. Urbana: University of Illinois Press, 1982. 
Vint, Sherryl. 'Double Identity: Interpellation in Gwyneth Jones's Aleutian Trilogy.' Science Fiction Studies \#85, Volume 28, Part 3. (November 2001): 399-426.

Vitruvius. The Ten Books on Architecture. Trans. Morris Hicky Morgan. New York: Dover Publications, 1960.

Wagar, W. Warren. Terminal Visions: The Literature of Last Things. Bloomington, Indiana: Indiana U. P., 1982.

Wall, D. and W. Borek. Visionary Cities: The Arcology of Paolo Soleri. New York: Praeger, 1970.

Watts, Peter. Blindsight. New York: Tor, 2006.

Watts, Peter. Blindsight. Various digital editions on author's Rifters website. $25^{\text {th }}$ July, 2010. <http://www.rifters.com/real/Blindsight.htm>

Weintraub, Pamela. Illus. Diz Wallis. 'Visions of Man Evolved.' Omni Vol. 5, No. 2 (November 1982). 90-5.

Wells, H. G. The Complete Science Fiction Treasury of H. G. Wells. New York: Avernel Books 1978 (facsimile of Seven Famous Novels, 1934).

---. Early Writings in Science and Science Fiction. Eds. Robert M. Philmus and David Y. Hughes. Berkeley: University of California Press, 1975.

---. Experiment in Autobiography. 2 vols. London: Victor Gollancz and the Cresset Press, 1934.

---. The First Men in the Moon. Harmondsworth: Penguin Books, 2005.

---. H. G. Wells: Journalism and Prophecy 1893-1946. Ed. W. Warren Wagar. Boston: Houghton Mifflin Company, 1964.

---. The War of the Worlds. Harmondsworth: Penguin Classics, 2005.

---. World Brain. London: Methuen and Co., 1938.

Wertheim, Margaret. The Pearly Gates of Cyberspace: A History of Space from Dante to the Internet. Sydney, Auckland, Toronto, New York and London: Doubleday, 1999.

---. Pythagoras' Trousers: God, Physics and the Gender Wars. London: Fourth Estate, 1996.

Wiener, Norbert. The Human Use of Human Beings: Cybernetics and Society. Garden City, NY: Anchor Books, 1954.

Williams, Raymond. Marxism and Literature. Oxford: Oxford U. P., 1977.

Wilson, Bee. The Hive: The Story of the Honeybee and Us. London: John Murray, 2004. 
Wilson, Edward O. Sociobiology: The New Synthesis. Cambridge, MA: Belknap Press of Harvard U. P., 1978.

Wilson, Robert Charles. Axis. New York: Tor, 2007.

---. Bios. New York: Tor, 1999.

---. Blind Lake. New York: Tor, 2003.

---. Darwinia. London: Millennium, 1999.

---. The Harvest. London: New English Library, 1993.

---. Mysterium. London: New English Library, 1995.

---. Spin. New York: Tor, 2005.

Wolfe, Bernard. Limbo '90. Harmondsworth: Penguin, 1961.

Wolmark, Jenny. Aliens and Others: Science Fiction, Feminism and Postmodernism. Iowa City: University of Iowa Press, 1994.

Wright, Patrick. Tank: The Progress of a Monstrous War Machine. London: Faber and Faber, 2001.

Wu, Nelson I. Chinese and Indian Architecture. London: Studio Vista, 1968.

Yates, Frances A. The Art of Memory. London: Pimlico, 1992.

Yeats, W. B. A Vision. New York: Collier, 1973.

Zaleski, Carol. Otherworld Journeys: Accounts of Near-Death Experiences in Medieval and Modern Times. New York: Oxford U. P., 1987. 